\title{
Exploring Sources of Innovation in the Knowledge-Based Economy The Case of Los Angeles
}

\author{
Marlon Graf
}

This document was submitted as a dissertation in May 2016 in partial fulfillment of the requirements of the doctoral degree in public policy analysis at the Pardee RAND Graduate School. The faculty committee that supervised and approved the dissertation consisted of Rafiq Dossani (Chair), Trey Miller, and Martin Kenney. 
For more information on this publication, visit http://www.rand.org/pubs/rgs_dissertations/RGSD376.html

Published by the RAND Corporation, Santa Monica, Calif.

(C) Copyright 2016 RAND Corporation

RAND $^{\circledR}$ is a registered trademark

\section{Limited Print and Electronic Distribution Rights}

This document and trademark(s) contained herein are protected by law. This representation of RAND intellectual property is provided for noncommercial use only. Unauthorized posting of this publication online is prohibited. Permission is given to duplicate this document for personal use only, as long as it is unaltered and complete. Permission is required from RAND to reproduce, or reuse in another form, any of its research documents for commercial use. For information on reprint and linking permissions, please visit www.rand.org/pubs/permissions.html.

The RAND Corporation is a research organization that develops solutions to public policy challenges to help make communities throughout the world safer and more secure, healthier and more prosperous. RAND is nonprofit, nonpartisan, and committed to the public interest.

RAND's publications do not necessarily reflect the opinions of its research clients and sponsors.

Support RAND

Make a tax-deductible charitable contribution at

www.rand.org/giving/contribute

www.rand.org 


\title{
Exploring sources of innovation the knowledge-based economy: the case of Los Angeles
}

\section{Doctoral Candidate:}

Marlon Graf (Pardee RAND Graduate School)

\section{Dissertation Committee: \\ Dr. Rafiq Dossani (Chair), \\ Dr. Trey Miller and \\ Dr. Martin Kenney}

\begin{abstract}
My dissertation uses a mix of both quantitative and qualitative methods to help policy makers identify sources of innovation in the knowledge-based economy and to best leverage these sources for regional economic growth. Specifically, I am evaluating two case studies in Los Angeles:

As part of my first case study, I develop a stakeholder map to inform USC's efforts to build a Biotech Science Park in South-East Los Angeles. As part of this undertaking, I conducted interviews and focus groups with USC faculty members and researchers, community residents, local small and large business owners, policy makers and academic experts in order to both assess entrepreneurial needs and community capacities. I find that while the Los Angeles region appears to have all the necessary ingredients for a highly innovative and entrepreneurial ecosystem such as world class research institutions, funding mechanisms, business support entities and a very creative, diverse and highly-skilled workforce, the vast geographic spread and insular nature of its neighborhoods prevents these resources from being connected with one another. The medical and health sciences industries in particular are dispersed across the region and in need of a centralized location or hub such as the proposed Biotech Science Park around USC's Health Sciences Campus.

For my second case study, I carry-out an exploratory analysis of the Silicon Beach technology innovation movement in West Los Angeles. In order to do so, I constructed a geocoded venture capital database from Crunchbase.com, an open-source startup registry, and used correlational and time series analyses in order to detect predictors of firm success and patterns of locational
\end{abstract}


decisions. When looking at the geographic spread of firms over time, a clear pattern emerges, suggesting that the Silicon Beach movement originated between Santa Monica and Venice Beach and has since spread to Marina Del Rey, Mar Vista and Playa Vista in the South as well as Westwood, Beverly Hills and Hollywood in the North-East. These particular paths of expansion can be explained by the rising rents on the Westside of Los Angeles, the agglomeration effects around the new campuses of large technology corporations in Playa Vista and the location of most LA-based investors along the Wilshire Corridor between Santa Monica and Downtown Los Angeles. In terms of predominant industries, I find strong associations between technology-related fields and traditional strongholds of the Los Angeles economy that are related to fashion, lifestyle and the Hollywood entertainment cluster.

Following a thorough analysis of these two case studies, I conclude by recommending that policy makers in Los Angeles work to establish a framework to enhance connectivity and visibility of regional sources of innovation, including entrepreneurs, research institutions, business support entities and investors in order to nurture and cultivate a vibrant entrepreneurial network. Furthermore, I describe the requirement to better understand the emerging business environment and to tailor the regulatory framework to most effectively meet the needs of an increasingly startup and small firm-dominated high-tech economy. 


\section{Table of Contents}

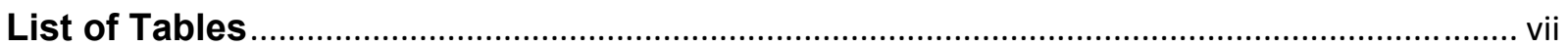

List of Figures

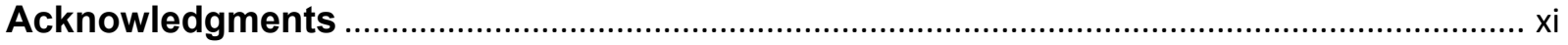

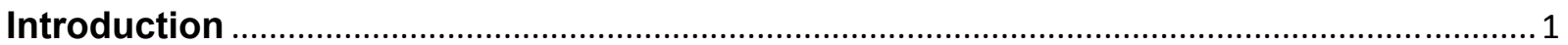

Describing the transition from an industrial to a knowledge-based economy......................... 1

Los Angeles in the context of the knowledge-based economy ............................................... 3

The University of Southern California as an emerging entrepreneurial university ........... 8

A Biotechnology Science Park for South-East Los Angeles? ................................................. 8

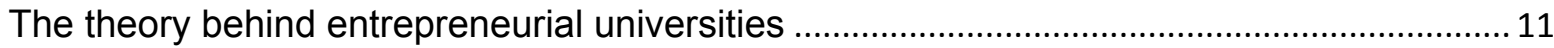

Making sense of the relationship between university technology transfer and economic growth: knowledge-based clusters around entrepreneurial universities................................ 18

Constructing a stakeholder map for the USC Biotech Corridor .............................................. 30

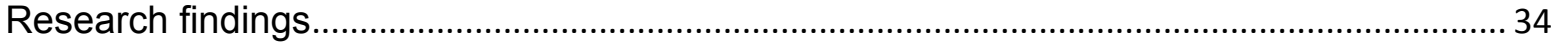

Main takeaways and policy recommendations …..................................................................... 54

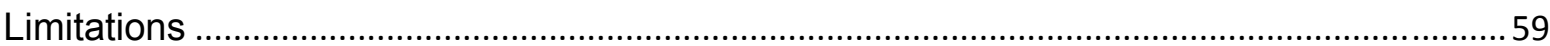

Silicon Beach as a new wave of the digital economy in Los Angeles ...............................60

Telling the story about Silicon Beach and the rise of the Los Angeles tech movement........60

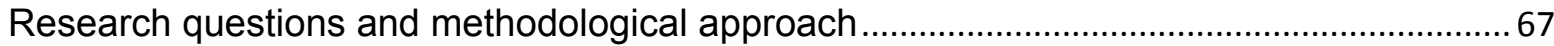

Exploring data sources for analysis and bounding the Los Angeles innovation movement. 69 Breaking-down the Los Angeles innovation movement ….................................................... 84

Adding a temporal dimension to the analysis of the Los Angeles innovation movement .....90

Examining underlying trends in cluster formation and locational patterns ............................. 96

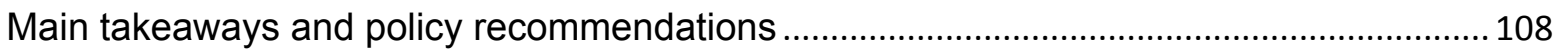

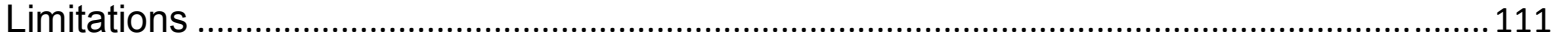

Outlining a future research agenda for Silicon Beach and Crunchbase Geo ...................... 112

Conclusion and Policy Recommendations ...................................................................... 114

Understanding the knowledge-based economy in Los Angeles: from entrepreneurial

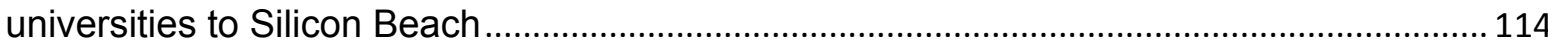

Concluding thoughts and policy recommendations ........................................................... 116 


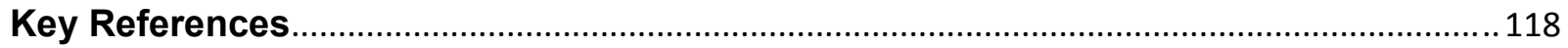

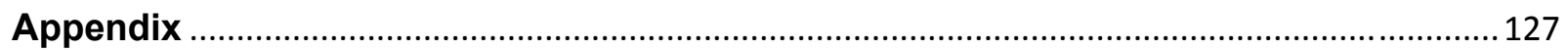

USC Stakeholder Analysis - Focus Group Protocol ............................................................ 127

USC Stakeholder Analysis - Questionnaire for Faculty Entrepreneurs ................................ 130

USC Stakeholder Analysis - Policy Questionnaire ................................................................ 135

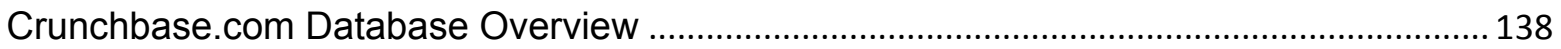

Distribution of firms by industry (scatter plots of latitude-longitude combinations) ..............151

Stem and Leaf Plots to estimate mode industry centroids (Longitudes) .............................. 152

Stem and Leaf Plots to estimate mode industry centroids (Latitudes) ................................. 154

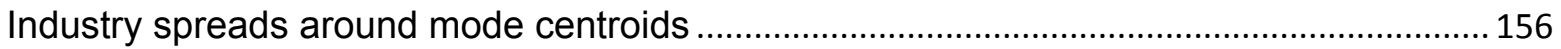

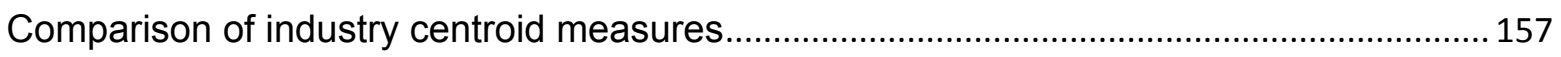




\section{List of Tables}

Table 1 - Influential Zip codes (Share $>3 \%$ in a single category), using Represent.la. 70

Table 2 - Constructed Silicon Beach Map - Adjacent Influential Zip codes (by firm type), using

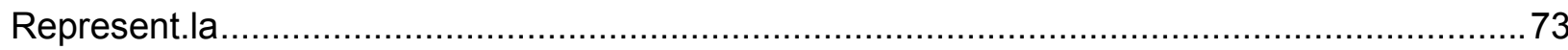

Table 3 - Influential Zip codes (Share $>3 \%$ in a single category), using Crunchbase................77 Table 4 - Constructed Silicon Beach Map - Adjacent Influential Zip codes (by firm type), using Crunchbase. 78

Table 5 - Constructed Silicon Beach Map - Adjacent Influential Zip Codes, using VentureXpert

Table 6- Industries and Zip code distribution (Share $>3 \%$ in a single category)

Table 7 - Silicon Beach Startup Growth over time, 1990-2015 ..........................................90

Table 8 - Share of firms in Silicon Beach zip codes 1990-2015 ...........................................92

Table 9 - Share of new firms in Silicon Beach zip codes per 5-year interval, 1990-2015 ..........94

Table 10 - Share of industries in Silicon Beach zip codes, 1990-2015 ................................96

Table 11 - Share of new firm growth by industry in Silicon Beach zip codes per five year

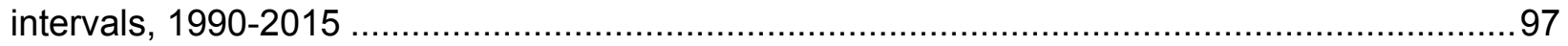

Table 12 - Geographic spreads by industry (summary measures) .......................................99

Table 13 - Geographic spreads by industry (distributions of distances from geographic industry centroid)

Table 14 - Geographic spreads by industry (distributions of distances from geographic industry centroid, using median estimates instead of means) ................................................... 102

Table 15 - Mode industry centroids ........................................................................ 103

Table 16 - Geographic spreads by industry (distributions of distances from geographic industry centroid, using mode estimates instead of medians). 104

Table 16 - Levels of concentration to Los Angeles Covariates by industry (distributions of distances from geographic industry centroid)..... 106 



\section{List of Figures}

Figure 1 - Proposed site for the USC Biotechnology Park ............................................. 10

Figure 2 - Knowledge spillover in an Entrepreneurial University ....................................... 13

Figure 3 - Theory of Change Model for USC Biotech Corridor ......................................... 28

Figure 4 - Knowledge transfer flows within the USC Biotech Park ...................................... 30

Figure 5 - Research Approach for USC Stakeholder Map .............................................. 32

Figure 6 - Assessing people's previous interactions and experiences with USC......................35

Figure 7 - Community perceptions about the Science Park ................................................. 38

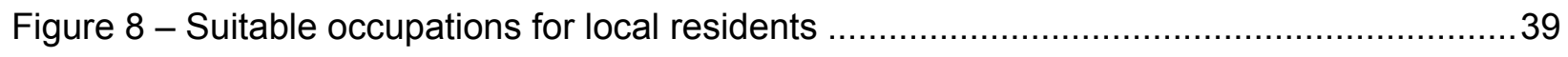

Figure 9 - Getting the community involved in the Science Park .......................................41

Figure 10 - Assessing the local innovation ecosystem in Los Angeles .................................43

Figure 11- USC Biotech Corridor Stakeholder Map ...................................................55

Figure 12 - Silicon Beach success factors and challenges based on Re/code Special Series on

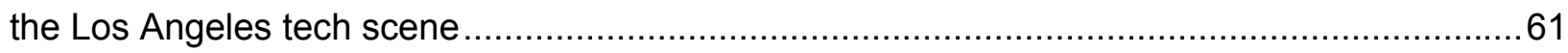

Figure 13 - Startups in Represent.la ...................................................................... 71

Figure 14 - Represent.la startups located in Silicon Beach Zip codes...................................72

Figure 15 - L.A. City Geohub Map of the Los Angeles Tech Community...............................75

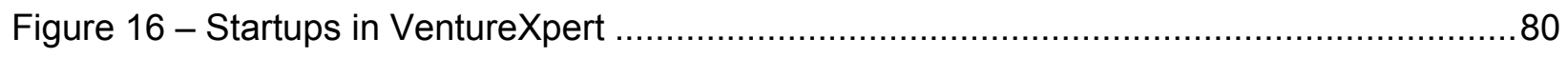

Figure 17 - Constructed Silicon Beach Map - Adjacent Influential Zip Codes..........................83

Figure 18 - Pile Sort of Startup Categories Reported in Crunchbase ................................. 85

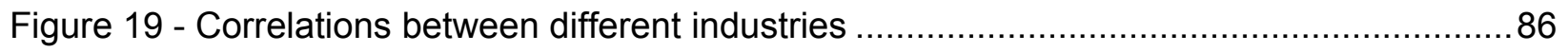

Figure 20 - Correlations between industries and Influential Zip codes ................................89

Figure 21 - Silicon Beach Startup Growth over time, 1990-2015......................................91

Figure 22 - Share of firms in Silicon Beach Zip codes 1990-2015 .....................................93

Figure 23 - Share of new firms in Silicon Beach zip codes per 5-year interval, 1990-2015.......95

Figure 24 - Geographic spreads by industry (distributions of distances from geographic industry

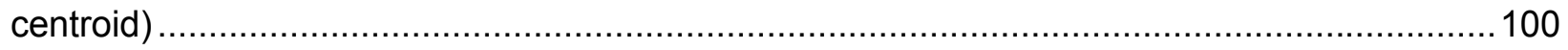

Figure 25 - Median Industry Centroids and Los Angeles County Covariates ........................ 105

Figure 26 - Policy recommendations for nurturing the knowledge-based economy in Los Angeles 



\section{Acknowledgments}

More people than I can possibly thank here have contributed to this work. First and foremost, I would like to thank my dissertation committee, Rafiq Dossani, Trey Miller and Martin Kenney, for their guidance, enthusiastic encouragement and useful critiques of the research. Their willingness to give their time so generously has been very much appreciated. In particular, I would like to express my gratitude to Rafiq Dossani for his tireless efforts and enthusiasm to support this work, I could not have hoped for a better dissertation chair. Over time, his passion and excitement for this work continued to motivate and inspire me, and to push me to become a better researcher. I would also like to thank Trey Miller for keeping me honest and for always ensuring that the research remained focused on solving policy problems that actually matter, as well as Martin Kenney, who was instrumental in guiding this work as a subject matter expert and who spurred my curiosity in the Los Angeles high-tech economy. Furthermore, I would like to thank Zul Surani at USC and everyone who participated in focus groups and interviews.

I received a great deal of guidance and support from RAND and the Pardee RAND Graduate School communities and am greatly indebted to researchers and faculty members who helped me think through theoretical and analytical issues and brought me onto their research projects. Rosalie Pacula, Charles Wolf and Emmett Keeler in particular have been great mentors to me. I am also grateful for the School's staff, and especially Rachel Swanger, for her continuous support and encouragement. Moreover, this work would not have been possible without the generous funding from Anne and James Rothenberg and the John Randolph Haynes and Dora Haynes Foundation. Last but not least, I am grateful for the assistance I received from fellow students at the Pardee RAND Graduate School in classes and regular exchanges. Over the years, many have become great colleagues and dear friends to me. For the purpose of this research, I would like to thank David Manheim for his help in constructing the dataset used for the Silicon Beach chapter and Bill Gelfeld for his thorough editing of the monograph.

On a more personal note, I am thankful for my family back home in Germany, especially my dad Horst, my sister Pia-Serena and my grandmother Emmi without whom none of this would have been possible. Lastly, I would like to thank my wonderful wife Alexandra who has been just amazing throughout this entire journey and who continues to support and inspire me in everything that I do. This work is dedicated to her! 



\section{Introduction}

The purpose of this dissertation is to help policy makers detect and leverage areas of entrepreneurship and innovation in order to develop clusters of competitive advantages in their region. Using the setting of Los Angeles, two separate case studies with the potential to significantly impact regional economic growth are explored: one case covers the role of entrepreneurial universities and one focuses on the digital economy.

\section{Describing the transition from an industrial to a knowledge-based economy}

Before analyzing the specific case studies, it is important to make sense of the broader economic framework and underlying contextual environment. In the wake of a shift from an industrial to a knowledge-based economy, regions across the United States are undergoing a dramatic transition with respect to the factors that determine their ability to grow economically. Along those lines, regional clusters are no longer dependent on "hard" factors of production but are now relying on measures targeted at attracting the high-technology community (Florida 2014).

In this fast-changing economic environment, a region's endowment of knowledge-producing entities such as universities is becoming increasingly important in sustaining the local economy and in maintaining steady levels of growth. In order to understand what leads regions to thrive in this knowledge-centric innovation environment, it is crucial to take a look at the dynamics of knowledge spillover and the mechanisms through which the raw material of knowledge can be brought to market in order to drive local economic growth. In 2005, the Organization of Economic Cooperation and Development (OECD) defined the knowledge-based economy as "an expression coined to describe trends in advanced economies towards greater dependence on knowledge, information and high skill levels, and the increasing need for ready access to all of these by the business and public sectors."

In essence, this means that in this new economic framework, intellectual and human capital, as well as institutional frameworks and innovative ideas, are becoming key production inputs and sources of regional competitive advantage. While most physical inputs are increasingly available on a global scale, Maskell (2001) contends that other, more intangible factors of 
production have emerged as drivers of economic growth. He states that cognitive distance in particular has become a very powerful predictor of cluster formation, with firms increasingly seeking to co-locate according to their preferences for the local institutional setup, talent pool and social networks. Along those lines, in a study aimed at assessing the economic performance of regions, Cooke (2001) describes three stages of cluster formation: the need to rely on shared inputs and the resulting agglomeration of like-minded firms or individuals; the presence of innovation and creative disruption as sources of growth; and the cross-fertilization and mutual learning that lead to secondary and tertiary innovation. While it might initially seem counter-intuitive to think of knowledge as a geographically-bound good, one needs to distinguish between codified knowledge transmitted through open science, academic publications, patent filings and other avenues that are available to the wider public and tacit or personalized knowledge that is centered around the actual inventor or researcher (Lissoni 2001).

In order for knowledge to act as a key production input and to have an impact on economic growth, proximity to the source of innovation is therefore essential. In consequence, in the knowledge-based economy, agglomeration effects often occur around innovative hubs such as universities or other research institutions, due to their propensity to develop new products and ideas based on their research.

In order to remain competitive in this knowledge-driven economy, it is thus imperative for governments at all levels to understand the changing environment and to establish a policy framework that addresses the needs of a new kind of knowledge-oriented firm. Accordingly, this dissertation analyzes the cases of two emerging high-technology movements in the Los Angeles region and aims to equip policy makers with effective strategies to better identify and address the needs of the all actors involved, including individual entrepreneurs, research institutions, local communities and business support entities. 


\section{Los Angeles in the context of the knowledge-based economy}

In its most recent efforts to attract high technology firms to Los Angeles, the Los Angeles County Economic Development Corporation (LAEDC) outlined the main selling points of the areas as a hotbed for innovation and entrepreneurship ${ }^{1}$ :

- "Access to capital. Venture capital and Angel Investors continue to increase their focus on Los Angeles, with new practices explicitly focused on the greater LA area, from Pasadena to the "Silicon Beach" on the west side. Since 2009, venture investors have invested more than \$3.5 billion in technology companies in Greater Los Angeles. (CB Insights 2013). Access to capital is rapidly expanding, and fueling increased opportunity for startups.

- Access to an innovation ecosystem. The idea economy in LA draws strength from its serial entrepreneurs, R\&D pipelines from our universities, creative workforce, well developed industry clusters and their skilled workforces, and much more.

- Abundance of accelerators, incubators and co-working spaces, and world-class universities and colleges producing more graduates than any other county in America.

- LA ranks as third best city in the world for startups. (Startup Genome 2012)

- LA County ranks as the top creative economy in the U.S, in terms of employment and workforce in the creative economy (Otis College 2014)

- A unique and diverse voice. Innovators from 150 countries speaking 250 languages, gender diversity, and broad participation in the innovation economy.

- Quality of life."

Economic growth has always been a major concern for both local and regional policy makers, but the set of incentives used to attract and retain businesses have changed substantially due to the transition to a knowledge-based economy. While tax rebates and discounts on production locations used to be the most important tool that regions used to compete with one another, new sources of innovation no longer rely on substantial manufacturing operations and thus value an entirely different set of offerings (Bradshaw and Blakely 1999, Hanley and Douglass 2014). As outlined above by LAEDC, access to startup financing and early-stage investment and the presence of an innovation ecosystem, appear to be more attractive and critical in the location decisions of existing high technology firms and aspiring entrepreneurs. In a world where

\footnotetext{
${ }^{1}$ See http://laedc.org/innovate-in-los-angeles/\#panel-reasons-to-locate-your-innovation-company-in-la
} 
innovation is no longer tied to large production facilities, factors such as quality of life and access to knowledge producers such as universities take the place of more traditional regional competitive advantages. In response to these changing dynamics, LAEDC describes what it deems to be components of a modern innovation ecosystem, namely the presence of "serial entrepreneurs, R\&D pipelines from our universities, creative workforce, well developed industry clusters and their skilled workforces."

In this new, knowledge-based economic framework, attracting businesses has become a more complex, nuanced proposition. Due to the fact that incentives have largely shifted from policy levers such as taxes or subsides for production to more intrinsic factors such as quality of life, a region's natural endowment of innovative assets such as universities or an entrepreneurial community offers a valuable selling point. The role of policy has thus shifted significantly, from a main source of competitive advantage towards one of enabling and enhancing already existing sources. When trying to generate economic growth in their region, policy makers are thus faced with two main sets of challenges:

- First, in order to promote already existing innovative assets in their region, policy makers need to develop a sound strategy for identifying what these sources are. LAEDC generally references university R\&D, serial entrepreneurship and the creative workforce; however, these categories are very broad and do not naturally distinguish Los Angeles from any other large metropolitan regions such as New York or Chicago. Taking university $R \& D$ as an example, most institutions of higher education specialize in certain areas of research such as biotechnology, nanotechnology, computer science, engineering, or a variety of other scientific disciplines, while very few such as Cal Berkeley, Stanford and MIT have the capacity to excel in all disciplines. Consequently, this dissertation aims to provide guidance on how to effectively detect competitive advantages and strengths that cannot be easily replicated by other regions. LAEDC rightfully mentions the creative economy, probably referring to the Hollywood movie industry and its offspring, and presumably, this is one of Los Angeles' most glaring natural innovation endowments. However, it remains to be seen if and how this native innovation asset translates to the digital economy and to movements such as "Silicon Beach".

- Second, once policy makers have systematically identified areas of competitive advantage, they need to devise a set of policies to best leverage these sources to generate economic growth. Depending on the types of institutions and businesses, as 
well as the area of operation, regional economic actors vastly differ in their regional policy needs. While a specific policy such as Santa Monica's City Net broadband internet initiative $^{2}$ might be particularly helpful to small, internet based firms, it is unlikely to affect firms operating in the life sciences who might prefer policies to increase available laboratory space, or larger firms who may be more likely to respond to traditional incentives such as tax breaks. Understanding the needs of a region's business constituency is essential in building an innovation ecosystem and taking advantage of the natural endowment of innovation assets that defines a region's competitive advantage in the knowledge-based economy.

The aforementioned pattern of detecting and leveraging regional innovative assets applies to a broad set of policy makers across the United States and even globally. The purpose of this dissertation is to help policy makers to detect and leverage areas of entrepreneurship and innovation in order to develop clusters of competitive advantages in their region. Using the setting of Los Angeles, this dissertation explores two separate case studies with the potential to significantly impact regional economic growth: one case examines the role of entrepreneurial universities and the other focuses on the digital economy.

\section{The role of universities in knowledge-based economic growth}

Over the past decade, policy makers have increasingly looked at universities as drivers of local economic growth. The business incubation and research commercialization activities of large entrepreneurial universities like MIT are at the core of innovation as their surrounding regions transitioned from an industrial to a knowledge-based economy. Consequently, Thorp and Goldstein (2013) have argued that it is the duty of universities to become "Engines of Innovation", to step up and become major economic actors and job creators for their regions. The economic impact of university spin-offs and other business ventures that emerge from academic research institutions are further outlined by Etzkowitz (2003), Rasmussen and Borch (2010), Van Looy, Landoni et al. (2011), Bramwell and Wolfe (2008) and others.

Using this rationale, in February of 2015, the University of Southern California (USC) announced its plans to develop a Biotechnology Park in the Montecito Heights area of Los

\footnotetext{
${ }^{2}$ See http://ilsr.org/wp-content/uploads/2014/03/santa-monica-city-net-fiber-2014-2.pdf for a detailed description and analysis of Santa Monica's initiative to make high speed broadband internet connections available as a business attraction policy.
} 
Angeles, in a joint effort with the City of Los Angeles, the L.A. County Board of Supervisors, the L.A. Unified School District (LAUSD) and the California Institute of Technology (Cal Tech). One of the main justifications for this large-scale effort is the observation that "in the last 15 years, nearly 50 USC start-ups have headquartered themselves outside Los Angeles because of the city's lack of infrastructure and facilities." This is a concern that is often raised when such efforts fail, which has happened frequently, particularly in the IT and life sciences. For instance, Johns Hopkins University and the city of Baltimore is a frequently-cited example of a research university/city pairing with limited entrepreneurial impact (Feldman 1994, Feldman and Desrochers 2003a, Feldman and Desrochers 2003b, Feldman and Desrochers 2004).

Aware of the stakes, several local institutions have decided to work together with USC to develop a mechanism to help capitalize upon knowledge in the region and to limit the start-up brain drain going forward. Naturally, a large, long-term project such as the development of a Biotechnology Park adjacent to USC's Health Sciences Campus requires careful financial planning and a thorough strategic analysis of the different actors involved in the process. Balancing the interests of all stakeholders and understanding the diverse motivations of concerned parties will be critical in sustaining widespread support for the project's efforts.

\section{The emergence of a digital economy in Los Angeles}

Traditionally, Los Angeles has not been thought of as an innovation hub with a vibrant startup community, particularly compared to other locations in California such as Silicon Valley (in regard to IT) or San Diego with its vibrant biotechnology cluster. However, since the early 2000s, Los Angeles has experienced a substantial increase in startup activity as well as venture capital investment, particularly in the digital media space(CB Insights 2013). This fact is a very interesting phenomenon given that Los Angeles started out as the main funding destination in the 1940s due to its strong early computing industry, but has since gradually lost a lot of its initial share to other California regions such as Silicon Valley. In a recent study conducted by the Startup Genome project (2012), the Los Angeles region ranked as one of the most attractive startup and innovation ecosystems in the world, placing third and only trailing Silicon Valley and Tel Aviv. This index takes into account startup output, funding, performance, talent, support systems, mindset and trendsetting ability and combines business data with entrepreneur interviews in order to present a well-rounded picture of the innovation ecosystem. While this

${ }^{3}$ See https://news.usc.edu/76533/usc-summit-marks-rebirth-of-biotech-era-in-los-angeles/ and http://www.latimes.com/opinion/oped/la-oe-0226-nikias-los-angeles-biotech-corridor-20150226-story.html 
ranking fails to account for a variety of factors and thus may overestimate the importance of the Los Angeles region, it certainly provides a good indication of the increased role that Los Angeles aspires to play in the larger innovation community. In the eyes of many informed observers, this spike in entrepreneurial activity has come as a direct result of the so-called Silicon Beach movement.

Despite receiving a lot of attention in the popular media as well as from the local policy and business communities, many questions remain to be answered about Silicon Beach. Vanderhoef (2014) argues that while Silicon Beach companies have been very successful in early stage fundraising and have shown great promise in turning Los Angeles into a new center of digital and creative entrepreneurship, the movement to-date has not produced a major corporation and the relative strengths and competitive advantages compared to other innovative regions are not yet well defined. For policy makers who seek to draw on Silicon Beach entrepreneurs as drivers of local economic growth, it will be critical to understand the needs of these companies in terms of infrastructure, funding, labor force and policies in order to maximize its potential as a local and regional innovation hub. 


\section{The University of Southern California as an emerging entrepreneurial university}

\section{A Biotechnology Science Park for South-East Los Angeles?}

Over the past decade, policy makers have increasingly looked at universities as drivers of local economic growth. The business incubation and research commercialization activities of large entrepreneurial universities like MIT are perceived to have been at the core of innovation as their surrounding regions transitioned from an industrial to a knowledge-based economy (Etzkowitz 2010). The federal government provided much of the funding for the industrialization of MIT's research. During and after the Second World War, the federal government, in an attempt to create regional diversification in its R\&D portfolio, spread out its funding to include universities and firms in the Western part of the country, particularly in California. This is believed to have facilitated the emergence of industrial clusters around Cal Berkeley and Stanford that later grew into the larger cluster now known as Silicon Valley (Sturgeon 2000). In addition to soliciting and receiving federal funds, universities in some cases did much more, including soliciting private support for commercialization and spending resources on increasing the size of their programs in the science and technology fields.

Along those lines, Thorp and Goldstein (2013) of the University of North Carolina argue that it is the duty of universities to become "Engines of Innovation", to step up and become major economic actors and job creators for their regions. The economic impact of university spin-offs and other business ventures that emerge from academic research institutions are further outlined by Etzkowitz (2003), Bramwell and Wolfe (2008), Rasmussen and Borch (2010), Van Looy, Landoni et al. (2011) and others.

Since the enactment of the Bayh-Dole Act in $1980^{4}$, universities own (and can retain or dispose of) the intellectual property developed by their federally funded research, thus increasing their and their faculty and students' willingness to commercialize research that was undertaken using federal funds. Mowery and Ziedonis (2000), Mowery, Sampat et al. (2002), Shane (2004), Stevens (2004), Mowery and Sampat (2005), Sampat (2006), Rafferty (2008), Leydesdorff and

\footnotetext{
${ }^{4}$ See legislative text at http://www.gpo.gov/fdsys/pkg/STATUTE-94/pdf/STATUTE-94-Pg3015.pdf
} 
Meyer (2010), Aldridge and Audretsch (2011), Grimaldi, Kenney et al. (2011), Kenney and Patton (2011), Thursby and Thursby (2011) and others have investigated the impact of universities' patenting capabilities before and after Bayh-Dole was signed into law and have found an increase in technology transfer activities as well as a shift toward practical research in many universities, although it is difficult to isolate the impact of Bayh-Dole from other effects and broader research trends. In the meantime, many universities have developed frameworks to facilitate the commercialization of research, such as technology transfer offices and rules for licensing and joint venture (JV) agreements with industry. While the actual effect of Bayh-Dole on university research agendas is somewhat disputed, the legislation at the very least appears to have contributed to the emergence of applied scientific fields such as IT, biotech and nanotech, which now account for a majority of university patents.

\section{Containing knowledge spillover in Los Angeles}

In February of 2015, the University of Southern California (USC) announced its plans to develop a Biotechnology Park in the Boyle Heights area of Los Angeles, in a joint effort with the City of Los Angeles, the L.A. County Board of Supervisors, the L.A. Unified School District (LAUSD) and the California Institute of Technology (CalTech) (Di Rado and North-Hager 2015). One of the important justifications for this large-scale effort is the observation that "in the last 15 years, nearly 50 USC start-ups have headquartered themselves outside Los Angeles because of the city's lack of infrastructure and facilities" (Battelle Technology Partnership Practice 2012, Battelle Technology Partnership Practice 2013).

In response, local institutions have decided to work together to develop a mechanism to help contain knowledge in the region and to limit the start-up brain drain going forward. Naturally, a large, long-term project such as the development of a Biotechnology Park adjacent to USC's Health Sciences Campus requires careful financial planning and a thorough strategic analysis of the different actors involved in the process. Balancing the interests of all stakeholders and understanding the diverse motivations of concerned parties is critical in sustaining widespread support for the project efforts. 


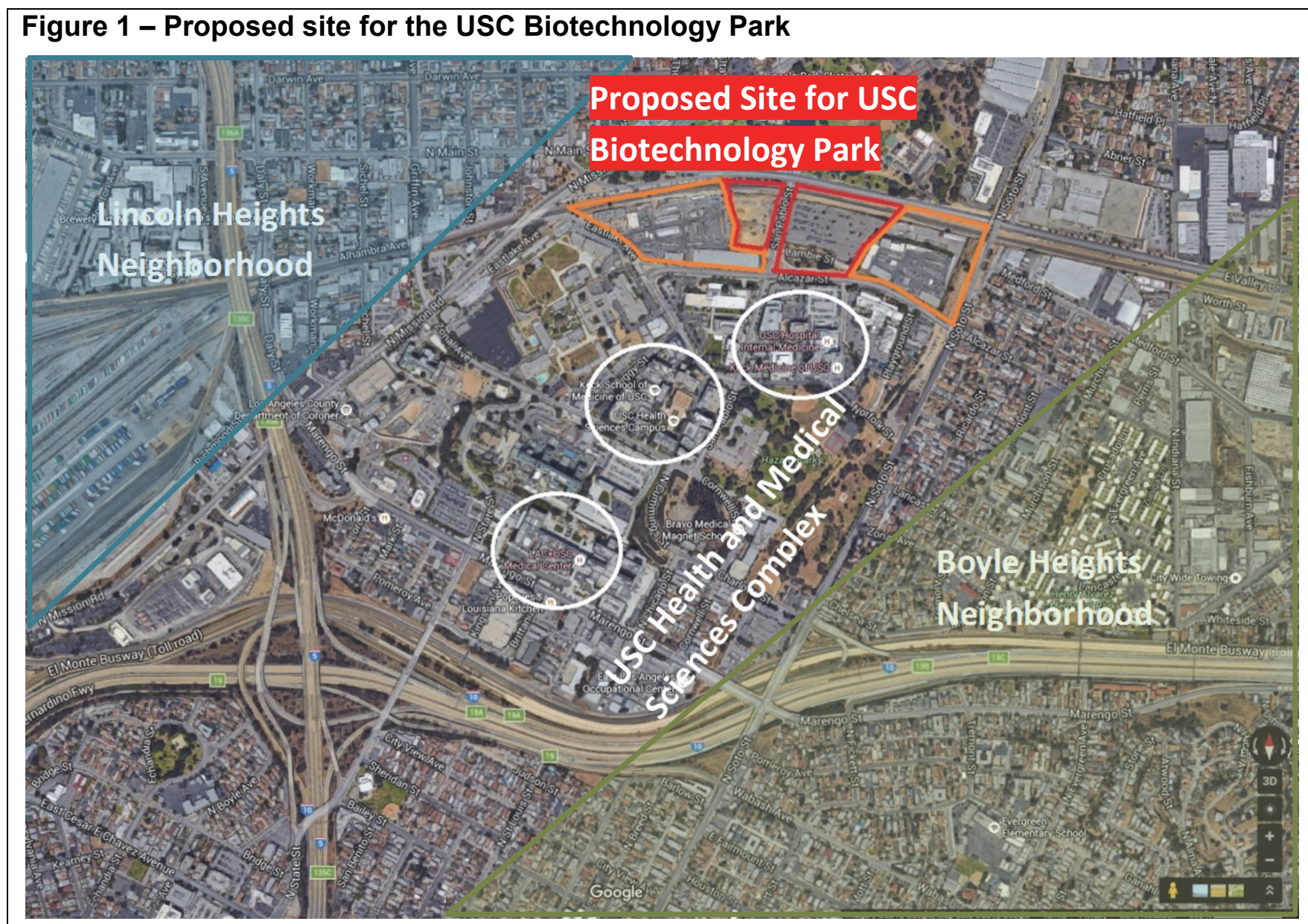




\section{The theory behind entrepreneurial universities}

\section{Outlining the idea behind entrepreneurial universities as engines of economic growth}

USC's plans to increase its entrepreneurial presence in the Los Angeles region stems directly from the idea that universities as producers of knowledge ought to assume a centralized role in the knowledge-based economy. (Nikias 2015) The ability to produce knowledge locally has turned into a key regional competitive advantage, particularly when assuming that tacit knowledge transmitted in person rather than codified and easily-dispersed knowledge is the main mechanism through which knowledge spillover into the economy occurs. This emphasis on local knowledge transfer has led to the emergence of a third mission for universities as sources of knowledge: calling on these institutions to become drivers of their local economies through commercializing research outputs and moving beyond the traditional functions of teaching and scientific research (Etzkowitz and Zhou 2007, Youtie and Shapira 2008, Guerrero and Urbano 2012). However, prior to looking into the entrepreneurial impact of USC and its plans to build a biotechnology hub in South-East Los Angeles, it is important to understand the broader implications of this shift for universities towards entrepreneurial objectives and to describe the ensuing challenges for university leadership, faculty, researchers and administrators.

Why are universities regarded as drivers of local, regional and states economies? What makes them special?

For a long time, policymakers have viewed universities as critical for driving local economies, particularly for training the workforce. However, over time, the economic mandate of universities has expanded to include wider objectives such as spurring economic growth by creating entrepreneurs and scientists through new innovations that can lead to commercial success. For instance, Tornatzky (2000) states in a report on behalf of the National Governors' Association that in an economy that is increasingly based on knowledge rather than industrial production and tangible outcomes, it is imperative for states to avoid brain-drain and to consider their local universities as both talent retention factors and knowledge hubs. Specifically, he points to the rise of the knowledge-based economy, the emergence of new industries and products from university-industry collaborations, as well as the vast potential for interdisciplinary, boundaryspanning research and innovation as key drivers for this new role of universities in their regional economies. Etzkowitz and Zhou (2007) further add that the mission of entrepreneurial 
universities extends far beyond short-term economic gains. University research can seed entirely new industries and anchor regional science-based clusters and thus, over time become its host regions' key source of competitive advantage. Knowledge-based industries no longer represent niche businesses at the periphery of the economy. On the contrary, they are assuming a centralized role, thus propelling entrepreneurial universities to become engines of local economic growth and natural incubators of new, innovative business ideas.

\section{What are the underlying mechanisms that allow universities to act as drivers of economic growth and hubs of entrepreneurship?}

In the age of globalization, there is a diminished locational advantage due to the fact that resources are increasingly interconnected and easily obtainable. Rothaermel and Ku (2008), however, posit that while this is true for raw materials and production resources, the opposite holds for knowledge-based industries in that are mainly driven by innovative ideas from individual entrepreneurs. Knowledge spillovers tend to be spatially constrained and their impact decreases with distance from the source due to increasing transaction costs. With increasing complexity of an innovation, the role of individual entrepreneurs, such as university researchers, assumes a central role in the application of the innovation in other settings. Given the reliance on a few key individuals in the spillover process, the locational preferences of these individuals present natural boundaries to knowledge spillover. In essence, the innovation differentials between regional clusters can be explained by each region's endowment of financial, intellectual and human capital. Porter (2011) adds that

"the enduring competitive advantages in a global economy lie increasingly in local things - knowledge, relationships, and motivations that distant rivals cannot match."

Youtie and Shapira (2008) as well as Patton and Kenney (2010) further contend that while universities largely operate in an open science environment that is focused on sharing information across global boundaries, tacit knowledge that is specific to the original inventor is often highly context based and hard to replicate in other geographical settings.

In consequence, the fact that knowledge-driven innovation is highly dependent on the intellectual capital housed within universities or other research entities such as firms or laboratories generates a new form of localized competitive advantage for regions with a critical 
mass of world-class research institutions that have the ability to attract and retain research talent.

\section{Understanding the knowledge spillover framework}

While scientific innovation within a university is a necessary ingredient to the university's ability to catalyze knowledge-based economic growth, it may not be sufficient. At the very least, universities need to have a sound technology transfer process in place in order to ensure that the knowledge their researchers create actually translates into economic activity and ultimately leads to increased regional prosperity. The specific elements of this process are depicted in Figure 2:

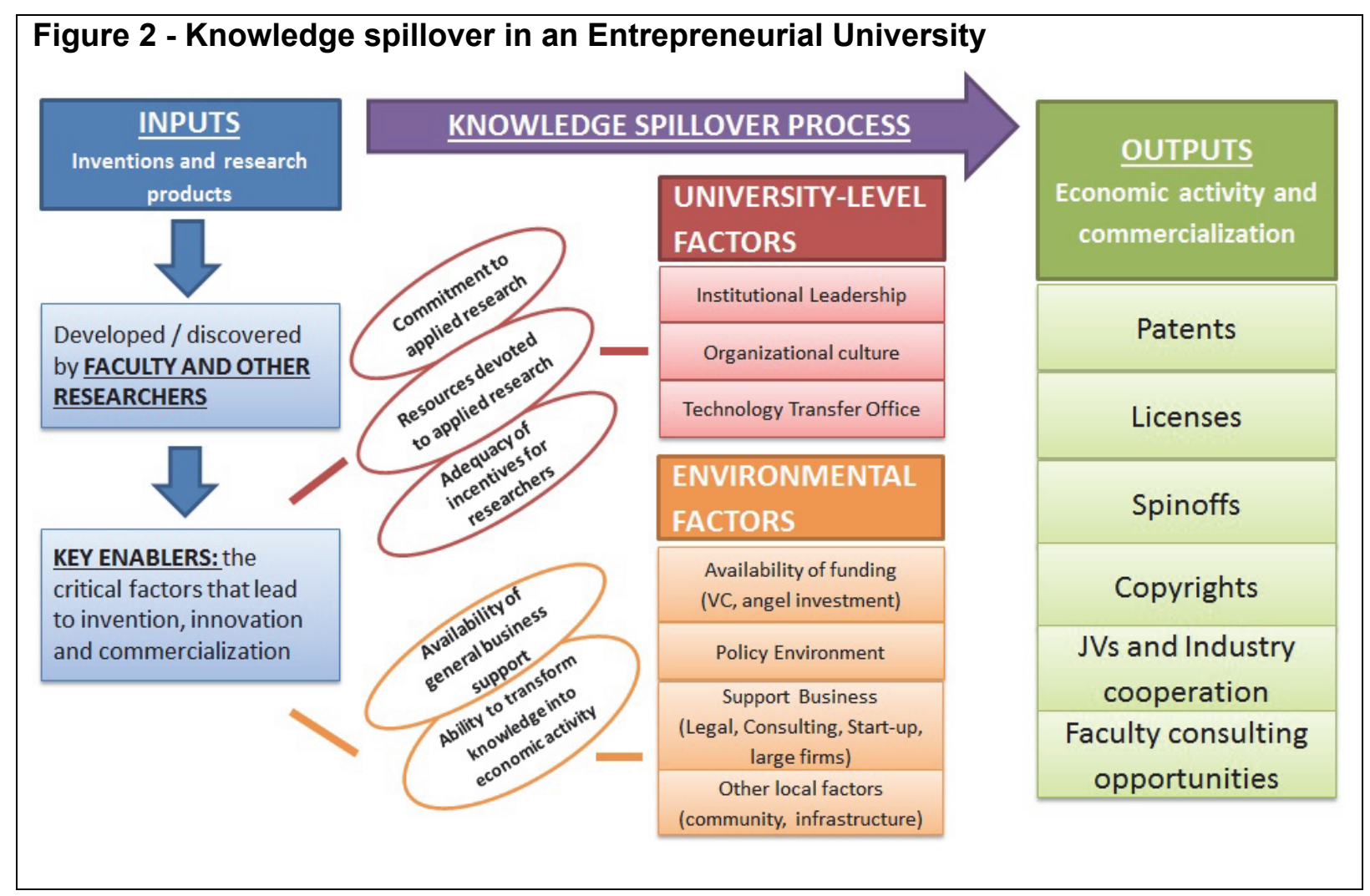

The term knowledge spillover describes a university's ability to convert knowledge-related inputs such as inventions by its researchers into outputs that directly or indirectly generate economic activity in the region (Mueller 2006, Thorp and Goldstein 2013). The rate at which knowledge spillover occurs depends on several factors internal to the university such as institutional 
policies, setup and leadership, the effectiveness and level of resources of its technology transfer office, and its general entrepreneurial culture. In addition to this formal technology transfer process, various external or environmental factors can either enhance or hinder a university's ability to convert invention to innovation. In that regard, the availability of funding and business support functions in the region, the general local suitability and friendliness toward businesses and the policy environment hold particular importance. Accordingly, Rothaermel, Agung et al. (2007) develop a framework to evaluate the entrepreneurial setup of a university and its ability to act as an engine of economic growth consisting of four key determinants: the internal institutional setup of the university itself, the productivity and effectiveness of its technology transfer office, its ability to create new firms, and the environmental context including innovation networks.

In order for a university to become a successful driver of local economic growth, its leadership needs to establish various internal mechanisms to ensure that inventors and researchers inside the university are set-up to become academic entrepreneurs. In their thorough review of the academic literature on university entrepreneurship, Rothaermel and colleagues find that the extent of a university's entrepreneurial orientation can be measured in a variety of ways, all of which capture the underlying inputs, outputs, processes and impacts that lead to successful university entrepreneurship. Among others, these measures include the existence of a formal commercialization agenda and program, the number of cooperation agreements and joint ventures between the university and non-academic actors, the amount of commercialization revenues as measured by patenting and licensing revenues, the amount of resources devoted to commercialization activities such as R\&D-related spending and marketing budgets and the overall quality of applied research as signified by faculty reputation and citation frequency.

As outlined above, one of the most critical tasks in achieving economic growth through academic entrepreneurship and applied research is the ability to effectively translate inventions and scientific discoveries into marketable innovation. Technology transfer offices within universities often act as a link between university scientists and commercial interests and function as gateways to the local economy. Essentially, these offices evaluate invention for their marketability and help with the patenting and licensing processes. While not typically part of their core mandate, some offices may also connect university researchers to funding sources and specialized business support functions such as real estate agents and industry experts. Rothaermel and colleagues suggest that these technology transfer offices play a crucial role in the commercialization process and that their endowment with appropriate staffing, as well as 
their relative standing within the university hierarchy, are essential in fostering university entrepreneurship. A strong technology transfer office within a university often suggests a firm commitment to applied research and commercialization objectives and signifies university leadership's desire to encourage its faculty to become academic entrepreneurs. On the contrary, universities with limited technology transfer resources may not have a strong entrepreneurial culture (Trune and Goslin 1998, Rogers, Takegami et al. 2001, Powers 2003, Chapple, Lockett et al. 2005, Markman, Gianiodis et al. 2005, Markman, Phan et al. 2005).

A university's ability to generate spinoff firms from its research depends directly on the interactions between researchers and the technology transfer office. Both patents and licensing agreements can be thought of as indirect commercialization strategies where researchers have little-to-no involvement with the business following commercialization, mainly focused on the creation and protection of intellectual capital and not as much bound locally. University spinoff or startup ventures as well as joint ventures on the other hand are more directly tied to the university's specific location and personnel, and are therefore more likely to have an impact on local economies in the short term through attracting local investments and creating jobs as well as other business opportunities. Patents and licenses are typically classified as codified knowledge that is not locationally constrained, but joint ventures and spinoff firms frequently rely on the expertise of their academic founders and other university personnel, as well as the intellectual capacity housed within the university from which they originated. As a result, close proximity to the original source is instrumental to their sustained success (Di Gregorio and Shane 2003, Lockett, Wright et al. 2003, Link and Scott 2005, O'Shea, Allen et al. 2005, O'Shea, Chugh et al. 2008).

Lastly, the environment surrounding a university is critical in determining its ability to foster innovation and economic growth. A vibrant entrepreneurial support network surrounding the university, consisting of business support firms in management, legal and real estate functions, highly specific technical support, and abundant venture capital resources, is crucial in generating a marketplace that allows research-based firms to thrive. Since a supportive business environment rarely arises in a vacuum, a suitable university environment for commercializing its researchers' inventions is not likely to result in local spillover without policy support for the creation of a supportive business environment. Thus, it is of the essence for policy makers to understand the needs and requirements of these kinds of research clusters in order to establish and maintain a suitable regulatory environment for knowledge-based economic growth. 
In summary, the technology transfer process describes the various steps involved in getting from knowledge-based inputs within universities, such as faculty inventions and disclosures, to marketable economic outputs, such as patents, licenses, joint venture agreements and spin-off or startup companies. Along the way, both internal university- factors and external environmental factors determine whether knowledge inputs can be translated locally into innovation and economic activity. Chief among the internal factors are the overall entrepreneurial culture as well as the effectiveness of a university's technology transfer, while the key environmental factors consist of a region's endowment of entrepreneurial networks and business-friendly policy institutions.

\section{What are the key impacts of this entrepreneurial mandate on universities?}

According to Röpke (2000), the transition from a traditional, research or teaching university to an entrepreneurial university has numerous impacts on their institutional setups and actions. When universities begin to act as agents of innovation, their staff has to act as carriers of knowledge due to the fact that knowledge is transmitted mainly through personal interactions and networks. In consequence, three stages in the entrepreneurial transformation of universities can be discerned: at first, the university starts acting in entrepreneurial ways. Secondly, people within the university become entrepreneurs. Finally, a refinement of the relationships between the university and its environment, mainly consisting of government and industry, toward applied research and collaboration occurs.

In their work on entrepreneurial universities, Etzkowitz and Zhou (2007) observe three primary characteristics that are indicative of a successful adoption of the entrepreneurial mission:

- "Entrepreneurial activities are accepted and systematically supported

- Interface mechanisms (e.g. a technology transfer office) and corresponding achievement

- Significant numbers of staff members form firms, which can generate income to support university research and other activities."

Feller (1990), however, cautions that while universities can have tremendous impacts on economic growth and localized innovation, an increased entrepreneurial orientation could adversely affect academic outcomes and scientific discovery. Traditionally, the strengths of academic institutions have been in teaching, invention and scientific discovery rather than in 
business ventures and adding a third mandate calls for institutional change within these institutions. He further suggests that while there have been various success stories, expanding a university's technology transfer capacity also comes at great cost. Inherently, the revenues from commercialization of research are best categorized as high-risk, high-reward business opportunities, yet the costs in setting up a technology transfer office and shifting the focus of the institutions are fixed and occur regardless of business success or failure. Therefore, technology transfer outcomes are uncertain while the costs of setting-up and maintaining commercialization capabilities inflict a substantial financial burden on the institution. In addition to the costs of technology transfer, the third mandate further affects research priorities and could lead to a shift away from basic science toward research and development and applied questions, and the increased emphasis on commercialization might endanger the open science model that has been a key driver behind universities' abilities to share knowledge and thus advance regional economies. 
Making sense of the relationship between university technology transfer and economic growth: knowledge-based clusters around entrepreneurial universities

The impact of entrepreneurial universities on cluster formation and knowledge-based local economic growth has been well documented. Notable examples that have been covered extensively in the academic literature are Silicon Valley around Stanford University and the University of California, Berkeley (Kenney and Von Burg 1999, Castilla, Hwang et al. 2000, Kenney 2000, Lee 2000, Sturgeon 2000), Route 128 in Massachusetts connecting Boston, Harvard and MIT (Dorfman 1983, O'Shea, Allen et al. 2007) and the North Carolina Research Triangle Park between the University of North Carolina at Chapel Hill, North Carolina State University and Duke University (Link and Scott 2003, Hardin 2008).

While these cases are frequently presented as role models for technology-based economic growth that is fueled by university research, a key question is whether the lessons learned from these cases can be applied to other regions with world class research institutions such as the Los Angeles metropolitan region which is home to the California Institute of Technology (CalTech), the University of Southern California (USC) and the University of California, Los Angeles (UCLA) (Salmi 2009, Rivera 2012). On the contrary, the absence of a university-based cluster in Los Angeles despite the presence of major research institutions suggests that while universities might be a necessary condition for knowledge-driven economic growth, they might not be sufficient. Looking at two case studies that are presumed to be particularly relevant to Los Angeles, this dissertation aims to discern how contextual factors contribute to the success of a particular innovation cluster.

The two case studies that are explored in detail are Johns Hopkins University and the Baltimore region as a counterfactual to the idea of entrepreneurial universities and the San Diego biotechnology cluster surrounding the University of California, San Diego, an innovation hub that is often referenced as a best practice by policy makers in Los Angeles due to its close geographic proximity and the focus on health sciences and technology.

\section{The biotechnology cluster in San Diego}

In a study performed by a team of researchers at UCSD Global Connect (2010), the San Diego biotechnology cluster is used as a case study of economic growth policy and the formation of technology clusters in remote areas. In essence, the underlying research question the team is trying to answer is whether lessons from the San Diego regional economy can be applied to 
other locations. In their analysis, the authors focus on the roles of governments, early flagship corporations and anchors, as well as innovation intermediaries in the development and ongoing success of the cluster.

Governments at various levels have affected the San Diego research cluster over time: the U.S. federal government has supplied basic research funding to UCSD and the surrounding research institutes and the longstanding tradition of mission-oriented contract work for various branches of the military has proven to be a great starting point for the technology sector in the San Diego region. In addition, the State of California continues to provide a substantial share of funding to public universities such as UCSD and has invested heavily in the physical infrastructure of the entire region. Furthermore, it has encouraged innovation partnerships between UCSD and other University of California branches, for example the California Institute for Telecommunications and Information Technology, operated jointly between UCSD and UC Irvine, though little innovation has come out of these partnerships to-date. Lastly, the local government in San Diego has ensured that zoning and land use regulations create and maintain a local environment that is conducive to research-driven innovation and has largely refrained from imposing a regulatory burden on local businesses in this sector.

Prior to the emergence of biotechnology and a research-driven cluster around its research institutions, San Diego's economy was largely dominated by military contractors focused on defense technology and military health care services. The presence of these firms generated a technically trained science and engineering workforce that would later become one of the backbones of the greater San Diego technology cluster. However, in addition to the large defense companies, the formation of anchoring firms in the health sciences proved to be a critical factor in establishing the biotechnology movement.

According to a study conducted by Walshok, Furtek et al. (2002), San Diego's academic research institutions were identified as potential anchors for a research-based cluster as early as the 1970s. The University of California, San Diego (UCSD) was able to recruit world class scientists to the region and as a result, managed to attract federal research and development funding, thus establishing an initial seed of intellectual capital. As other research institutions such as the Salk and Scripps Institutes emerged around UCSD, boundaries between academic research and industry became increasingly fluid, and San Diego developed into a very fertile research ground with a particular focus on applied, inter-disciplinary research areas. Furthermore, enabled by regional initiatives such as UCSD CONNECT ${ }^{5}$, university scientists

\footnotetext{
${ }^{5}$ For an overview of the UCSD CONNECT program, see http://www.connect.org/
} 
began to obtain dual appointments and started to forge invaluable connections outside the academic environment. In essence, the original purpose for UCSD CONNECT was to act as a biotech startup accelerator, but over time, the organization has expanded into a local biotech advocacy institution, serving to link researchers to policy and industry stakeholders. Lastly, following the establishment of a vibrant university-industry network, local research institutions played an important role in sustaining the cluster through a constant supply of talented graduates and researchers in a variety of research areas and hierarchical levels, as well as research-based startup companies.

While San Diego has not produced a major biotech corporation such as Amgen in the Los Angeles region or Genentech in the Bay Area, Casper (2014) suggests that the rise and fall of Hybritech have contributed substantially to the success of the region. Hybritech was founded in 1978, based on UCSD research in the field of molecular diagnosis and from the start pursued a very proactive commercialization agenda, with a strong emphasis on intellectual property protection and applied research. Throughout its tenure, Hybritech maintained close ties and collaborations with UCSD, and eventually, the company's ongoing success led to an acquisition by the large pharmaceutical firm Eli Lilly. Following the acquisition, many senior researchers who at the time held shared appointments between Hybritech and the region's premier research institutions decided to leave the company due to the increasingly traditional corporate environment and the deviation from a research-based startup culture. While these departures caused the slow demise of Hybritech, San Diego's flagship biotechnology firm, the acquisition had created a group of wealthy, entrepreneurially-minded scientists based in San Diego who proceeded to act as venture capital investors for an emerging biotechnology cluster. By the 1990s, this former cadre of Hybritech managers had transformed into a network of biotechnology leaders, providing funding, contacts, referrals and experience to academic entrepreneurs across the San Diego region.

In a separate study, Casper (2007) states that it is precisely this kind of entrepreneurial social network that allows the San Diego biotechnology cluster to thrive. Looking at career affiliation networks of founders for San Diego-based startups, he finds that, Hybritech managers were of fundamental importance in seeding and anchoring the cluster, especially in its early days. Aside from Hybritech itself, managers went on to form numerous other startups in the region, which subsequently spun-out a tertiary wave of firms. While biotechnology startups are often very risky, cost-intensive enterprises with high failure rates, the fully-formed entrepreneurial network surrounding San Diego's research institutions has created an environment that encourages risk- 
taking and, through an emphasis on weak social ties and high levels of job mobility, provides a sufficient safety net for failing entrepreneurs. Along those lines, the research team at UCSD Global Connect (2010) adds that the San Diego cluster is dominated by small, highly innovative firms due to the fact that the region does not have the space, facilities, resources or infrastructure to support larger corporate players. While constrained space typically leads to higher rents and higher fixed costs of conduction business, thus favoring larger economic entities over small firms, biotech firms in San Diego have been able to thrive on pooled resources and shared space. Based on these observations, Walshok, Furtek et al. (2002) conclude that the area's amenities and high quality of life, its solid core group of innovators and entrepreneurs, the presence of world class research institutions as well as its sustained entrepreneurial culture and spirit have emerged as the main factors leading to the formation of a strong entrepreneurial social network in San Diego.

Lastly, the research team at UCSD Global Connect (2010) attributes the success of the San Diego biotechnology cluster to its unique ability to cope with the particular set of limitations of the region as well as the industry. As research in biotechnology-related areas is very costintensive and high-risk, with lengthy research and development phases on low odds of success, it promotes a culture of risk taking, collaboration and resource-sharing. Consequently, choosing the right innovation partners and being able to draw on a steady entrepreneurial network have emerged as the key challenges for startup firms in the biotechnology space. In a way, locating in incubators around UCSD and other research institutions reduces some of these risks due to the broader availability of shared lab space and lowers the transaction costs to venture capital funders, but the San Diego region has also responded to these challenges by putting in place a strong set of innovation intermediaries such as the UCSD CONNECT initiative and industrybased organizations such as $\mathrm{BIOCOM}^{6}$, the local life sciences trade association. These associations serve as bottom-up, privately funded business initiatives to leverage biotechnology research and local innovation capacity as well as gathering places that cultivate a vibrant entrepreneurial network. The fact that most key players in the San Diego biotechnology economy are located in close proximity to each other and are further connected by an extensive social network leads Walcott (2002) to the conclusion that San Diego has emerged as a primary example of a cluster fueled by small firm and personal entrepreneurship with a culture of cooperation and enhanced ability to take advantage of knowledge spillovers. While many of the mechanisms that are in place to support the San Diego biotechnology cluster such as UCSD

\footnotetext{
${ }^{6}$ For further information on BIOCOM, see http://www.biocom.org
} 
CONNECT, industry trade organizations and specialized incubators present relatively inexpensive activities and are somewhat easy to replicate in other regions, San Diego's ongoing success suggests a mix of observable and unobservable factors as drivers of the cluster. As an example, Crescenzi (2005) suggest that the level of education and human capital accumulation in a region serves as a good approximation of that region's capacity to absorb knowledge-based innovation. In the case of San Diego and particularly the areas surrounding UCSD and the biotech cluster, the high overall levels of education, along with the solid base of technical and engineering talent developed as a result of the military contractors' demands for a well-trained labor pool, have led to the emergence of a highly-skilled local workforce able to support and enable research and knowledge-based innovation.

\section{Johns Hopkins University and the Baltimore region}

While prominent cases such as the San Diego Biotechnology Cluster, Silicon Valley, the North Carolina Research Triangle Park and Massachusetts' Route 128 present success stories of universities acting as engines of economic growth, there has been some criticism of the entrepreneurial role of universities presented by both popular media and academic scholars. For instance, both Auletta (2012) and Rao (2013) have raised the question whether universities should actually be involved in the running of such incubators due to the fact that academic institutions are not traditionally cut-out to pursue commercial interests and are not well-equipped to manage corporate operations. To the contrary, acting primarily as an entrepreneurial university may distract from a university's original mission of education and unbiased, academic research, and MIT's decision to reduce its involvement in applied research and focus more on blue-sky topics in the 1980s illustrates this line of thinking. (Vest 2004, Kaiser 2010)

In consequence, Feldman (1994) posits that while the presence of a world class research university may be a necessary condition for the formation of a high-tech cluster and knowledgebased, localized economic growth, it may not be sufficient. Using the example of Johns Hopkins and the Baltimore region, she conducted several studies to show that while researchers at the university have traditionally been very successful at obtaining federal research funding, economic development in the surrounding areas does not reflect the success of its high quality, local research institution and knowledge factory.

At first glance, Johns Hopkins University fulfills all necessary criteria for an entrepreneurial university: it receives copious amounts of federal research funding, conducts science-based 
research (mainly in medical and health-sciences related fields) and its faculty is highly reputable and respected across the globe. To a certain extent, this means that the university produces all the raw materials that are needed to spur innovation and economic growth in the knowledgebased economy: scientific breakthroughs, trained scientists, engineers and technicians. However, for one reason or another, the Baltimore region has not been able to reap the benefits of this entrepreneurial university model.

Often, entrepreneurial universities are very strong in research and discovery, but in order to ultimately commercialize the ensuing inventions and generate economic benefits, they need local infrastructure to supply development and commercialization capacity. A social innovation structure needs to be in place in order to absorb the benefits from university research and to translate them into tangible economic output. The San Diego biotechnology cluster as described above can be viewed as a role model for this kind of innovation ecosystem, with a highly flexible and nimble innovation support system full of small, highly-specialized and agile firms, but the Baltimore region has been characterized by large firm employment, working on inflexible, longterms contracts for the defense industries, particularly in areas such as applied physics. The fact that a majority of work is funded by the defense industries further places a boundary on knowledge spillover through classification, restricted distribution of results and intellectual property regulations. In her comparison of Silicon Valley and Route 128, Saxenian (1996) states that once technology firms in the Boston grew in size and developed into larger corporations, the region's innovative edge diminished, and it started to fall behind Silicon Valley, which managed to nurture a second wave of entrepreneurs once its initial seeding firms outgrew their startup cultures. Large corporations frequently value the protection of value of existing assets over risk-taking, thus making it increasingly difficult to remain innovative. The wave of healthsciences spinoffs surrounding Genentech serves to illustrate this story and as described above, the San Diego biotechnology cluster underwent a similar experience following the demise of Hybritech.

Given all of these factors, the Baltimore region has found it difficult to recruit and retain technology-oriented engineering and science graduates and has experienced severe brain-drain to more startup-friendly locations such as Silicon Valley. Moreover, while most firms in the Baltimore region work for common clients, there appears to be no unifying theme and no strong concentration of a particular industry, thus leading to a severely disjointed economy with little chance of a coherent cluster to take advantage of agglomeration dynamics. The lack of a specialized Science Park or highly-developed corporate research complex with innovation 
support entities such as law firms, patent lawyers, venture capital and consulting firms further exacerbates these problems.

Despite the fact that the innovation ecosystem surrounding an entrepreneurial university is an important factor in determining its success in serving as a driver of local economic growth, Feldman and Desrochers (2004) suggest that there are factors internal to the university that need to be considered as well. In an analysis of technology transfer data from the Association of University Technology Manufacturers (AUTM), Feldman and Desrochers (2003) find that while Johns Hopkins ranked highest in research expenditures in its peer group of world class research universities in 1997, it ranked near the bottom in all technology transfer-related outcome measures such as invention rates, royalty-generating licenses, total royalties received per license and the number of startups formed based on university research.

The culture of universities matters just as much as the innovation ecosystem when trying to assess a university's economic impact. Along those lines, it is important to consider that Johns Hopkins University, from its inception, has had a very different focus from universities such as Stanford University, which has traditionally been open to the idea of applied, practical research. On the contrary, Johns Hopkins University very early-on decided to pursue an open science model of research, with researchers focused on conducting science for science's sake rather than for commercial purposes, while ultimately trying to advance society through the creation of public knowledge. According to Brody (1999), this institutional pro-science mandate led to internal debates within the Johns Hopkins leadership and between university and industry representatives about what types of discoveries should be patented or licensed and whether there should be any university patents and licenses at all, ultimately resulting in an open science approach. Due to this strong commitment to basic science, more applied fields such as engineering, which are traditionally thought of as sources of applied research and innovation, gradually declined in importance within the university hierarchy and ceased to be top priorities. These developments have been viewed with great concerns by industry representatives as they have led to a legacy of generating theoretical, non-applicable and thus non-commercial research. As a result, Johns Hopkins has received little funding from industry sources and its researchers and faculty were lacking the connections to their colleagues in commercial enterprises that are often found in research-driven innovation ecosystems such as the San Diego biotech cluster;, San Diego, on the other hand, is characterized by an environment in which researchers move back and forth between UCSD, the Salk and Scripps Institutes and the plethora of startups surrounding these academically-oriented institutions. Different from most 
successful entrepreneurial universities, Johns Hopkins has been unable to retain most of it faculty entrepreneurs following a spinoff and has actively discouraged dual appointments between the university and industry.

Summarizing the work of Maryann Feldman and colleagues, a threefold explanation for this phenomenon is presented: first off, Johns Hopkins University leadership actively discouraged its faculty from pursuing entrepreneurial ventures for a long time, thus preventing the emergence of an entrepreneurial culture around the university; secondly, a substantial share of research funding was provided by the U.S. Department of Defense for the purpose of classified research, hence putting a limit on knowledge spillover; lastly, the surrounding region did not provide an environment conducive to academic entrepreneurship due to a variety of reasons. The human capital within the host region of an entrepreneurial cluster must be capable to receive the knowledge and must possess the necessary infrastructure to benefit from knowledge spillover. As a consequence, educational disparities between regions can thus becoming increasingly important in determining an area's suitability and capacity for knowledge-based innovation and economic growth. Universities can act as sources of knowledge and have increasingly developed internal processes to transfer this knowledge and technology into the local economy through their Technology Transfer Offices and other commercialization initiatives. However, knowledge spillover and containment of the economic benefits of university research in the local region may not be possible if the region is not endowed with the necessary innovation ecosystem including transportation and housing, local workforce training and supply, availability of support services such as finance, legal and administrative, as well as appropriate entrepreneurial and social networks. While the historical emphasis on basic science research at Johns Hopkins might have discouraged its faculty from pursuing applied and commercializable research, the region's failure to develop an infrastructure suitable to such innovation further exacerbated the lack of knowledge-based economic growth stemming from academic research.

\section{Implications for USC and South-East Los Angeles}

Following a thorough analysis of both successful and unsuccessful cases of academic entrepreneurship, it appears clear that both internal and external factors play important roles in determining whether a university is able to anchor a research-oriented cluster. In the case of Johns Hopkins University, the fact that university leadership is pursuing an open science model and has therefore has been unable or unwilling to foster an entrepreneurial culture and spirit among its faculty has been a major inhibitor to academic entrepreneurship. Aside from this 
institutional constraint, there also appears to be a lack of absorptive capacity in the Baltimore region. In contrast to thriving entrepreneurial regions such as Silicon Valley, Baltimore's economy is largely characterized by low-skilled and highly-fragmented industries. Furthermore, the area lacks resources precisely in areas that are attractive to knowledge-based workers and entrepreneurs such as availability of capital and venture capital, the presence of an entrepreneurial support network and a high overall quality of life (Florida 2014).

The biotechnology cluster in San Diego on the other hand is characterized by a strong entrepreneurial network of research scientists at UCSD and other research institutions, venture capitalists, serial entrepreneurs and other support factors such as specialized legal and real estate. Casper (2009) describes this phenomenon as a marketplace for ideas, a vibrant social network that links together managers, founders, scientists and investors:

"The marketplace for ideas is the social context in which ideas are brought together with human and financial capital to build a vibrant cluster. In asking why some clusters develop superior capabilities to commercialize science compared to others, the marketplace for ideas concept provides a framework to understand the missing link between the existence of world class scientific research facilities and a vibrant, well-performing biotechnology cluster."

When comparing biotechnology industries across San Diego, San Francisco and Los Angeles, he further notes that while Los Angeles has an impressive track record in scientific discoveries and inventions, commercialization happens predominantly in biotechnology destinations such as San Diego, San Francisco and Boston, a claim that is consistent with the ones used as justification for USC's Biotechnology Park initiative. The overarching research question of Casper's study is to determine whether Los Angeles possesses the necessary infrastructure to become a biotech cluster that is comparable to the top biotechnology destinations. In his investigation, he begins by looking at Los Angeles universities as the source of innovative capacity and by comparing commercialization activities across the major research clusters in California. He finds that LA-based research institutions were slow to adopt technology transfer practices, but have recently expanded and are slowly catching-up to their counterparts in San Diego and the Bay Area. Nonetheless, he contends that simply focusing on the so-called "push" factors of technology transfer, the ones that are internal to the university system, is not sufficient to achieve research-based economic growth. Additionally, it is very important to consider factors outside the university, so-called "pull" factors, such as the local innovation ecosystem and marketplace. Along those lines, he points to the importance of linked scientists and researchers 
that are collaborating across institutional boundaries. When examining entrepreneurial networks in the three California regions, he observes that inventors in both San Francisco and San Diego tend to be connected in a variety of ways, while inventors in the Los Angeles region tend to operate in a more isolated fashion. This higher degree of connectedness leads to increased inter-firm and inter-institution mobility and a more flexible labor market, and it ultimately encourages the emergence of a risk-taking culture that allows research-oriented entrepreneurs to pursue their ventures without being afraid to fail.

In summarizing Los Angeles' progress, Steven Casper states that the city is making strides towards developing a successful biotech industry, particularly in lower-risk industry segments such as devices, medical diagnostics and pharmaceuticals, fueled by the region's exceptionally large and diverse labor pool, the vibrant startup scene in certain areas and the readiness to invest in physical infrastructure. However, in order for a vibrant biotechnology cluster to emerge in the region, he emphasizes the need to develop credible social networks through anchoring firms, research universities or spillovers from other high-tech sectors in the region:

- Anchoring firms: both San Francisco's and San Diego's biotechnology clusters were initially seeded by researchers and managers from major firms, specifically Genentech and Hybritech. When looking at the social networks of inventors and biotech entrepreneurs in those regions, it is very apparent that they are anchored early-on by few major firms and spinoffs from these firms. The area surrounding Johns Hopkins University is missing such a potential anchoring firm, and while the Los Angeles region technically hosts a biotech champion in Amgen, its isolated location in Thousand Oaks does not position it well to anchor an entire cluster in the region.

- University anchors: with Cal Tech, UCLA and USC, the Los Angeles region is host to a number of world-class research institutions that bear the potential to generate inventions and scientific discoveries, the raw ingredients of economic growth and innovation in a research-oriented economy. However, researchers at these institutions currently tend to work in an isolated fashion and do not collaborate with researchers at other institutions or even industry.

- Spillovers from local high-tech industries: the Los Angeles region has recently experienced a rise in technology-oriented startup formation, particularly in the areas surrounding Santa Monica and Venice Beach (see Chapter 4 on the emergence of Silicon Beach). Given the fact that many biotechnology ventures are considered to be high-risk, high-cost investments, attracting venture capital funding is difficult, especially 
in a region that does not have a long-standing tradition of life sciences and technologyoriented investment. However, an emerging high-tech sector could lead to an increasingly entrepreneurial culture and mindset, thus bringing investors and entrepreneurially-minded people to the region and acting as a catalyst for the local biotechnology industry.

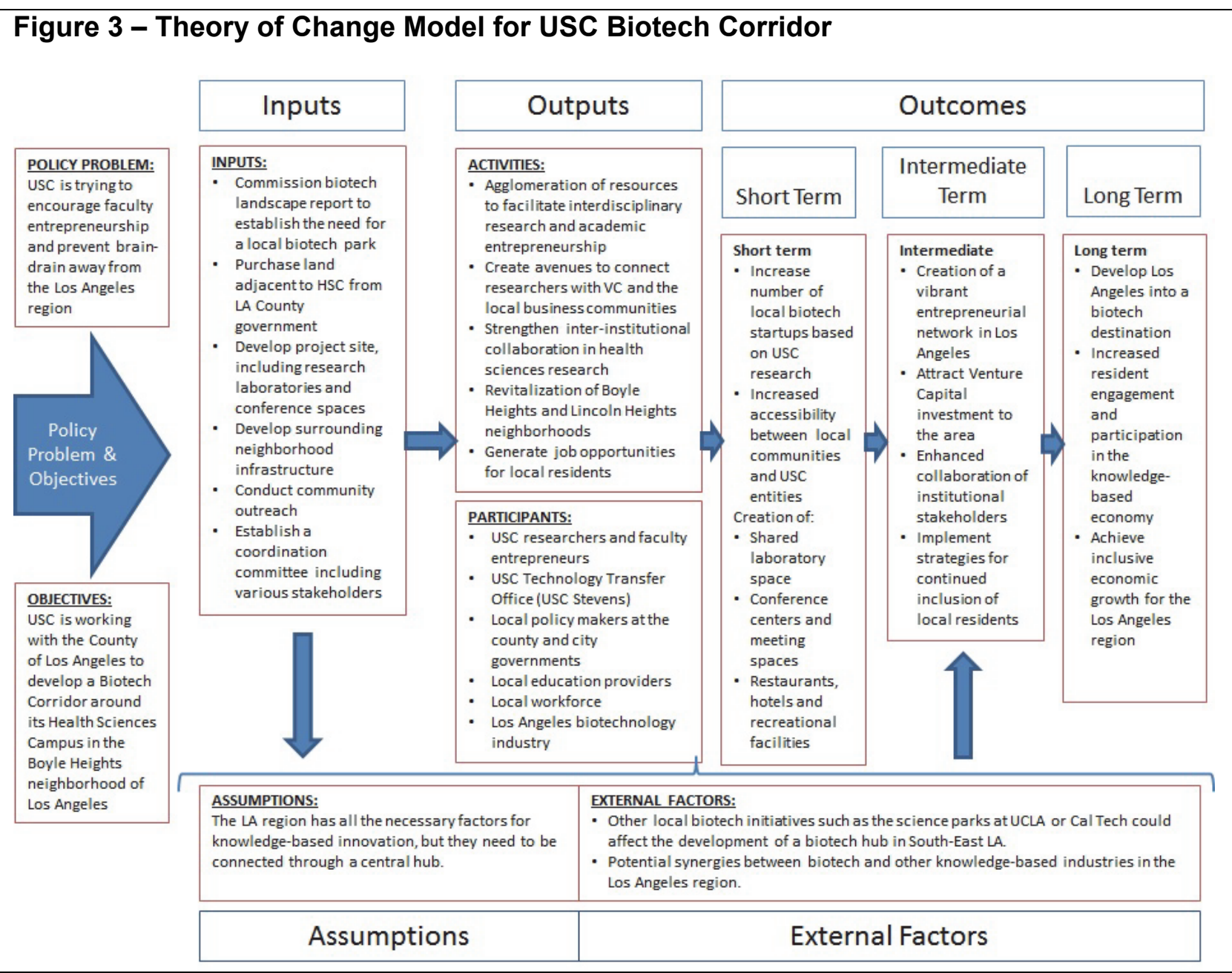

The theory of change model displayed in Figure 3 outlines the key factors and agents involved in the development process of a Biotech Science Park surrounding USC's Health Sciences Campus in the Boyle Heights neighborhood. In pursuing the ultimate objective of developing biotechnology research and commercialization capacity in South-East Los Angeles, acquiring the land that will host a potential research park, reaching out to the local communities and establishing a coordinating committee consisting of representatives of all key stakeholder 
groups are all crucial inputs at early stages in the process. In a way, the creation of a Science Park around USC's Health Sciences Campus can be viewed as an attempt to provide a hub or point of agglomeration for Los Angeles' vast but widely dispersed biotech industry. Therefore, once the initiative is under way and the Science Park is in operation, it is important to ensure that the park meets all the physical infrastructure needs of researchers and academic entrepreneurs, such as shared lab spaces, work areas and conference rooms, and the broader need of establishing avenues to connect USC researchers to venture capital resources and the wider Los Angeles business support network. Given the lessons learned from other cases such as Johns Hopkins and the Baltimore region, it is also critical to find ways to actively involve local communities in the revitalization process through job creation and the development of the local transportation infrastructure, as well as recreational facilities, hotels and restaurants.

In order to effectively gauge the success of the USC Biotech Park initiative, various short, medium and long-term objectives can be evaluated. In the short-term, enhanced research output as measured by patents, licenses and local spinoffs that are established locally around the Science Park would be indicators of success; additionally, the emergence of a vibrant network of biotech support firms in specialized legal and real estate functions, as well as higher levels of connectivity between the university and the local communities would demonstrate this success as well. In the medium term, the Science Park should serve as an anchor for a vibrant regional network of biotech industry representatives, venture capital investors and academic entrepreneurs, and should spur interaction between USC and other research institutions across the Los Angeles region to institutions such as UCLA and Cal Tech. Moreover, it should provide steady pathways toward reliable employment in STEM-related fields for local residents. Along those lines, it will be critical for all stakeholders to work together in order to develop a local support system for innovation and knowledge-based economic growth. In the long-run, the Science Park, along with similar initiatives spearheaded by other local research institutions, should lead to the establishment of the Los Angeles region as a major biotech and health sciences destination, capable of attracting outside funding and outside entrepreneurs. Due to the fact that the Health Sciences campus is located in an under-developed area, pursuing economic development in an inclusive manner and investing heavily in local human capital advancement will be instrumental to the sustained success of a potential biotechnology cluster. 


\section{Constructing a stakeholder map for the USC Biotech Corridor}

\section{Analyzing stakeholder objectives for USC's Biotech Park initiative}

Building on the findings outlined above, this dissertation develops a comprehensive stakeholder analysis for the USC Biotech Park, using qualitative methods to describe the various interests and concerns that ought to be considered in planning this initiative. Again, following the comparative analysis done by Casper (2009), both internal and external factors are important determinants of the Los Angeles region's ability to develop a thriving biotechnology cluster: internal or push factors are mainly related to the universities' capacity to commercialize research, while external or pull factors are made up of what he refers to as the local marketplace for ideas as well as supply factors such as infrastructure and human capital endowment. Accordingly, at least five different interest groups can be identified (see Figure 4):

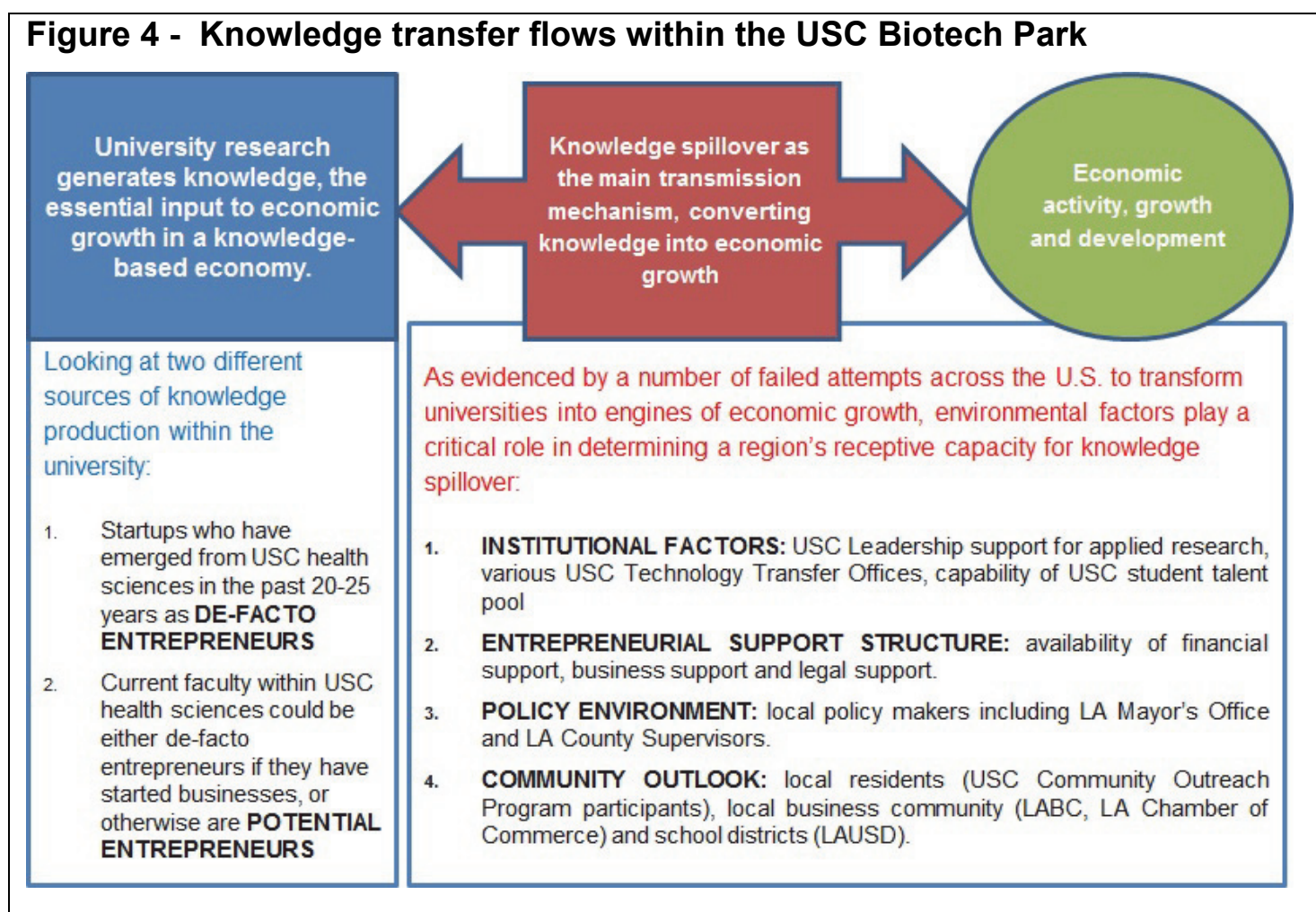

The key audience for this initiative is defined by USC as faculty entrepreneurs that are thinking about starting a business based on their research. In essence, incentivizing these academic entrepreneurs to stay in Los Angeles is the core idea behind the Biotechnology Park, thus 
spurring local economic growth in the region. This dissertation conducted semi-structured interviews with USC researchers who have started businesses based on their research, as well as current faculty in fields with high startup potential - medical and health sciences, engineering, biosciences and chemistry. These interviews are used to understand the motivations behind actual or potential location decisions and to develop measures that can improve startup retention under the new Biotech Park infrastructure. Results from the interviews are drawn upon in order to identify what factors entrepreneurs consider critical in their location decisions and what determines a sound innovation infrastructure. In the long-run, addressing these needs in the local infrastructure planning process will make it easier for Los Angeles to both retain local startups and attract outside entrepreneurs as well as entrepreneurial support ventures.

In efforts that are primarily focused on generating high-tech economic growth, one fact that often receives little attention is the impact that such large-scale initiatives might have on the local neighborhood and population. As is the case with both USC and Johns Hopkins, the university as a source of knowledge resides within a community that may not be sufficiently trained or resourceful to play a supporting role by providing the key features that an entrepreneur contemplating a spin-off locally will need, such as labor, finance and lab space. Building a Biotech Park in the Boyle Heights area of Los Angeles might, on the contrary, lead to considerable resistance of the local population for fear of being left out or even displaced in the process of transitioning to an economic environment focused on high-technology. In order to accurately outline people's concerns and to develop concrete recommendations for accommodating measures, focus groups were held with local residents and neighborhood council representatives. Such measures conventionally include re-training in areas more closely aligned with the startup local workforce needs determined in the faculty interviews above and raise the questions of whether and how the local community can access and take advantage of such training, the costs and the process.

Lastly, interviews were conducted with the following key interest groups directly involved in the planning process in order to understand their motivations and objectives for the USC Biotech Initiative:

- Local policy makers at the city and county levels

- University leadership at USC as well as other local education providers such as the school districts, community colleges and other universities

- Representatives of the local business community

- Biotech industry stakeholders 
- Academic experts in the areas of knowledge-based economic growth and technology transfer

Using a multi-method approach, this dissertation identifies each stakeholder's unique interests and needs in the biotech corridor efforts to both assess entrepreneurial needs and local capacity as described in Figure 5:

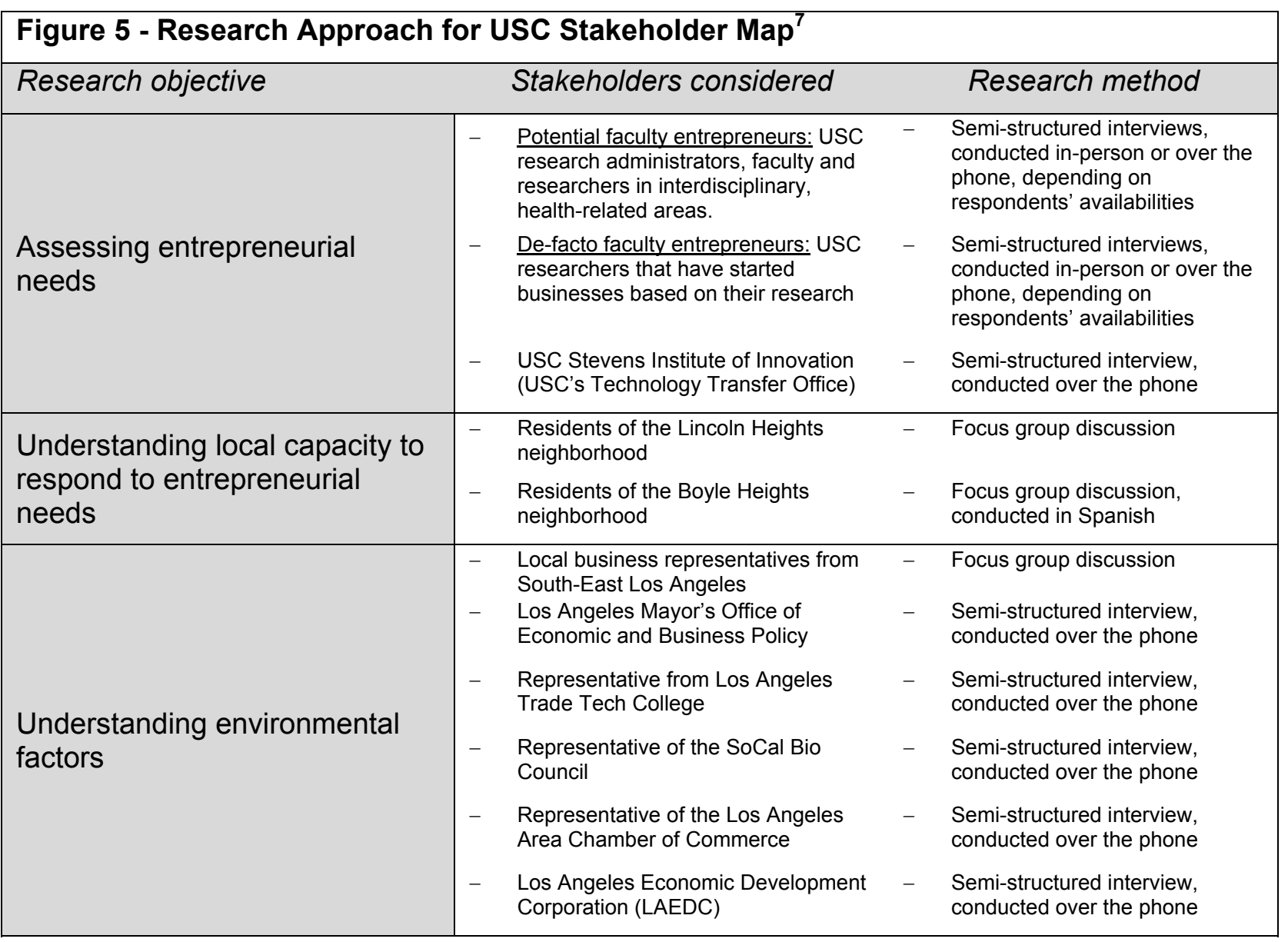

\footnotetext{
${ }^{7}$ See Appendix for Focus Group and Interview Protocols
} 
In the following section, results from the various stakeholder interest assessments are combined in order to derive a set of conclusions and policy recommendations geared at both helping USC to assess the needs of its faculty entrepreneurs and the state to boost the innovative capacity of the local environment. Specifically, the following research questions are addressed:

\section{Entrepreneurial needs assessment}

- Based on the interviews with faculty entrepreneurs, what are the main elements that make-up an innovation-friendly environment that incentivizes startups to stay? What are the missing ingredients in Los Angeles?

- What is it that regions like Silicon Valley and San Diego have to offer to startups that the Los Angeles innovation environment is missing?

\section{Local capacity to respond to entrepreneurial needs}

- What is the specific role of institutional and policy stakeholders?

- What role can the local community play in addressing the gaps in LA's innovation environment? 


\section{Research findings}

\section{Understanding local capacity to respond to entrepreneurial needs}

In an article from the Yale Daily News, Kofman (2013) describes the development of New Haven's Science Park, a project that was started in 1982 in order to spur science-based innovation and economic development based on research coming out of Yale University. While the park set out to bring economic growth and prosperity to the region, it has thus far failed to attract many businesses and has been viewed with increasing skepticism by the underserved local communities. As an example, with regards to a new housing development adjacent to the science park, the author states that "it seemed, to those living in Newhallville-Dixwell, that forces no one had told them about were shaping a development nearby that they would never work at, let alone ever see." In addition, she points out that the science park effectively presents a tradeoff between economic development and innovation on one hand, and gentrification and displacement of local communities on the other hand, a concept that is outlined similarly in an analysis of AvePark, a science park in Guimares, Portugal (Carvalho 2009) .

Therefore, it is important to consider the impact that science and technology parks have on local communities and the environment. Frequently, these kinds of parks are created in former industrial areas with low rents and an abundance of space, largely inhabited by underserved communities. Thus, in order to achieve inclusive economic growth, local residents have to actively be involved from the start, and the planning agencies in charge of a science park initiative have to think carefully about potential ways to facilitate community participation and to overcome potential challenges that the community might face. Consequently, this dissertation begins by conducting focus groups with representatives from the two major neighborhoods surrounding USC's Health Sciences Campus in South-East Los Angeles. During the two focus groups with local community representatives from the Boyle Heights and Lincoln Heights neighborhoods of Los Angeles, three overarching research questions were discussed, covering people's previous interactions and experiences with USC, their perceptions about the planned Science Park, and the ways in which they can get involved in the initiative.

When looking at selected quotes from both focus groups, it appears that residents have generally had positive experiences with the university (see Figure 6). As both communities are located around USC's Health Sciences Campus and Medical Center in South-East Los Angeles, they have received a great deal of health-related training. However, it was mentioned on several occasions that while the university has done a lot to develop the community, such as improving 
local streets, funding community-initiated programs such as a local farmers' market in Lincoln Heights, and working with the local school system, its efforts have gone somewhat unnoticed by the local residents. The fact that surrounding areas such as Highland Park continue to develop at the expense of the local community triggers fear of gentrification among local residents, a fear of being pushed-out and priced-out of a neighborhood that they have been living in for decades. Both the potential construction of new college dormitories and USC's general eagerness to expand were referenced as concerns. To illustrate this fact, one participant in the first focus group asked why USC keeps constructing new buildings without telling the community about its plans.

\begin{tabular}{|c|c|c|}
\hline \multicolumn{3}{|c|}{ Figure 6 - Assessing people's previous interactions and experiences with USC } \\
\hline $\begin{array}{l}\text { Selected quotes from Boyle Heights } \\
\text { Focus Group }\end{array}$ & Convergent themes & $\begin{array}{l}\text { Selected quotes from Lincoln Heights } \\
\text { Focus Group }\end{array}$ \\
\hline $\begin{array}{l}\text { - USC provides training and is educating the } \\
\text { community } \\
\text { - USC provides support to low income people } \\
\text { - Investments in local infrastructure like the } \\
\text { new street (Norfolk St) for example: feels } \\
\text { safer, has more light post. Allows us to walk } \\
\text { more at night }\end{array}$ & $\begin{array}{l}\text { USC has done a lot for the local } \\
\text { communities and is well respected by } \\
\text { those who are aware of that fact. }\end{array}$ & $\begin{array}{l}\text { USC has made its impact, but only for the } \\
\text { employees of that community } \\
\text { At Lincoln High School, USC has a really } \\
\text { good name, does research on health - for } \\
\text { example those wristbands that measure } \\
\text { heart rates. And with the Hospital just down } \\
\text { the street, our students know about USC. }\end{array}$ \\
\hline $\begin{array}{l}\text { - Why is USC expanding and keeps } \\
\text { constructing new buildings without telling us } \\
\text { about their plans? }\end{array}$ & $\begin{array}{l}\text { There is an awareness issue, need to } \\
\text { promote more what USC is doing in } \\
\text { the community. } \\
\text { USC needs to communicate its } \\
\text { expansion plans more clearly to the } \\
\text { local community in order to avoid } \\
\text { misunderstandings. }\end{array}$ & $\begin{array}{l}\text { - At this moment, I feel that there isn't a big } \\
\text { connection - the residents don't understand } \\
\text { that USC is trying to be involved. } \\
\text { People would be really excited to know that } \\
\text { USC is taking an interest in the community, } \\
\text { because for the majority of the time I've been } \\
\text { living here, there hasn't really been a } \\
\text { spotlight on the city. }\end{array}$ \\
\hline $\begin{array}{l}\text { Concerned about new dorms on Alcazar: } \\
\text { college towns have a bad reputation } \\
\text { Dorms mean more attractions which are } \\
\text { going to raise the cost of living. Yes, there } \\
\text { will be more jobs but everything is going to } \\
\text { cost more. Boyle Heights is a low income } \\
\text { area. } \\
\text { - Concerned that apartment rents could be } \\
\text { going up }\end{array}$ & $\begin{array}{l}\text { Local residents are generally skeptical } \\
\text { and somewhat afraid of gentrification } \\
\text { and being priced out of their own } \\
\text { neighborhood. }\end{array}$ & $\begin{array}{l}\text { - The word gentrification triggers fear: we don't } \\
\text { want to lose that feeling of knowing your } \\
\text { neighbor, and there has to be some } \\
\text { assurance that there is an overall masterplan } \\
\text { for the area. }\end{array}$ \\
\hline
\end{tabular}


Following a general discussion about the university's impact on the neighborhood and people's personal experiences, residents were presented with a broad overview of USC's Biotechnology Park plans ${ }^{8}$ and were then asked to discuss various aspects of a potential science park (see Figure 7).

As with the previous experiences, local residents expressed both hopes and concerns with regard to a prospective science park. Essentially, participants from both groups viewed the science park as a tradeoff between a tight-knit and cohesive community on the one hand and an economic uplift and development on the other. While the prospects for new jobs and opportunities were welcomed, several people pointed out that there need to be mechanisms in place to ensure that benefits remain in the local community and that residents can share in the development. Both groups suggested that job creation through the science park sounded like a great idea, but only if there were ways in which the local youth in particular could be involved. Creating jobs that are attainable for local residents and providing adequate and targeted training to bridge any potential skills gaps were mentioned as particularly important. As a resident from Lincoln Heights put it, having people commute into the area to work at the science park and then leaving is not really a desirable way of developing the area. Rather, local home ownership should be fostered in order to achieve inclusive growth.

Generally, the group from Lincoln Heights appeared to have a positive and welcoming attitude towards the science park, and some participants even pointed out that a diverse mix of new and old residents could increase the reputation of the area and entirely transform it, making it a more attractive destination for everyone. The predominantly Spanish-speaking group from Boyle Heights, however, expressed concerns that an influx of strangers through the science park could jeopardize current community dynamics and that a potential increase in police presence could be perceived as racial profiling. In addition, the fact that a science park would lead to many more people in the community could cause increased traffic congestion and lead to a pronounced scarcity of parking spaces, an issue that seems to already be at the forefront of people's minds in Boyle Heights following the construction of student dormitories in the neighborhood.

While there appear to be some reservations, particularly in regard to the potential of the science park to entirely transform the neighborhood and to crowd-out current residents, people expressed a general willingness to learn as long as opportunities were perceived as accessible and worthwhile. In addition, many participants suggested that there is a real need for high

\footnotetext{
${ }^{8}$ USC's flyer on the Biotechnology Park can be found at https://communities.usc.edu/files/2014/10/USCBiotechOutreachFlyer.pdf
} 
quality and affordable food vendors and super markets, and that this could be an area where the needs of both USC students and local residents are converging. Boyle Heights residents added that the current transportation infrastructure in the area presents a major challenge, given that many locals do not own a car and are relying exclusively on public transportation to shop for groceries. The Lincoln Heights group further remarked that this is an area where local residents could get involved as food vendors, although some business training would be needed in order to do so. 
Figure 7 - Community perceptions about the Science Park

\begin{tabular}{|l|l|l|}
\hline $\begin{array}{l}\text { Selected quotes from Boyle Heights } \\
\text { Focus Group }\end{array}$ & Convergent themes & $\begin{array}{l}\text { Selected quotes from Lincoln Heights } \\
\text { Focus Group }\end{array}$ \\
\hline
\end{tabular}

Discussion item: How do you feel about more people coming into your area?

\begin{tabular}{|c|c|c|c|c|}
\hline- & $\begin{array}{l}\text { More people means more traffic. Students } \\
\text { are already parking in residential areas and } \\
\text { taking up people's parking spaces. }\end{array}$ & $\begin{array}{l}\text { Concerns about the increase in traffic } \\
\text { and density. }\end{array}$ & & $\begin{array}{l}\text { Is Lincoln Heights ready to house people? } \\
\text { Thinking about density, will people have the } \\
\text { ability to live, walk and have places to eat anc } \\
\text { play? We need a safe and walkable place. } \\
\text { Housing won't be a problem if it's built in a } \\
\text { way such that it is transportation-developed. }\end{array}$ \\
\hline- & $\begin{array}{l}\text { Depending on what kind of people are going } \\
\text { to work around the community, don't want } \\
\text { outsiders } \\
\text { Need more employment for locals, youth and } \\
\text { students: If you have jobs but hire people } \\
\text { who are not from the area or the community, } \\
\text { there is no point. } \\
\text { Employment should stay in the local } \\
\text { community; give a chance to the youth to } \\
\text { help the community. }\end{array}$ & $\begin{array}{l}\text { Facing a tradeoff between tightness of } \\
\text { the community and small-town feel on } \\
\text { one hand and economic uplift on the } \\
\text { other hand. } \\
\text { Looking for local employment and } \\
\text { people who are committed to the area, } \\
\text { not strangers }\end{array}$ & - & $\begin{array}{l}\text { USC's homeownership program needs to be } \\
\text { better balanced. The radius around the } \\
\text { Medical School is much tilted toward Boyle } \\
\text { Heights. They have to create a larger radius } \\
\text { around Lincoln Heights so that there are } \\
\text { more choices for people to live or even buy a } \\
\text { home. } \\
\text { Prefer residents who own property in Lincoln } \\
\text { Heights over residents who simply rent. } \\
\text { How exactly should this area be developed? } \\
\text { We need to influence the leaders and tell } \\
\text { them what we want - safe and healthy } \\
\text { spaces for people. We don't want high-rise } \\
\text { buildings where you don't know who your } \\
\text { neighbors are. }\end{array}$ \\
\hline
\end{tabular}

Discussion item: The Science Park's potential for new jobs in the area

Focus on creating jobs that are attainable for local residents.

Provide adequate training for residents to be able to work in the Science Park.

living in Ramona Gardens

Keep giving trainings to be able to get jobs, focus on also training the housewives and older people in the community.
General willingness to learn in the community, if opportunities are perceived to be accessible and worthwhile.
- $\quad$ There also have to be places for people to eat and people who live here need to be ready to attain the jobs provided by the Biotech Park.

- When I go to school, there are always a lot of older people, always wanting to learn. Not just young people are interested in working with USC.

- $\quad$ People are always looking for new jobs and opportunities. If Biotech is presented as an opportunity, people will be interested.

- When we heard that they were going to be at the local high school, even our older neighbor showed up.

\section{Discussion item: General impact on safety and the community}

- Having more cops in the area can be a benefit, but do not want a lot of unfamiliar strangers.

- Cops have a tendency for racial profiling, would prefer to have community watch programs instead.

\section{The Science Park should not disrupt} the local community.

Greater diversity in the community could be a good thing and will enhance the area's reputation.

There is a fear that enhanced safety and security means racial profiling by the police.

Discussion item: New businesses forming around the Science Park

- Why do they not make a supermarket close to the area? Would benefit both the community and also the USC students (not a fancy chain, but something that would appeal to everyone such as Food for less)

- Currently, super markets are far away and difficult to access: No car, some bus lines got moved
There is a need for high-quality, affordable food vendors that satisfy both the needs of USC students I faculty and local residents.
More people in the community could lead to greater diversity - currently mostly have Asians and Hispanics here. This neighborhood has a bad reputation for being East-LA, a bad place that people don't want to go to. 
Lastly, concrete strategies were discussed through which local communities could be actively involved in the science park, given the particular challenges and roadblocks to both Boyle Heights and Lincoln Heights residents (see Figure 9). USC's ability to develop an effective outreach and communication strategy in order to promote the science park was cited as the single most important issue in getting the community on board. The idea of biotechnology and research-driven economic growth is difficult to grasp for many people in the local communities and might lead to misunderstandings and a default negative attitude. A complex project such as the USC Biotechnology Park, if not properly explained, may seem overwhelming and even intimidating to local residents and the lack of understanding might lead to the emergence of rumors and misconceptions about the initiative.

In order to avoid such issues, several mitigating strategies were proposed. Boyle Heights residents suggested that community leaders should give tours of the science park to their neighbors in order to increase familiarity with the facilities and portray the concept in a more approachable way. In addition, participants from Lincoln Heights added that local high schools could serve as a great starting point for community outreach since children in the local communities have served as catalysts in the past, connecting their families and local institutions such as USC. As one participant elaborated, if USC can effectively energize local children and students about the biotechnology initiative, they will relay the message to their parents and convince them of the potential benefits.

In terms of job opportunities, residents were excited about the general prospect of growth across all occupational areas. While the small sample sizes of the two community focus groups do not allow for a rigorous statistical analysis, residents of both Lincoln Heights and Boyle Heights seem to agree that jobs are needed at all levels (see Figure 8):

\section{Figure 8 - Suitable occupations for local residents}

\begin{tabular}{|c|c|c|c|}
\hline $\begin{array}{l}\text { A Science Park will need people to } \\
\text { work in a large variety of jobs such as: }\end{array}$ & $\begin{array}{c}\text { FG } 1 \\
\text { Mean (SD) }\end{array}$ & $\begin{array}{c}\text { FG } 2 \\
\text { Mean (SD) }\end{array}$ & Comments \\
\hline Research and technical support & $\begin{array}{c}2.364 \\
(1.367)\end{array}$ & $\begin{array}{c}2.2 \\
(1.469)\end{array}$ & $\begin{array}{l}\text { - would require more education, hardest to attain } \\
\text { - for the youth, this is the most important area }\end{array}$ \\
\hline Maintenance and facilities & $\begin{array}{c}2.182 \\
(1.029)\end{array}$ & $\begin{array}{c}2.6 \\
(1.019)\end{array}$ & - training is easier, wage is high \\
\hline Administrative and clerical work & $\begin{array}{l}2.364 \\
(0.771)\end{array}$ & $\begin{array}{c}2.8 \\
(0.748)\end{array}$ & - education is easiest to attain \\
\hline Local business and retail & $\begin{array}{l}3.091 \\
(0.996)\end{array}$ & $\begin{array}{c}2.4 \\
(1.019)\end{array}$ & $\begin{array}{l}\text { - } \quad \text { very possible with help from the Mayor's office } \\
\quad \text { with so many jobs created, the local business } \\
\text { would thrive as long as there is further training on } \\
\text { how to develop business }\end{array}$ \\
\hline
\end{tabular}


While all opportunities were generally perceived as very beneficial, residents pointed out that there is a stark difference between opportunities for younger and older residents. While younger people are mostly interested in research-related and technical areas, maintenance and clerical work are perceived to be more accessible to older individuals.

Consequently, it is important for USC to develop training programs targeted at a variety of different career fields and relevant for various sub-populations in the local community. Thus, both STEM pipeline programs for school-aged children and adolescents as well as re-training programs for adults should be part of the science park initiative. Due to the fact that public transportation in the area is poorly developed, classes should be offered in close collaboration with local entities such as community colleges and trade schools. English language and computing skills in particular were referenced as instrumental in building up local capacity and in helping local residents to be involved in the science park.

When designing these resources, it will be essential to be aware of the practical challenges that could prevent the local community from participating. Specifically, several people mentioned the steep opportunity costs that they would incur while attending training sessions. Effectively, many local residents face a tradeoff between training and time spent working in order to be able to provide a living for their families. Going to school for an extended period of time such as six months or more places a heavy burden on people's support systems that they oftentimes are unable to bear. In general, people appeared to be willing to learn and to invest time if there were clearly discernable benefits and if the newly acquired skills would be easily translated into working at the science park and into improving people's career prospects as well as earning potential. 
Figure 9 - Getting the community involved in the Science Park

\begin{tabular}{|l|l|l|}
\hline $\begin{array}{l}\text { Selected quotes from Boyle Heights } \\
\text { Focus Group }\end{array}$ & Convergent themes & $\begin{array}{l}\text { Selected quotes from Lincoln Heights } \\
\text { Focus Group }\end{array}$ \\
\hline
\end{tabular}

Discussion item: Ways in which the local community can participate in the Science Park

\begin{tabular}{|c|c|c|c|}
\hline $\begin{array}{l}\text { - USC should have a mentorship program } \\
\text { starting in kindergarten, targeted at low } \\
\text { income families. } \\
\text { - Offer programs to schools in the area that } \\
\text { can serve as a pipeline into the science park. }\end{array}$ & $\begin{array}{l}\text { A natural way to involve the local } \\
\text { community is to establish STEM } \\
\text { pipeline programs in local schools. } \\
\text { Train the local youth to be able to } \\
\text { attain high-earning jobs in the future to } \\
\text { achieve long-term improvement for the } \\
\text { local community. }\end{array}$ & - & $\begin{array}{l}\text { I am thinking about research and technical } \\
\text { support: Lincoln High School is trying to get } \\
\text { more students to graduate, get certificates } \\
\text { and even go to college. With the biotech park, } \\
\text { even more students will try to take that } \\
\text { opportunity, because it's so close to home } \\
\text { and more attainable. } \\
\text { Younger people are more interested in } \\
\text { research and technical support and also } \\
\text { wouldn't mind being involved in local } \\
\text { business, because it makes money and is the } \\
\text { most attractive to them } \\
\text { As a researcher, you definitely have more of } \\
\text { a way to get higher wages, so we don't just } \\
\text { want people to work, but we want people to } \\
\text { have the ability to increase their incomes so } \\
\text { that } 10-20 \text { years later, they aren't having } \\
\text { issues. }\end{array}$ \\
\hline
\end{tabular}

Discussion item: Developing an effective outreach and communication strategy

- Need to really explain to the community what a biotech science park is.

- $\quad$ Loss of information is a big problem. Need to avoid rumors spreading about the biotech park

- It is a challenge to get people to show up at the forums and information sessions People have poor interest in topics they don't know much about. Need to motivate them and to get them interested so that they can have a good future and be able to work in these parks

- Biotech park might be intimidating for some people: Should give tours to the community, explaining to them what the park is and what its used for, and to ultimately recruit people to go to the park (Tours need to be given by community leaders to make it approachable).
Need more education on what the biotech park is about, helping people understand the project and the consequences as well as opportunities associated with it.

USC needs to be careful in developing an outreach strategy to get the community on board.
For Biotech to really be successful in the community there needs to be effective outreach from the beginning so that it doesn't turn into chaos because of ignorance and people asking "what's this" and spreading fear of gentrification. People see what is happening in Highland Park and they are worried.

- Biotech in particular is overwhelming and a bit scary. The community may be lost in terms of what it means for locals.

- Best shot to involve locals is to tell the kids in high school specifically what they need for a specific career path, work with the guidance counselors at the schools.

- Most effective presentation of biotech would be to show examples, such as the Fitbit we talked about earlier. Have something interesting that will make it seem fun and engaging.

Discussion item: Challenges to involving the community in the Science Park

Is the training going to cost? Need free English and computer classes with good, patient teachers
The main practical challenges that local residents face are a lack of skills in computing and English language skills, as well as safe and accessible places to receive training in these areas.

Focus on teaching practical, highlyapplicable skills that lead into specific jobs.

Opportunity costs present a major challenge to retraining: people cannot afford to participate in a 6 month program if they have to make a living for their families as well.
If you are looking to train people for jobs in biotech, need develop targeted skills in computing and English language.

- Training measures should be much focused to the particular job requirements (i.e. how to work in a lab): train people in specific areas, provide hands-on, on the job experience

- Sometimes you can't get to a school or you have kids and can't just leave, so places that are walkable would help a lot

- Need to create spaces where people can go to do homework or work on completing a certificate program.

- Time is of the essence. The reason why people don't spend 4-5 years in school is that their support system is only there for 3 months. You start doing things that take years, things start to break down and you have to get a job.

It's hard to maintain support systems for more than about 6 months to a year at maximum. People will get turned off if an opportunity is too taxing and takes away from their ability to work and make a living. 


\section{Assessing entrepreneurial needs}

When thinking of ways to facilitate research-based economic growth, inventors or academic entrepreneurs should be at the heart of the agenda. One of the key aims of USC's biotechnology park is to retain academic spinoff and startup firms locally and to prevent them from moving to other, presumably more innovative areas such as San Diego or San Francisco.

In order to assess both the current innovation ecosystem surrounding the Health Sciences Campus and to shed light on the key determinants of academic firms' location decisions, interviews were conducted with selected USC faculty members and research administrators from a variety of academic fields that were deemed to be especially likely to generate commercializable research output and spinoff ventures. In recruiting key faculty members to participate in this study, particular emphasis was given to USC departments operating at the intersections of engineering, life sciences and medicine.

At the beginning of the interviews, participants were asked to outline their areas of study and to describe their experiences with the research commercialization process at USC. While researchers generally stated that USC provides adequate support and advice for questions related to patenting and licensing, they also pointed out that a single technology transfer office might not be able to handle all of the complex issues in the commercialization process, and that it might be beneficial to put in place a more specialized technology transfer system that can focus on the specific demands of a given set of related industries. Several researchers stated that in terms of pure technology transfer, USC performed on par with most other universities in the United States, but they also contended that there is a stark difference between technology transfer and technology development that ought to be considered: while it is useful to get help with the formal process and in some cases even initial funding to cover patenting costs, it is at least as important to be set up to succeed in the marketplace and to be connected to both potential funders as well as managerial staff:

"But where things really failed was this: my lab raised several million dollars, so while USC spent \$200,000, we brought-in \$4-5 million along with all of the indirect costs that come with that, so we paid for that $\$ 200,000$ several times over. We were clearly exceeding expectations and exceeding any competition, and so it should have become a company and started selling. We had people who wanted to buy what we had to offer, but USC failed completely at helping to establish the process of forming a company and at connecting us with someone who would know how to move things forward and who would be there to help make it successful." 
While some researchers were fully content with USC's technology transfer process, others argued that it failed to effectively connect them to the local innovation ecosystem. Ultimately, this might come down to a question of mandate and objective. If USC faculty entrepreneurs are looking for well-rounded technology development rather than simple commercialization support, the current process may not be able to satisfy their needs, thus suggesting that a potential science park should focus on addressing the gaps between technology transfer and development. Along those lines, it should be noted that while some entrepreneurs expressed discontent with USC's technology transfer capabilities and practices, the issues might be due to the fact that these entrepreneurs are simply expecting too much in terms of technology development and business support.

As a follow-up to this issue, people were asked to elaborate on the ways in which the local environment has affected their work. Figure 10 presents a summary of both strengths and challenges of the Los Angeles innovation ecosystem that were discussed by faculty members during the interviews.

\section{Figure 10 - Assessing the local innovation ecosystem in Los Angeles}

\section{Strengths}

- $\quad$ Creative economy, suited for digital production and arts

- Global presence

- Los Angeles has a strong cluster of world class research institutions that provide the raw materials for biotech-most importantly research and talent

- Wealthy individuals and plenty of funding opportunities

- LA has a different, exciting kind of entrepreneurial network made up of interdisciplinary agents
Challenges

- Traffic in Los Angeles is a problem and the public transportation system is inadequate

- $\quad$ The USC Health Science Campus in particular is not very well connected: lack of restaurants, hotels, amenities and transportation make it difficult to work there

- People do not consider Los Angeles as a research or technology place, which makes it difficult to retain a talented labor force

- $\quad$ Cost of living is high in Los Angeles

- $\quad$ All the key ingredients for a biotech cluster appear to be present in Los Angeles, but they are spread out and hard to find and connect to

Almost all of the study participants expressed great excitement about the future of Los Angeles as a biotechnology hub. The word opportunity was mentioned in nearly every interview, suggesting a great deal of optimism when gauging Los Angeles' potential to develop clusters based around science and technology.

The very fact that the biotechnology landscape is just beginning to emerge in Los Angeles appeared to be very exciting for several researchers. Along those lines, it was deemed critical for the region to set itself apart from more traditional biotechnology hubs such as Boston, San Diego or San Francisco and to build on its local comparative advantages: 
"We need to leverage the strengths of $L A$, its creative nature, its massive influence and global presence as well as the immediate access to all socioeconomic frameworks as well as full ethnic diversity. I came to USC, in part, because of digital arts; the cinematics are the best in the world, and I believe digital arts has a lot to offer in terms of bridging the sciences, engineering and medicine.

One of the weaknesses that I thought initially was there isn't this cluster of biotech or entrepreneurs or entrepreneurial CEOs in senior management. What l've now come to appreciate having been here for a year and really listening to people, is that it's not the same type of people, it's a different breed of CEOs. I actually view that as an advantage and an opportunity. For biotech in Los Angeles, there isn't going to be a unique advantage if LA just tries to duplicate San Diego, Boston, or San Francisco. But, if Los Angeles emphasizes what is unique about Los Angeles...?

You have the film industry, you have the aerospace industry; you have these other industries that are really strong here, that is unique and so, if you can take advantage of that opportunity and have a whole new breed of biotech entrepreneurs, then I think it's going to be wildly successful."

Therefore, it is critical for Los Angeles to develop its own footprint in the biotechnology realm. According to various interviewees, Los Angeles has a lot to offer to biotechnology researchers and entrepreneurs, but it is a long way from competing with the more traditional powerhouse regions. Accordingly, the region must emphasize its ability to merge together different strains of research from health and life sciences to digital and imaging technologies as well as lifestyle and nutrition-related fields. The high levels of creative thinking and talent in the region make it an atypical fit for biotech, but in the eyes of the study participants also set it up nicely for future innovations at the intersection of creative talent and scientific research. Going forward, it will thus be critical to focus on establishing conditions that enable interdisciplinary innovation while maintaining the flexibility needed to explore future avenues of growth.

Nonetheless, the word opportunity also implies that a lot of work still needs to be done in order for said clusters to emerge. The vast geographic spread and insular nature of Los Angeles as a whole, and the downtown area as well as Boyle Heights neighborhoods in particular, were frequently referenced as the key hurdles impeding cluster formation. While everyone appears to agree that Los Angeles offers most of the necessary ingredients for research-based economic growth such as a talented labor force, world class universities and wealthy individuals that could serve as venture capital funders, connecting these ingredients remains the central challenge. 
Nonetheless, even when considering the geographic spread and transportation issues in Los Angeles, several respondents suggested that it is more about forming a closely-knit network than a single, geographically contained cluster in a specific area of the city:

"In all these places, there need to be multiple science parks. When people thing of San Diego, they think it's one location, but it's actually 5 different locations around San Diego, where they have these different hubs, the Torrey Pines area is just the most famous one. In San Francisco, it's the same thing. There's more like 7 concrete hubs."

In Los Angeles, both the California Institute of Technology and the UCLA Harbor Medical Center have developed science parks focused on biotechnology and health sciences, and ultimately, having multiple, connected and potentially complementary hubs in the region was seen as most promising by faculty entrepreneurs. Along those lines, both the area surrounding the Health Science Campus in Boyle Heights and the area surrounding USC's main campus in downtown Los Angeles were referenced as ideal locations, along with a potential location on the Westside, preferably around the University of California, Los Angeles (UCLA) campus in Westwood.

However, while establishing multiple biotech-oriented research parks across the Los Angeles region could lead to the emergence of a broader cluster, participants warned that the neighborhoods surrounding Health Sciences Campus (HSC) in particular present a variety of challenges that ought to be addressed in order to effectively connect local researchers with the wider Los Angeles biotechnology community:

"Well there are no hotels and no place to go to lunch. The reality is that if you organize a meeting out there you send people to stay in Pasadena. So, the last place in the world that I would want to put a business is out there. It's 40 minutes from the airport, there's no place to get lunch. I can't have someone visit and stay overnight."

Thus, it appears to be very important to invest in a diversity of infrastructure around the biotechnology park in Boyle Heights, including places to eat, recreational facilities and other amenities in order to attract people to the area. 
Following up on this very issue, respondents were invited to talk about the potential impact that a science park in Boyle Heights could have on the L.A. innovation ecosystem as a whole and on their work specifically. In addition, the need and usefulness of various features of the science park were discussed, including measures such as enhanced business training for academic entrepreneurs, the development of a strong and interconnected entrepreneurial network, business support structure and increased lab space and research support staff.

In general, people once again expressed great excitement for the idea of a science park around HSC, suggesting that the greater downtown area around USC is in dire need of an anchor facility for its emergent biotechnology cluster. In terms of the specific elements that are needed in such a science park however, people's suggestions and opinions differed substantially:

- Expanded business training for faculty entrepreneurs: a few interviewees addressed this particular feature, possibly due to the fact that many academic entrepreneurs typically choose to remain in their academic position to continue their focus on research rather than management, even following a successful spinoff.

- Expanded technology transfer: participants thought that a science park might be a good opportunity to develop a higher degree of specialization in selected industries to better service individual fields of commercializable research.

- Additional laboratory and research space: a variety of researchers pointed out that the need for lab space, and along with it the value that they attribute to this particular feature in a science park, will depend strongly on the nature of their research. Nonetheless, people seemed to mostly agree that there currently is not enough lab space in Los Angeles, particularly wet lab space where researchers can conduct experiments that require the handling of volatile materials, and that existing spaces are spread out around the greater Los Angeles region, thus suggesting a need for substantial investment in mixed-use research facilities.

- Entrepreneurial support networks: all participants agreed that facilitating the establishment of vibrant entrepreneurial networks ought to be one of the core objectives of the biotechnology park. The key to a well-functioning cluster is not just the core business, in this case USC research, but also the surrounding support system of venture capital funding, specialized real estate and legal support as well as a highly-trained and readily-available labor force. Investing in an enhanced capacity to connect with other biotech entrepreneurs and the greater Los Angeles biotech environment was cited as the most critical contribution of the park and as the feature that will ultimately determine its success or failure. As discussed previously, the ability to find funders and managers and staff in Los Angeles is a vital skill for academic entrepreneurs and the biotechnology park should serve as a meeting point in that regard. 
To sum up, researchers view it as a major objective of the science park to lead a critical mass of key actors to the area around HSC in order to anchor an entrepreneurial cluster:

"The Science Park needs to reach critical mass as quickly as possible. USC's main campus is one part of the cornerstone, and then there needs to be a few big labs or companies in the space to give encouragement to the smaller ones to start there and interact. Then, some space for the service providers including VCs, legal, bankers, etc... We also need a big real estate firm to take the lead."

Lastly, researchers were asked to talk about their interaction with the local communities in Boyle Heights and Lincoln Heights and to discuss the role that local residents could play in the science park development. A number of researchers seemed to be very interested in the issue of community involvement and talked about the need to carefully think about how the science park should be developed. The fact that the science park will be focused on biotechnology in particular might make it seem inapproachable and overwhelming to the local community, and thus, interviewees suggested that the outreach strategy be focused on explaining and breaking-down the actual science in ways that are understandable:

"You really cannot just put things behind walls and then expect people to accept them. You have got to find ways to get the community involved and you have got to get rid of that intimidation factor. Expressing it as an intimidation factor really hits the nail on the head, and once they know what is behind the wall and there is a maybe a guided tour that allows every generation to become familiar - it works out great. But you have to do something, you cannot just plant it there."

Once the initial intimidation factor has been overcome and the local communities are on board with the initiative, interviewees suggested that a science park requires employees in all different fields and levels of hierarchy from research and technical support to facilities management and clerical or administrative work, thus providing ample opportunities for local residents. In order to overcome potential practical or financial challenges that might make these jobs difficult to attain for some residents, one respondent further suggested that people should be paid while receiving training: 
"Let's say that they're in a minimum wage job and maybe they are doing two jobs and both of them are 50 hours per week. If you pay them a little bit more while they are doing that training, and bring them down to 40 hours a week, they're going to be able to spend more time with their family, they'll be able to meet their financial obligations, and they'll probably have better opportunities for employment in the future. There are no guarantees, but it depends on what it is that you are willing to put up while a person is being trained or being an apprentice."

In addition to getting involved through gaining employment, interviewees also cited the rise of the shared economy and social media applications such as AirBnB, the need for vendors in the food and service industries as well as the need for staff in recreational facilities and other supporting ventures as great opportunities for local residents.

\section{Understanding environmental factors}

One of the faculty entrepreneurs interviewed for this study suggested that while Los Angeles has come a long way in developing its capacity to become a biotechnology destination, the current debate is by no means a recent phenomenon. Instead, the researcher suggested that this topic has been on the minds of Los Angeles policy makers for years, yet progress has been slow to come by:

"One of the stories that I heard was that there was a supervisor. One of the $L A$ Supervisors was supportive of Biotech in LA, and he turned out two or three years ago. One of the questions that I kept asking when I was being recruited was: Why hasn't biotech taken off in LA? It's been a year that I've attended some of these meetings, and if LA wants to do this, we are putting up this incubator--we are not going to wait for this stuff. We are going to build this incubator, and if we get these people that into the incubator that go from 2-3 people to 10-12 people, if they move to San Diego, then that's a loss for $L A$."

In order to understand the policy environment and its impact on the biotechnology landscape in Los Angeles, this dissertation conducted semi-structured interviews with key policy organizations such as the Los Angeles Mayor's Office and business organizations both locally around the Health Sciences Campus and in the wider Los Angeles region, as well as local biotech experts. 
To begin with, one of the interviewees emphasized the need of a well-rounded, stakeholder-oriented approach to developing the biotechnology industry in Los Angeles:

"There needs to be a concerted effort that involves USC, the county and the city in addition to industry stakeholders and community leaders. You have to bring these five parties to the table and iron out a social contract. USC cannot do it by itself, you cannot do it between just USC and the county - you have to involve the city. In the absence of any of these stakeholders, nothing will end up happening."

In the same vein, the interviewee pointed out that the conversation about a biotech-focused research park in the Boyle Heights area is by no means a new one. As an example, in 2005, Antonio Villaraigosa ran for Mayor of Los Angeles on a platform that included the development of a Biotech Industrial Park, connecting Cal State Los Angeles and the USC Health Sciences Campus. ${ }^{9}$ Nonetheless, the interviewee adds that while there have been movements toward a biotechnology park at various points in the past, Los Angeles thus far has been unable to bring everyone together and to carry forward an actual project due to the lack of coordination between the different stakeholders involved:

"And that is why (...) nothing happened, because either one party gets interested but the others are not, or all of them get interested but nobody is paying attention to the bigger problems in the neighborhood that you need to pay attention to, so you have to bring the five stakeholders together into one room and then do a memo of understanding, a social contract or whatever, an agreement about how to move forward and to mobilize the resources. And most importantly, do it in a timely fashion."

Most of the other participants agreed that there is a window of opportunity and that the Los Angeles biotech landscape is in dire need of an anchoring institution or hub such as the proposed science park. Generally, people felt positively about the innovation ecosystem and referenced the rise of the technology industry and Silicon Beach as signs that the overall situation appears to be improving. However, they also stated that the current biotech industry in Los Angeles is highly fragmented and spread across the county, which makes it virtually impossible to rely on common resources, to take

${ }_{9}^{9}$ See for example http://www.ladowntownnews.com/news/biotech-park-could-arrive-near-downtown/article_c7b03c7b-e33f-5d99-99c7898ce7104f $40 . \mathrm{html}$ 
advantage of agglomeration effects, and to form a cohesive entrepreneurial network. Despite the fact that Los Angeles appears to have all of the necessary preconditions for biotech and research-driven growth such as world class research institutions, a talented workforce and high levels of creativity, interviewees discussed a variety of factors that have prevented the emergence of a vibrant, sciencebased biotechnology cluster:

- Funding environment: biotechnology is a high-risk, high-cost industry, with many firms heavily relying on early-stage funding and angel investments. While Los Angeles has a strong track record of philanthropic funding through rich individuals, it has thus far failed to develop the kind of life sciences-oriented funding mechanisms needed to sustain a local biotech industry. One interviewee attributed this fact to path dependency, citing that while San Francisco has a longstanding history of venture capital funding for technology firms, particularly since the early 1990s, the main drivers of the Los Angeles economy such as the entertainment and aerospace industries were mainly financed by governmental and private sources. As a result, the region is left without local venture funding sources, which in turn leads people to go elsewhere to find funding. One interviewee added that when entrepreneurs have to fly to other locations to look for venture capital funding, they are incentivized to relocate to those areas in order to enhance their financial prospects.

- Availability of lab space: all of the interviewees agreed that apart from funding, the availability and affordability of space is the second largest issue facing biotech entrepreneurs in Los Angeles. ${ }^{10}$ In their eyes, the lack of dedicated lab space is another factor that draws people away from the region towards locations that are better prepared to accommodate biotechnology firms. As summarized by one participant:
"People go to San Francisco or San Diego or back East from USC, because you can go there and there are going to be facilities for you to open up shop. Here, where do you open up? They just don't know, there probably are some, but the infrastructure is just not in place and that is why they migrate to an area where that exists; and that is how things get concentrated."

On a positive note however, all respondents agreed that if an appropriate infrastructure were developed in Los Angeles, entrepreneurs would be very likely to stay. Along those lines, one interviewee suggested

\footnotetext{
${ }^{10}$ Space accounts for a substantial share of costs in operating biotech businesses, see for example http://wtnnews.com/articles/4175/ and http://www.areadevelopment.com/Biotech/july2010/biotech-pharmaceuticals-rent-labs9502.shtml
} 
that any investments in the local biotech infrastructure and the innovation ecosystem should take into account the geographic reality of the region. Given the vast geographic spread of Los Angeles and the insular nature of neighborhoods, taking a polycentric approach to economic development and the creation of various biotech hubs in areas, including the Boyle Heights neighborhood around USC'S Health Science Campus would be the best option. The cities of Paris and London were referenced as examples of this approach.

- Local labor force and talent pool: once again, all respondents agreed that with its cluster of wellregarded research institutions, the Los Angeles region is producing a more than adequate and highly-talented workforce. Consequently, Los Angeles has copious amounts of intellectual capital; the challenge is to provide sufficient opportunities for graduates to stay locally.

After reflecting upon the general innovative ecosystem in Los Angeles, participants were asked to talk in greater detail about the USC Biotechnology Park project, and to elaborate how they think it would contribute to the development of a local biotechnology cluster. Regarding the selection of Boyle Heights as a location, interviewees laid-out several key advantages and challenges. One of the major advantages of developing a science park in the Boyle Heights area is the neighborhood's proximity to various research hospitals, to the USC Health Science Campus and to Downtown Los Angeles. Therefore, while Boyle Heights might seem isolated from other areas in Los Angeles at first, it has the potential to act as a regional hub within the larger biotech landscape. The second advantage that was mentioned is the fact that space is rarely available in Los Angeles, particularly space that is large enough and readily convertible to biotech lab space. The fact that there is a large, open and nonresidential space in a strategic location presents a great opportunity.

However, interviewees also pointed-out some challenges that ought to be overcome in order to develop a successful biotech hub in the area, mainly with respect to effective community development and neighborhood advancement. Similar to the faculty entrepreneurs, policy stakeholders remarked that the area surrounding the Health Sciences Campus currently offers very few amenities such as restaurants, hotels and recreational facilities, features that are needed to build a cohesive and sustainable cluster and to host venture capital investors and business support agents such as specialized law and real estate firms. In addition, participants from the local business focus group added that there currently is very limited interaction between the Health Sciences Campus and local stores and restaurants, mainly due to the lack of connectivity in the area. USC is perceived as somewhat isolated and respondents complained that due to the void of public transit options, many employees at HSC never leave campus to explore the local neighborhoods, thereby failing to generate business in the local communities. Aside 
from the need to build up local infrastructure, interviewees were very vocal about the necessity to address concerns of the local community, and to work with community leadership to ensure inclusive growth through the biotech park development.

"At the end of the day, whether it feels comfortable or not, the more revenue and workforce and jobs that you can bring into a community, the better the community will do, but you have to be sensitive to the existing community and its infrastructure, especially when you have insular communities like you do in certain parts of the county, who really do not want this kind of stuff there.

They want all the revenue that comes in, they want the better streets and the increased tax income and the subway that goes down the street and the Starbucks that has a drivethru, but they do not want all the people that are going to come with it. A lot of times you just have to spend more time thinking about what it is that you can do to intertwine with the community, and not so much just put a stamp in the middle of it and say here is our footprint."

One interviewee compared the project in question to San Francisco's efforts in revitalizing the Mission Bay area into a flourishing business and technology park, due to the fact that Boyle Heights has similarly high levels of abandoned manufacturing space that could be taken over by biotechnology support firms and could become a driver for local job opportunities. Along those lines, respondents unequivocally agreed that jobs are the one thing that the local community needs the most. A science park has the potential to revitalize and boost the area as well as the local community by creating as many as 3,000 to 5,000 jobs across all levels, from maintenance and facilities management to research and technical support. However, various interviewees contended that a lot of outreach needs to be conducted in order to excite members of the local communities about these job prospects. As one participant noted, when talking about a biotechnology science park with involvement from a major research university, local residents might jump to the conclusion that anything below a four-year college degree would not qualify them to work in such jobs. In the experience of this interviewee, residents are often willing to pursue certificates or even two-year, associate's level degrees, but they cannot afford to be in school for four years, given the vast challenges that many of them face, such as the dual burden of studying and supporting their families or deficits in math and English language skills. However, the interviewee also noted that there would be a lot of interest by local residents if they perceived that there are real opportunities in the Science Park: 
A lot of the students that we do get in Biotech are interested in science, but they were never really thinking that they were good in science. So I think if they see that, see that locally there is something... I mean, right now, we do have biotech industry in the area, but it is sparse, there are sprinkles here and there and you have to search them out, but if there is a park where it's local and people could relate, I think people will understand."

Generating partnerships between firms in the Science Park, USC and local community colleges such as LA Trade Tech College or even Cal State Los Angeles can therefore serve to create clearly visible pathways into biotech careers, which increase awareness among local residents and present tangible opportunities. Existing partnerships between LA Trade Tech College and biotechnology firms such as Grifols or Baxter can be taken as best practices in that regard.

Ultimately, however, all interviewees suggested that crafting a very careful message and educating the local community about all aspects of the park will be critical. Developments in Downtown Los Angeles and the Highland Park neighborhood have triggered fear of gentrification and development that occurs at the expense of, rather than for the benefit of local communities. While one participant stated that local residents should be somewhat accustomed to health sciences due to the existing USC medical cluster and the county hospital in the area, another one contended that the prospect of science-based growth might not be very tangible and might in fact be difficult to comprehend and to relate to. Instead, the respondent suggested that in addition to talking about jobs, the outreach strategy should actively involve the community in designing the physical space and layout of the Science Park, in order to ensure that local residents feel like the park is a part of their community. 


\section{Main takeaways and policy recommendations}

Following a close examination of attitudes towards USC's proposed Biotechnology Park, it is apparent that a wide variety of interests need to be considered in the planning of this large-scale effort. The objective reaches far beyond simply expanding USC's Health Sciences Campus in trying to address the broader issue of providing an anchor or hub for the local biotechnology industry in Los Angeles and to ultimately seed a vibrant and entrepreneurial, research-oriented cluster. Accordingly, a wide variety of stakeholders from the local communities, the L.A. policy environment and the university were asked about their opinions about and suggestions for the science park. While initially aimed at spurring knowledge-based economic development, especially in the life sciences, the science park also holds the potential to develop the local neighborhoods and provide jobs for the local communities at all levels. In order to present a well-rounded picture and to ensure that all key interests are incorporated early on in the planning stages, this dissertation develops a stakeholder map, looking at the perspectives of entrepreneurs, local communities and policy makers (see Figure 11). In doing so, several research questions were addressed: 


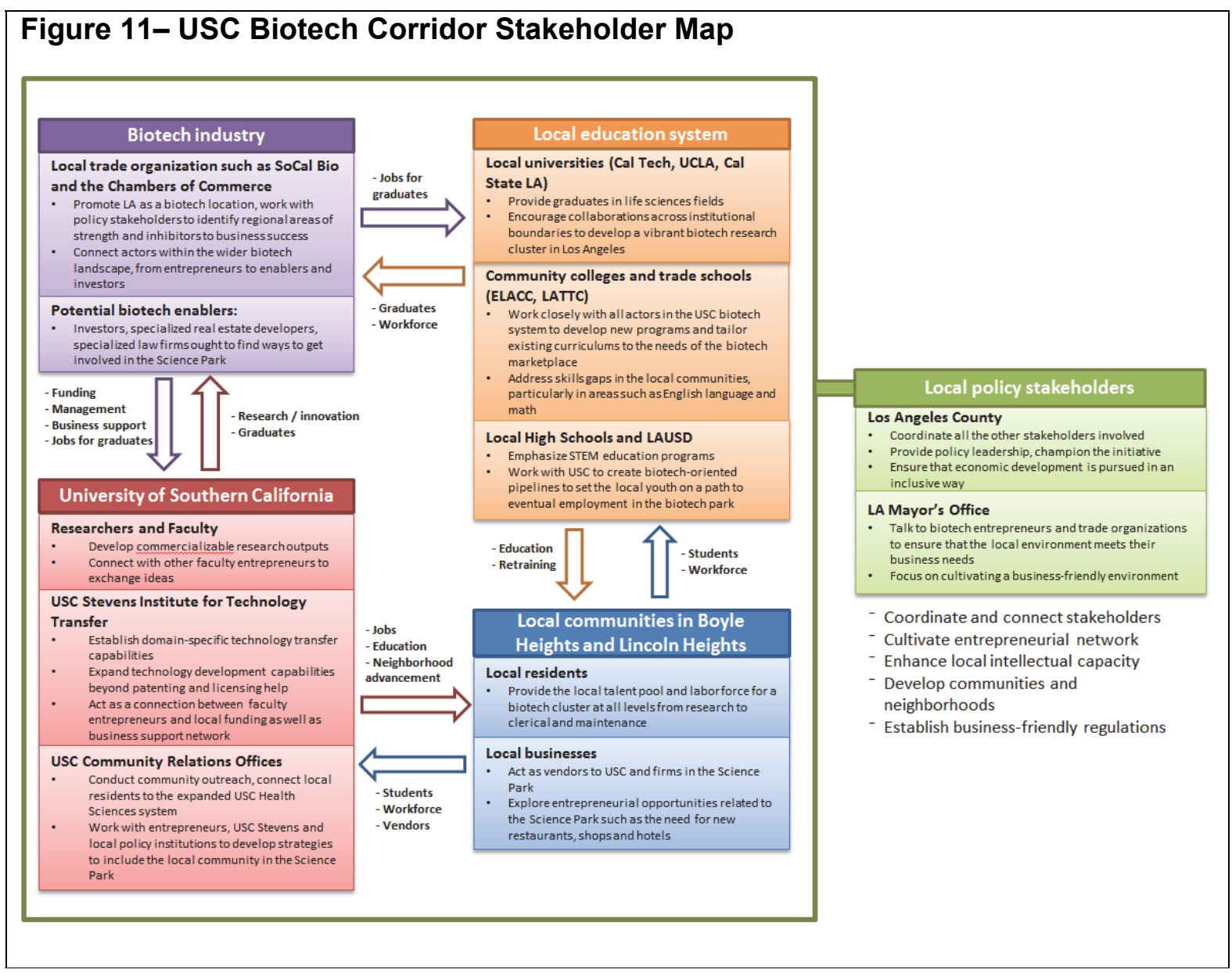

Based on the interviews with faculty entrepreneurs, what are the main elements that make-up an innovation-friendly environment that incentivizes startups to stay? What are the missing ingredients in Los Angeles?

Across the board, all faculty entrepreneurs referred to the availability of funding and capital as the most critical ingredient for a sound local innovation ecosystem. While many suggested that Los Angeles offers plenty of funding, especially from philanthropic sources, they also conceded that finding the money presented a significant problem due to the widespread nature of the region. In addition, various entrepreneurs suggested that being connected to the broader Los Angeles innovation landscape and a local business support network including specialists in areas such as IP protection and biotech-oriented real estate were two key needs that remain to be filled in the Los Angeles region. Despite the fact that some entrepreneurs expressed criticism toward the fact that UCS's technology transfer office provides limited support in connecting entrepreneurs to the broader business community, it must be noted that those tasks might be beyond the mandate of a traditional technology transfer office, which are traditionally set-up to handle patenting and licensing agreements and procedures. However, when trying 
to expand the university's commercialization capabilities and the success of university-related entrepreneurial ventures, it may be necessary to invest in broader technology development and to establish numerous specialized technology transfer groups rather than one general office, which have a very good understanding of industry-specific requirements and procedures and are capable of truly covering all entrepreneurial needs in a given industry segment.

What is it that regions like Silicon Valley and San Diego have to offer to startups that the Los Angeles innovation environment is missing?

When asked to specifically compare and contrast the innovation environment in Los Angeles with successful biotech clusters such as the ones in San Francisco, Boston and San Diego, faculty entrepreneurs noted that it is imperative for the biotechnology industry in Los Angeles to find its own niche. Several entrepreneurs pointed-out that trying to compete with regions that have long-standing and well-established research clusters might not be the best strategy. Instead, the L.A. region ought to emphasize its natural strengths in areas such as lifestyle, digital imaging technologies and entertainment and try to develop ties between those areas and the health sciences. This focus on interdisciplinary clusters was seen as the best way to leverage Los Angeles' key locational advantages and to establish a vibrant cluster going forward.

What role can the local community play in addressing the gaps in LA's innovation environment?

As shown in the case of Johns Hopkins University and the Baltimore region, the local environment plays a very important role in determining a region's capacity to translate scientific discoveries into innovation and economic growth. When picturing a science park in the Boyle Heights neighborhood of Los Angeles, many entrepreneurs stated that substantial investment would be necessary in order to develop a local infrastructure that would be suited to host a science-based cluster, including enhanced public transportation, restaurants, hotels and other amenities.

The local communities on the other hand were rather skeptical of these changes to the local areas, potentially due to the gentrification processes seen in surrounding areas such as Highland Park and even Downtown Los Angeles. While a biotechnology park has the potential to create thousands of jobs, many of which could be attainable to local residents, it was apparent in the focus groups that the term biotechnology brings-about an initial intimidation factor, with residents thinking that any science-related job would require at least a college degree and would therefore be out of question for them. As a 
consequence, it is very critical to emphasize the availability of suitable and readily-accessible jobs in the initial community outreach, and to work with local skills centers to create pathways to employment in the science park. In developing training and re-training programs, it is further important to remain cognizant of the plethora of challenges that local residents face, including the lack of public transportation in the area, the high opportunity costs of being in school and therefore unable to earn money to support their families and the deficits in basic English language as well as computing skills. While these measures are geared specifically toward adult learners in the local communities, expanded STEM programs in local schools and fellowship such as the Neighborhood Academic Initiative present effective ways to address the local youth. The BRIDGE program implemented in San Diego from 2012-2014 could serve as an example for this broad retraining initiative, since it was a collaboration between various local universities, governmental institutions and biotech industry associations, specifically aimed at developing biotechrelated skills among the local veteran populations. ${ }^{11}$

In addition to providing employment directly with firms located in the science park, a secondary avenue to involve the local community is to promote local businesses as vendors, and to connect them to both entrepreneurs in the Science Park and students based on the Health Sciences Campus. Leaders in the local education system, including community colleges, universities and the Los Angeles Unified School District (LAUSD), will therefore play a critical role in working with entrepreneurs and the broader biotech industries in order to develop curricula and pathway programs that are suited to generate a local biotech and research-oriented workforce.

\section{What is the specific role of institutional and policy stakeholders?}

When thinking about the role of policy stakeholders, most interviewees agreed that enhancing the connectivity between the various actors involved is the most critical mandate. Policy makers at the Los Angeles County Supervisors' Offices and the Los Angeles Mayor's Office in particular are well positioned to talk to all stakeholders involved and to provide leadership in pushing the biotech project forward while ensuring that the needs of local industry and entrepreneurs as well as local communities are addressed in a sufficient manner. In addition to connecting stakeholders through convening meetings, a key input for governmental agencies will be to invest in the local transportation infrastructure to ensure that the Biotechnology Park is well connected and accessible to members of the local communities as well as biotech industry agents across the region. Furthermore, it is crucial to understand the current business environment in Los Angeles and to work closely with industry trade organizations such as the Chambers of Commerce or labor unions, in order to eliminate any

\footnotetext{
${ }^{11}$ For a description of San Diego's Biotechnology Readiness, Immersion, Certification and Degrees for Gainful Employment program (BRIDGE), see for example http://newscenter.sdsu.edu/sdsu_newscenter/news_story.aspx?sid=71904
} 
unnecessary hurdles to business creation and operation and to cultivate a business-friendly framework of local policies that contribute to a vibrant and highly entrepreneurial ecosystem. 


\section{Limitations}

Due to the fact that the USC Biotech Park project is still in the early stages of the planning process, this dissertation is only able to provide preliminary conclusions and suggestions on various aspects that should be considered. These recommendations are based on conversations and interactions with few key individual stakeholders that participated in focus groups and interviews and therefore, might not be representative of all stakeholders involved in the process. In order to address this issue, more interviews and focus groups should be conducted and the range of stakeholders should be expanded to obtain a more well-rounded assessment. 


\section{Silicon Beach as a new wave of the digital economy in Los Angeles}

Telling the story about Silicon Beach and the rise of the Los Angeles tech movement

Universities are not the only source of innovation in LA's knowledge-based economy. In addition to its cluster of major research universities, the Los Angeles region has experienced a substantial increase in innovative and entrepreneurial activities in recent years through a movement sometimes referred to as Silicon Beach. The vast majority of startup companies in this movement have been related to the digital economy, with a focus on areas in which Los Angeles has been traditionally strong, such as animation, video production and social media. Identifying the main drivers of the LA-based digital economy will help policy makers to better understand the relative strengths of the regional economy and centers of excellence in innovation.

To date, this new phenomenon has received considerable attention by news outlets such as The New York Times, Time Magazine and The Los Angeles Times and has been prominently featured in blog posts and op-ed pieces, but it has not yet been a subject of entrepreneurial research. To begin to address this gap, this dissertation draws on a systematic review of the available literature on Silicon Beach in order to formulate various hypotheses about the geographic and industrial makeup of the movement.

In the summer of 2014, Nelly Bowles of Re/code.net and The Guardian published a series of articles on the Los Angeles tech scene in a seven part web series entitled "LA Stories" (Bowles 2014). In her research for the story, the author conducted interviews and site visits with more than thirty companies and fifty entrepreneurs in the L.A. region, trying to find answers to her key question of where all of the recent startups are coming from and why Los Angeles has seen such as strong resurgence of the tech economy. Based on her initial research, she posits that there are five main reasons for success that make up the comparative advantage of the L.A. region in attracting startup talent and investment, while there remain six challenges faced by the expanding tech community (see Figure 12). 


\section{Figure 12 - Silicon Beach success factors and challenges based on Re/code Special Series on the Los Angeles tech scene}

\begin{tabular}{|l|ll|}
\hline \multicolumn{1}{|c|}{ Success factors } & \multicolumn{1}{c|}{ Challenges } \\
\hline - Entrepreneurs are having fun & $\bullet \begin{array}{l}\text { Sometimes, the focus is more on having a good time } \\
\text { than on working hard }\end{array}$ \\
- $\begin{array}{l}\text { Ease and comfort in dealing with mass-market consumer } \\
\text { attitudes }\end{array}$ & $\begin{array}{l}\text { Lacking a central location or theme } \\
\text { - } \begin{array}{l}\text { Ability to quickly turn profits in an environment with } \\
\text { limited venture capital resources }\end{array}\end{array}$ & $\begin{array}{l}\text { L.A. has somewhat of a track record of massive firm } \\
\text { collapse in the past }\end{array}$ \\
- $\begin{array}{l}\text { Creativity and attention to aesthetics } \\
\text { Emphasis on producing playful and cost-effective web } \\
\text { and mobile apps rather than meaningful products }\end{array}$ & $\bullet \quad \begin{array}{l}\text { Lack of anchoring firms and entrepreneurial universities } \\
\text { - Large geographic distances and travel times }\end{array}$ \\
\hline
\end{tabular}

\section{Creativity and attention to aesthetics as a comparative advantage}

In an article published in Time Magazine, Pickert (2014) describes the emergence of West Los Angeles as a technology hotbed, proclaiming that entrepreneurs are increasingly looking to move to places outside Silicon Valley, and that Silicon Beach has developed into a viable alternative, given L.A.'s high quality of life, nice weather and creativity stemming from Hollywood and the entertainment industry. As described by Scott (2005), De Propris and Hypponen (2008), Gupta, Jacobi et al. (2006) and others, the entertainment and media cluster surrounding Hollywood has been one of the main driving forces behind the Los Angeles economy for decades.

L.A.'s focused emphasis on entertainment and content production has manifested itself in the rise of Silicon Beach startups as well. While Silicon Valley-based technology firms are often focused on creating platforms, Silicon Beach firms seem to focus more on creating content for those platforms, effectively tying themselves to the already existing cultural production cluster in Hollywood. While the key medium for most of these startups has become the internet, the ultimate objective is still strongly related to digital content. Due to the fact that firms no longer need to rely on massive production infrastructure to build a company, startups can set up shop anywhere and thus, a great number of entrepreneurs are gravitating towards the attractive and sunny neighborhoods of West Los Angeles. Given the dramatic decrease in cost of business precipitated by advances in cloud computing and mobile technologies, many entrepreneurs are further finding it much easier to produce high-quality, lowcost output. Aside from the nice weather, the Los Angeles technology scene offers strong links to gaming and access to Hollywood and its celebrity culture, both in terms of creative output and funding opportunities, as well as endorsements and publicity. Along those lines, the major products to come out of Silicon Beach to-date have been lifestyle-oriented mobile apps in addition to digital video content and 
production--creative output that fits in well with the traditional local Los Angeles marketplace. Compared to Silicon Valley, L.A. is bringing diverse views into technology according to Zimmerman (2013), seeing technological possibility through the eyes of graffiti artists, photographers, entertainers and musicians, a feat which Gaddie (2013) ultimately describes as Los Angeles' evolvement from a pure content producer to a creative hub that now successfully merges technology and entertainment. The emergence of firms such as Netflix and Hulu and the move of many traditional movie studios to set-up online portals further underscore this convergence of two industries that used to be in competition with one another.

\section{Ease and comfort in dealing with mass-market consumer attitudes}

The fact that many Silicon Beach entrepreneurs have previously been exposed to the Los Angeles culture has provided them with a sound understanding of social media outreach and the benefits of generating a large followership for their products. While many tech firms are initially focused on products and technology, L.A.-based startups have been quick to learn from Hollywood when it comes to marketing and promotion strategies. TV and movie studios in particular have developed localized pipelines to advertising agencies and celebrities, and many Silicon Beach entrepreneurs have been able to take advantage of these connections. Bowles (2014) suggests that some firms in Silicon Beach have been very successful in their use of celebrities as business partners due to the fact that they bring trust and familiarity to consumers, although she also contends that endorsements alone have had little impact on long-term success and customer retention.

\section{Overcoming the lack of Venture Capital investment}

Frequently, the lack of venture capital funding and the lack of adequate technical talent are cited as some of the main hurdles to business incubation and startup activity in Los Angeles. While Los Angeles started out as the main destination for venture capital in the late 1940s and 1950s due to its strong defense-related computing industry, it has consistently fallen short of Silicon Valley since the 1960s (Norberg 1976). However, since the early 2000s, Los Angeles has experienced a substantial increase in startup activity as well as venture capital investment, particularly in the digital media space (CB Insights 2013). Graham (2012) and Lee (2012) therefore conclude that the venture capital industry is slowly catching up with the startup movement, and Vanderhoef (2014) states that Silicon Beach by now has become well supported by a network of venture capitalists, incubators, startups and co-working spaces, with a strong emphasis on shared working spaces and collaboration. Bowles (2014) questions this very fact by observing that the recent success of L.A.-based technology firms might be due to their ability to 
develop effective coping mechanisms rather than due to an influx of capital. Simply put, she posits that Silicon Beach startups have been forced to produce more with less and to develop outputs that can quickly and easily turn profits while imposing minimal cost. Along those lines, the cluster's focus on creating web and mobile applications focused on entertainment and lifestyle as well as end-customers illustrates a fundamental difference to Silicon Valley firms which may be geared more towards creating computing solutions for bigger issues, ultimately aimed at larger-scale clients in business-to-business settings.

\section{Exploring the local talent pool}

The fact that industry titans such as Google and Facebook have been working to significantly expand their L.A. presence suggests that Silicon Beach is becoming a credible player in the technology community.(Chang and Jamison 2015) This new influx of high-level employers from Silicon Valley, along with the increase in tech-oriented startups might go a long way toward retaining graduates from L.A.based universities such as UCLA, CalTech and USC to stay local rather than leaving for other regions immediately following graduation. According to Bowles (2014), Silicon Beach has drawn heavily on the more design and entertainment-oriented engineers trained locally in Los Angeles universities and is now competing with Hollywood for graduates. Gaddie (2013) however argues that while Los Angeles

universities are producing world class talent in fields such as engineering and computer sciences, students might not yet be prepared to become entrepreneurs:

"Like the Bay Area, they also have the opportunity to recruit fresh talent from top schools like, USC, UCLA and Caltech. Each of these schools has top-notch programs, and their graduates are well prepared for start-up excellence. However, when experience is considered, we come to a complete stop. 'USC and UCLA graduates just don't have the hands on experience' (...)."

Therefore, instilling greater entrepreneurial orientation in their students will be a major challenge for local universities going forward and will contribute largely to the eventual success or failure of the innovation movement, particularly given the lack of high-risk, early-stage angel investment in the region and the resulting mandate to produce tangible and profitable results early on in the business cycle.

Apart from the entertainment cluster surrounding Hollywood, Downtown Los Angeles has a longstanding tradition of fashion manufacturing (Scott 1996, Williams and Currid-Halkett 2011). While the fashion district has been struggling to sustain itself in the past decades, Bowles (2014) attributes the rise of creative, fashion-oriented e-commerce firms in Downtown Los Angeles to the preexisting infrastructures 
of the old manufacturing cluster with its cheap rents and suitable facilities for all stages of the manufacturing process including not just designers, but also sewers, dyers and label makers.

\section{Distance, travel times and the difficulty to form a cohesive entrepreneurial community}

As described by Sorensen, Wachs et al. (2008) and many others, traffic congestion in Los Angeles is among the worst in the entire United States, and the widespread nature of the Los Angeles metropolitan region makes travel time an important consideration in conducting business. Particularly when trying to attract venture capital funding, geographic proximity and overall accessibility to the source of funding are instrumental, and the lack thereof can at least in part explain why venture capitalists have concentrated their efforts in San Francisco and San Diego, rather than Los Angeles, a region of long traveling distances and high-volume traffic (Florida and Kenney 1988, Lerner 1995).

Aside from the problem of attracting venture capital, distances in L.A. have also made it very difficult for entrepreneurial networks to emerge. Both Storper, Kemeny et al. (2015) and Casper (2009) suggest that L.A.'s failure to develop highly-flexible social networks and an innovative ecosystem in which startups can thrive have been the main causes that led to the region fall behind San Francisco's vibrant technology cluster and San Diego's biotechnology hub.

Due to the insular and isolated nature of neighborhoods in Los Angeles, most startups have initially emerged in a small, well-defined three-mile strip between Santa Monica and Venice Beach, and these early Silicon Beach entrepreneurs took the initial strides toward self-organization (Hood 2013). However, the sudden spike in popularity as a startup region could actually hinder development as it leads to increasing rents and housing prices driven by hype rather than actual monetary impact and performance. As Langlois (2015) points out, the surge in rents and general cost of living in the original Silicon Beach areas of Santa Monica and Venice Beach has led to a secondary wave of firms settling further South in El Segundo and Playa Vista.

The difficulty in getting together and forming a cohesive entrepreneurial community is further signified in the cluster's struggle for a name. According to Zimmerman (2013), choosing the name Silicon Beach holds back the region: most innovation occurring in Los Angeles is native to the region and has no connection whatsoever to Silicon Valley and many suggest that the movement's greatest strength is its distance from it, as well as its proximity to the customer base in Los Angeles and its ability to avoid close-mindedness. Furthermore, Bowles (2014) adds that the cluster in Los Angeles has nothing to do with "Silicon" and that the word "Beach" caters to all bad stereotypes surrounding Los Angeles such as 
having a laid-back, lazy and non-serious attitude. Ultimately, however, she contends that for now, and in the absence of a better nickname, Silicon Beach has been a suitable alternative to generate a community of entrepreneurs as well as sufficient coverage of the movement in media and policy circles.

\section{The lack of anchoring firms and local role models}

While there have been various successful startups in the region such as Oculus Rift and Maker Studios, they have been acquired by Silicon Valley-based investors, leaving the L.A. region without a major corporation that can serve as an anchor for its technology cluster. Vanderhoef (2014) sees this as evidence that Silicon Beach has yet to turn promise into profits, and Bowles (2014) as well as Hood (2013) maintain that it will be critical for the region to develop a milestone firm through initial public offering, endowed with the capital to acquire other local startups and to ensure that economic growth and innovation remain in the Los Angeles area. Many L.A.-based firms have cited their location away from other technology hubs such as Silicon Valley as an advantage and have attributed much of their success to the diversity of influences and the heterogeneity of Los Angeles as compared to Silicon Valley. Eventually, in order for the region to transform into a competitive technology and entertainment hub, large firms and alternative investors such as the movie and TV studios need to emerge as backbones and champions of the local technology economy.

Based on an initial review of the literature on Silicon Beach and the larger Los Angeles innovation movement, three ideas seem to stand out in particular:

- There is a lack of venture capital investment in the region, and while local startups have developed certain coping strategies, it will ultimately be crucial for the L.A. Tech cluster to build up local investment capacity to continue its growth trajectory and to become self-sustaining in the long-run. Although, it is worth noting that several successful clusters such as the San Diego biotechnology cluster have managed to survive by flying in venture capitalists.

- One important factor that has made it difficult for the Los Angeles technology sector to grow in the past has been the dominance of technology firms in other areas such as Silicon Valley, and those areas' ability to pry away the most suitable technical talents and university graduates. The increased focus on interdisciplinary innovation at the intersection of technology and entertainment as well as lifestyle has enabled L.A.-based startups to recruit and retain suitable talent locally in ways that had not previously been possible. 
- The spread-out and insular nature of the Los Angeles region makes it very difficult to organize and to develop a common identity, something that is critical when trying to develop a cohesive innovation movement. The role of both policy makers and self-organizing entrepreneurs will be crucial in developing the kind of entrepreneurial social network that has been a leading force behind other successful clusters such as Silicon Valley or San Diego. 


\section{Research questions and methodological approach}

Following a thorough review of the news coverage and detailed reports on Silicon Beach and the Los Angeles innovation movement, several research questions emerge that will be investigated in greater detail in this dissertation:

\section{Where is the epicenter of the movement and is it changing over time?}

To date, the recent innovation and startup wave in Los Angeles has received considerable attention by the media, policy makers, investors and the wider public. However, when people refer to Silicon Beach, it is not yet well defined to which specific area they are referring. While there is some consensus that the movement originated in Santa Monica and Venice Beach, it is unclear how far it reaches nowadays and whether startups emerging in areas as far away as Pasadena, Long Beach or Burbank should be considered as part of Silicon Beach. Furthermore, it would be interesting to find out more about the causes behind these expansions.

In order to shed light on this initial research question, this dissertation explores three publically-available and one commercial startup and venture capital data sources. In particular, trends of firm location and regional growth are analyzed and compared across Represent.la, L.A. City Geohub, Crunchbase.com and VentureXpert with the ultimate objective of establishing boundaries for Silicon Beach and identifying patterns of cluster growth over time.

\section{What are the main drivers of this movement in terms of skills, talent, industry and funding?}

For policy makers who seek to draw on Silicon Beach entrepreneurs as facilitators of local economic growth, it will be critical to understand the needs of these companies in terms of infrastructure, funding, labor force and policies. Identifying the main drivers of the LA-based digital economy will help policy makers to better understand the relative strengths of the regional economy and centers of excellence in innovation. Based on the initial literature review, one of the strengths of the Silicon Beach movement appears to be its ability to draw on existing factors of production in the Los Angeles economy and to share in the resources and infrastructure developed by the fashion industry in Downtown Los Angeles as well as the entertainment cluster around Hollywood.

Using data from Crunchbase.com, this dissertation investigates whether there are clear patterns in terms of firm location and agglomeration effects, with firms clustering around other firms that operate in 
related industries and taking advantage of shared resources such as topical incubators and accelerators, specialized law firms and workers.

Are there specific anchoring institutions such as universities, movie studios, investors or corporations that attract different kinds of startups?

Closely related to the second research question outlined above, this study further looks at areas of operations, as well as location of startups, to examine potential patterns in firm location and to investigate whether topical sub-clusters can be detected within the movement. Once sub-clusters by industry have been identified using data from Crunchbase.com, a qualitative analysis is performed to find out whether the location and density of particular industries can be explained by the current landscape of key institutions in Los Angeles, such as key investors, large corporate entities, movie studios, universities or fashion manufacturers. 


\section{Exploring data sources for analysis and bounding the Los Angeles innovation movement}

Prior to conducting a detailed exploratory analysis of the Silicon Beach phenomenon in Los Angeles, it is essential to gain a deeper understanding of the available data sources and their respective advantages and limitations. In the following section, this dissertation compares four competing data sources that provide information on startups and technology firms:

\section{Represent.la ${ }^{12}$}

Represent.la has emerged as an online tool with the purpose of tracking startups to help organize the Los Angeles-based innovation community. The dataset is self-reported, asking startups, service companies, accelerators, incubators, investors, co-working spaces and hackerspaces to enter their addresses and a brief description of their services. This setup naturally presents certain limitations in terms of completeness or generalizability; however, it may be safe to assume that companies with a vested interest in the LA innovation scene are most likely to respond, thus leading to an overrepresentation rather than an under-representation of companies of interest. Represent.la presents a rich dataset that allows for a range of interesting analyses with respect to the Los Angeles innovation movement, particularly due to the fact that it includes geographic coordinates and business descriptions. Following a methodology used by Scott (2005), this dissertation examines the concentration of firms by zip code, in order to gain a better understanding of the innovation movement and to define the area that is commonly referred to as Silicon Beach. The dataset contains firms in 168 unique zip codes within Los Angeles County, however, when limiting the count of zip codes to only those who house at least $3 \%$ of a single type of firm as described above, it becomes obvious that a mere thirty-four zip codes make up a vast majority of firms, suggesting that the epicenter of the LA innovation movement lies somewhere among these selected areas (see Figure 13 and Table 1).

\footnotetext{
${ }^{12}$ The Represent.la map and API data hub can be accessed at www.represent.la
} 


\begin{tabular}{|c|c|c|c|c|c|c|c|c|}
\hline Zip code & $\begin{array}{c}\text { Accelerator } \\
\quad \mathrm{n}=26\end{array}$ & $\begin{array}{c}\text { Coworking } \\
\qquad n=50\end{array}$ & $\begin{array}{l}\text { Incubator } \\
n=42\end{array}$ & $\begin{array}{c}\text { Investor } \\
n=68\end{array}$ & $\begin{array}{c}\text { Service } \\
n=272\end{array}$ & $\begin{array}{l}\text { Startup } \\
n=1045\end{array}$ & $\begin{array}{c}\text { Total } \\
\mathrm{n}=1519\end{array}$ & Zip Description \\
\hline 90007 & $0.00 \%$ & $4.00 \%$ & $2.38 \%$ & $0.00 \%$ & $0.00 \%$ & $0.38 \%$ & $0.46 \%$ & South Central \\
\hline 90010 & $0.00 \%$ & $0.00 \%$ & $4.76 \%$ & $0.00 \%$ & $0.37 \%$ & $0.57 \%$ & $0.59 \%$ & Wilshire Blvd \\
\hline 90012 & $0.00 \%$ & $6.00 \%$ & $0.00 \%$ & $0.00 \%$ & $0.37 \%$ & $0.48 \%$ & $0.59 \%$ & Civic Center / Chinatown \\
\hline 90013 & $3.85 \%$ & $6.00 \%$ & $2.38 \%$ & $0.00 \%$ & $1.84 \%$ & $2.87 \%$ & $2.70 \%$ & Downtown Los Angeles \\
\hline 90024 & $0.00 \%$ & $0.00 \%$ & $7.14 \%$ & $7.35 \%$ & $1.47 \%$ & $3.35 \%$ & $3.09 \%$ & Westwood \\
\hline 90025 & $3.85 \%$ & $0.00 \%$ & $0.00 \%$ & $5.88 \%$ & $3.68 \%$ & $2.30 \%$ & $2.57 \%$ & Sawtelle / West LA \\
\hline 90028 & $0.00 \%$ & $8.00 \%$ & $2.38 \%$ & $2.94 \%$ & $1.84 \%$ & $2.68 \%$ & $2.63 \%$ & Hollywood \\
\hline 90034 & $3.85 \%$ & $0.00 \%$ & $0.00 \%$ & $0.00 \%$ & $0.37 \%$ & $1.24 \%$ & $0.99 \%$ & Palms \\
\hline 90035 & $0.00 \%$ & $0.00 \%$ & $0.00 \%$ & $0.00 \%$ & $1.10 \%$ & $0.57 \%$ & $0.59 \%$ & West Fairfax \\
\hline 90036 & $3.85 \%$ & $2.00 \%$ & $0.00 \%$ & $0.00 \%$ & $1.10 \%$ & $1.53 \%$ & $1.38 \%$ & Park La Brea \\
\hline 90039 & $0.00 \%$ & $4.00 \%$ & $0.00 \%$ & $0.00 \%$ & $0.74 \%$ & $0.86 \%$ & $0.86 \%$ & Atwater Village \\
\hline 90046 & $0.00 \%$ & $2.00 \%$ & $7.14 \%$ & $1.47 \%$ & $1.47 \%$ & $0.96 \%$ & $1.25 \%$ & Mount Olympus \\
\hline 90049 & $0.00 \%$ & $0.00 \%$ & $0.00 \%$ & $5.88 \%$ & $0.00 \%$ & $0.86 \%$ & $0.86 \%$ & Bel Air Estates / Brentwood \\
\hline 90067 & $3.85 \%$ & $2.00 \%$ & $0.00 \%$ & $7.35 \%$ & $2.57 \%$ & $0.77 \%$ & $1.45 \%$ & Century City \\
\hline 90069 & $3.85 \%$ & $0.00 \%$ & $2.38 \%$ & $1.47 \%$ & $2.21 \%$ & $1.24 \%$ & $1.45 \%$ & West Hollywood \\
\hline 90089 & $0.00 \%$ & $0.00 \%$ & $4.76 \%$ & $0.00 \%$ & $0.00 \%$ & $0.00 \%$ & $0.20 \%$ & USC \\
\hline 90095 & $3.85 \%$ & $2.00 \%$ & $4.76 \%$ & $0.00 \%$ & $0.00 \%$ & $0.10 \%$ & $0.33 \%$ & Los Angeles \\
\hline 90210 & $0.00 \%$ & $0.00 \%$ & $0.00 \%$ & $4.41 \%$ & $1.47 \%$ & $0.29 \%$ & $0.66 \%$ & Beverly Hills \\
\hline 90212 & $0.00 \%$ & $0.00 \%$ & $0.00 \%$ & $4.41 \%$ & $2.21 \%$ & $0.96 \%$ & $1.25 \%$ & Beverly Hills \\
\hline 90232 & $0.00 \%$ & $4.00 \%$ & $0.00 \%$ & $1.47 \%$ & $2.57 \%$ & $2.78 \%$ & $2.70 \%$ & Culver City \\
\hline 90245 & $7.69 \%$ & $2.00 \%$ & $4.76 \%$ & $1.47 \%$ & $1.84 \%$ & $3.73 \%$ & $3.29 \%$ & El Segundo \\
\hline 90254 & $3.85 \%$ & $0.00 \%$ & $0.00 \%$ & $0.00 \%$ & $0.00 \%$ & $0.67 \%$ & $0.53 \%$ & Hermosa Beach \\
\hline 90291 & $3.85 \%$ & $4.00 \%$ & $2.38 \%$ & $7.35 \%$ & $8.09 \%$ & $6.51 \%$ & $6.52 \%$ & Venice Beach \\
\hline 90292 & $7.69 \%$ & $2.00 \%$ & $2.38 \%$ & $1.47 \%$ & $1.47 \%$ & $3.73 \%$ & $3.16 \%$ & Marina Del Rey \\
\hline 90401 & $30.77 \%$ & $16.00 \%$ & $4.76 \%$ & $13.24 \%$ & $6.99 \%$ & $13.21 \%$ & $12.11 \%$ & Santa Monica \\
\hline 90404 & $3.85 \%$ & $0.00 \%$ & $2.38 \%$ & $0.00 \%$ & $4.04 \%$ & $4.88 \%$ & $4.21 \%$ & Santa Monica \\
\hline 90405 & $0.00 \%$ & $2.00 \%$ & $2.38 \%$ & $4.41 \%$ & $3.68 \%$ & $5.45 \%$ & $4.74 \%$ & Santa Monica \\
\hline 91001 & $0.00 \%$ & $0.00 \%$ & $4.76 \%$ & $1.47 \%$ & $0.37 \%$ & $1.05 \%$ & $0.99 \%$ & Altadena \\
\hline 91016 & $0.00 \%$ & $0.00 \%$ & $4.76 \%$ & $0.00 \%$ & $1.10 \%$ & $0.00 \%$ & $0.33 \%$ & Monrovia \\
\hline 91103 & $3.85 \%$ & $2.00 \%$ & $2.38 \%$ & $0.00 \%$ & $0.00 \%$ & $0.96 \%$ & $0.86 \%$ & Pasadena \\
\hline 91403 & $3.85 \%$ & $2.00 \%$ & $0.00 \%$ & $0.00 \%$ & $1.47 \%$ & $1.05 \%$ & $1.25 \%$ & Sherman Oaks / Van Nuys \\
\hline 91406 & $0.00 \%$ & $4.00 \%$ & $0.00 \%$ & $0.00 \%$ & $0.00 \%$ & $0.10 \%$ & $0.20 \%$ & Van Nuys \\
\hline 91505 & $3.85 \%$ & $0.00 \%$ & $0.00 \%$ & $1.47 \%$ & $0.37 \%$ & $0.38 \%$ & $0.46 \%$ & Burbank \\
\hline 91522 & $3.85 \%$ & $0.00 \%$ & $0.00 \%$ & $0.00 \%$ & $0.00 \%$ & $0.00 \%$ & $0.07 \%$ & Burbank \\
\hline$\%$ Covered & $100.00 \%$ & $74.00 \%$ & $69.05 \%$ & $73.53 \%$ & $54.78 \%$ & $66.51 \%$ & $65.31 \%$ & \\
\hline
\end{tabular}




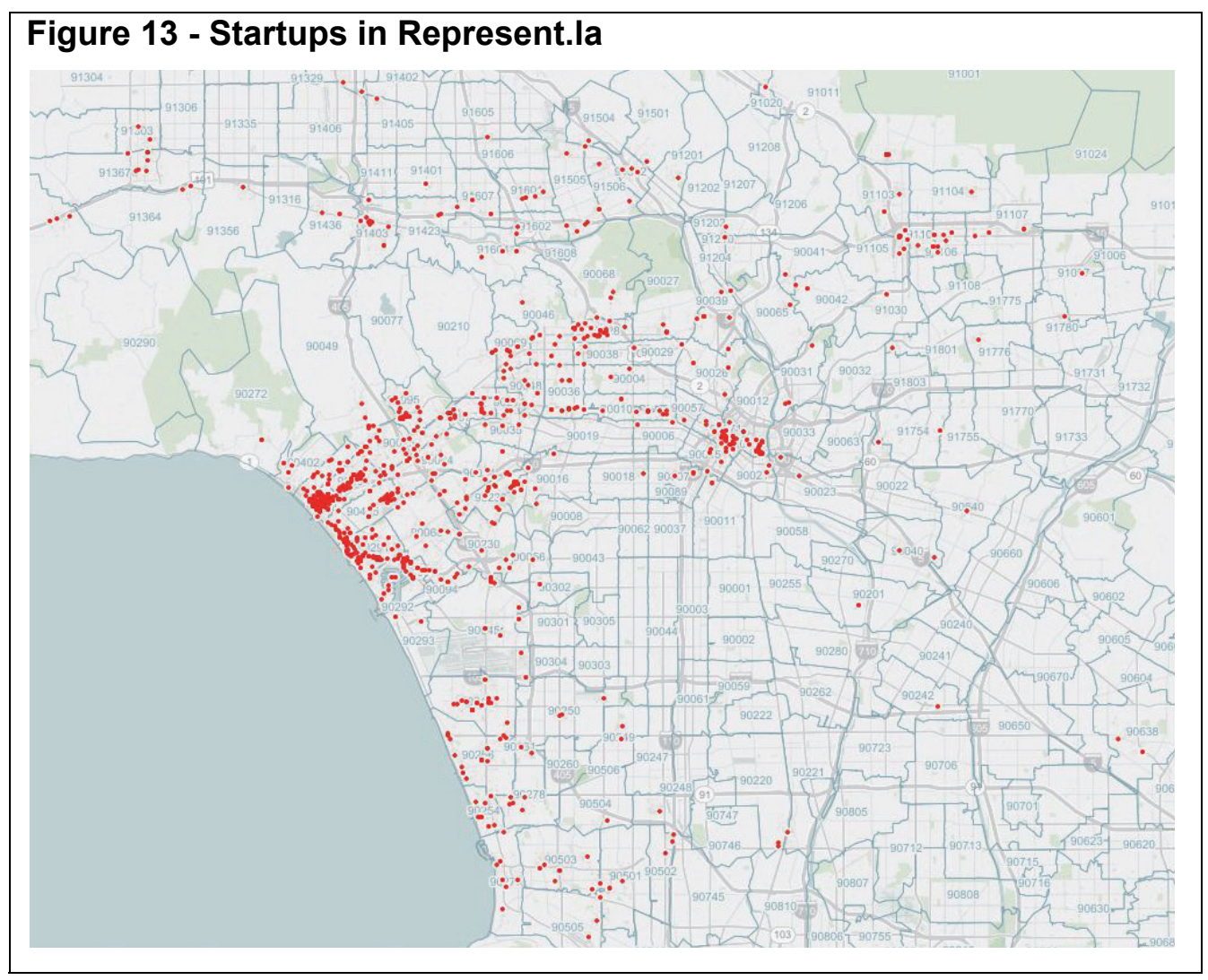

When using the breakdown above, one can see that about two thirds of all startups in the Los Angeles area are positioned within thirty-four zip codes. Upon further examining Table 1, it is very interesting to see that the areas around Santa Monica (zip codes 90401-90405) and Venice / Mar Vista (90291, 90292) are indeed hosting most of the firms in the sample.

Implicitly, the share of firms in the Represent.la dataset that is housed in a specific zip code functions as a measure of concentration of innovative and entrepreneurial activity. Taking Santa Monica and Venice Beach as the epicenter and origin of the innovation movement, one can move to the north, east and south and observe how the share of firms evolves. When following this method, a very interesting pattern emerges, effectively outlining the boundaries for Silicon Beach. Based on the zip code analysis, the areas that are adjacent to Santa Monica and Venice and house a notable share of startup companies are Mar Vista, Palms, Westwood, Sawtelle / West Los Angeles, Culver City, Century City, El Segundo and parts of Beverly Hills (see Figure 14). 


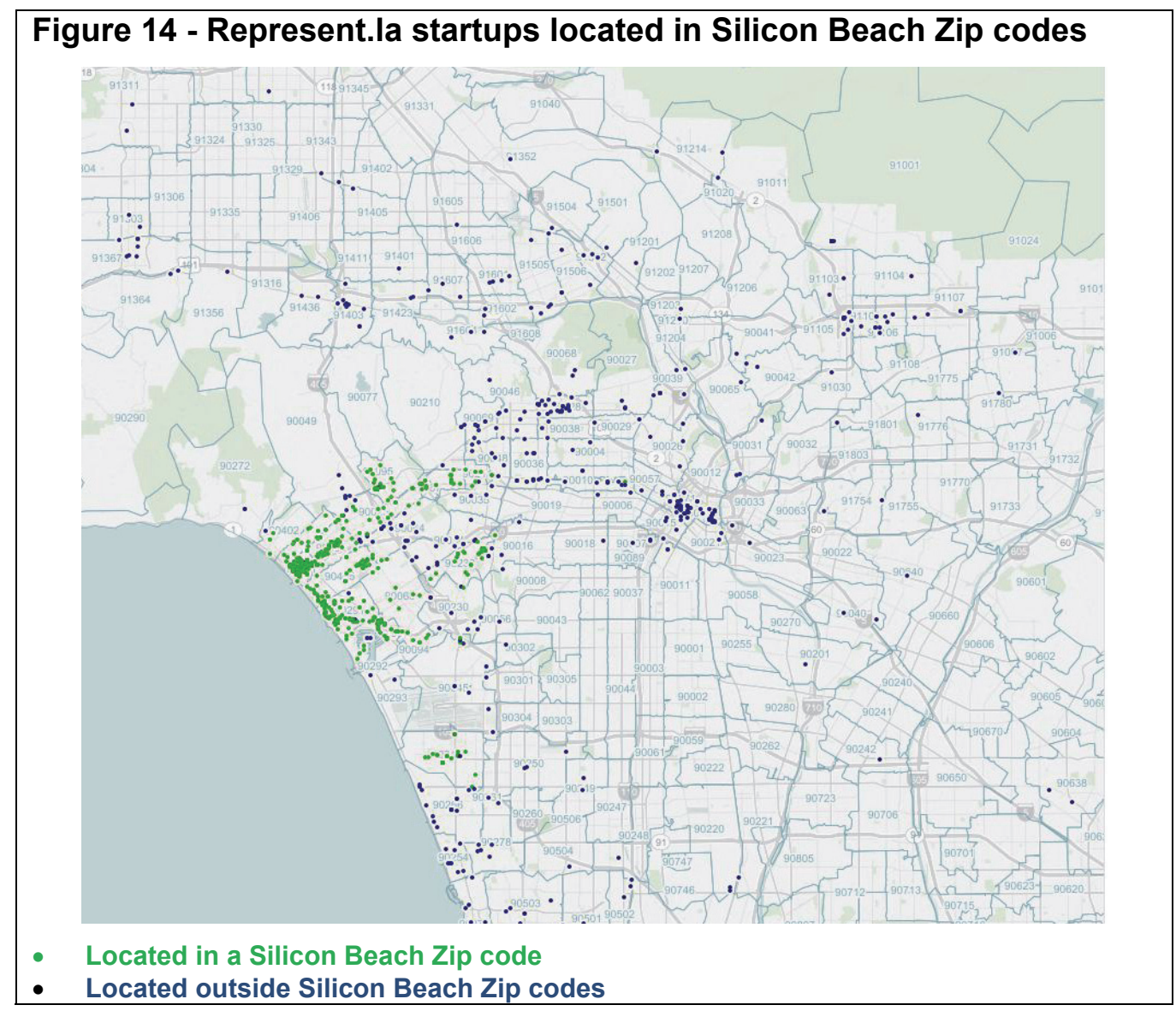

When restricting the dataset to these influential zip codes, the coverage of most types of firms remains fairly high, suggesting that a substantial proportion of entities in the dataset are in fact located in the areas immediately adjacent to Santa Monica and Venice as described above. For example, the sixteen zip codes identified through this analysis cover $52 \%$ of total startups or approximately half of all the firms in the dataset--a significant share when considering that there are a total of 168 unique zip codes represented in the data (see Table 2). 


\begin{tabular}{|c|c|c|c|c|c|c|c|c|c|}
\hline $\begin{array}{l}\text { Firm Type } \\
\text { Zip code }\end{array}$ & $\begin{array}{c}\text { Accelerator } \\
n=26\end{array}$ & $\begin{array}{c}\text { Co- } \\
\text { working } \\
n=50\end{array}$ & $\begin{array}{c}\text { Hackerspace } \\
n=16\end{array}$ & $\begin{array}{c}\text { Incubator } \\
n=42\end{array}$ & $\begin{array}{c}\text { Investor } \\
\mathrm{n}=68\end{array}$ & $\begin{array}{c}\text { Service } \\
\mathrm{n}=272\end{array}$ & $\begin{array}{l}\text { Startup } \\
n=1045\end{array}$ & $\begin{array}{l}\text { Total } \\
\mathrm{n}=1519\end{array}$ & ZIP DESCRIPTION \\
\hline 90024 & $0.00 \%$ & $0.00 \%$ & $0.00 \%$ & $7.14 \%$ & $7.35 \%$ & $1.47 \%$ & $3.35 \%$ & $3.09 \%$ & Westwood \\
\hline 90025 & $3.85 \%$ & $0.00 \%$ & $0.00 \%$ & $0.00 \%$ & $5.88 \%$ & $3.68 \%$ & $2.30 \%$ & $2.57 \%$ & Sawtelle / West LA \\
\hline 90066 & $0.00 \%$ & $2.00 \%$ & $0.00 \%$ & $0.00 \%$ & $2.94 \%$ & $2.57 \%$ & $1.44 \%$ & $1.65 \%$ & Mar Vista \\
\hline 90067 & $3.85 \%$ & $2.00 \%$ & $0.00 \%$ & $0.00 \%$ & $7.35 \%$ & $2.57 \%$ & $0.77 \%$ & $1.45 \%$ & Century City \\
\hline 90095 & $3.85 \%$ & $2.00 \%$ & $0.00 \%$ & $4.76 \%$ & $0.00 \%$ & $0.00 \%$ & $0.10 \%$ & $0.33 \%$ & Los Angeles \\
\hline 90211 & $0.00 \%$ & $2.00 \%$ & $0.00 \%$ & $2.38 \%$ & $2.94 \%$ & $0.37 \%$ & $0.57 \%$ & $0.72 \%$ & Beverly Hills \\
\hline 90212 & $0.00 \%$ & $0.00 \%$ & $0.00 \%$ & $0.00 \%$ & $4.41 \%$ & $2.21 \%$ & $0.96 \%$ & $1.25 \%$ & Beverly Hills \\
\hline 90232 & $0.00 \%$ & $4.00 \%$ & $12.50 \%$ & $0.00 \%$ & $1.47 \%$ & $2.57 \%$ & $2.78 \%$ & $2.70 \%$ & Culver City \\
\hline 90245 & $7.69 \%$ & $2.00 \%$ & $0.00 \%$ & $4.76 \%$ & $1.47 \%$ & $1.84 \%$ & $3.73 \%$ & $3.29 \%$ & El Segundo \\
\hline 90291 & $3.85 \%$ & $4.00 \%$ & $0.00 \%$ & $2.38 \%$ & $7.35 \%$ & $8.09 \%$ & $6.51 \%$ & $6.52 \%$ & Venice Beach \\
\hline 90292 & $7.69 \%$ & $2.00 \%$ & $0.00 \%$ & $2.38 \%$ & $1.47 \%$ & $1.47 \%$ & $3.73 \%$ & $3.16 \%$ & Marina Del Rey \\
\hline 90401 & $30.77 \%$ & $16.00 \%$ & $0.00 \%$ & $4.76 \%$ & $13.24 \%$ & $6.99 \%$ & $13.21 \%$ & $12.11 \%$ & Santa Monica \\
\hline 90402 & $0.00 \%$ & $0.00 \%$ & $0.00 \%$ & $0.00 \%$ & $1.47 \%$ & $1.10 \%$ & $0.38 \%$ & $0.53 \%$ & Santa Monica \\
\hline 90403 & $0.00 \%$ & $0.00 \%$ & $0.00 \%$ & $0.00 \%$ & $1.47 \%$ & $2.21 \%$ & $2.58 \%$ & $2.24 \%$ & Santa Monica \\
\hline 90404 & $3.85 \%$ & $0.00 \%$ & $0.00 \%$ & $2.38 \%$ & $0.00 \%$ & $4.04 \%$ & $4.88 \%$ & $4.21 \%$ & Santa Monica \\
\hline 90405 & $0.00 \%$ & $2.00 \%$ & $0.00 \%$ & $2.38 \%$ & $4.41 \%$ & $3.68 \%$ & $5.45 \%$ & $4.74 \%$ & Santa Monica \\
\hline$\%$ Covered & $65.38 \%$ & $38.00 \%$ & $12.50 \%$ & $33.33 \%$ & $63.24 \%$ & $44.85 \%$ & $52.73 \%$ & $50.56 \%$ & Silicon Beach? \\
\hline
\end{tabular}

After narrowing down an area of interest, one can begin to explore the business descriptions of startups, searching for key words that may indicate their activity area and may present further opportunity for analysis.

Unfortunately, the fact that firms' areas of operation can only be extracted from a brief company description significantly affects the reliability and completeness of the information. Because these paragraphs are a self-reported statement about firms, there is a lack of consistency in which keywords are used, thus making it very difficult to classify firms into different topic areas.

While Represent.la provides a very interesting entry point into the Silicon Beach component of this dissertation, the limitations appear to be too severe to make it the first-choice, primary analysis dataset. Rather, Represent.la is used to initially explore the region's startup landscape and to verify the dynamics found in subsequent analysis performed with other, complementary data sources. 


\section{L.A. City Geohub ${ }^{13}$}

In order to promote Los Angeles as an emergent technology destination, the City of Los Angeles has developed its own dataset on the L.A. Tech industry, based on data on the Listing of Active Businesses registered in the City of Los Angeles, dating back to 1933 and including businesses across all sectors. While there is some overlap with the data presented in Represent.la, this data source uses the North American Industry Classification System (NAICS) to identify firms that are in technology-related sectors and can therefore be thought of as more reliable in terms of industry categorization.

Specifically, L.A. City Geohub follows a methodology outlined in a recent study on the technology sector in New York City (HR\&A Advisors 2014):

"Where prior studies have treated tech as an independent silo, this study considers the entire economy, as tech is distributed throughout the greater New York City economy. The New York City tech ecosystem is defined by three categories of jobs that all directly enable, produce or facilitate technology: 1) tech jobs in tech industries, 2) non-tech jobs in tech industries and 3) tech jobs in non-tech industries. This study uniquely includes jobs not only from tech industries, but also from tech occupations in non-tech industries. The inclusion of tech occupations in non-tech industries is a significant addition to traditional methodologies and enables an accounting of tech jobs located in industries not typically considered tech-related."

Thus, compared to Represent.la, the L.A. City Geohub is likely to present both a more exhaustive list of firms due to the fact that it is based on business registration data, as well as a more systematic way of classifying firms into industry categories. Broadly, technology-related firms are classified into five industries: medical technologies, consulting and IT services, internet and data services, consumer technologies and business-to-business technologies. Similar to the locational patterns exhibited by startups in Represent.la, firms appear to be located along the original Silicon Beach stretch between Santa Monica and Venice Beach, in Downtown Los Angelesand along the Wilshire Corridor, one of the major East-West connectors between these two areas. When taking a closer look at the L.A. City Geohub map, consulting and IT services and medical technology firms appear to make up the majority of tech-related firms in the Los Angeles region (See Figure 15).

\footnotetext{
${ }^{13}$ A brief description of the L.A. Tech Industry Map can be found at 


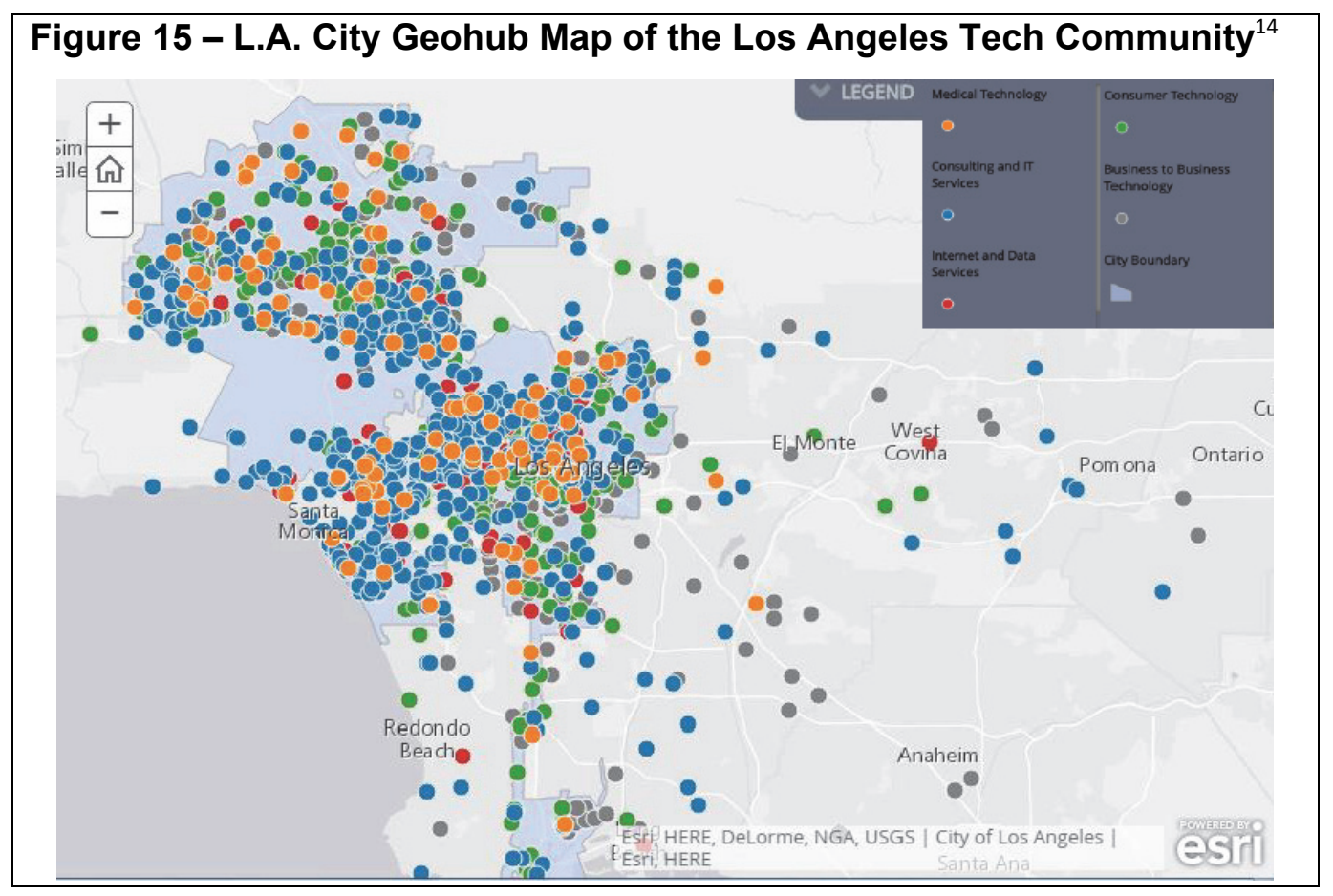

While this analysis presents some valuable insights into the distribution of technology firms and subsectors across L.A., there remain certain limitations that are inherent to the underlying data source. As outlined above, the Los Angeles metropolitan area is fragmented and somewhat insular and while many parts fall under the jurisdiction of the City of L.A., various key Silicon Beach communities such as Santa Monica or Beverly Hills are independent cities. Given this status, firms located in these areas consequently do not have to register with the City of Los Angeles and are hence categorically omitted from any dataset based on firm registration. In addition, relying on NAICS codes in order to categorize firms into sub-sectors of the technology industry creates a variety of issues; with tech firms becoming increasingly interdisciplinary and operating at the intersection of fields such as entertainment, gaming, lifestyle and technology, it becomes virtually impossible to classify them into mutually-exclusive fields based on their tax code. As a result, while L.A. City Geohub presents a more reliable resource for analyzing the L.A. innovation movement than Represent.la, it has some limitations with respect to more detailed, industry-level analyses. On the positive side however, it is very encouraging that tech firms in both datasets exhibit a similar geographic distribution.

${ }^{14}$ This map is a screenshot from http://lahub.maps.arcgis.com/apps/MapSeries/index.html?appid=326872b3726b4e79a85b7a6f98367ec3 


\section{Crunchbase.com ${ }^{15}$}

Crunchbase is a publicly-available, self-reported venture capital database with a complete list of investments made in companies in the United States, including those in Los Angeles. While Crunchbase contains a rich set of data on startups and investors, such as funding rounds, business categories, founding dates, operating status and potential exits or acquisitions, and top-level management composition, it is currently lacking a systematic geographic identifier beyond the city level.

Through web-scraping techniques, this dissertation supplements original data from Crunchbase with geographic coordinates for each firm, allowing for a similar, yet more detailed analysis compared to the one performed by Represent.la. While the Crunchbase data hub Application Program Interface (API) does not include detailed geographic information on firms, actual online profiles of most companies do. Therefore, this dissertation uses a combination of an automated script written in Python and manual web-scraping to elicit specific addresses and to impute a geocode consisting of latitudes and longitude based on the listed addresses of firms. Aside from its usefulness for researching geographical patterns in the Los Angeles innovation movement, this process enhances Crunchbase's usefulness for economic geography research as it generates an open-source, geocoded dataset focused on venture capital investments and startup activity. ${ }^{16}$

For the purpose of this dissertation, the Los Angeles sub-section of Crunchbase is used as the central tool to investigate whether firms cluster around certain topic areas or locations and whether these patterns are changing over time. Once completed, this analysis offers further insights into whether there are larger, anchoring institutions within Los Angeles that attract startups in related fields.

In order to conduct this analysis, the first step is to test the imputed geocode and to replicate the findings described above in terms of geographic concentration of startup activity. Again, looking at zip codes provides a good entry point. Firms in the dataset span as many as 203 individual zip codes and consist of operating startups, previously acquired startups, startups that have exited through an initial public offering (IPO), firms that have invested in startups and firms that have acquired startups. When performing an influence analysis, limiting the dataset to only the zip codes that host at least $3 \%$ of firms in a single category, the pattern looks very similar to the one found using Represent.la - a mere twentyseven zip codes account for roughly half of the startup and investment activity in the Los Angeles area, a fact that is remarkably consistent regardless of the type of company (see Table 3).

\footnotetext{
${ }^{15}$ An overview of Crunchbase data contents is given at http://data.crunchbase.com/ and in the Appendix

${ }^{16}$ In order to verify the accuracy of geographic patterns in this revised version of Crunchbase, findings are compared to VentureXpert, a commercially available Venture Capital below.
} 


\begin{tabular}{|c|c|c|c|c|c|c|c|}
\hline $\begin{array}{l}\text { Firm Type } \\
\text { Zip code }\end{array}$ & $\begin{array}{c}\text { Startup (op) } \\
n=1063 \\
\end{array}$ & $\begin{array}{c}\text { Startup (ipo) } \\
\mathrm{n}=39 \\
\end{array}$ & $\begin{array}{c}\text { Startup (aqrd) } \\
n=110 \\
\end{array}$ & $\begin{array}{l}\text { Invest } \\
\mathrm{n}=184\end{array}$ & $\begin{array}{c}\text { Acquire } \\
\mathrm{n}=123\end{array}$ & $\begin{array}{l}\text { Total } \\
1519 \\
\end{array}$ & ZIP Description \\
\hline 90024 & $2.73 \%$ & $10.26 \%$ & $0.91 \%$ & $8.15 \%$ & $3.25 \%$ & $3.49 \%$ & Westwood \\
\hline 90025 & $3.39 \%$ & $2.56 \%$ & $1.82 \%$ & $5.43 \%$ & $5.69 \%$ & $3.69 \%$ & Sawtelle / West LA \\
\hline 90048 & $1.98 \%$ & $0.00 \%$ & $0.00 \%$ & $2.17 \%$ & $4.07 \%$ & $1.97 \%$ & West Beverly \\
\hline 90049 & $1.03 \%$ & $2.56 \%$ & $0.91 \%$ & $3.80 \%$ & $0.81 \%$ & $1.38 \%$ & Bel Air Estates / Brentwood \\
\hline 90067 & $0.75 \%$ & $0.00 \%$ & $0.00 \%$ & $9.78 \%$ & $4.88 \%$ & $2.11 \%$ & Century City \\
\hline 90069 & $1.69 \%$ & $2.56 \%$ & $3.64 \%$ & $0.00 \%$ & $3.25 \%$ & $1.78 \%$ & West Hollywood \\
\hline 90071 & $0.75 \%$ & $0.00 \%$ & $0.00 \%$ & $3.80 \%$ & $0.81 \%$ & $1.05 \%$ & Los Angeles \\
\hline 90210 & $1.60 \%$ & $5.13 \%$ & $0.91 \%$ & $7.07 \%$ & $4.07 \%$ & $2.50 \%$ & Beverly Hills \\
\hline 90212 & $1.51 \%$ & $2.56 \%$ & $0.91 \%$ & $3.26 \%$ & $2.44 \%$ & $1.78 \%$ & Beverly Hills \\
\hline 90232 & $2.92 \%$ & $0.00 \%$ & $3.64 \%$ & $2.17 \%$ & $1.63 \%$ & $2.70 \%$ & Culver City \\
\hline 90245 & $2.45 \%$ & $2.56 \%$ & $6.36 \%$ & $2.17 \%$ & $8.13 \%$ & $3.16 \%$ & El Segundo \\
\hline 90291 & $3.29 \%$ & $0.00 \%$ & $4.55 \%$ & $0.54 \%$ & $0.81 \%$ & $2.76 \%$ & Venice \\
\hline 90401 & $9.41 \%$ & $0.00 \%$ & $4.55 \%$ & $7.07 \%$ & $8.13 \%$ & $8.43 \%$ & Santa Monica \\
\hline 90404 & $3.57 \%$ & $2.56 \%$ & $3.64 \%$ & $1.09 \%$ & $2.44 \%$ & $3.16 \%$ & Santa Monica \\
\hline 90405 & $3.39 \%$ & $0.00 \%$ & $5.45 \%$ & $1.09 \%$ & $3.25 \%$ & $3.16 \%$ & Santa Monica \\
\hline 91101 & $1.03 \%$ & $5.13 \%$ & $0.91 \%$ & $3.80 \%$ & $0.00 \%$ & $1.38 \%$ & Pasadena \\
\hline 91107 & $0.94 \%$ & $5.13 \%$ & $0.91 \%$ & $1.63 \%$ & $0.00 \%$ & $1.05 \%$ & Pasadena \\
\hline 91301 & $0.56 \%$ & $5.13 \%$ & $1.82 \%$ & $1.63 \%$ & $3.25 \%$ & $1.12 \%$ & Agoura/Oak Park \\
\hline 91302 & $0.75 \%$ & $7.69 \%$ & $1.82 \%$ & $0.00 \%$ & $0.00 \%$ & $0.86 \%$ & Calabasas/Hidden Hills \\
\hline 91320 & $0.19 \%$ & $5.13 \%$ & $0.00 \%$ & $0.00 \%$ & $0.00 \%$ & $0.26 \%$ & Thousand Oaks \\
\hline 91362 & $0.75 \%$ & $0.00 \%$ & $3.64 \%$ & $0.00 \%$ & $0.00 \%$ & $0.79 \%$ & Westlake Village \\
\hline$\%$ Covered & $44.68 \%$ & $58.97 \%$ & $46.36 \%$ & $64.67 \%$ & $56.91 \%$ & $48.58 \%$ & \\
\hline
\end{tabular}

The regional breakdown of firm types depicted above seems to be at least somewhat similar to the breakdown generated through Represent.la. However, in order to determine whether a common area for Silicon Beach can be identified, the sample will once more be limited to firms in the zip codes previously suggested to contain a substantial share of startups and related firms, notably Santa Monica and Venice, Mar Vista, Palms, Westwood, Sawtelle / West Los Angeles, Culver City, Century City, El Segundo and Beverly Hills (see Table 4). 


\begin{tabular}{|c|c|c|c|c|c|c|c|}
\hline $\begin{array}{l}\text { Firm Type } \\
\text { Zip code }\end{array}$ & $\begin{array}{c}\text { Startup (op) } \\
n=1063\end{array}$ & $\begin{array}{c}\text { Startup (ipo) } \\
n=39\end{array}$ & $\begin{array}{c}\text { Startup (aqrd) } \\
n=110\end{array}$ & $\begin{array}{l}\text { Invest } \\
n=184\end{array}$ & $\begin{array}{c}\text { Acquire } \\
\mathrm{n}=123\end{array}$ & $\begin{array}{c}\text { Total } \\
n=1519\end{array}$ & ZIP Description \\
\hline 90024 & $2.73 \%$ & $10.26 \%$ & $0.91 \%$ & $8.15 \%$ & $3.25 \%$ & $3.49 \%$ & Westwood \\
\hline 90025 & $3.39 \%$ & $2.56 \%$ & $1.82 \%$ & $5.43 \%$ & $5.69 \%$ & $3.69 \%$ & Sawtelle / West LA \\
\hline 90066 & $0.94 \%$ & $0.00 \%$ & $1.82 \%$ & $1.09 \%$ & $0.00 \%$ & $0.92 \%$ & Mar Vista \\
\hline 90067 & $0.75 \%$ & $0.00 \%$ & $0.00 \%$ & $9.78 \%$ & $4.88 \%$ & $2.11 \%$ & Century City \\
\hline 90095 & $0.09 \%$ & $0.00 \%$ & $0.91 \%$ & $0.00 \%$ & $0.00 \%$ & $0.13 \%$ & Los Angeles \\
\hline 90210 & $1.60 \%$ & $5.13 \%$ & $0.91 \%$ & $7.07 \%$ & $4.07 \%$ & $2.50 \%$ & Beverly Hills \\
\hline 90211 & $1.03 \%$ & $0.00 \%$ & $0.00 \%$ & $0.54 \%$ & $0.81 \%$ & $0.86 \%$ & Beverly Hills \\
\hline 90212 & $1.51 \%$ & $2.56 \%$ & $0.91 \%$ & $3.26 \%$ & $2.44 \%$ & $1.78 \%$ & Beverly Hills \\
\hline 90232 & $2.92 \%$ & $0.00 \%$ & $3.64 \%$ & $2.17 \%$ & $1.63 \%$ & $2.70 \%$ & Culver City \\
\hline 90245 & $2.45 \%$ & $2.56 \%$ & $6.36 \%$ & $2.17 \%$ & $8.13 \%$ & $3.16 \%$ & El Segundo \\
\hline 90291 & $3.29 \%$ & $0.00 \%$ & $4.55 \%$ & $0.54 \%$ & $0.81 \%$ & $2.76 \%$ & Venice Beach \\
\hline 90292 & $2.26 \%$ & $0.00 \%$ & $1.82 \%$ & $1.63 \%$ & $0.00 \%$ & $1.91 \%$ & Marina Del Rey \\
\hline 90401 & $9.41 \%$ & $0.00 \%$ & $4.55 \%$ & $7.07 \%$ & $8.13 \%$ & $8.43 \%$ & Santa Monica \\
\hline 90402 & $0.09 \%$ & $0.00 \%$ & $0.00 \%$ & $0.00 \%$ & $1.63 \%$ & $0.20 \%$ & Santa Monica \\
\hline 90403 & $1.60 \%$ & $2.56 \%$ & $0.00 \%$ & $0.00 \%$ & $1.63 \%$ & $1.32 \%$ & Santa Monica \\
\hline 90404 & $3.57 \%$ & $2.56 \%$ & $3.64 \%$ & $1.09 \%$ & $2.44 \%$ & $3.16 \%$ & Santa Monica \\
\hline 90405 & $3.39 \%$ & $0.00 \%$ & $5.45 \%$ & $1.09 \%$ & $3.25 \%$ & $3.16 \%$ & Santa Monica \\
\hline$\%$ Covered & $41.02 \%$ & $28.21 \%$ & $37.27 \%$ & $51.09 \%$ & $48.78 \%$ & $42.26 \%$ & Silicon Beach? \\
\hline
\end{tabular}

Once more, shares of firm types remain close to $40 \%$, even when imposing a fairly heavy restriction on the area, suggesting that the area containing these zip codes can be considered an epicenter of startup activity in Crunchbase. Zip codes related to Santa Monica in particular (90401-90405) contain substantial shares of operating startups, investors and firms that have acquired other L.A.-based startups. 


\section{VentureXpert}

Exploring open source data such as Crunchbase and Represet.la can provide valuable insights into the makeup of the Los Angeles technology landscape, but at the same time, using self-reported data frequently imposes severe limitations in terms of representativeness and reliability. Effectively, when relying on data from Crunchbase, researchers are facing a tradeoff between an affordable and readilyavailable data source and various other commercially-maintained databases that can be presumed to be more complete and reliable. While there are some concerns about the sole use of Crunchbase data to analyze the Los Angeles innovation movement, the data are widely used by policy makers across the region and even the country and have received heightened attention by academic researchers as well.

In order to test the validity of the data for the sake of this dissertation, VentureXpert is taken as a baseline comparison to determine whether the underlying geographical differ across commerciallymaintained and self-reported investment datasets.

To accomplish this comparison, data were extracted from VentureXpert to most closely align with the startup populations covered in Represent.la and the Los Angeles sub-section of Crunchbase. The key variables used to decide whether data should be included were the location of a firm's headquarters, the timing of investments received, and the industry code. This query eventually generated a set of 947 firms that are headquartered in Los Angeles, received investments between 1995 and 2015 and were listed under the category "Information Technology", which can be presumed to include most technologyrelated firms. A map of these firms is displayed in Figure 16. 


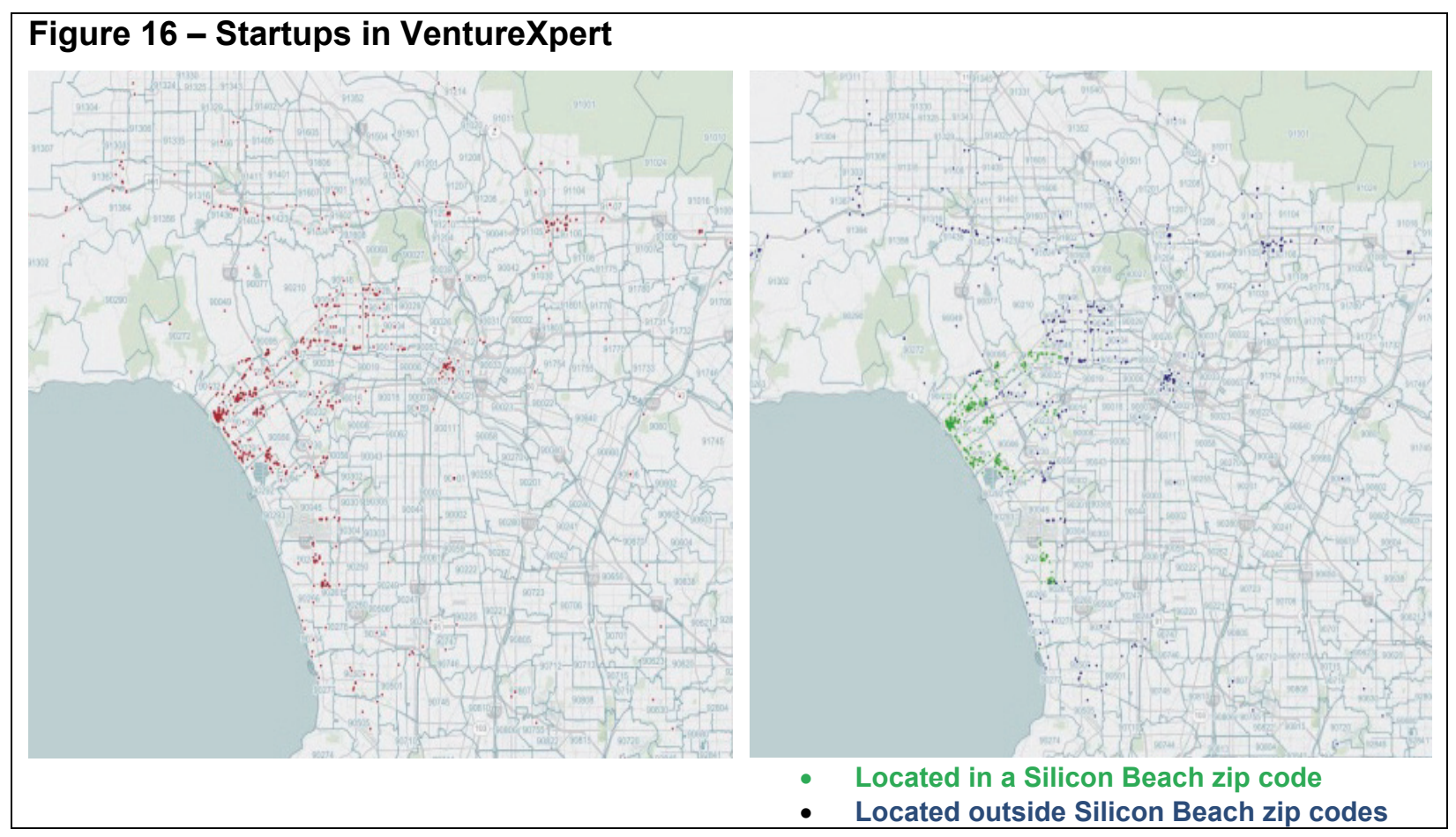

When restricting the data to the influential zip codes that contain a share in excess of $3 \%$ of startups in VentureXpert, a very interesting picture emerges: while 155 unique zip codes are represented, only six of them host a substantial fraction of startups, five of which are among the Silicon Beach zip codes identified above (90245, 90294, 90401, 90404 and 90405 all represent Silicon Beach, while 90001 represented Downtown Los Angeles). Thus, it seems that startups in VentureXpert are even more concentrated in the key Silicon Beach areas than startups in Crunchbase and Represent.la. However, when taking a look at startups contained in all zip codes that have previously been determined as Silicon Beach, the share amounts to roughly $38 \%$, a number that is very similar to the $40 \%$ of operating startups found using Crunchbase (see Table 5.).

\begin{tabular}{|c|c|c|c|}
\hline Zip Code & Firms (out of $n=947$ ) & Share of Firms & ZIP Description \\
\hline 90024 & 15 & $1.58 \%$ & Westwood \\
\hline 90025 & 25 & $2.64 \%$ & Sawtelle / West LA \\
\hline 90066 & 12 & $1.27 \%$ & Mar Vista \\
\hline 90067 & 8 & $0.84 \%$ & Century City \\
\hline 90095 & 0 & $0.00 \%$ & Los Angeles \\
\hline 90210 & 6 & $0.63 \%$ & Beverly Hills \\
\hline 90211 & 9 & $0.95 \%$ & Beverly Hills \\
\hline 90212 & 8 & $0.84 \%$ & Beverly Hills \\
\hline 90232 & 12 & $1.27 \%$ & Culver City \\
\hline
\end{tabular}




\begin{tabular}{|l|c|c|l|}
90245 & 32 & $3.38 \%$ & El Segundo \\
90291 & 32 & $3.38 \%$ & Venice Beach \\
90292 & 27 & $2.85 \%$ & Marina Del Rey \\
90401 & 69 & $7.29 \%$ & Santa Monica \\
90402 & 1 & $0.11 \%$ & Santa Monica \\
90403 & 13 & $1.37 \%$ & Santa Monica \\
90404 & 44 & $4.65 \%$ & Santa Monica \\
90405 & 44 & $4.65 \%$ & Santa Monica \\
\hline \multicolumn{2}{|c|}{ \% Covered (out of $\mathbf{9 4 7}$ firms overall) } & $\mathbf{3 5 7}$ & Silicon Beach? \\
\hline
\end{tabular}

Ultimately, it seems that based on an initial comparison of similar firms in VentureXpert, the geographic distribution of L.A.-based firms in Crunchbase is at least somewhat representative, which increases confidence in using Crunchbase as a research tool for entrepreneurial research as well as policy. 


\section{Bounding the Los Angeles innovation movement}

When aiming to explore the rise of the Los Angeles innovation movement, choosing an appropriate dataset for analysis is critical. Represent.la and Crunchbase.com are publicly-available databases that contain information on startups in the Los Angeles region and are free of charge for non-commercial users such as academic researchers and public sector employees. However, the fact that these data are not as rigorously maintained and quality-controlled as commercial investment databases such as VentureXpert calls into question their reliability and representativeness.

Nonetheless, when comparing all three data sources, as well as an L.A. tech industry map developed by the City of Los Angeles based on business registration data, there appears to be a strong convergence and a central theme in the location decisions of startups in Los Angeles. All four datasets suggest a bimodal locational pattern, with firms concentrated heavily in an area that is defined above as Silicon Beach as well as Downtown Los Angeles, areas that correspond to the ones described in the literature review and that are consistent with the hypothesis that the movement has spread from Santa Monica and Venice towards cheaper areas in the South such as Playa Vista and EI Segundo and closer to the entertainment cluster near Hollywood and Burbank in the North-East. The concentration of firms near Downtown could be attributable to the resurgence of the fashion industry and the growing e-commerce sector. 
Figure 17 - Constructed Silicon Beach Map - Adjacent Influential Zip Codes

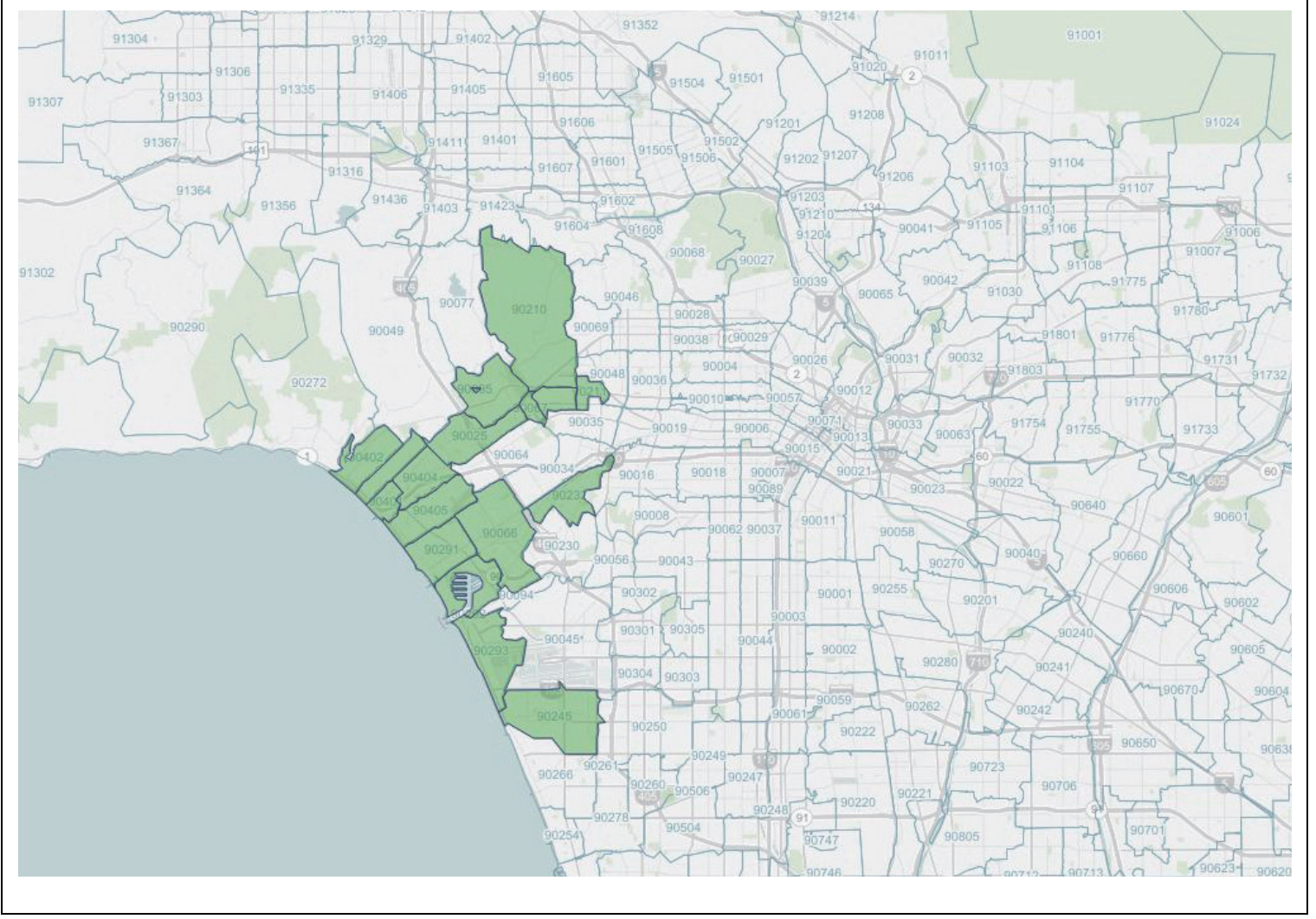




\section{Breaking-down the Los Angeles innovation movement}

While it is certainly encouraging to see that the locational distribution of firms in all four datasets show a strong convergence and are highly suggestive of the fact that Silicon Beach may be defined as the area surrounding Santa Monica and Venice and reaching out as far to the North-West as Beverly Hills and Westwood and as far South-East as Culver City and El Segundo, the richness of data available in Crunchbase allow for a much more detailed analysis of the Los Angeles innovation movement, beyond simple descriptive statistics and firm counts. The dataset has information on opening and closure dates of businesses, allowing for location decisions to be tracked over time and to find out whether there has been a gradual shift away from Santa Monica and Venice towards more affordable areas such as Hollywood or Downtown Los Angeles. Furthermore, investment amounts as well as relationships between funders and companies are reported on a quarterly basis, thus making it possible to investigate whether startups gravitate towards certain areas that have seen strong investment activity and whether certain areas in Los Angeles seem to have a better funding environment for certain industries. The fact that firms are asked to classify themselves into a pre-defined set of industry categories further enables this dissertation to look at the relationship between industry, area of operation and firm location by grouping key words into industry classifications as sketched-out in Figure 18.

Compared to other industry classification strategies (such as the one used by L.A. City), using NAICS codes to determine firms that operate in technology-related sectors has several distinct advantages and offers a more holistic approach. It allows for a more open classification of firms into categories that are far more specific than a broad overview label such as information technology while also taking account of the fact that firms could be working in an interdisciplinary field, spanning multiple industries by making classifications not mutually exclusive. While the classification is undoubtedly somewhat subjective, it might be a better way to categorize startups based on the interdisciplinary nature of technology firms, particularly in the Los Angeles setting, an environment that is focused on combining technology and entertainment. 


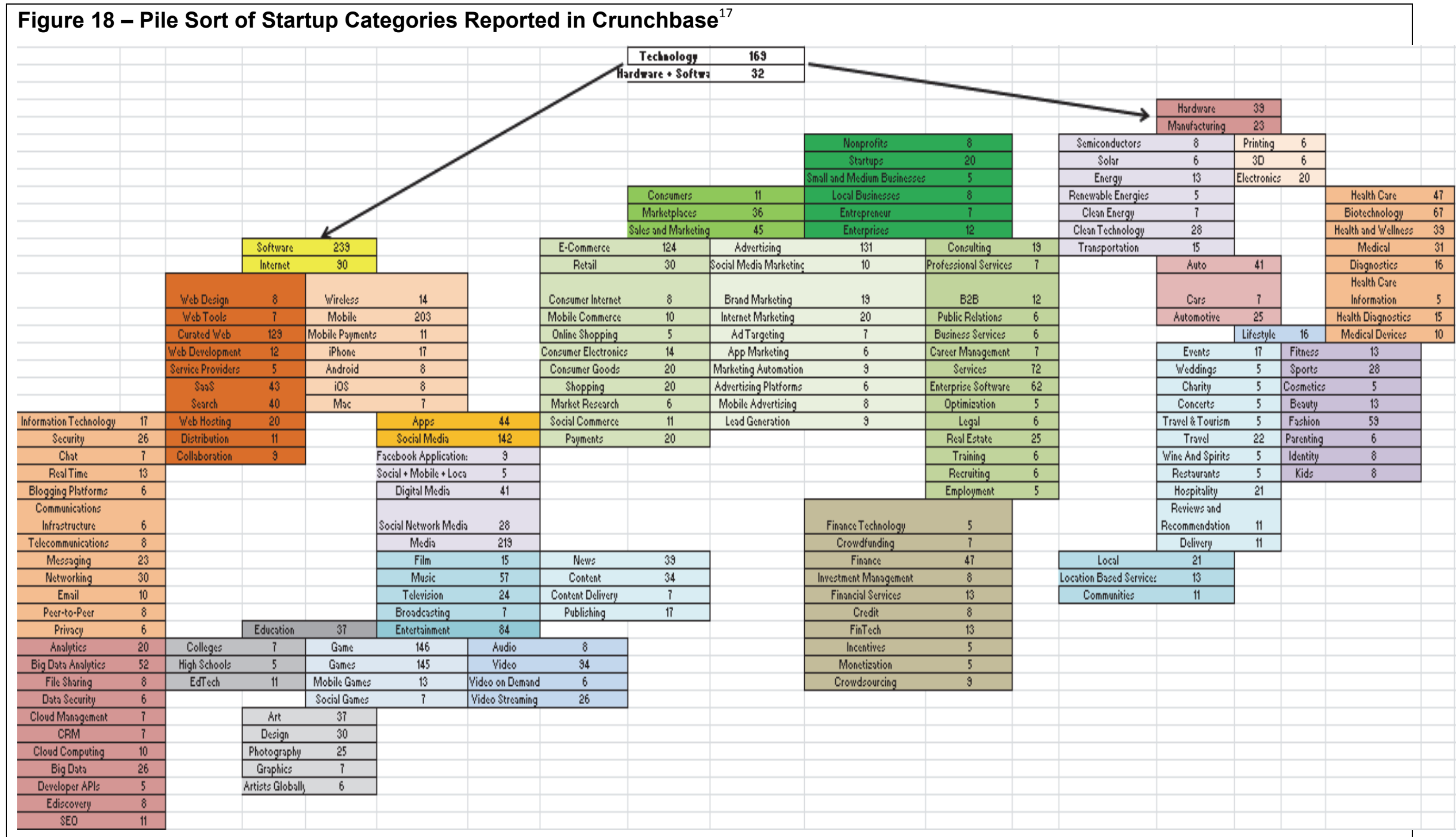

\footnotetext{
${ }^{17}$ Categories are pulled out from the drop-down menu that Crunchbase provides and then grouped according to industry themes.
} 
When classifying firms into industry groupings based on self-reported key words from the Crunchbase drop-down menu, thirteen categories emerge based on 514 unique terms. All terms that were mentioned by at least five startups in the dataset were included in the electronic pile sorting exercise, ranging from technical, mainly computing-related phrases to lifestyle, beauty and entertainment concepts.

Due to the fact that there could potentially be substantial overlap between categories, the first step in the industry analysis is to examine correlations between different industries and identifying themes that are common across domains (see Figure 19).

\begin{tabular}{|c|c|c|c|c|c|c|c|c|c|c|c|c|c|}
\hline \multicolumn{14}{|c|}{ Figure 19 - Correlations between different industries } \\
\hline & TEC & ICT & DTA & EDU & ENT & SMA & MOB & WEB & BIZ & MNS & MFT & LST & MED \\
\hline \multicolumn{14}{|l|}{ TEC } \\
\hline ICT & $\begin{array}{c}0.1535^{\circ} \\
0.000 \\
\end{array}$ & 1 & & & & & & & & & & & \\
\hline DTA & $\begin{array}{r}0.1216^{*} \\
0.000 \\
\end{array}$ & $\begin{array}{c}0.2091^{1} \\
0.000\end{array}$ & 1 & & & & & & & & & & \\
\hline EDU & $\begin{array}{r}-0.008 \\
0.637\end{array}$ & $\begin{array}{l}0.009 \\
0.590\end{array}$ & $\begin{array}{c}0.1229^{-1} \\
0.000\end{array}$ & 1 & & & & & & & & & \\
\hline ENT & $\begin{array}{c}0.0580^{\circ} \\
0.000\end{array}$ & $\begin{array}{l}0.028 \\
0.083\end{array}$ & $\begin{array}{c}0.1198^{-} \\
0.000\end{array}$ & $\begin{array}{c}0.6805^{*} \\
0.000\end{array}$ & 1 & & & & & & & & \\
\hline SMA & $\begin{array}{r}0.0976^{\circ} \\
0.000\end{array}$ & $\begin{array}{r}\mathbf{0 . 1 1 3 0 ^ { - }} \\
0.000\end{array}$ & $\begin{array}{c}0.1559^{-1} \\
0.000\end{array}$ & $\begin{array}{c}0.1954^{-1} \\
0.000\end{array}$ & $\begin{array}{c}0.3400^{\circ} \\
0.000\end{array}$ & 1 & & & & & & & \\
\hline MOB & $\begin{array}{r}0.0566^{\circ} \\
0.000\end{array}$ & $\begin{array}{c}0.1232^{\circ} \\
0.000\end{array}$ & $\begin{array}{c}0.2075^{*} \\
0.000\end{array}$ & $\begin{array}{c}\mathbf{0 . 1 4 4 7} \\
0.000\end{array}$ & $\begin{array}{c}\mathbf{0 . 1 3 5 0 ^ { - }} \\
0.000\end{array}$ & $\begin{array}{c}0.3156^{*} \\
0.000\end{array}$ & 1 & & & & & & \\
\hline WEB & $\begin{array}{r}0.0985^{\circ} \\
0.000\end{array}$ & $\begin{array}{c}\mathbf{0 . 1 3 9 ^ { - 1 }} \\
0.000\end{array}$ & $\begin{array}{c}0.1733^{-} \\
0.000\end{array}$ & $\begin{array}{c}0.0590^{\circ} \\
0.000\end{array}$ & $\begin{array}{c}0.0989^{\circ} \\
0.000\end{array}$ & $\begin{array}{c}0.1746^{-} \\
0.000\end{array}$ & $\begin{array}{c}0.0932^{\circ} \\
0.000\end{array}$ & 1 & & & & & \\
\hline BIZ & $\begin{array}{r}0.0889^{\circ} \\
0.000\end{array}$ & $\begin{array}{l}0.003 \\
0.873\end{array}$ & $\begin{array}{c}0.0932^{\circ} \\
0.000\end{array}$ & $\begin{array}{c}-0.0349^{\circ} \\
0.028\end{array}$ & $\begin{array}{c}-0.0883^{\circ} \\
0.0000\end{array}$ & $\begin{array}{l}0.009 \\
0.564\end{array}$ & $\begin{array}{r}0.0424^{\circ} \\
0.008\end{array}$ & $\begin{array}{r}0.0902^{\circ} \\
0.000\end{array}$ & 1 & & & & \\
\hline MNS & $\begin{array}{c}0.0620^{\circ} \\
0.000\end{array}$ & $\begin{array}{c}0.0756^{\circ} \\
0.000\end{array}$ & $\begin{array}{c}0.1932^{*} \\
0.000\end{array}$ & $\begin{array}{c}0.0669^{\circ} \\
0.000\end{array}$ & $\begin{array}{c}0.1472^{-} \\
0.000\end{array}$ & $\begin{array}{c}0.2684^{\circ} \\
0.000\end{array}$ & $\begin{array}{c}0.2212^{*} \\
0.000\end{array}$ & $\begin{array}{c}0.1759^{\circ} \\
0.000\end{array}$ & $\begin{array}{c}-0.017 \\
0.294\end{array}$ & 1 & & & \\
\hline MFT & $\begin{array}{c}\mathbf{0 . 1 9 8 7} \\
0.000\end{array}$ & $\begin{array}{l}0.005 \\
0.759\end{array}$ & $\begin{array}{l}0.018 \\
0.271\end{array}$ & $\begin{array}{r}0.0358^{\circ} \\
0.024\end{array}$ & $\begin{array}{r}0.011 \\
0.503\end{array}$ & $\begin{array}{c}0.0380^{\circ} \\
0.017\end{array}$ & $\begin{array}{l}-0.001 \\
0.958\end{array}$ & $\begin{array}{c}-0.008 \\
0.604\end{array}$ & $\begin{array}{r}-0.020 \\
0.217\end{array}$ & $\begin{array}{c}0.1091^{\circ} \\
0.000\end{array}$ & 1 & & \\
\hline LST & $0.0499^{\circ}$ & $0.0997^{*}$ & 0.007 & $\frac{0.0 \angle 4}{0.0891^{\circ}}$ & $0.0772^{\circ}$ & $0.01464^{-1}$ & $0.1423^{-1}$ & $0.0706^{\circ}$ & $\frac{0.211}{-0.014}$ & $0.2241^{\circ}$ & $0.2417^{-1}$ & 1 & \\
\hline \multirow[b]{2}{*}{ MED } & $\begin{array}{l}0.002 \\
-0.011\end{array}$ & $\begin{array}{r}0.000 \\
0.015\end{array}$ & $\frac{0.679}{-0.0339^{\circ}}$ & $\begin{array}{c}0.000 \\
-0.0667\end{array}$ & \begin{tabular}{|c|c|}
0.000 \\
-0.0525
\end{tabular} & $\frac{0.000}{-0.026}$ & $\frac{0.000}{-0.026}$ & $\frac{0.000}{-0.0742}$ & $\begin{array}{c}0.374 \\
-0.1179^{2}\end{array}$ & $\frac{0.000}{-0.023}$ & \begin{tabular}{|c|c|}
0.000 \\
$-0.0421^{\circ}$
\end{tabular} & 0.007 & 1 \\
\hline & 0.487 & 0.353 & 0.033 & 0.000 & 0.001 & 0.106 & 0.098 & 0.000 & 0.000 & 0.146 & 0.008 & 0.657 & \\
\hline \multicolumn{4}{|c|}{$\begin{array}{l}\text { correlation coefficient }>0.10 \\
\text { correlation coefficient }>0.15 \\
\text { correlation coefficient }>0.20 \\
\text { correlation coefficient }<-.0 .5 \\
\text { correlation coefficient }<-0.10\end{array}$} & $\begin{array}{l}\text { The upper } \\
\text { denotes } \mathrm{p} \\
\text { Coefficien } \\
\text { confideno }\end{array}$ & $\begin{array}{l}\text { ir value in e: } \\
\text {-value. } \\
\text { nts marked } \\
\text { ce level (i.e. }\end{array}$ & $\begin{array}{l}\text { ach cell de } \\
\text { with an ast } \\
p<0.05)\end{array}$ & enotes the & $\begin{array}{l}\text { correlatio } \\
\text { atistically }\end{array}$ & $\begin{array}{l}\text { coefficient } \\
\text { ignificantly }\end{array}$ & t between & the two vari & $\begin{array}{l}\text { ables, bo } \\
\text { the } 95 \%\end{array}$ & \\
\hline
\end{tabular}

When examining the correlations between industry groups to which startups belong, it is apparent that various industries are highly correlated with one another. As an example, firms who are classified as education-related tend to also be classified as entertainment-related, which could be due to the fact that Los Angeles has a strong focus on gaming, which could be seen as both educational and entertaining. 
This type of correlational analysis serves as the first step towards exploring which industries are cooccurring and may be in the best position to take advantage of shared (already-existing or newlycreated) resources in the LA region.

Following the creation of industry groupings within Crunchbase, an influence analysis, using shares of firms in excess of $3 \%$ that are contained within specific zip codes, can again be performed in order to get a more nuanced view of sub-clusters within the Los Angeles innovation movement and to obtain some initial evidence behind the industry-location hypotheses outlined above. Carrying out this kind of analysis can be instrumental in helping policy-makers to identify the relative strengths of their regions.

After grouping firm categories into industries and breaking them down by zip code, it is very interesting to see that the core Silicon Beach areas surrounding Santa Monica and Venice seem to have a broad appeal and thus attract startups in almost every topic area, while areas that are further outside these areas such as Thousand Oaks, Sherman Oaks and Van Nuys appear to attract startups in very specific business areas like medical and health sciences as well as data analytics (see Table 6). This lends credence to the idea that Silicon Beach is a very interdisciplinary innovation movement, connecting technology with other areas such as lifestyle, entertainment, education and even manufacturing.

Furthermore, when extending this type of analysis by looking at correlations between the different industries and all influential zip codes with a share of $3 \%$ or more firms in a single industry category, this dissertation finds strong positive and statistically significant correlations between 90210 (Beverly Hills) and education, entertainment and social media, as well as 90291 (Venice) and business support, suggesting that startups related to education, entertainment and social media are most likely to be located in these zip codes. On the opposite side, the strongest negative and statistically significant correlations are found between 90212 (Beverly Hills) and web, business support, and marketing and sales, suggesting that startups in those industries are less likely to be found in said zip code. Interestingly, there do not seem to be many strong positive or negative correlations between Santa Monica zip codes (90401-90405) and any industry clusters, again supporting the hypothesis that Santa Monica holds a broader variety of startups in different industries and has become host to a very diverse innovation landscape (see Figure 20). While these are very interesting findings, it must however be noted that they are exploratory in nature given the relatively small positive and negative correlations ranging from -0.073 to +0.1483 and that it is difficult to establish any causal linkages based on these numbers. 


\section{Table 6- Industries and Zip code distribution (Share $>\mathbf{3} \%$ in a single category)}

\begin{tabular}{|c|c|c|c|c|c|c|c|c|c|c|c|c|c|c|}
\hline Industry & Technology & ICT & Data Science & Education & Entertainment & Social Media $\$$ Apps & Mobile & Veb & Business Support & Marketing * Sales & Manufacturing & Lifestyle & Med $t$ Health & ZIP DESCRIPTON \\
\hline ZIP & 437 & 147 & 123 & 300 & 451 & 283 & 242 & 304 & 360 & 443 & 132 & 303 & 167 & ZIP DESLAIPIIUN \\
\hline 90015 & $0.75 \%$ & $1.27 \%$ & $0.00 \%$ & $0.00 \%$ & $0.78 \%$ & $0.64 \%$ & $1.35 \%$ & $0.60 \%$ & $0.50 \%$ & $1.48 \%$ & $3.57 \%$ & $0.51 \%$ & $0.00 \%$ & Los Angeles \\
\hline 90024 & $2.26 \%$ & $1.27 \%$ & $2.67 \%$ & $4.40 \%$ & $3.52 \%$ & $3.85 \%$ & $4.05 \%$ & 4.19\% & $2.50 \%$ & $3.70 \%$ & $4.76 \%$ & $2.56 \%$ & $0.00 \%$ & Westwood \\
\hline 90025 & $2.26 \%$ & $5.06 \%$ & $4.00 \%$ & $4.40 \%$ & $4.69 \%$ & $5.13 \%$ & $2.70 \%$ & 4.19\% & $1.00 \%$ & $3.70 \%$ & $1.19 \%$ & $4.10 \%$ & $3.70 \%$ & Sawtelle r West LA \\
\hline 90028 & $4.15 \%$ & $1.27 \%$ & $0.00 \%$ & $2.52 \%$ & $2.34 \%$ & $1.28 \%$ & $0.68 \%$ & $0.60 \%$ & $1.50 \%$ & $1.11 \%$ & $4.76 \%$ & $2.05 \%$ & $3.70 \%$ & Hollywood \\
\hline 90034 & $2.26 \%$ & $2.53 \%$ & $0.00 \%$ & $1.89 \%$ & $1.95 \%$ & $1.92 \%$ & $3.38 \%$ & $2.40 \%$ & $2.00 \%$ & $0.74 \%$ & $2.38 \%$ & $1.03 \%$ & $0.00 \%$ & Los Angeles \\
\hline 90036 & $1.5 \%$ & $2.53 \%$ & $0.00 \%$ & $3.77 \%$ & $1.95 \%$ & $1.28 \%$ & $2.70 \%$ & $1.80 \%$ & $1.00 \%$ & $2.96 \%$ & $1.19 \%$ & $2.56 \%$ & $2.78 \%$ & Park la Brea \\
\hline 90048 & $2.64 \%$ & $1.27 \%$ & $5.33 \%$ & $1.89 \%$ & $1.95 \%$ & $2.56 \%$ & $2.70 \%$ & $1.80 \%$ & $1.50 \%$ & $2.22 \%$ & $1.19 \%$ & $2.05 \%$ & $2.78 \%$ & West Beverly \\
\hline 90049 & $0.75 \%$ & $2.53 \%$ & $2.67 \%$ & $0.63 \%$ & $1.17 \%$ & $1.28 \%$ & $0.00 \%$ & 4. $19 \%$ & $1.00 \%$ & $1.11 \%$ & $0.00 \%$ & $1.03 \%$ & $0.00 \%$ & Los Angeles \\
\hline 90211 & $1.13 \%$ & $3.80 \%$ & $1.33 \%$ & $0.63 \%$ & $1.17 \%$ & $1.92 \%$ & $0.68 \%$ & $1.80 \%$ & $2.00 \%$ & $1.48 \%$ & $0.00 \%$ & $1.03 \%$ & $0.93 \%$ & Beverly Hills \\
\hline 90232 & 4. $15 \%$ & $1.27 \%$ & $0.00 \%$ & $3.77 \%$ & $2.73 \%$ & $3.21 \%$ & $2.03 \%$ & $1.80 \%$ & $0.50 \%$ & $2.96 \%$ & $2.38 \%$ & $2.56 \%$ & $5.56 \%$ & Culver City \\
\hline 90245 & $2.64 \%$ & $1.27 \%$ & $0.00 \%$ & $1.89 \%$ & $1.56 \%$ & $3.21 \%$ & $0.68 \%$ & 4.19\% & $3.00 \%$ & $2.59 \%$ & $3.57 \%$ & $3.08 \%$ & $1.85 \%$ & El Segundo \\
\hline 90254 & $1.13 \%$ & $0.00 \%$ & $0.00 \%$ & $1.26 \%$ & $0.78 \%$ & $0.64 \%$ & $0.68 \%$ & $0.60 \%$ & $1.50 \%$ & $0.74 \%$ & $3.57 \%$ & $0.51 \%$ & $0.00 \%$ & Hermosa Beach \\
\hline 90291 & $2.64 \%$ & $2.53 \%$ & $2.67 \%$ & $4.40 \%$ & $3.91 \%$ & $1.92 \%$ & $2.70 \%$ & $2.99 \%$ & $4.00 \%$ & $3.70 \%$ & $2.38 \%$ & $2.56 \%$ & $2.78 \%$ & Venice \\
\hline 90292 & $3.02 \%$ & $0.00 \%$ & $1.33 \%$ & $3.14 \%$ & $3.13 \%$ & $2.56 \%$ & $3.38 \%$ & $2.99 \%$ & $1.50 \%$ & $3.70 \%$ & $2.38 \%$ & $1.03 \%$ & $0.00 \%$ & Marina Del Rey \\
\hline 90401 & $7.55 \%$ & $11.39 \%$ & $18.67 \%$ & $9.43 \%$ & $9.77 \%$ & $8.33 \%$ & $10.81 \%$ & $13.17 \%$ & $6.50 \%$ & $10.37 \%$ & $11.90 \%$ & $8.72 \%$ & $8.33 \%$ & Santa Monica \\
\hline 90403 & $1.51 \%$ & $1.27 \%$ & $4.00 \%$ & $1.26 \%$ & $2.73 \%$ & $3.21 \%$ & $2.03 \%$ & $0.60 \%$ & $1.50 \%$ & $0.37 \%$ & $0.00 \%$ & $1.54 \%$ & $0.93 \%$ & Santa Monica \\
\hline 90404 & $5.28 \%$ & $1.27 \%$ & $2.67 \%$ & $4.40 \%$ & $4.30 \%$ & $5.77 \%$ & $6.08 \%$ & $1.80 \%$ & $3.00 \%$ & $2.59 \%$ & $2.38 \%$ & $1.54 \%$ & $2.78 \%$ & Santa Monica \\
\hline 90405 & $2.64 \%$ & $2.53 \%$ & $5.33 \%$ & $3.14 \%$ & $3.52 \%$ & $5.13 \%$ & $0.68 \%$ & $4.79 \%$ & $5.00 \%$ & $4.44 \%$ & $3.57 \%$ & $3.08 \%$ & $3.70 \%$ & Santa Monica \\
\hline 91101 & $1.13 \%$ & $0.00 \%$ & $0.00 \%$ & $0.00 \%$ & $0.00 \%$ & $0.00 \%$ & $0.68 \%$ & $1.20 \%$ & $1.00 \%$ & $0.74 \%$ & $4.76 \%$ & $1.54 \%$ & $0.00 \%$ & Pasadena \\
\hline 91103 & $1.13 \%$ & $2.53 \%$ & $0.00 \%$ & $1.89 \%$ & $1.17 \%$ & $1.92 \%$ & $1.35 \%$ & $0.60 \%$ & $2.00 \%$ & $1.85 \%$ & $3.57 \%$ & $2.05 \%$ & $1.85 \%$ & Pasadena \\
\hline 91203 & $0.75 \%$ & $1.27 \%$ & $1.33 \%$ & $0.63 \%$ & $0.39 \%$ & $0.64 \%$ & $0.68 \%$ & $0.00 \%$ & $1.50 \%$ & $0.00 \%$ & $3.57 \%$ & $0.51 \%$ & $0.00 \%$ & Glendale \\
\hline 91355 & $0.38 \%$ & $1.27 \%$ & $0.00 \%$ & $0.00 \%$ & $0.39 \%$ & $1.28 \%$ & $1.35 \%$ & $0.00 \%$ & $1.00 \%$ & $1.48 \%$ & $4.76 \%$ & $0.51 \%$ & $0.00 \%$ & Santa Clarita \\
\hline 91361 & $0.75 \%$ & $3.80 \%$ & $4.00 \%$ & $0.63 \%$ & $0.39 \%$ & $1.92 \%$ & $0.68 \%$ & $1.20 \%$ & $0.50 \%$ & $2.22 \%$ & $1.19 \%$ & $1.54 \%$ & $0.93 \%$ & Thousand Daks \\
\hline 91367 & $1.13 \%$ & $3.80 \%$ & $1.33 \%$ & $1.89 \%$ & $1.56 \%$ & $1.28 \%$ & $0.00 \%$ & $0.60 \%$ & $1.50 \%$ & $0.74 \%$ & $1.19 \%$ & $1.54 \%$ & $0.93 \%$ & Woodland Hills \\
\hline 91403 & $1.51 \%$ & $0.00 \%$ & $0.00 \%$ & $0.00 \%$ & $0.39 \%$ & $0.00 \%$ & $0.68 \%$ & $0.60 \%$ & $0.50 \%$ & $1.11 \%$ & $0.00 \%$ & $1.54 \%$ & $3.70 \%$ & Sherman Oaks t Van Nuys \\
\hline 92688 & $1.13 \%$ & $2.53 \%$ & $4.00 \%$ & $0.00 \%$ & $0.39 \%$ & $0.64 \%$ & $0.00 \%$ & $0.60 \%$ & $1.00 \%$ & $0.37 \%$ & $1.19 \%$ & $0.00 \%$ & $1.85 \%$ & Rancho Santa Margarita \\
\hline \% Covered & $56.23 \%$ & $58.23 \%$ & $61.33 \%$ & $57.86 \%$ & $56.64 \%$ & $61.54 \%$ & $52.70 \%$ & $59.28 \%$ & $48.50 \%$ & $58.52 \%$ & $71.43 \%$ & $50.77 \%$ & $49.07 \%$ & Silicon Beach? \\
\hline
\end{tabular}




\section{Figure 20 - Correlations between industries and Influential Zip codes}

\begin{tabular}{|c|c|c|c|c|c|c|c|c|c|c|c|c|c|c|}
\hline ZIP ${ }^{\text {Industry }}$ & TEC & ICT & DTA & EDU & ENT & SMA & MOB & WEB & BIZ & MNS & MFT & LST & MED & \\
\hline \multirow{2}{*}{90024} & -0.003 & $0.0354^{\circ}$ & -0.010 & 0.013 & 0.007 & -0.009 & -0.030 & 0.015 & -0.019 & -0.016 & 0.006 & -0.023 & 0.010 & \\
\hline & 0.839 & 0.026 & 0.518 & 0.425 & 0.681 & 0.568 & 0.057 & 0.344 & 0.245 & 0.320 & 0.726 & 0.145 & 0.543 & \\
\hline \multirow{2}{*}{90025} & -0.002 & -0.012 & -0.012 & 0.031 & 0.023 & 0.011 & -0.009 & 0.005 & 0.0917 & 0.021 & -0.007 & -0.003 & 0.010 & \\
\hline & 0.885 & 0.438 & 0.457 & 0.054 & 0.142 & 0.492 & 0.579 & 0.757 & 0.000 & 0.187 & 0.665 & 0.861 & 0.542 & \\
\hline \multirow{2}{*}{90028} & 0.024 & -0.004 & -0.025 & 0.013 & 0.012 & -0.026 & $-0.0325^{\circ}$ & -0.017 & 0.0585 & -0.028 & -0.016 & -0.022 & -0.028 & \\
\hline & 0.129 & 0.805 & 0.116 & 0.421 & 0.460 & 0.106 & 0.041 & 0.295 & 0.000 & 0.079 & 0.321 & 0.168 & 0.079 & \\
\hline \multirow{2}{*}{90036} & 0.002 & 0.015 & -0.017 & 0.018 & 0.031 & -0.005 & -0.009 & 0.006 & -0.016 & $0.0350^{\circ}$ & -0.017 & $0.0660^{\circ}$ & $0.0393^{\circ}$ & \\
\hline & 0.925 & 0.344 & 0.297 & 0.251 & 0.050 & 0.743 & 0.576 & 0.728 & 0.327 & 0.027 & 0.276 & $\begin{array}{l}0.000 \\
\end{array}$ & 0.013 & \\
\hline \multirow{2}{*}{90045} & 0.013 & -0.005 & -0.004 & -0.019 & $0.0858^{\circ}$ & $0.0849^{\prime}$ & -0.001 & -0.002 & -0.0375 & -0.001 & $0.0357^{\circ}$ & -0.007 & 0.005 & \\
\hline & 0.416 & 0.777 & 0.791 & 0.235 & 0.000 & 0.000 & 0.928 & 0.892 & 0.018 & 0.951 & 0.025 & 0.647 & 0.747 & \\
\hline \multirow{2}{*}{90046} & -0.018 & 0.000 & -0.016 & -0.025 & -0.004 & 0.007 & -0.008 & -0.003 & 0.001 & $0.0468^{\circ}$ & $0.0930^{\prime}$ & 0.022 & 0.026 & \\
\hline & 0.263 & 0.992 & 0.307 & 0.114 & 0.797 & 0.673 & 0.608 & 0.874 & 0.935 & 0.003 & 0.000 & 0.162 & 0.100 & \\
\hline \multirow{2}{*}{90048} & -0.014 & -0.014 & -0.002 & -0.030 & $-0.0353^{\circ}$ & -0.002 & 0.012 & 0.018 & -0.0408 & -0.013 & -0.015 & -0.005 & -0.007 & \\
\hline & 0.370 & 0.394 & 0.890 & 0.059 & 0.026 & 0.895 & 0.447 & 0.266 & \begin{tabular}{|l}
0.010 \\
\end{tabular} & 0.413 & 0.354 & 0.762 & 0.649 & \\
\hline \multirow{2}{*}{90064} & -0.027 & -0.008 & 0.019 & 0.004 & -0.018 & -0.015 & -0.016 & -0.016 & 0.005 & 0.008 & -0.009 & 0.025 & 0.001 & \\
\hline & 0.090 & 0.636 & 0.233 & 0.780 & 0.263 & 0.342 & 0.312 & 0.311 & 0.736 & 0.606 & 0.586 & 0.110 & 0.955 & \\
\hline & $0.0448^{\circ}$ & -0.015 & 0.004 & 0.003 & 0.003 & -0.023 & -0.004 & -0.017 & -0.005 & 0.017 & -0.015 & 0.005 & 0.001 & \\
\hline 90066 & 0.005 & 0.362 & 0.795 & 0.844 & 0.838 & 0.148 & 0.800 & 0.292 & 0.760 & 0.294 & 0.346 & 0.761 & 0.969 & \\
\hline 90067 & $0.0973^{\prime}$ & 0.008 & 0.004 & $-0.0451^{\circ}$ & $-0.0446^{\circ}$ & $-0.0379^{\circ}$ & 0.0533 & 0.011 & -0.007 & $-0.0408^{\prime}$ & $\mid-0.0480^{\circ}$ & $-0.0680^{\circ}$ & 0.002 & \\
\hline Jovor & 0.000 & 0.603 & 0.814 & 0.005 & 0.005 & 0.017 & $\begin{array}{l}0.001 \\
\end{array}$ & 0.505 & 0.658 & 0.010 & 0.003 & 0.000 & 0.889 & \\
\hline 90071 & $-0.0356^{\circ}$ & $0.0395^{\circ}$ & -0.018 & $-0.0361^{\circ}$ & $-0.0490^{\circ}$ & $-0.0378^{\circ}$ & $-0.0359^{\circ}$ & -0.019 & -0.0667 & -0.029 & -0.029 & 0.000 & -0.031 & \\
\hline 50071 & 0.025 & 0.013 & 0.259 & 0.023 & 0.002 & 0.017 & 0.024 & 0.231 & 0.000 & 0.068 & 0.069 & 0.992 & 0.052 & \\
\hline 90095 & -0.008 & -0.005 & $0.0505^{\circ}$ & -0.007 & -0.009 & -0.008 & -0.006 & -0.009 & 0.013 & -0.009 & -0.005 & -0.007 & $0.0446^{\circ}$ & \\
\hline 50035 & 0.604 & 0.762 & 0.002 & 0.642 & 0.553 & 0.631 & 0.696 & 0.565 & 0.423 & 0.573 & 0.754 & 0.656 & 0.005 & \\
\hline 90210 & 0.007 & -0.029 & $-0.0415^{\circ}$ & $0.1391^{-}$ & $0.1433^{-}$ & $0.1049^{\prime}$ & $-0.0436^{\circ}$ & -0.030 & 0.0862 & -0.0546 & $0.0770^{\circ}$ & 0.0783 & $-0.0346^{\circ}$ & \\
\hline 50210 & 0.666 & 0.070 & 0.009 & 0.000 & 0.000 & 0.000 & 0.006 & 0.062 & 0.000 & 0.001 & 0.000 & 0.000 & 0.030 & \\
\hline 90211 & -0.008 & 0.016 & 0.000 & -0.014 & -0.004 & -0.004 & 0.005 & $0.0831^{\prime}$ & 0.0624 & -0.011 & -0.017 & -0.001 & -0.018 & \\
\hline $50<11$ & 0.636 & 0.312 & 0.993 & 0.382 & 0.797 & 0.792 & 0.763 & 0.000 & 0.000 & 0.483 & 0.286 & 0.952 & 0.253 & \\
\hline 90212 & $-0.0443^{\circ}$ & $-0.0442^{\circ}$ & $-0.0438^{\circ}$ & -0.0635 & -0.0508 & -0.0576 & -0.017 & -0.0730 & -0.0675 & -0.0712 & -0.028 & -0.0474 & $-0.0321^{\circ}$ & \\
\hline $90 \angle 12$ & 0.005 & $\begin{array}{l}0.005 \\
\end{array}$ & \begin{tabular}{|l|}
0.006 \\
\end{tabular} & 0.000 & 0.001 & 0.000 & 0.277 & 0.000 & 0.000 & 0.000 & 0.081 & 0.003 & 0.044 & \\
\hline 90232 & -0.010 & -0.004 & -0.014 & $0.0422^{\circ}$ & $0.0483^{\circ}$ & $0.0314^{\circ}$ & -0.007 & -0.010 & -0.0385 & $0.0417^{\circ}$ & 0.005 & 0.008 & 0.011 & \\
\hline $90<32$ & 0.549 & 0.805 & 0.370 & 0.008 & 0.002 & 0.048 & 0.659 & 0.513 & \begin{tabular}{|l|l|}
0.016 \\
\end{tabular} & 0.009 & 0.762 & 0.596 & 0.498 & \\
\hline 90241 & -0.012 & -0.007 & -0.007 & -0.010 & -0.013 & -0.011 & -0.009 & -0.013 & -0.019 & -0.013 & -0.007 & -0.010 & -0.008 & \\
\hline $30<41$ & 0.463 & 0.668 & 0.671 & 0.511 & 0.402 & 0.496 & 0.581 & 0.416 & 0.244 & 0.425 & 0.657 & 0.528 & 0.635 & \\
\hline 90245 & 0.029 & 0.013 & 0.013 & 0.007 & 0.004 & 0.031 & -0.019 & 0.001 & -0.008 & 0.0620 & -0.018 & $0.0382^{\circ}$ & -0.012 & \\
\hline 90245 & 0.067 & 0.424 & 0.404 & 0.677 & 0.794 & 0.055 & 0.233 & 0.943 & 0.614 & 0.000 & 0.248 & 0.016 & 0.454 & \\
\hline & -0.019 & 0.012 & 0.012 & -0.017 & -0.009 & -0.002 & 0.023 & -0.022 & -0.020 & 0.021 & $0.0563^{\prime}$ & $0.0335^{\circ}$ & 0.030 & \\
\hline 90266 & 0.223 & 0.446 & 0.435 & 0.276 & 0.585 & 0.890 & 0.151 & 0.177 & 0.215 & 0.191 & 0.000 & 0.035 & 0.058 & \\
\hline 90291 & -0.024 & -0.003 & 0.022 & -0.031 & -0.013 & -0.007 & 0.019 & 0.000 & $0.1483^{\prime \prime}$ & -0.012 & 0.003 & 0.023 & -0.017 & \\
\hline $50<31$ & 0.134 & 0.864 & 0.171 & 0.053 & 0.423 & 0.674 & 0.237 & 0.987 & 0.000 & 0.445 & 0.864 & 0.152 & 0.300 & \\
\hline 90292 & $0.0635^{\circ}$ & -0.008 & $0.0451^{\circ}$ & 0.004 & -0.018 & 0.002 & 0.025 & -0.001 & -0.019 & $0.0391^{\circ}$ & $0.0416^{\circ}$ & $0.0347^{*}$ & -0.011 & \\
\hline $30<32$ & 0.000 & 0.636 & 0.005 & 0.780 & 0.263 & 0.883 & \begin{tabular}{|l|}
0.110 \\
\end{tabular} & 0.957 & 0.229 & 0.014 & 0.009 & 0.029 & 0.491 & \\
\hline 90401 & -0.0671 & -0.024 & $0.0978^{-1}$ & 0.022 & -0.013 & 0.009 & $0.0537^{-}$ & 0.000 & $0.3129^{\circ}$ & 0.012 & $-0.0355^{\circ}$ & $-0.0455^{\circ}$ & -0.0545 & - The upper value in each cell \\
\hline J0401 & 0.000 & 0.137 & 0.000 & 0.164 & 0.432 & 0.578 & 0.001 & 0.980 & 0.000 & 0.469 & 0.025 & 0.004 & 0.001 & denotes the correlation \\
\hline 90402 & $0.0433^{\circ}$ & -0.003 & -0.003 & -0.005 & -0.007 & -0.005 & -0.004 & -0.007 & -0.009 & -0.006 & -0.004 & -0.005 & -0.004 & coefficient between the two \\
\hline 3070 & 0.006 & 0.830 & 0.832 & 0.743 & 0.675 & 0.734 & 0.782 & 0.684 & 0.560 & 0.690 & 0.825 & 0.752 & 0.812 & \\
\hline 90403 & $0.0381^{\circ}$ & -0.014 & 0.026 & 0.006 & -0.004 & 0.005 & 0.029 & 0.008 & -0.001 & 0.009 & $0.0423^{\circ}$ & 0.022 & 0.020 & \\
\hline 90403 & 0.016 & 0.391 & 0.106 & 0.709 & 0.783 & 0.779 & 0.069 & 0.601 & 0.975 & 0.558 & 0.008 & 0.176 & 0.203 & \\
\hline 90404 & 0.017 & -0.007 & 0.013 & 0.014 & $0.0326^{\circ}$ & 0.017 & $0.0603^{-}$ & $0.0710^{-}$ & -0.017 & $0.0384^{\circ}$ & 0.011 & -0.004 & -0.012 & - Coefficients marked with an \\
\hline 90404 & 0.297 & 0.653 & 0.404 & 0.397 & 0.040 & 0.280 & 0.000 & 0.000 & 0.274 & 0.016 & 0.509 & 0.784 & 0.454 & asterisk are statisticaily \\
\hline 90405 & -0.016 & 0.018 & 0.019 & $0.0359^{\circ}$ & 0.001 & 0.011 & 0.011 & $0.0407^{*}$ & 0.003 & 0.030 & 0.005 & $0.0322^{\circ}$ & 0.002 & significantly different from \\
\hline & 0.327 & 0.259 & 0.243 & 0.024 & 0.977 & 0.495 & 0.503 & 0.010 & 0.857 & 0.057 & 0.737 & 0.043 & 0.919 & \\
\hline 90503 & 0.022 & 0.011 & -0.012 & $0.0439^{\circ}$ & 0.016 & -0.019 & -0.015 & -0.009 & -0.011 & 0.018 & -0.012 & -0.017 & 0.028 & at the $95 \%$ confidence \\
\hline 5050ง & 0.160 & 0.504 & 0.462 & 0.006 & 0.329 & 0.238 & 0.338 & 0.560 & 0.489 & 0.256 & 0.442 & 0.274 & 0.081 & level (i.e. p<0.05) \\
\hline 91103 & $0.0453^{\circ}$ & -0.006 & 0.009 & -0.011 & -0.022 & -0.021 & -0.003 & -0.004 & -0.001 & -0.003 & $0.0466^{\circ}$ & -0.009 & 0.016 & - Coefficients are color-coded \\
\hline 91103 & 0.004 & 0.726 & 0.588 & 0.504 & 0.166 & 0.177 & 0.853 & 0.782 & 0.964 & 0.840 & 0.003 & 0.579 & 0.309 & \\
\hline 91203 & -0.006 & -0.012 & -0.012 & -0.003 & -0.010 & -0.004 & $0.0385^{*}$ & -0.022 & -0.011 & 0.005 & $0.0529^{-}$ & -0.001 & $0.0481^{\circ}$ & \\
\hline 91203 & 0.704 & 0.457 & 0.462 & 0.870 & 0.520 & 0.817 & 0.015 & 0.158 & 0.489 & 0.766 & 0.001 & 0.931 & 0.002 & \\
\hline $\mathbf{s}$ & 0.028 & 0.014 & -0.011 & -0.017 & -0.021 & 0.016 & $0.0449^{\circ}$ & -0.006 & -0.018 & $0.0530^{\circ}$ & $0.0602^{-}$ & -0.016 & 0.010 & \\
\hline 91353 & 0.076 & 0.386 & 0.502 & 0.299 & 0.184 & 0.317 & 0.005 & 0.703 & 0.264 & 0.001 & 0.000 & 0.318 & 0.513 & correlation coefficient $>0.05$ \\
\hline 1403 & 0.028 & 0.007 & -0.013 & 0.021 & $0.0548^{-}$ & 0.020 & -0.001 & $0.0573^{-}$ & -0.017 & $0.0351^{\circ}$ & -0.014 & -0.019 & 0.004 & correlation coefficient $>0.075$ \\
\hline 91403 & 0.076 & 0.666 & 0.410 & 0.179 & 0.001 & 0.220 & 0.949 & 0.000 & 0.284 & 0.027 & 0.389 & 0.221 & 0.820 & \\
\hline 91436 & 0.015 & 0.016 & 0.016 & -0.016 & -0.005 & 0.001 & 0.008 & $0.0717^{-}$ & 0.009 & 0.0580 & 0.015 & 0.022 & -0.011 & correlation coefficient $>0.10$ \\
\hline 51430 & 0.337 & 0.324 & 0.315 & 0.324 & 0.746 & 0.942 & 0.638 & 0.000 & 0.582 & 0.000 & 0.362 & 0.168 & 0.476 & correlation coefficient $<-.0 .5$ \\
\hline & $0.0403^{\circ}$ & $0.0496^{\circ}$ & 0.021 & -0.014 & -0.018 & 0.005 & -0.012 & 0.017 & -0.025 & 0.001 & $0.0475^{\circ}$ & -0.013 & 0.017 & \\
\hline 92688 & 0.011 & 0.002 & 0.194 & 0.385 & 0.267 & 0.734 & 0.465 & 0.276 & 0.123 & 0.965 & 0.003 & 0.404 & 0.293 & correlation coefficient $<-0.075$ \\
\hline
\end{tabular}




\section{Adding a temporal dimension to the analysis of the Los Angeles innovation movement}

Aside from looking at different industry sub-clusters within the Los Angeles innovation movement, this dissertation also examines the relationships between the year that a firm was founded and its choice of location in the greater Los Angeles area. Doing so adds a temporal element to the analysis of Silicon Beach and sets-up a detailed analysis of its growth over time, providing some insights into the way the technology sector has expanded in the region.

While to-date there has been limited systematic research on the evolution of the Los Angeles innovation movement, various authors agree that the movement originally started between Santa Monica and Venice Beach and has since spread to other areas in West Los Angeles. Both Hood (2013) and Zimmerman (2013) agree that the new wave of technology companies originally emerged in the threemile stretch between Venice and Santa Monica and is now gradually expanding to other areas such as Hollywood and Downtown Los Angeles.

In order to test the validity of these claims, founding date indicators are added to Crunchbase, differentiating between firms that were created between 1990 and 2015 and are still operating as of today, leading to six distinct categories as exhibited in Table 7.

\begin{tabular}{|c|c|c|}
\hline Time $\quad$ Startup count & $\begin{array}{l}\text { Total startups that are still operating } \\
\text { (cumulative, since before 1990) }\end{array}$ & $\begin{array}{l}\text { New startups, added since last } 5 \text { - } \\
\text { year period }\end{array}$ \\
\hline Founded before 1990 & 67 & - \\
\hline Founded before 1995 & 92 & $\begin{array}{l}\mathbf{9 2 - 6 7}=\mathbf{2 5} \text { new firms created } \\
\text { between } 1990 \text { and } 1995\end{array}$ \\
\hline Founded before 2000 & 184 & $\begin{array}{l}184-92=92 \text { new firms created } \\
\text { between } 1995 \text { and } 2000\end{array}$ \\
\hline Founded before 2005 & 337 & $\begin{array}{l}\text { 337-184 = } 154 \text { new firms created } \\
\text { between } 2000 \text { and } 2005\end{array}$ \\
\hline Founded before 2010 & 834 & $\begin{array}{l}\text { 834-337 = } 497 \text { new firms created } \\
\text { between } 2005 \text { and } 2010\end{array}$ \\
\hline Founded before 2015 & 1576 & $\begin{array}{l}\text { 1576-834 }=742 \text { new firms created } \\
\text { between } 2010 \text { and } 2015\end{array}$ \\
\hline
\end{tabular}

As can be seen in the table, as well as in the detailed maps displayed in Figure 21, initial growth was fairly slow and not many firms were created before 1995, but between 1995 and 2015, the number of firm creations in the Los Angeles region nearly doubled every five years, suggesting an exponential growth pattern and to a certain extent validating the recent hype surrounding the region. 
Figure 21 - Silicon Beach Startup Growth over time, 1990-2015

Startups founded pre-1990

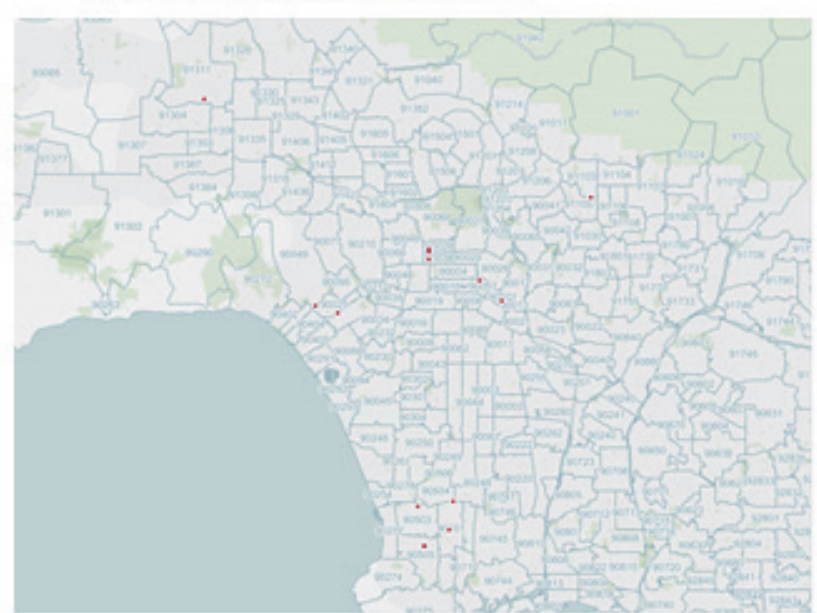

Startups founded pre-2005

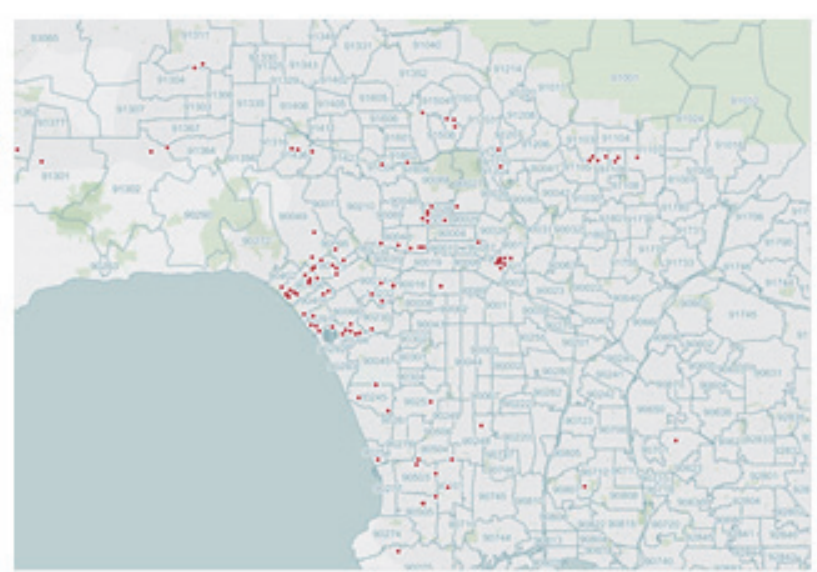

Startups founded pre-1995

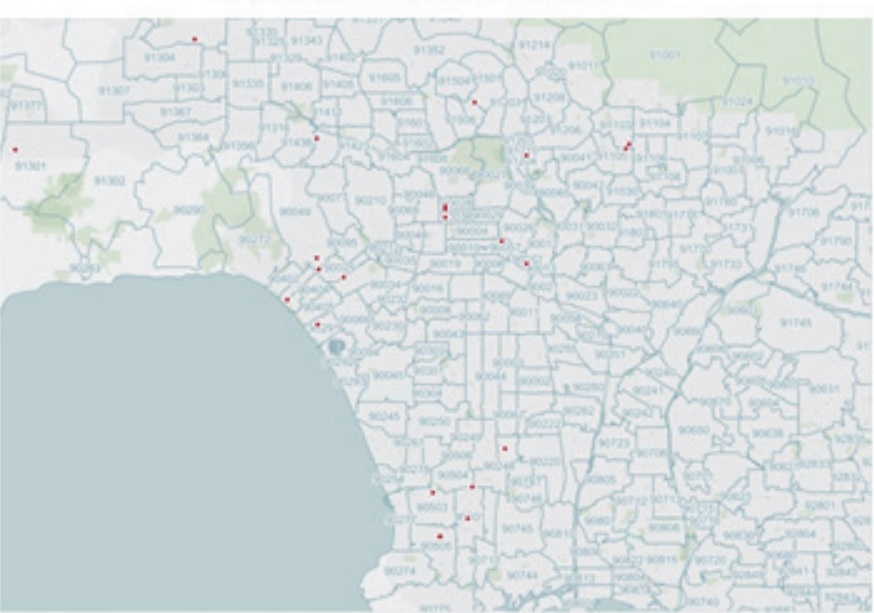

Startups founded pre-2010

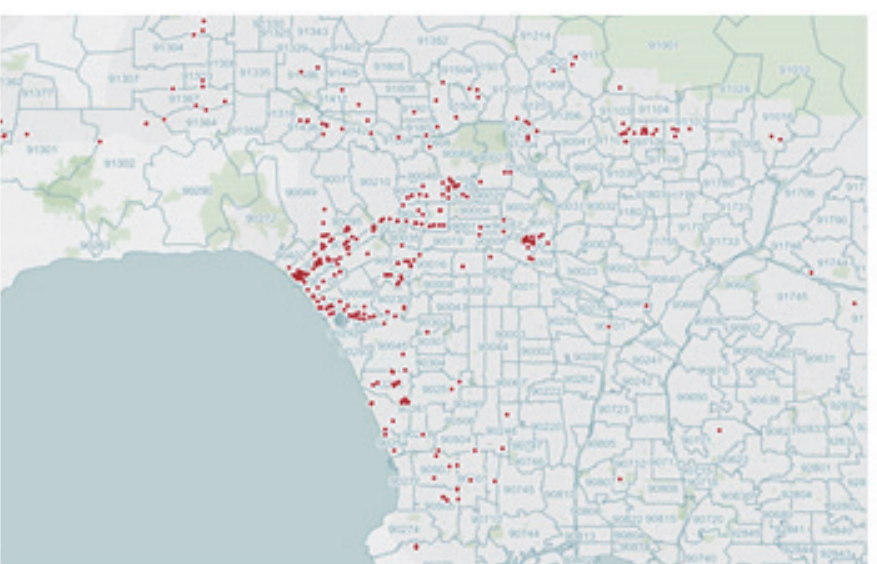

Startups founded pre-2000

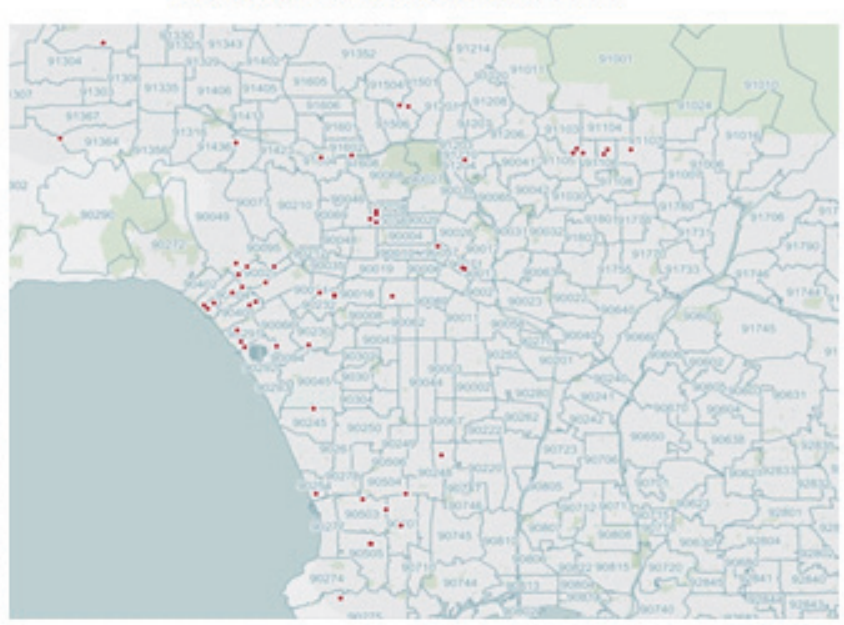

Startups founded pre-2015

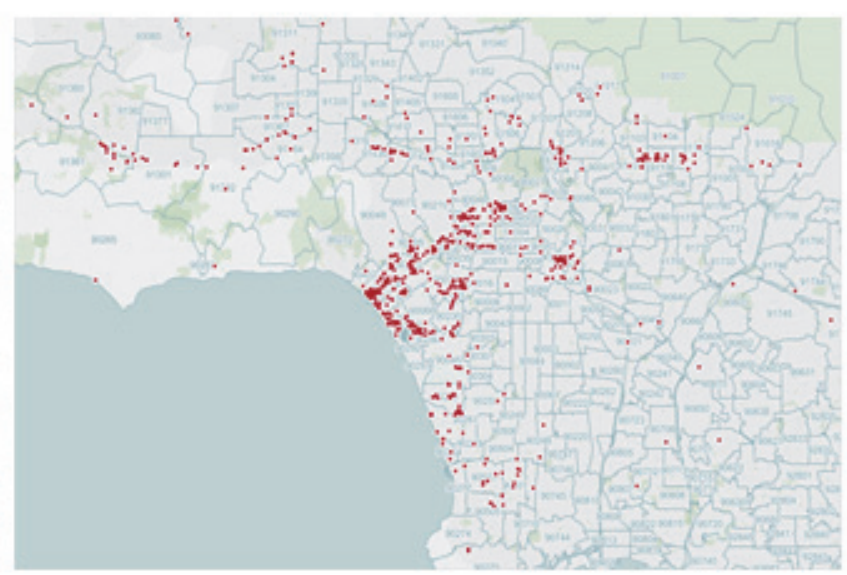


Furthermore, the historical maps do in fact corroborate the hypothesis that the growth originated in West Los Angeles around Venice and Santa Monica. The first batch of firms appears to locate precisely along the coast and the area densifies over time, while the movement is also expanding outwards toward Hollywood and Downtown, along the Wilshire corridor that is referenced in the L.A. City Geohub map of the L.A. Tech industry.

To ensure that Silicon Beach has in fact contributed meaningfully to the impressive startup growth in the region and has grown in importance throughout the time period under study, this dissertation further examines the historical shares of firms inside and outside Silicon Beach zip codes (see Table 8).

\begin{tabular}{|c|c|c|c|c|c|c|}
\hline $\begin{array}{r}\text { Time } \\
\text { Silicon Beach Zip }\end{array}$ & 1990 & 1995 & 2000 & 2005 & 2010 & 2015 \\
\hline 90024 & $0.00 \%$ & $0.00 \%$ & $0.00 \%$ & $0.73 \%$ & $2.06 \%$ & $2.07 \%$ \\
\hline 90025 & $1.59 \%$ & $1.23 \%$ & $3.11 \%$ & $3.65 \%$ & $3.16 \%$ & $3.19 \%$ \\
\hline 90066 & $0.00 \%$ & $0.00 \%$ & $1.24 \%$ & $2.19 \%$ & $1.42 \%$ & $1.03 \%$ \\
\hline 90067 & $0.00 \%$ & $0.00 \%$ & $0.00 \%$ & $0.00 \%$ & $0.79 \%$ & $0.69 \%$ \\
\hline 90095 & $0.00 \%$ & $0.00 \%$ & $0.00 \%$ & $0.36 \%$ & $0.16 \%$ & $0.09 \%$ \\
\hline 90210 & $3.17 \%$ & $2.47 \%$ & $1.24 \%$ & $0.73 \%$ & $0.63 \%$ & $0.95 \%$ \\
\hline 90211 & $0.00 \%$ & $0.00 \%$ & $0.00 \%$ & $1.09 \%$ & $1.11 \%$ & $0.78 \%$ \\
\hline 90212 & $0.00 \%$ & $0.00 \%$ & $0.62 \%$ & $0.36 \%$ & $1.27 \%$ & $1.81 \%$ \\
\hline 90232 & $0.00 \%$ & $0.00 \%$ & $3.11 \%$ & $2.55 \%$ & $3.48 \%$ & $3.53 \%$ \\
\hline 90245 & $1.59 \%$ & $2.47 \%$ & $1.86 \%$ & $1.82 \%$ & $4.59 \%$ & $3.19 \%$ \\
\hline 90291 & $0.00 \%$ & $1.23 \%$ & $1.24 \%$ & $1.09 \%$ & $2.85 \%$ & $8.01 \%$ \\
\hline 90292 & $0.00 \%$ & $0.00 \%$ & $1.86 \%$ & $1.82 \%$ & $1.74 \%$ & $1.81 \%$ \\
\hline 90401 & $0.00 \%$ & $1.23 \%$ & $1.86 \%$ & $3.28 \%$ & $6.49 \%$ & $8.35 \%$ \\
\hline 90402 & $0.00 \%$ & $0.00 \%$ & $0.00 \%$ & $0.00 \%$ & $0.00 \%$ & $0.09 \%$ \\
\hline 90403 & $0.00 \%$ & $0.00 \%$ & $1.24 \%$ & $1.46 \%$ & $1.11 \%$ & $1.12 \%$ \\
\hline 90404 & $0.00 \%$ & $0.00 \%$ & $1.86 \%$ & $2.19 \%$ & $3.16 \%$ & $3.36 \%$ \\
\hline 90405 & $0.00 \%$ & $0.00 \%$ & $1.86 \%$ & $1.82 \%$ & $2.85 \%$ & $3.19 \%$ \\
\hline Non-Silicon Beach & $93.65 \%$ & $91.36 \%$ & $78.88 \%$ & $74.82 \%$ & $63.13 \%$ & $56.76 \%$ \\
\hline \multicolumn{4}{|c|}{ Highlight cell rules } & $>3 \%$ & $>5 \%$ & $>10 \%$ \\
\hline
\end{tabular}

Specifically, this analysis is comparing the cumulative shares of all firms operating in Los Angeles at a given point in time and finds that Silicon Beach zip codes are becoming increasingly important over time. While the area hosted a mere $7-10 \%$ of firms throughout the $1990 \mathrm{~s}$, by the mid-2000s, this proportion had increased to about a fourth, and in 2015 has climbed to almost half of all startups. In essence, this means that by now, a relatively small area spanning only 17 zip codes accounts for about $45 \%$ of all 
operating startups in the Los Angeles area. The remarkable startup growth trajectory of Silicon Beach as compared to all other areas in the Los Angeles region is further exemplified graphically in Figure 22.

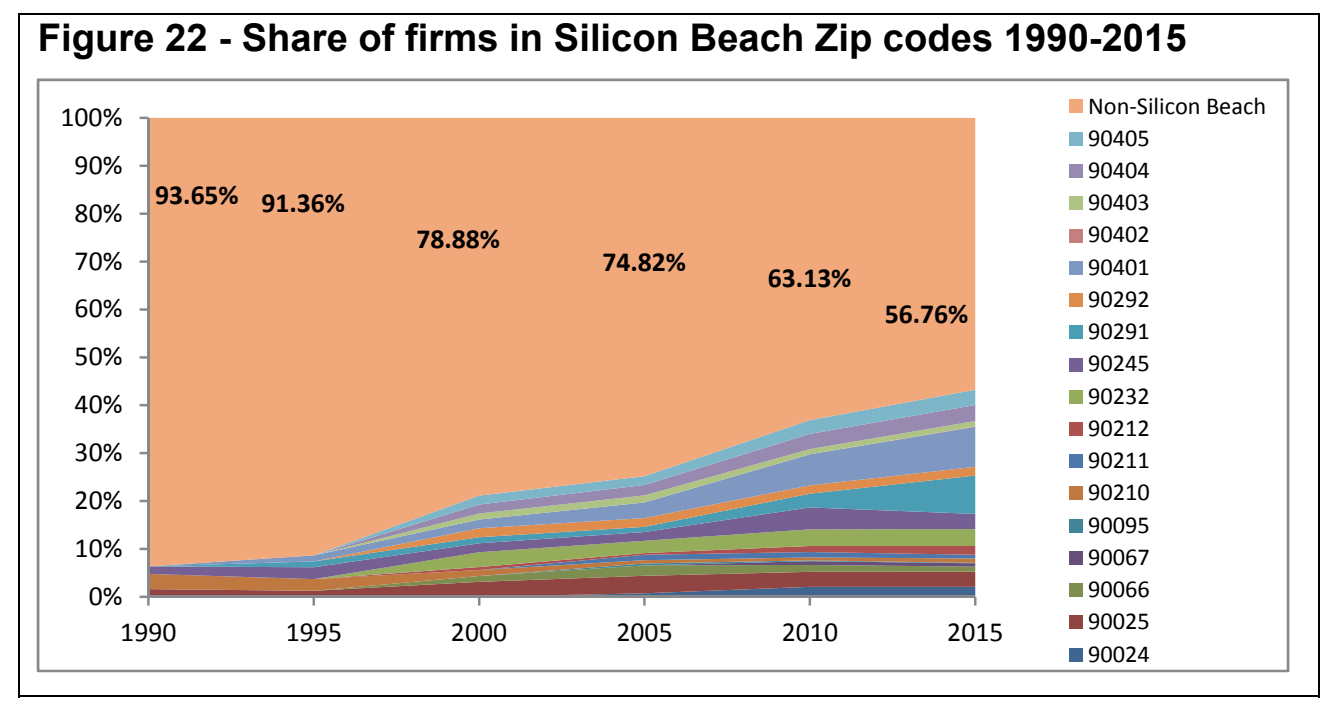

While it is already fairly impressive to see the growth in importance of Silicon Beach as a host for all startups, looking at the growth of the area in individual, five-year time intervals paints an even clearer picture of the strong influence that the Silicon Beach area has had in growing the technology industry in the Los Angeles region. When examining Table 9, it is striking that Venice Beach and Santa Monica in particular have been the place of inception for a large share of firms since the early 2000s. Notably, Venice Beach has recently overcome the core Santa Monica zip code (90401) as the most popular new firm location within Silicon Beach, though it must be said that startups in all Santa Monica zip codes taken together still make up the majority of newly-founded ventures, even between 2010 and 2015.

The relative importance of locations outside of Silicon Beach has been gradually declining since the early 1990s, and in the period of 2010-2015, Silicon Beach for the first time was responsible for hosting more than half of newly-founded firms in the Los Angeles region (see Figure 23). Therefore, it seems reasonable to conclude that Silicon Beach has in fact played a very meaningful role in the expansion of the Los Angeles innovation movement and that the role of this relatively small, contained region has been growing in importance as the clusters have progressed over the years. It should however be noted that while Santa Monica and Venice continue to be a the heart of the movement, other areas such as Culver City, Westwood and West LA / Sawtelle have become key firm locations as well and have become almost as popular as the outskirts of Santa Monica (90402-90405), thus suggesting and outward spread of Silicon Beach over time. 


\begin{tabular}{|c|c|c|c|c|c|c|}
\hline $\begin{array}{l}\text { Time } \\
\text { Silicon Beach Zip }\end{array}$ & $\begin{array}{l}\text { pre - } \\
1990\end{array}$ & $\begin{array}{l}1990- \\
1995\end{array}$ & $\begin{array}{l}1995- \\
2000\end{array}$ & $\begin{array}{l}2000- \\
2005\end{array}$ & $\begin{array}{l}2005- \\
2010\end{array}$ & $\begin{array}{l}2010- \\
2015\end{array}$ \\
\hline 90024 & $0.00 \%$ & $0.00 \%$ & $0.00 \%$ & $1.77 \%$ & $3.07 \%$ & $2.08 \%$ \\
\hline 90025 & $1.59 \%$ & $0.00 \%$ & $5.00 \%$ & $4.42 \%$ & $2.79 \%$ & $3.21 \%$ \\
\hline 90066 & $0.00 \%$ & $0.00 \%$ & $2.50 \%$ & $3.54 \%$ & $0.84 \%$ & $0.57 \%$ \\
\hline 90067 & $0.00 \%$ & $0.00 \%$ & $0.00 \%$ & $0.00 \%$ & $1.40 \%$ & $0.57 \%$ \\
\hline 90095 & $0.00 \%$ & $0.00 \%$ & $0.00 \%$ & $0.88 \%$ & $0.00 \%$ & $0.00 \%$ \\
\hline 90210 & $3.17 \%$ & $0.00 \%$ & $0.00 \%$ & $0.00 \%$ & $0.56 \%$ & $1.32 \%$ \\
\hline 90211 & $0.00 \%$ & $0.00 \%$ & $0.00 \%$ & $2.65 \%$ & $1.12 \%$ & $0.38 \%$ \\
\hline 90212 & $0.00 \%$ & $0.00 \%$ & $1.25 \%$ & $0.00 \%$ & $1.96 \%$ & $2.46 \%$ \\
\hline 90232 & $0.00 \%$ & $0.00 \%$ & $6.25 \%$ & $1.77 \%$ & $4.19 \%$ & $3.59 \%$ \\
\hline 90245 & $1.59 \%$ & $5.56 \%$ & $1.25 \%$ & $1.77 \%$ & $6.70 \%$ & $1.51 \%$ \\
\hline 90291 & $0.00 \%$ & $5.56 \%$ & $1.25 \%$ & $0.88 \%$ & $4.19 \%$ & $14.18 \%$ \\
\hline 90292 & $0.00 \%$ & $0.00 \%$ & $3.75 \%$ & $1.77 \%$ & $1.68 \%$ & $1.89 \%$ \\
\hline 90401 & $0.00 \%$ & $5.56 \%$ & $2.50 \%$ & $5.31 \%$ & $8.94 \%$ & $10.59 \%$ \\
\hline 90402 & $0.00 \%$ & $0.00 \%$ & $0.00 \%$ & $0.00 \%$ & $0.00 \%$ & $0.19 \%$ \\
\hline 90403 & $0.00 \%$ & $0.00 \%$ & $2.50 \%$ & $1.77 \%$ & $0.84 \%$ & $1.13 \%$ \\
\hline 90404 & $0.00 \%$ & $0.00 \%$ & $3.75 \%$ & $2.65 \%$ & $3.91 \%$ & $3.59 \%$ \\
\hline 90405 & $0.00 \%$ & $0.00 \%$ & $3.75 \%$ & $1.77 \%$ & $3.63 \%$ & $3.59 \%$ \\
\hline Non-Silicon Beach & $93.65 \%$ & $83.33 \%$ & $66.25 \%$ & $69.03 \%$ & $54.19 \%$ & $49.15 \%$ \\
\hline \multicolumn{4}{|c|}{ Highlight cell rules } & $>3 \%$ & $>5 \%$ & $>10 \%$ \\
\hline
\end{tabular}




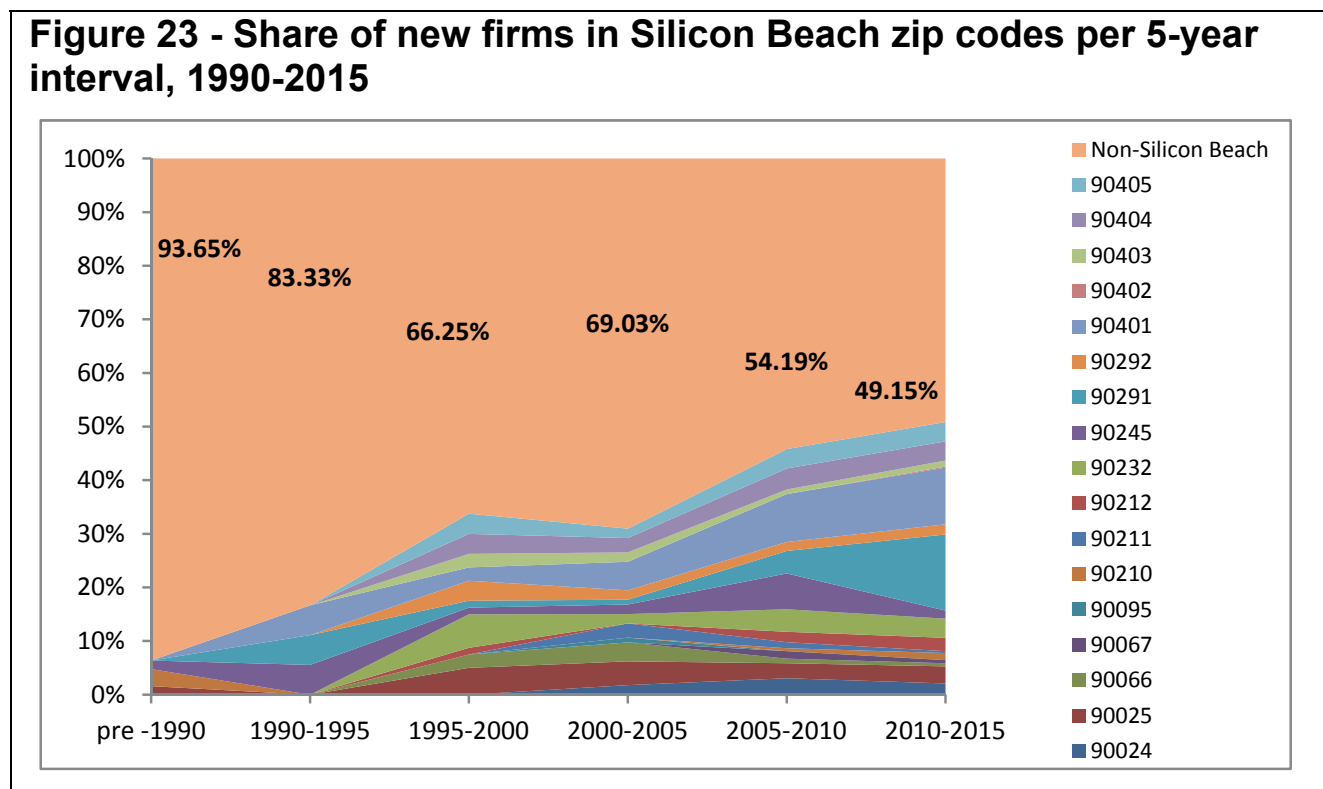




\section{Examining underlying trends in cluster formation and locational patterns}

After conducting both temporal and industry-level analyses of the Los Angeles innovation movement, this dissertation proceeds to explore joint patterns between the two dimensions in trying to find out whether specific industries have contributed disproportionally to the growth of the technology landscape in the L.A. region. Following this line of thinking, the initial step is to perform a similar set of analyses to the ones above between zip codes and firm founding dates, but this time using industry codes rather than zip codes as a measure of analysis (Table 10).

\begin{tabular}{|l|cccccc|}
\hline \multicolumn{6}{|c|}{ Table $\mathbf{1 0}$ - Share of industries in Silicon Beach zip codes, $\mathbf{1 9 9 0 - 2 0 1 5}$} \\
\hline \multirow{2}{*}{ Founded by } & $\mathbf{1 9 9 0}$ & $\mathbf{1 9 9 5}$ & $\mathbf{2 0 0 0}$ & $\mathbf{2 0 0 5}$ & $\mathbf{2 0 1 0}$ & $\mathbf{2 0 1 5}$ \\
\hline \multicolumn{1}{|c}{$\mathrm{N}=$} & 63 & 81 & 161 & 274 & 632 & 1161 \\
\hline Technology & $9.52 \%$ & $11.11 \%$ & $17.39 \%$ & $20.80 \%$ & $20.89 \%$ & $19.55 \%$ \\
ICT & $0.00 \%$ & $0.00 \%$ & $2.48 \%$ & $5.47 \%$ & $7.28 \%$ & $6.29 \%$ \\
Data Science & $0.00 \%$ & $0.00 \%$ & $1.86 \%$ & $3.28 \%$ & $3.32 \%$ & $4.22 \%$ \\
Education & $6.35 \%$ & $9.88 \%$ & $13.04 \%$ & $13.14 \%$ & $11.87 \%$ & $10.85 \%$ \\
Entertainment & $0.00 \%$ & $0.00 \%$ & $1.86 \%$ & $1.46 \%$ & $4.59 \%$ & $5.68 \%$ \\
Social Media and Apps & $0.00 \%$ & $0.00 \%$ & $1.24 \%$ & $2.19 \%$ & $5.85 \%$ & $6.12 \%$ \\
Mobile & $0.00 \%$ & $0.00 \%$ & $0.62 \%$ & $2.19 \%$ & $3.32 \%$ & $4.48 \%$ \\
Web & $14.29 \%$ & $14.81 \%$ & $15.53 \%$ & $12.41 \%$ & $9.81 \%$ & $8.35 \%$ \\
Business Support & $11.11 \%$ & $9.88 \%$ & $7.45 \%$ & $5.47 \%$ & $5.54 \%$ & $11.02 \%$ \\
Marketing and Sales & $3.17 \%$ & $3.70 \%$ & $4.97 \%$ & $4.74 \%$ & $6.80 \%$ & $7.15 \%$ \\
Manufacturing & $1.59 \%$ & $6.17 \%$ & $4.97 \%$ & $6.57 \%$ & $4.27 \%$ & $3.19 \%$ \\
Lifestyle & $0.00 \%$ & $0.00 \%$ & $1.24 \%$ & $0.73 \%$ & $2.22 \%$ & $3.01 \%$ \\
Medical and Health & $50.79 \%$ & $40.74 \%$ & $24.84 \%$ & $17.52 \%$ & $12.18 \%$ & $8.18 \%$ \\
No Category & $3.17 \%$ & $3.70 \%$ & $2.48 \%$ & $4.01 \%$ & $2.06 \%$ & $1.89 \%$ \\
\hline \hline Total & 1.00 & 1.00 & 1.00 & 1.00 & 1.00 & 1.00 \\
\hline & & Highlight Cell Rules & $>10 \%$ & $>20 \%$ & $>30 \%$ \\
\hline
\end{tabular}

Table 10 once again breaks down the share of operating startups in a particular industry at a given point in time. In this analysis, it is very interesting to find that firms related to medical and health sciences appeared to be the main drivers of growth in the technology-based economy of Los Angeles in the 1990s, but the importance of these industries has been declining steeply ever since (from as many as $50 \%$ of all firms before 1990 to only $8 \%$ by 2015). Conversely, the share of firms that operate businesses related to technology increased dramatically in the early 2000 s and has remained steady at about $20 \%$ since then. In addition, firms in areas related to web and education have played a steady role 
over the years, while fields such as entertainment, social media and mobile technologies have been growing sharply over the past decade, a fact that supports the idea of a recent convergence between entertainment and technology. Furthermore, both business support and marketing and sales firms have seen resurgence since 2010, a picture that suggests an expansion of the local entrepreneurial and innovation ecosystem.

While this type of analysis is informative in trying to assess the importance of various industries over time, it does not necessarily provide sufficient detail to draw any conclusion more specific than the observations above. Therefore, looking at the share of new firms by industry that were added in fiveyear time intervals between 1990 and 2015 provides some increased granularity and an opportunity to isolate divergent industry trends in a systematic way (see Table 11).

\begin{tabular}{|c|c|c|c|c|c|c|}
\hline Founded by & $\begin{array}{l}\text { pre - } \\
1990\end{array}$ & $\begin{array}{l}1990- \\
1995\end{array}$ & $\begin{array}{l}1995- \\
2000\end{array}$ & $\begin{array}{l}2000- \\
2005\end{array}$ & $\begin{array}{l}2005- \\
2010\end{array}$ & $\begin{array}{l}2010- \\
2015\end{array}$ \\
\hline$N=$ & 63 & 81 & 161 & 274 & 632 & 1161 \\
\hline Technology & $9.52 \%$ & $16.67 \%$ & $23.75 \%$ & $25.66 \%$ & $20.95 \%$ & $17.96 \%$ \\
\hline ICT & $0.00 \%$ & $0.00 \%$ & $5.00 \%$ & $9.73 \%$ & $8.66 \%$ & $5.10 \%$ \\
\hline Data Science & $0.00 \%$ & $0.00 \%$ & $3.75 \%$ & $5.31 \%$ & $3.35 \%$ & $5.29 \%$ \\
\hline Education & $6.35 \%$ & $22.22 \%$ & $16.25 \%$ & $13.27 \%$ & $10.89 \%$ & $9.64 \%$ \\
\hline Entertainment & $0.00 \%$ & $0.00 \%$ & $3.75 \%$ & $0.88 \%$ & $6.98 \%$ & $6.99 \%$ \\
\hline Social Media and Apps & $0.00 \%$ & $0.00 \%$ & $2.50 \%$ & $3.54 \%$ & $8.66 \%$ & $6.43 \%$ \\
\hline Mobile & $0.00 \%$ & $0.00 \%$ & $1.25 \%$ & $4.42 \%$ & $4.19 \%$ & $5.86 \%$ \\
\hline Web & $14.29 \%$ & $16.67 \%$ & $16.25 \%$ & $7.96 \%$ & $7.82 \%$ & $6.62 \%$ \\
\hline Business Support & $11.11 \%$ & $5.56 \%$ & $5.00 \%$ & $2.65 \%$ & $5.59 \%$ & $17.58 \%$ \\
\hline Marketing and Sales & $3.17 \%$ & $5.56 \%$ & $6.25 \%$ & $4.42 \%$ & $8.38 \%$ & $7.56 \%$ \\
\hline Manufacturing & $1.59 \%$ & $22.22 \%$ & $3.75 \%$ & $8.85 \%$ & $2.51 \%$ & $1.89 \%$ \\
\hline Lifestyle & $0.00 \%$ & $0.00 \%$ & $2.50 \%$ & $0.00 \%$ & $3.35 \%$ & $3.97 \%$ \\
\hline Medical and Health & $50.79 \%$ & $5.56 \%$ & $8.75 \%$ & $7.08 \%$ & $8.10 \%$ & $3.40 \%$ \\
\hline No Category & $3.17 \%$ & $5.56 \%$ & $1.25 \%$ & $6.19 \%$ & $0.56 \%$ & $1.70 \%$ \\
\hline Total & 1.00 & 1.00 & 1.00 & 1.00 & 1.00 & 1.00 \\
\hline \multicolumn{4}{|c|}{ Highlight Cell Rules } & $>10 \%$ & $>20 \%$ & $>30 \%$ \\
\hline
\end{tabular}

The decline in importance of the medical and health sciences industry is even more pronounced when looking at the industry share of new firms by period. While more than half of all firms at the starting point of the analysis were operating in fields related to medical and health sciences, this percentage declined to around $8 \%$ throughout the 2000 s and has recently dropped even further to values as low as $3.5 \%$. On 
the other hand, technology-, web- and education-related firms have been at the forefront of startup growth during the 2000s, while by 2010 , the leading roles have shifted toward technology as the major driving force, with business support firms rapidly catching-up in the 2010-2015 time period.

Another interesting observation is related to manufacturing firms: while this particular area of operation seems to bear few startups in most periods, it was very influential in the late 1990s, accounting for more than twice the share of startups than it did in any other period. While this is certainly an important finding, it could be enhanced by the fact that sample sizes increase almost exponentially over time, with the number of new startups nearly doubling every five years. Therefore, it is unclear whether the importance of the manufacturing industry is due to a temporary shift in the startup landscape, or due to a combination of small sample size and business success and longevity. The data at-hand only include firms that are contained in Crunchbase and were therefore at the very least still operating at the time of Crunchbase's inception in 2006. Therefore, the pronounced role played by both the medical and health sciences industry as well as manufacturing may be due to the fact that these kinds of businesses require substantial infrastructural investment and tend to be less prone to failure than startups in other areas which could be subject to differential attrition.

In proceeding with a detailed analysis of industry sub-clusters within the Los Angeles innovation movement, this dissertation calculates geographic midpoints for each cluster, as well as distances between all firms in a particular cluster and its midpoint. Specifically, in order to determine the geographic midpoint of all firms by industry, the following formulation is applied:

$$
[\text { Latitude } \mid \text { Longitude }] \text { for industry }(i)=\Sigma\left[\frac{\text { Latitude }(i)}{n(i)}\right], \Sigma\left[\frac{\text { Longitude }(i)}{n(i)}\right]
$$

While these central points are rough measures and could be subject to outliers due to the fact that they are averages of all firms classified in a particular industry, they provide a good entry point for more sophisticated, cluster-level analysis. Based on these centroids, geodetic distances between each startup belonging to industry(i) and the centroid of that industry are calculated, using the geodist command in STATA 14 SE (Picard 2012):

"GEODIST computes geodetic distances, i.e. the length of the shortest curve between two points along the surface of a mathematical model of the earth. By default, the input coordinates are assumed to be based on the WGS 1984 datum (the same used by Google Earth/Map and GPS devices) and geodist calculates ellipsoidal distances using Vincenty's (1975) equations. Coordinates may be specified in any combination of variables, scalars, or strings of numerical coordinates (as long as) Latitudes range from 90 to 90 and longitudes from -180 to $180 . "$ 
Following the calculations of geodetic distances, the distributions of these distances in each cluster are investigated in order to find the densest areas as well as the general spread of each industry. Along those lines, clusters with bigger standard deviations around the mean distance are more spread out, while clusters with lower standard deviations are more concentrated as displayed in Table 12.

\begin{tabular}{|c|c|c|c|c|c|c|c|c|c|c|}
\hline \multirow[b]{2}{*}{ Industry } & \multirow[b]{2}{*}{$\mathrm{n}=$} & \multicolumn{2}{|c|}{ Industry Centroid } & \multicolumn{7}{|c|}{ Geographic Spread Measures (in Miles from Centroid) } \\
\hline & & Latitude & Longitude & $\begin{array}{l}\text { Mean } \\
{ }^{*} \text { correcteo } \\
\text { with distanc }\end{array}$ & $\begin{array}{l}\text { St. Dev. } \\
\text { or outliers } \\
>50 \text { miles }\end{array}$ & Min. & $\begin{array}{c}\text { 25th } \\
\text { percentile }\end{array}$ & Median & $\begin{array}{c}\text { 75th } \\
\text { percentile }\end{array}$ & Max. \\
\hline Technology & 381 & 34.142 & -118.4758 & 11.07708 & 5.38148 & 0.759933 & 6.951347 & 8.907622 & 14.67854 & 334.0909 \\
\hline ICT & 125 & 34.1841 & -118.5322 & 13.57893 & 6.755941 & 1.624373 & 11.02881 & 11.81282 & 18.26873 & 329.6353 \\
\hline Data Science & 134 & 34.0868 & -118.488 & 7.304565 & 4.427491 & 2.789098 & 4.796375 & 4.995758 & 8.873963 & 336.4068 \\
\hline Education & 295 & 34.1174 & -118.4956 & 8.996924 & 4.668754 & 2.913352 & 6.371412 & 6.920714 & 9.822523 & 334.5874 \\
\hline Entertainment & 448 & 34.1479 & -118.504 & 10.63211 & 4.320516 & 1.958994 & 8.247454 & 9.099021 & 12.83466 & 333.0731 \\
\hline Social Media \& Apps & 305 & 34.0674 & -118.4371 & 6.458119 & 4.439225 & 0.6061865 & 3.441033 & 4.962904 & 9.874982 & 339.3863 \\
\hline Mobile & 201 & 34.077 & -118.4534 & 7.74091 & 5.976096 & 1.376295 & 4.516254 & 4.959694 & 10.69548 & 338.2778 \\
\hline Web & 460 & 34.1547 & -118.3734 & 10.37717 & 4.499245 & 0.7151515 & 6.829706 & 10.53582 & 12.66193 & 2456.603 \\
\hline Business Support & 913 & 34.0657 & -118.4692 & 6.610008 & 5.645074 & 0.0653686 & 3.743424 & 3.936153 & 7.985331 & 338.3767 \\
\hline Marketing \& Sales & 396 & 34.0845 & -118.3263 & 9.820604 & 5.701089 & 0.7366201 & 6.363887 & 9.738686 & 10.96613 & 2456.109 \\
\hline Manufacturing & 150 & 34.1114 & -118.4645 & 10.44141 & 6.609918 & 3.39153 & 5.578341 & 7.656269 & 16.44825 & 335.905 \\
\hline Lifestyle & 258 & 34.0591 & -118.4272 & 6.87344 & 6.244113 & 0.2185585 & 2.986822 & 5.037895 & 9.940776 & 340.1014 \\
\hline Med and Health & 175 & 34.1528 & -118.5402 & 16.12196 & 6.991637 & 2.367591 & 10.36498 & 16.57578 & 22.11969 & 366.532 \\
\hline No Category & 870 & 34.177 & -118.4376 & 12.14129 & 5.06272 & 3.052212 & 8.017971 & 11.63485 & 16.92354 & 333.6942 \\
\hline
\end{tabular}

All of the centroids fall generally inside the Los Angeles region with latitudes around 34 and longitudes around -118 and after controlling for outliers with distances in excess of fifty miles from the centroid, it appears that the geographic midpoint between all startups in a cluster is a decent approximation of the actual hub, although median distances suggest that firms concentrations may be highest in areas about ten miles from the centroid in industries such as entertainment, ICT, technology and web, while for other industries like mobile technologies, social media and apps as well as data science and lifestyle, areas of high concentration are most likely about five miles from the centroid.

Looking at a combination of mean distances from the centroid and standard deviations as a measure of geographic spread unveils that firms in the medical and health sciences are particularly spread out over the Los Angeles region, with a vast majority of startups located anywhere from about ten miles to twenty-two miles away from the geographic midpoint. Conversely, firms operating in the mobile technology, lifestyle and social media and apps clusters appear to mostly be located in areas that are 
between three and eleven miles from the centroid and can hence be seen as relatively dense and interconnected. Figure 24 graphically illustrates these trends by plotting the frequency distribution of distances from the geographic midpoint for each cluster. Specifically, the share of firms with a given amount of distance in miles is plotted in order to obtain histograms with Kernel smoothing functions for each industry that can be explored to view detailed patterns of firm distribution and concentrations in relation to the midpoint. Spikes in the distribution suggest that many firms are located at points situated at the specific distance from the centroid, where this spike in the distribution occurs. For spikes in lower distance ranges (for example $<10$ miles), the geographic midpoint is a good approximation for cluster density, while for industries that show spikes in higher distance ranges (for example $>15$ miles), there might be multiple hubs or a generally higher level of geographic dispersion, with many firms located further away from the midpoint, but in a non-systematic, isolated manner.

\section{Figure 24 - Geographic spreads by industry (distributions of distances from geographic industry centroid)}

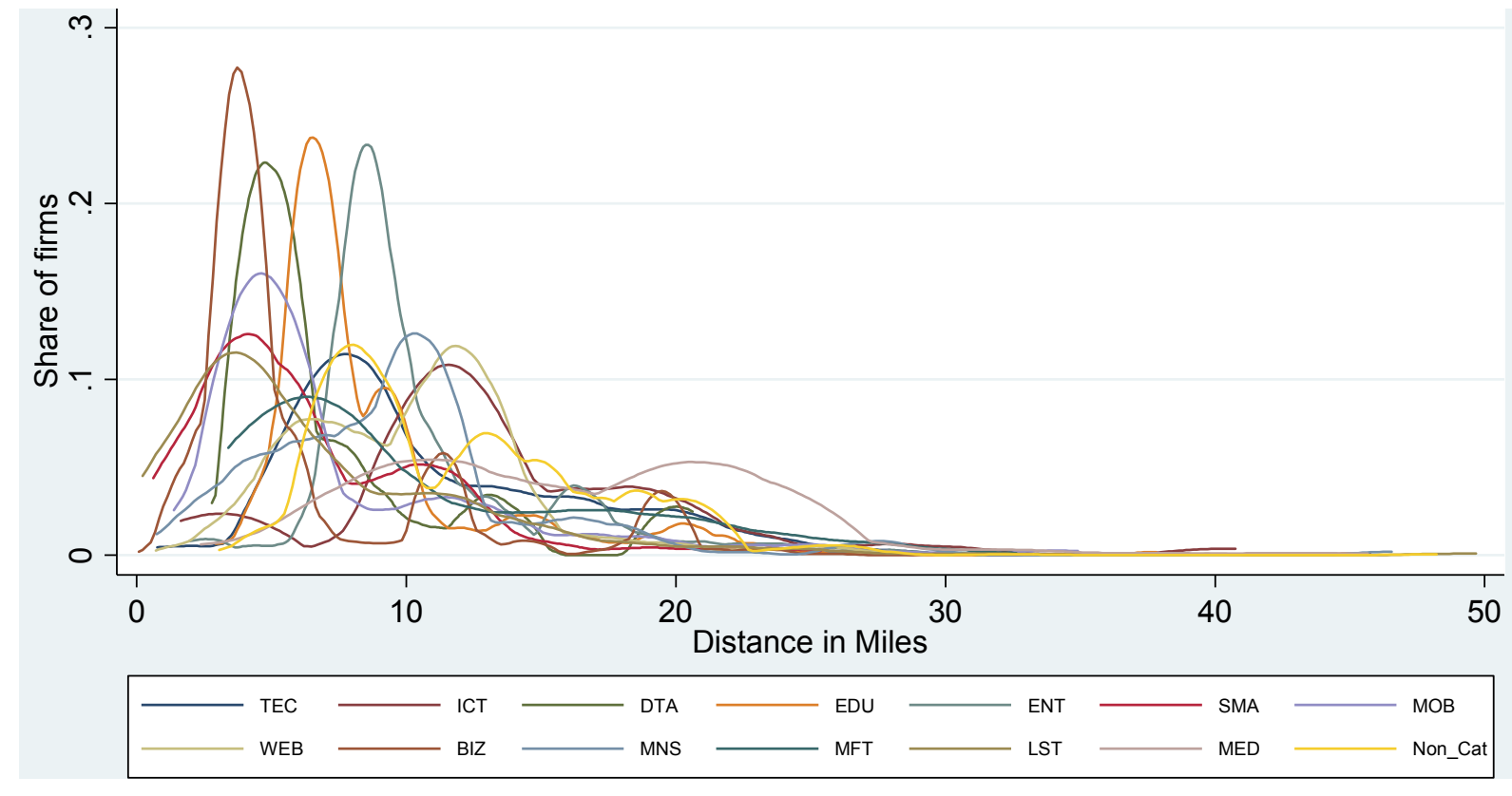

Additionally, Table 13 shows how many firms are located within a specific radius from the geographic midpoint in each industry. Cells that are highlighted in darker shades of red suggest a higher share of firms located in a particular distance bracket. It is very interesting to see that the highest levels of concentration are found at smaller distances, within five to ten miles from the midpoint for more than half of the firm in technology, education and entertainment and within less than five miles for more than half of all firms in mobile technology and business support functions. In this table, the fact that multiple cells 
are highlighted for a single industry suggests that the industry is particularly spread out. Following this logic, it appears that medical and health sciences firms as well as ICT firms are particularly dispersed across the region.

\begin{tabular}{|c|c|c|c|c|c|c|c|c|c|c|c|c|c|c|c|}
\hline \multirow{3}{*}{ Industry } & \multirow{3}{*}{$\mathrm{n}=$} & \multicolumn{2}{|c|}{ Industry Centroid } & \multicolumn{12}{|c|}{ Distances from Centroid } \\
\hline & & \multirow{2}{*}{ Latitude } & \multirow{2}{*}{ Longitude } & \multicolumn{2}{|c|}{$<1$ miles } & \multicolumn{2}{|c|}{$<5$ miles } & \multicolumn{2}{|c|}{ 5-10 miles } & \multicolumn{2}{|c|}{$10-15$ miles } & \multicolumn{2}{|c|}{$15-20$ miles } & \multicolumn{2}{|c|}{$>20$ miles } \\
\hline & & & & $\mathrm{n}$ & $\%$ & $\mathrm{n}$ & $\%$ & $\mathrm{n}$ & $\%$ & $\mathrm{n}$ & $\%$ & $\mathrm{n}$ & $\%$ & $\mathrm{n}$ & $\%$ \\
\hline Technology & 381 & 34.14203 & -118.4758 & 4 & $1.05 \%$ & 6 & $1.57 \%$ & 201 & $52.76 \%$ & 79 & $20.73 \%$ & 47 & $12.34 \%$ & 44 & $11.55 \%$ \\
\hline ICT & 125 & 34.18409 & -118.5322 & 0 & $0.00 \%$ & 13 & $10.40 \%$ & 4 & $3.20 \%$ & 62 & $49.60 \%$ & 23 & $18.40 \%$ & 23 & $18.40 \%$ \\
\hline Data Science & 134 & 34.0868 & -118.488 & 0 & $0.00 \%$ & 67 & $50.00 \%$ & 38 & $28.36 \%$ & 15 & $11.19 \%$ & 4 & $2.99 \%$ & 10 & $7.46 \%$ \\
\hline Education & 295 & 34.11742 & -118.4956 & 0 & $0.00 \%$ & 10 & $3.39 \%$ & 214 & $72.54 \%$ & 31 & $10.51 \%$ & 16 & $5.42 \%$ & 24 & $8.14 \%$ \\
\hline Entertainment & 448 & 34.14788 & -118.504 & 0 & $0.00 \%$ & 10 & $2.23 \%$ & 262 & $58.48 \%$ & 86 & $19.20 \%$ & 53 & $11.83 \%$ & 37 & $8.26 \%$ \\
\hline Social Media and Apps & 305 & 34.06739 & -118.4371 & 7 & $2.30 \%$ & 152 & $49.84 \%$ & 71 & $23.28 \%$ & 59 & $19.34 \%$ & 4 & $1.31 \%$ & 12 & $3.93 \%$ \\
\hline Mobile & 201 & 34.077 & -118.4534 & 0 & $0.00 \%$ & 106 & $52.74 \%$ & 42 & $20.90 \%$ & 29 & $14.43 \%$ & 8 & $3.98 \%$ & 16 & $7.96 \%$ \\
\hline Web & 460 & 34.15472 & -118.3734 & 2 & $0.43 \%$ & 38 & $8.26 \%$ & 160 & $34.78 \%$ & 209 & $45.43 \%$ & 21 & $4.57 \%$ & 30 & $6.52 \%$ \\
\hline Business Support & 913 & 34.06565 & -118.4692 & 4 & $0.44 \%$ & 552 & $60.46 \%$ & 141 & $15.44 \%$ & 122 & $13.36 \%$ & 66 & $7.23 \%$ & 28 & $3.07 \%$ \\
\hline Marketing and Sales & 396 & 34.08449 & -118.3263 & 3 & $0.76 \%$ & 60 & $15.15 \%$ & 138 & $34.85 \%$ & 137 & $34.60 \%$ & 35 & $8.84 \%$ & 23 & $5.81 \%$ \\
\hline Manufacturing & 150 & 34.11137 & -118.4645 & 0 & $0.00 \%$ & 34 & $22.67 \%$ & 57 & $38.00 \%$ & 19 & $12.67 \%$ & 15 & $10.00 \%$ & 25 & $16.67 \%$ \\
\hline Lifestyle & 258 & 34.0591 & -118.4272 & 8 & $3.10 \%$ & 119 & $46.12 \%$ & 71 & $27.52 \%$ & 33 & $12.79 \%$ & 9 & $3.49 \%$ & 18 & $6.98 \%$ \\
\hline Medical and Health & 175 & 34.15275 & -118.5402 & 0 & $0.00 \%$ & 5 & $2.86 \%$ & 34 & $19.43 \%$ & 38 & $21.71 \%$ & 34 & $19.43 \%$ & 64 & $36.57 \%$ \\
\hline No Category & 870 & 34.17696 & -118.4376 & 0 & $0.00 \%$ & 1 & $0.11 \%$ & 386 & $44.37 \%$ & 244 & $28.05 \%$ & 99 & $11.38 \%$ & 140 & $16.09 \%$ \\
\hline \multicolumn{11}{|c|}{ Highlight Cell Rules } & $15 \%$ & $20 \%$ & $30 \%$ & $40 \%$ & $50 \%$ \\
\hline
\end{tabular}

However, when looking at the spreads displayed in Table 13, it becomes apparent that mean estimates for industry centroid coordinates might not be best suited to approximate actual concentrations of industries across Los Angeles due to the fact that means tend to be very susceptible to outliers in the underlying distribution. Therefore, the mean estimates shown above are very well suited to show the level to which particular industries are spread-out across the Los Angeles region, but they do not reveal reliable information about actual centers of gravity. In order to address this concern, this dissertation proceeds by estimating median geographic centroids for industries, thus sorting all firms within a cluster by ascending latitude/longitude combinations and selecting the mid-point of these observations as an industry's center of gravity. Typically, median estimates are less prone to outliers and present a more accurate center of skewed distributions, a fact that also holds true when looking at the geographic spreads depicted below in Table 14. 


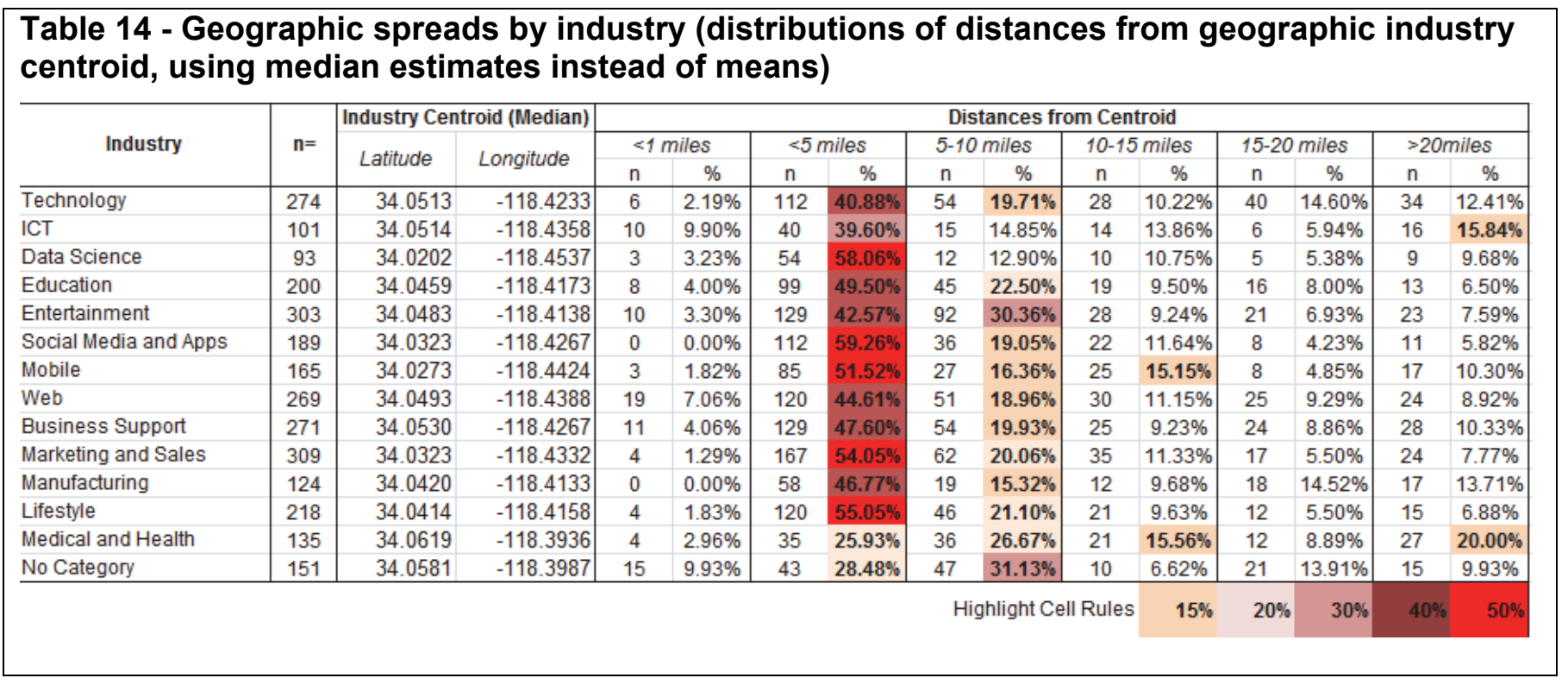

It is very interesting to see that in comparison with a relatively widespread distribution of firms around mean industry centroid estimates, firms are much more concentrated around industry centroids when using median estimates. Now, nearly half of all startup firms in almost all industries except for medical and health sciences as well as ICT are located within walking distance ( $<5$ miles) from their respective industry's centroid, suggesting that median industry centroids are a good representation of an industry's center of gravity. Similar to the analyses above, health and medical sciences remain the least concentrated industry. Even when using medians instead of means to identify the geographic midpoint of the cluster, the single highest count of firms is between five and ten miles away from the centroid and firms generally appear to be spread more or less evenly across distance levels. This finding further lends credence to the hypotheses outlined in the USC Biotech Chapter of this dissertation regarding the dispersed nature of the Los Angeles health sciences industry.

Nonetheless, while the locations of median industry centroids present a substantial improvement over mean estimates, they still fail to accurately represent the high levels of firm concentration in the areas of Santa Monica and Venice and instead cluster along the Wilshire corridor. In part, this might be due to the geographic reality of the region and the fact that both the Pacific Ocean in the West and the Santa Monica and Malibu Mountains in the North present physical boundaries, therefore inflicting an Eastward bias on the median estimate. In order to cope with this issue an estimate of the mode or most common value could be better suited to approximate the true concentration of each cluster. However, because latitudes and longitudes in the sample are effectively continuous numeric values, it is difficult to construct a mode estimate that reflects the densest level of firm concentration in each cluster. In response, this dissertation tested a combination of various descriptive statistical approaches, ranging from Kernel 
distributions to Stem and Leaf plots, with the ultimate objective of eliciting mode industry centroid estimates. ${ }^{18}$ Following close inspections of each method, Stem and Leaf plots were finally chosen as the appropriate measure, leading to the results depicted in Table 15:

\begin{tabular}{|l|c|c|c|ccc|}
\hline \multicolumn{7}{|c|}{ Table 15 - Mode industry centroids } \\
\hline \multicolumn{2}{|c|}{ Mode Estimate } & \multicolumn{2}{|c|}{ Estimated Mode Longitude } & \multicolumn{3}{c|}{ Estimated Mode Latitude } \\
\cline { 2 - 7 } Industry & Stem & Leaf & Mode Long & Stem & Leaf & Mode Lat \\
\hline Technology & -118.39 & 0.00193 & -118.39193 & 34.01 & 0.00526 & 34.01526 \\
ICT & -118.48 & 0.00817 & -118.48817 & 34.01 & 0.00731 & 34.01731 \\
Data Science & -118.49 & 0.00600 & -118.49600 & 34.01 & 0.00747 & 34.01747 \\
Education & -118.49 & 0.00620 & -118.49620 & 34.01 & 0.00343 & 34.01343 \\
Entertainment & -118.39 & 0.00236 & -118.39236 & 34.01 & 0.00238 & 34.01238 \\
Social Media \& Apps & -118.39 & 0.00225 & -118.39225 & 34.01 & 0.00367 & 34.01367 \\
Mobile & -118.49 & 0.00545 & -118.49545 & 34.01 & 0.00382 & 34.01382 \\
Web & -118.49 & 0.00646 & -118.49646 & 34.01 & 0.00276 & 34.01276 \\
Business Support & -118.49 & 0.00200 & -118.49200 & 34.01 & 0.00570 & 34.01570 \\
Marketing \& Sales & -118.49 & 0.00567 & -118.49567 & 34.01 & 0.00202 & 34.01202 \\
Manufacturing & -118.44 & 0.00313 & -118.44313 & 34.01 & 0.00742 & 34.01742 \\
Lifestyle & -118.39 & 0.00217 & -118.39217 & 34.01 & 0.00369 & 34.01369 \\
Health \& Medical & -118.39 & 0.00189 & -118.39189 & 34.05 & 0.00771 & 34.05771 \\
No Category & -118.44 & 0.00236 & -118.44236 & 34.14 & 0.00625 & 34.14625 \\
\hline
\end{tabular}

The mode estimates resulting from Stem and Leaf plots coincide with the various other alternative statistical measures investigated, suggesting that they present an accurate estimate of the most common firm locations and thus of the densest points in each industry cluster. However, it should be noted that several industries such as lifestyle, entertainment, web and manufacturing display multimodal firm distributions, suggesting that each of these clusters have two hubs across the region.

When again looking at geographic spreads of firms in each cluster with respect to the mode centroid, a very interesting pattern emerges, particularly compared to Table 14 displayed earlier for the median centroid measure (see Table 16).

${ }^{18}$ See Appendix for various plots and figures 


\begin{tabular}{|c|c|c|c|c|c|c|c|c|c|c|c|c|c|c|c|}
\hline \multirow{3}{*}{ Industry } & \multirow{3}{*}{$n=$} & \multicolumn{2}{|c|}{ | Industry Centroid (Mode) | } & \multicolumn{12}{|c|}{ Distances from Centroid } \\
\hline & & \multirow{2}{*}{ Latitude } & \multirow{2}{*}{ Longitude } & \multicolumn{2}{|c|}{$<1$ miles } & \multicolumn{2}{|c|}{$<5$ miles } & \multicolumn{2}{|c|}{$5-10$ miles } & \multicolumn{2}{|c|}{$10-15$ miles } & \multicolumn{2}{|c|}{ 15-20 miles } & \multicolumn{2}{|c|}{$>$ >20miles } \\
\hline & & & & $n$ & $\%$ & $\mathrm{n}$ & $\%$ & $\mathrm{n}$ & $\%$ & $\mathrm{n}$ & $\%$ & $\mathrm{n}$ & $\%$ & $\mathrm{n}$ & $\%$ \\
\hline Technology & 274 & 34.0153 & -118.3919 & 6 & $2.19 \%$ & 82 & $29.93 \%$ & 86 & $31.39 \%$ & 26 & $9.49 \%$ & 41 & $14.96 \%$ & 33 & $12.04 \%$ \\
\hline ICT & 101 & 34.0173 & -118.4882 & 16 & $15.84 \%$ & 20 & $19.80 \%$ & 26 & $25.74 \%$ & 17 & $16.83 \%$ & 3 & $2.97 \%$ & 19 & $18.81 \%$ \\
\hline Data Science & 93 & 34.0175 & -118.4960 & 19 & $20.43 \%$ & 29 & $31.18 \%$ & 16 & $17.20 \%$ & 15 & $16.13 \%$ & 1 & $1.08 \%$ & 13 & $13.98 \%$ \\
\hline Education & 200 & 34.0134 & -118.4962 & 31 & $15.50 \%$ & 46 & $23.00 \%$ & 53 & $26.50 \%$ & 33 & $16.50 \%$ & 15 & $7.50 \%$ & 22 & $11.00 \%$ \\
\hline Entertainment & 303 & 34.0124 & -118.3924 & 8 & $2.64 \%$ & 114 & $37.62 \%$ & 109 & $35.97 \%$ & 25 & $8.25 \%$ & 24 & $7.92 \%$ & 23 & $7.59 \%$ \\
\hline Social Media and Apps & 189 & 34.0137 & -118.3923 & 8 & $4.23 \%$ & 68 & $35.98 \%$ & 79 & $41.80 \%$ & 11 & $5.82 \%$ & 12 & $6.35 \%$ & 11 & $5.82 \%$ \\
\hline Mobile & 165 & 34.0138 & -118.4955 & 32 & $19.39 \%$ & 37 & $22.42 \%$ & 42 & $25.45 \%$ & 23 & $13.94 \%$ & 9 & $5.45 \%$ & 22 & $13.33 \%$ \\
\hline Web & 269 & 34.0128 & -118.4965 & 34 & $12.64 \%$ & 67 & $24.91 \%$ & 73 & $27.14 \%$ & 40 & $14.87 \%$ & 16 & $5.95 \%$ & 39 & $14.50 \%$ \\
\hline Business Support & 271 & 34.0157 & -118.4920 & 27 & $9.96 \%$ & 71 & $26.20 \%$ & 83 & $30.63 \%$ & 35 & $12.92 \%$ & 15 & $5.54 \%$ & 40 & $14.76 \%$ \\
\hline Marketing and Sales & 309 & 34.0120 & -118.4957 & 42 & $13.59 \%$ & 80 & $25.89 \%$ & 92 & $29.77 \%$ & 47 & $15.21 \%$ & 19 & $6.15 \%$ & 29 & $9.39 \%$ \\
\hline Manufacturing & 124 & 34.0174 & -118.4431 & 3 & $2.42 \%$ & 54 & $43.55 \%$ & 17 & $13.71 \%$ & 17 & $13.71 \%$ & 16 & $12.90 \%$ & 17 & $13.71 \%$ \\
\hline Lifestyle & 218 & 34.0137 & -118.3922 & 6 & $2.75 \%$ & 89 & $40.83 \%$ & 79 & $36.24 \%$ & 13 & $5.96 \%$ & 17 & $7.80 \%$ & 14 & $6.42 \%$ \\
\hline Medical and Health & 135 & 34.0577 & -118.3919 & 2 & $1.48 \%$ & 37 & $27.41 \%$ & 34 & $25.19 \%$ & 23 & $17.04 \%$ & 12 & $8.89 \%$ & 27 & $20.00 \%$ \\
\hline No Category & 151 & 34.1463 & -118.4424 & 0 & $0.00 \%$ & 2 & $1.32 \%$ & 80 & $52.98 \%$ & 25 & $16.56 \%$ & 21 & $13.91 \%$ & 23 & $15.23 \%$ \\
\hline & & & & & & & & & lighlight $\mathrm{Ce}$ & Rules & $15 \%$ & $20 \%$ & $30 \%$ & $40 \%$ & $50 \%$ \\
\hline
\end{tabular}

While a similar share of firms is located within a 5 mile radius from the centroid, about forty to fifty percent of firms in most clusters except health and medical sciences, there is a shift toward the centroid. When using median industry centroids, hardly any firms were located within one mile of the estimated center, but now, in almost all clusters except the ones that are distributed in a multi-modal fashion across the region such as manufacturing and lifestyle and entertainment, a sharp increase in this share can be observed. This suggests that mode industry centroids perform better than both median and mean estimates in approximating the true centers of gravity of most industries within the Los Angeles region.

After identifying industry centroids and measuring the geographic spread of each industry cluster, it is further important to see how the various industries relate to Los Angeles' pre-existing institutional infrastructure. In order to do so, Figure 25 displays a map of both industry centroids and potential anchoring institutions such as movie studios and universities, as well as investors that are listed in Crunchbase and that have actually invested in L.A.-based startups. 


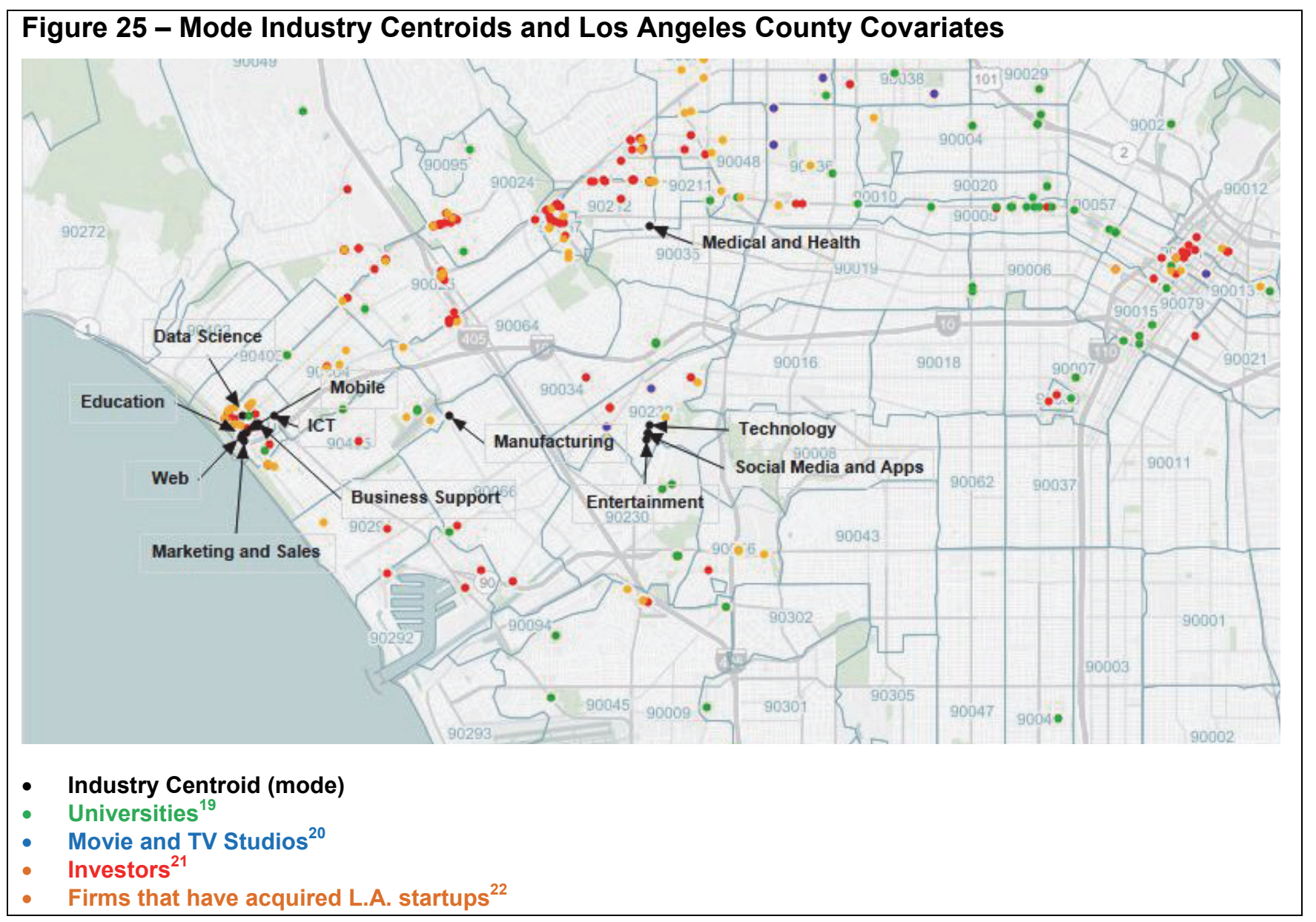

When looking at the map, it is encouraging that most of the industry centroids are located inside of the Silicon Beach areas, again supporting the claim that the areas between Santa Monica-Venice, Culver City and Hollywood are responsible for a vast majority of recent startup growth in the Los Angeles region. Likewise, it is noteworthy that a vast majority of funders are located along the Wilshire corridor, a factor that - along with increased rental prices in the core Silicon Beach areas of Santa Monica and Venice - could explain the gradual expansion of the startup population towards Hollywood and Downtown Los Angeles. Upon further examination, it appears that industry centroids are also located along the same line between Santa Monica in the West and Beverly Hills in the North-East. This suggests that startups tend to located around areas with a high availability of funding, although reverse causality could also be at play, with funders setting up shop in areas that have high concentrations of startups.

\footnotetext{
${ }^{19}$ See LA County GIS Data Portal at http://egis3.lacounty.gov/dataportal/2013/03/29/california-geoportal/

${ }^{20}$ See LA County GIS Data Portal at http://egis3.lacounty.gov/dataportal/2013/03/29/california-geoportal/

${ }^{21}$ Data obtained from the investments reported in Crunchbase

22 Data obtained from the acquisitions reported in Crunchbase
} 
In order to further examine these co-location dynamics, Table 16 explores the geographic concentrations of potential anchoring institutions within the existing Los Angeles landscape in relation to various industry centers within the Los Angeles innovation and startup movement:

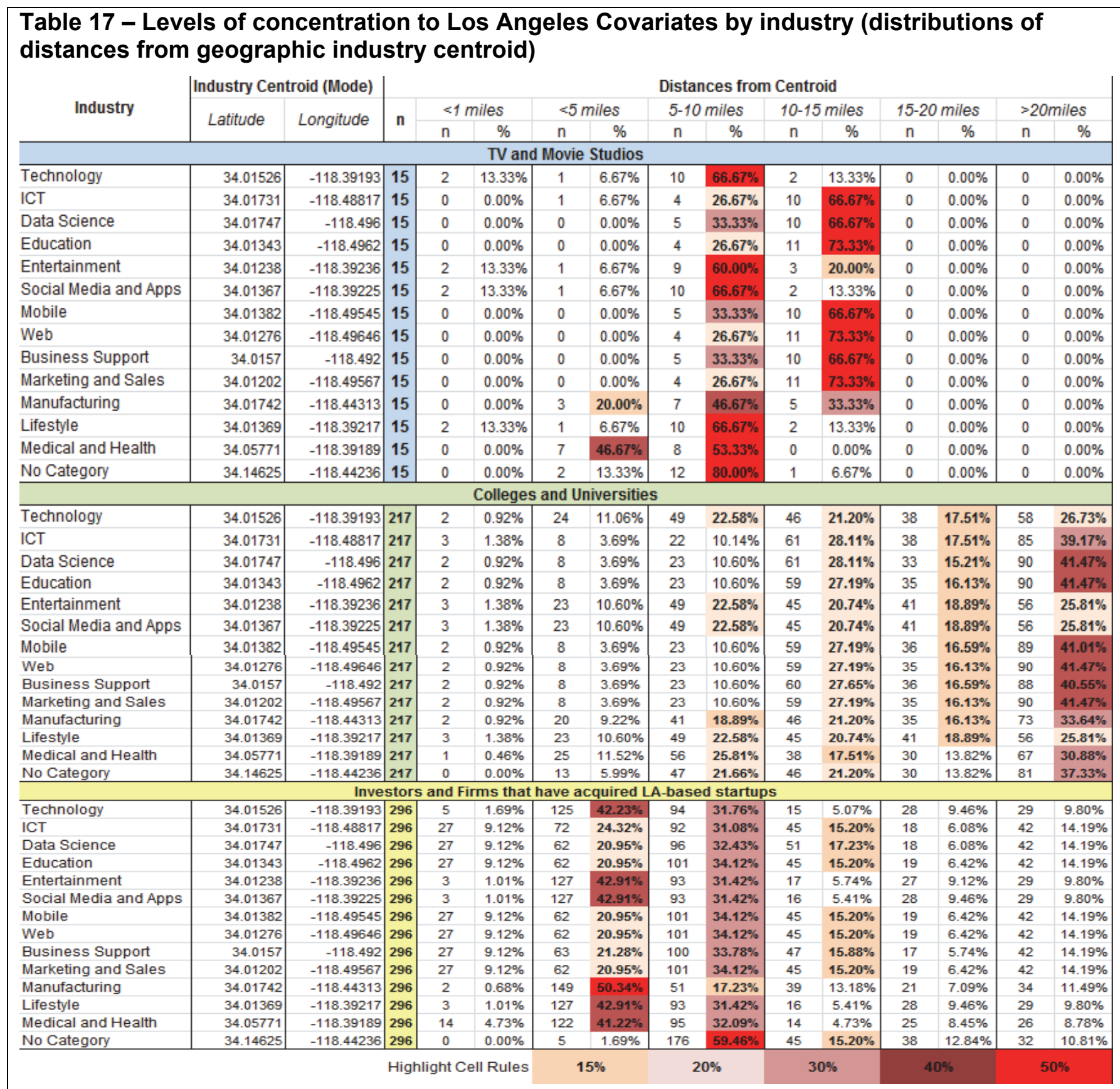


One of the key limitations in using the infrastructural data obtained from the LA County GIS data portal for this type of analysis is the fact that the list of colleges in particular includes a broad variety of educational institutions, many of which are highly unlikely to play a role in firm location, especially if they are not involved in research. Due to this limitation and the resulting high number of educational institutions, no particular pattern can be observed between industry centroids and proximity to universities, although when looking at the map displayed in Figure 25, the center of the medical and health sciences cluster seems to be located close to UCLA.

With respect to movie and TV Studios, it seems that the vast majority of firms within every industry is located within ten miles of these institutions. While this phenomenon could be due to the relatively small sample size of fifteen major movie and TV Studios, it could also suggest that Hollywood is starting to play a major role in the startup and innovation movement.

Lastly and perhaps most interestingly, the location of investors and firms that have previously acquired LA-based startups, appears to be closely tied to the centers of gravity for all industries. As outlined above, there are two plausible explanations for this observation: either startup firms are following the money and industries are expanding around financing resources, a story that could be consistent with the evolvement of Sand Hill Road in Silicon Valley, where investors over time moved from San Francisco to areas that display high concentrations of startup activity, such as Santa Clara and the South Bay, thus maximizing proximity to potential investments targets. 


\section{Main takeaways and policy recommendations}

Following a thorough analysis of Crunchbase data on startups and firms in the Los Angeles region, it is important to revisit the overarching research questions posed above:

\section{Where is the epicenter of the movement and is it changing over time?}

Looking at the historical evolution of startup locations within the Los Angeles region, it appears that the movement indeed originated in the stretch between Santa Monica and Venice Beach, although it has expanded over time to Marina Del Rey, Mar Vista and Culver City in the South and Westwood, Beverly Hills and even Hollywood in the North-East. When comparing firm formation trends and geographic locations across various data sources, an interesting picture emerges, with a disproportionate share of startups and new firms created in a relatively small, yet highly concentrated area, thus suggesting a set of boundaries for Silicon Beach. Over time, this trend appears to be remarkably consistent: while many new firms settle in areas further away from the original epicenter, Santa Monica and Venice Beach still remain the single most influential locations for new startups both within the Silicon Beach movement and Los Angeles as a whole.

Given the nature data at hand, it is difficult to assess the reasons for expansion away from the cluster's nucleus between Santa Monica and Venice, although rising cost of living and business operations could be responsible for driving firms to locate at the outskirts of the Silicon Beach area. In addition, the increasing proximity to the Hollywood entertainment cluster in the North-East or the former aerospace manufacturing cluster in the South might lead firms that are looking to draw on those resources to locate closer to their original hubs.

\section{What are the main drivers of this movement in terms of skills, talent, industry and funding?}

After generating broad industry affiliations for all firms listed in Crunchbase and identifying geographical as well as temporal patterns for each industry, several interesting findings emerge. In one key example, the medical and health sciences sector in Los Angeles indeed appears to be spread-out across the region, a fact that was likewise emphasized by various stakeholders that were interviewed for the USC Biotechnology case study. In addition, all industries appear to be somewhat concentrated around central locations within Silicon Beach, with more than half of all firms often located within walking distance $(<5$ miles) from their respective industry centroid. 
This suggests that firms within the Silicon Beach technology cluster are beginning to take advantage of agglomeration effects and are trying to leverage shared resources such as space or intellectual capital. Given this high level of startup concentration in a relatively small area, entrepreneurs in Silicon Beach are starting to form a coherent entrepreneurial network and are contributing to the bottom-up formation of a local innovation ecosystem. Compared to other neighborhoods within the Los Angeles region, Santa Monica and Venice Beach are rather well-connected and easily accessible, thus making it easier for entrepreneurs to meet up and talk to each other. Furthermore, this emergent entrepreneurial network is starting to provide opportunities for graduates from Los Angeles' cluster of world class universities and is beginning to curb the entrepreneurial brain-drain to other areas such as Silicon Valley, particularly for graduates of technical disciplines such as engineering or computer science.

Are there specific anchoring institutions such as universities, movie studios, investors or corporations that attract different kinds of startups?

Frequently, the first things that people associate with the Los Angeles economy is the entertainment cluster around Hollywood. Along with this cluster, the region has developed a highly-creative and diverse workforce that is now supplying the Silicon Beach technology innovation movement with a talented labor pool. Many startups across all industries operate at the intersections of technology and lifestyle as well as entertainment, both traditional strongholds of the regional economy. Upon closer examination of the newly-formed clusters within Silicon Beach, it appears that almost all of them are indeed located within a ten mile radius from all major movie and TV studios, therefore drawing on the resources and capacities developed as part of the Hollywood cluster.

While it is difficult to isolate the role that colleges and universities play in firm location choices, the Westwood neighborhood around UCLA in particular seems to be host to the hubs of several industry clusters. In addition, the areas surrounding Loyola Marymount University in Playa Vista, Mar Vista and Marina Del Rey are emerging as new centers of the movement, as evidenced by the decisions of Google and Yahoo to establish major offices nearby. This southbound expansion of Silicon Beach is interesting in a variety of ways as it suggests that one needs to distinguish between the initial bottom-up, startup-driven Silicon Beach movement originating in Santa Monica and Venice Beach and spreading to Westwood, Hollywood and Beverly Hills in the North-East and a secondary move of large-scale technology firms such as Google, Yahoo and Facebook. The fact that many startups are located along the Wilshire Corridor, the area within Los Angeles that is also host to most investors, might thus be explained by the need of those firms to "follow the money" and their effort to minimize transaction costs and to maximize their visibility to potential funding sources. On the contrary, firms locating along the 
beach south of Venice might be oriented more toward social media-related technologies and are thus looking for close proximity to large-scale technology firms as key customers for their products and services.

\section{What can policy-makers do to facilitate the growth of the local technology sector?}

In order to generate and maintain a highly innovative and entrepreneurial ecosystem in Los Angeles, policy makers need to establish a policy framework that adequately addresses the needs of the local technology sector, without imposing unnecessary restrictions. While some of the larger technology firms such as Google and Yahoo might respond well to traditional relocation incentives such as tax breaks and land, the large number of startup firms requires an entirely different set of policies. Given the fact that these firms tend to be small and oftentimes driven by a few, entrepreneurially-minded individuals, it is important to create a local environment that effectively connects these different firms. Relatedly, facilitating meetings between entrepreneurs and potential funders can be a key role for local policy makers going forward. In addition, further investments into the local infrastructure could make it easier for people within the broader Los Angeles innovation clusters to connect and share information and resources. Lastly, a factor that was mentioned by several entrepreneurs and business stakeholders in the USC case study was that Los Angeles as a whole needs to become more business-friendly and that the region's policy leaders ought to engage in regular conversations with entrepreneurs and businesses to more adequately assess the true challenges emerging from the Los Angeles marketplace.

To a certain extent, the key role that policy makers can assume in order to enable the Silicon Beach movement of technology firms is to act as coordinators, bringing actors from different industries together and increasing the visibility of startup firms across the region in order to attract outside investment. Initiatives such as the LA City Geohub mapping efforts or the Entrepreneurs in Residence program ${ }^{23}$ recently introduced by Los Angeles Mayor Eric Garcetti presents good starting points, and investing in similar initiatives going forward will be critical in sustaining and nurturing the Los Angeles tech community.

\footnotetext{
${ }^{23}$ See for example: http://lamayor.org/mayor-garcetti-announces-2016-entrepreneurs-residence
} 


\section{Limitations}

When relying on open-source, self-reported data bases such as Crunchbase.com, representativeness and reliability of the underlying data are always an issue to be considered. Most notably, compared to more traditional, expensive venture capital investment data sources such as VentureXpert, Crunchbase is not necessarily maintained and curated commercially to the same standard. While this dissertation uses various alternative data sources to assess validate Crunchbase findings with respect to locational trends in Los Angeles, the time series analyses in particular suffer from the fact that Crunchbase was only developed in 2005 , thus calling into question the accuracy of data preceding its inception.

A second limitation of the above analyses is the fact that it is very difficult to establish any causal relationship, thus making it nearly impossible to provide any definitive answers to questions about the underlying mechanisms behind the emergence of Silicon Beach. As a result, many of the phenomena studied and outlined above must be treated as exploratory in nature. Supplementing Crunchbase data with anecdotal evidence from systematic interviews with Silicon Beach entrepreneurs in various sectors, policy makers both in Los Angeles and Santa Monica and technology investors could serve to further underline the findings of this dissertation and to develop a historic account of the Los Angeles innovation movement. 


\section{Outlining a future research agenda for Silicon Beach and Crunchbase Geo}

Conceivably, this exploratory analysis of the Los Angeles innovation movement is setting up various avenues of future research on both entrepreneurship research in Los Angeles and more broadly any geographic area while using a geocoded version of Crunchbase.com, a highly policy relevant and widely available research tool. In this vein, a variety of interesting research questions immediately comes to mind:

\section{Comparing Crunchbase to VentureXpert}

This dissertation has shown that a geocoded version of Crunchbase comes reasonably close to approximating more sophisticated and commercially-maintained databases such as VentureXpert when it comes to firm location data. However, it remains to be seen whether Crunchbase can be similarly reliable with respect to other key aspects of VentureXpert, notably the rich information on investment rounds, investors, top-level management composition and business success data. Systematically testing these areas in ways similar to the ones undertaken in this dissertation will ultimately determine the usability of Crunchbase for academic researchers in entrepreneurship who seek to investigate business trends beyond geographic and temporal measures.

\section{Comparing Silicon Beach to other - formerly praised - innovative regions}

Michael Storper and colleagues (2015) recently published their findings of a large-scale, historical comparison between the San Francisco Bay Area and the Los Angeles metropolitan region, concluding that L.A. has gradually fallen behind in terms of per-capita income and degree of innovativeness. This type of comparative analysis is an important line of research to assess the long-term competitiveness of regions and their innovation ecosystems, and while Silicon Beach has truly captured public attention recently, it would be interesting to carry-out systematic comparisons between the movement at hand and other, formerly highly praised technology clusters such as Austin or New York's Silicon Alley.

\section{Identifying funding sources - inside or outside Los Angeles?}

When thinking about the innovation ecosystem in Los Angeles, one of the most common complaints heard is always the lack of venture capital in the region. Looking at Crunchbase, it is possible to investigate whether the majority of funding for Silicon Beach entrepreneurs has come from local sources 
or whether outside sources have started to gravitate more towards Los Angeles as a source of innovation.

\section{Exploring the entrepreneurial network in Silicon Beach using Crunchbase and Linkedln}

Butler, Garg et al. (2015) look at entrepreneurial networks across the United States by merging data from Crunchbase on firm founders and early-stage employees with their detailed Linkedln profiles. Following a similar strategy, it would be very interesting to construct an individual-level dataset on Los Angeles entrepreneurs, including both educational and professional background and to identify social network linkages between entrepreneurs, as well as individual-level predictors of firm successand choice of location and industry. 


\section{Conclusion and Policy Recommendations}

Understanding the knowledge-based economy in Los Angeles: from entrepreneurial universities to Silicon Beach

At first glance, USC's efforts to develop a biotech-oriented science park around its Health Sciences Campus and the Silicon Beach movement of technology-oriented startups in Santa Monica and Venice Beach that has recently captured public attention appear to be unrelated phenomena. However, both rely heavily on the Los Angeles region's native strengths such as its creative and diverse workforce.

Traditionally, the biotechnology industry in Los Angeles has been dispersed across the city. Successful biotech industries elsewhere, as we have discussed in this dissertation, address the particularly high risks, costs and time horizons of this industry through clustering. The dispersion of biotech in LA may be a factor behind the lack of a successful biotech industry. To overcome this, as the interviews showed, a critical mass of firms is needed in order to attract the support services and develop the supply chains that will help form a thriving cluster.

Now, the emergence of a bottom-up, startup driven technology movement in West Los Angeles has started to provide opportunities locally and has enhanced the visibility and availability of local resources. As outlined previously, it is much easier for technology entrepreneurs to attract venture funding than it is for science-based entrepreneurs, due to the higher levels of risk and complexity involved in life sciences financing. However, because technology startups have led to increased interest in the Los Angeles innovation environment and have raised the region's profile as a knowledge-based destination economy, it is generally becoming easier to conduct business out of Los Angeles. This could benefit science based industries such as biotech by making available the support services and helping the supply chains to develop. The Silicon Beach technology movement and the emerging biotech industry in the region alike are starting to understand how to best leverage the existing strengths of the local environment, namely the competencies developed as part of the digital production and entertainment cluster around Hollywood and the region's longstanding innovation track record in lifestyle-oriented domains such as food, fashion and beauty products. These trends suggest that in a global marketplace with fewer restraints to firm location choice, entrepreneurs are seeking out highly-specific market niches and are settling in places whose endowment of talent, skills and resources most closely aligns with their interests and needs. For the Los Angeles region, it might be difficult to compete with more traditional biotechnology or general technology destinations such as San Francisco, Boston or San Diego, but it is 
highly competitive in attracting firms that are looking to merge research and technology to digital production, imaging and lifestyle and entertainment--areas that have been strongholds of the regional economy for a long time. 


\section{Concluding thoughts and policy recommendations}

When developing a strategy to facilitate the formation of research and technology oriented clusters across the Los Angeles region, most actions, tools and policies can be placed under one of two overarching objectives, connecting people and resources or establishing multiple knowledge-hubs across the region. While attracting specific anchoring companies for the local knowledge-based economy might be a difficult task for policy makers, supporting universities in building their research capacities and using their convening power to build awareness and to help achieve critical mass are very powerful tools in expanding local capacity for economic growth.

Accordingly, Figure 26 presents an action plan for the development of the knowledge-based economy in Los Angeles, moving from high-level strategic objectives to more tangible goals for the operationalization of these objectives and ultimately a set of key action items related to both connecting people and resources and building-out various centers of excellence across the Los Angeles region.

\section{Figure 26 - Policy recommendations for nurturing the knowledge-based economy in Los Angeles}

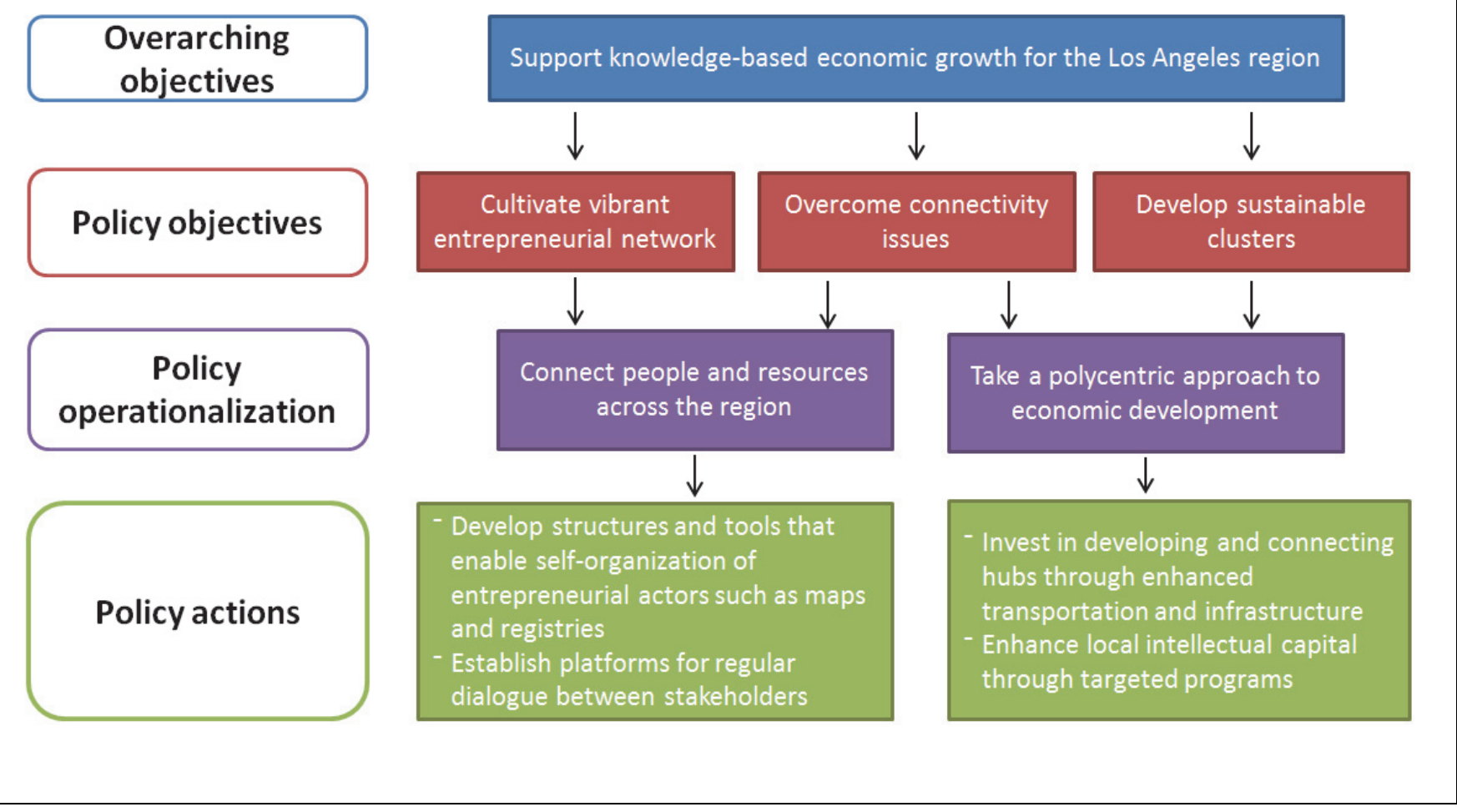

Local policy makers ought to assume a critical role in nurturing and sustaining the emergent technology and research-oriented clusters across the Los Angeles region. While startup founders and technology 
entrepreneurs often tend to think of regulation as barriers, policy can also serve to create a vibrant innovation ecosystem provided that there is a regular exchange of information between the two sides (Ablon and Golay 2016). Specifically with respect to the Los Angeles region, the key need for entrepreneurs appears to be connectedness and organization. Policy makers at the Los Angeles Mayor's Office, the Chambers of Commerce and the Los Angeles County Board of Supervisors are in a position to convene similarly-minded people and to connect entrepreneurs to each other and to resources. In taking lessons from well-functioning knowledge-based regions such as Silicon Valley's technology cluster and San Diego's biotech cluster, it appears that building a cohesive and highly interconnected entrepreneurial social network, consisting of entrepreneurs in various areas, business support function such as legal and real estate, investors and policy makers is the most critical element of success. However, it is likewise crucial to maintain flexibility and to invest in tools that enable clusters to self-organize and that help entrepreneurs to develop market niches for the knowledge-based economy in Los Angeles.

The widespread nature of the Los Angeles region indeed calls for a polycentric approach to developing innovative hubs where people can meet and collaborate to develop ideas, as was suggested by a policy stakeholder during the interviews conducted as part of this dissertation. (Hall and Pain 2006) Nevertheless, it will be very important going forward to expand the physical infrastructure that connects the different hubs such as a potential Biotech Science Park around USC's Health Sciences Campus in Boyle Heights and the epicenter of the Silicon Beach movement between Santa Monica and Venice Beach. Along those lines, policy makers ought to engage in regular information exchanges with entrepreneurs and businesses at all levels, from large technology corporation such as Google, Yahoo and Facebook to small startup companies of five people or less, in order to establish a regulatory framework that creates and maintains a local innovation environment that addresses entrepreneurial needs and helps spur inclusive economic growth in the region. 


\section{Key References}

Ablon, L. and A. Golay (2016). "How the 'Wonks' of Public Policy and the 'Geeks' of Tech Can Get Together." TechCrunch / RAND Corporation. Retrieved 03/18/2016, from http://techcrunch.com/2016/03/17/how-the-wonks-of-public-policy-and-the-geeks-of-tech-can-gettogether/.

Aldridge, T. T. and D. Audretsch (2011). "The Bayh-Dole act and scientist entrepreneurship." Research policy 40(8): 1058-1067.

Auletta, K. (2012). "Get Rich U. There are no walls between Stanford and Silicon Valley. Should there be?" The New Yorker. Retrieved 03/18/2016, from http://www.newyorker.com/magazine/2012/04/30/getrich-u.

Battelle Technology Partnership Practice (2012). "Feasibility Assessment and Master Plan for Advancing the Bioscience Industry Cluster in Los Angeles County." Retrieved 03/18/2016, from http://file.lacounty.gov/bc/q3_2014/cms1_217012.pdf.

Battelle Technology Partnership Practice (2013). Advancing a biomedical Research Park at USC's Health Sciences Campus - Feasiblity Assessment and Conceptual Plans.

Bowles, N. (2014). "Re/code Special Series on the Los Angeles tech scene, Parts 1-7." Retrieved 03/18/2016, from http://recode.net/special-series/la-stories/.

Bradshaw, T. K. and E. J. Blakely (1999). "What are "third-wave" state economic development efforts? From incentives to industrial policy." Economic Development Quarterly 13(3): 229-244.

Bramwell, A. and D. A. Wolfe (2008). "Universities and regional economic development: The entrepreneurial University of Waterloo." Research policy 37(8): 1175-1187.

Brody, W. (1999). "From minds to minefields: Negotiating the demilitarized zone between industry and academia." Remarks to the Biomedical Engineering Lectures Series, John Hopkins University 6.

Butler, J., et al. (2015). "Social Networks and Regional Advantages in Technology Entrepreneurship." Available at SSRN 2668918.

Carvalho, L. (2009). "Four challenges for a new science and technology park: AvePark in Guimarães, Portugal." Urban Research \& Practice 2(1): 103-108. 
Casper, S. (2007). "How do technology clusters emerge and become sustainable?: social network formation and inter-firm mobility within the San Diego biotechnology cluster." Research policy 36(4): 438-455.

Casper, S. (2009). "The marketplace for ideas: Can Los Angeles build a successful biotechnology cluster." A Report to the John Randolph Haynes Foundation, Keck Graduate Institute of Applied Life Sciences.

Casper, S. (2014). The University of California and the Evolution of the Biotechnology Industry in San Diego and the San Francisco Bay Area. Public Universities and Regional Growth: Insights from the University of California. M. Kenney and D. Mowery, Stanford University Press: 66-96.

Castilla, E. J., et al. (2000). "Social networks in silicon valley." The Silicon Valley edge: A habitat for innovation and entrepreneurship: 218-247.

CB Insights (2013). "Los Angeles Tech Venture Capital Almanac." Retrieved 08/04/2015, from www.cbinsights.com/venture-capital-los-angeles.

Chang, A. and P. Jamison (2015). "Playa Vista turning into Silicon Valley South as tech firms move in." Los Angeles Times. Retrieved 03/18/2016, from http://www.latimes.com/business/la-fi-silicon-valleysouth-20150118-story.html.

Chapple, W., et al. (2005). "Assessing the relative performance of UK university technology transfer offices: parametric and non-parametric evidence." Research policy 34(3): 369-384.

Cooke, P. (2001). "Clusters as key determinants of economic growth." Cluster policies-cluster development: 23-38.

Crescenzi, R. (2005). "Innovation and regional growth in the enlarged Europe: the role of local innovative capabilities, peripherality, and education." Growth and Change 36(4): 471-507.

De Propris, L. and L. Hypponen (2008). "11. Creative clusters and governance: the dominance of the Hollywood film cluster." Creative cities, cultural clusters and local economic development: 258.

Di Gregorio, D. and S. Shane (2003). "Why do some universities generate more start-ups than others?" Research policy 32(2): 209-227.

Di Rado, A. and E. North-Hager (2015). "USC summit marks rebirth of biotech era in Los Angeles." USC News. Retrieved 03/18/2016, from https://news.usc.edu/76533/usc-summit-marks-rebirth-of-biotech-erain-los-angeles/. 
Dorfman, N. S. (1983). "Route 128: the development of a regional high technology economy." Research policy 12(6): 299-316.

Etzkowitz, H. (2003). "Research groups as 'quasi-firms': the invention of the entrepreneurial university." Research policy 32(1): 109-121.

Etzkowitz, H. (2010). The triple helix: university-industry-government innovation in action, Routledge.

Etzkowitz, H. and C. Zhou (2007). Regional innovation initiator: the entrepreneurial university in various triple helix models. Triple Helix 6th Conference theme paper, Singapore.

Feldman, M. and P. Desrochers (2003). "The evolving role of research universities in technology transfer: lessons from the history of Johns Hopkins University." Industry and Innovation 10: 5-24.

Feldman, M. and P. Desrochers (2003). "Research universities and local economic development: Lessons from the history of the Johns Hopkins University." Industry and Innovation 10(1): 5-24.

Feldman, M. P. (1994). "The university and economic development: the case of Johns Hopkins University and Baltimore." Economic Development Quarterly 8(1): 67-76.

Feldman, M. P. and P. Desrochers (2004). "Truth for its own sake: academic culture and technology transfer at Johns Hopkins University." Minerva 42(2): 105-126.

Feller, I. (1990). "Universities as engines of R\&D-based economic growth: They think they can." Research policy 19(4): 335-348.

Florida, R. (2014). The Rise of the Creative Class--Revisited: Revised and Expanded, Basic books.

Florida, R. L. and M. Kenney (1988). "Venture capital, high technology and regional development*." Regional Studies 22(1): 33-48.

Gaddie, M. (2013). "The Rise of Silicon Beach: The Disruptive LA Tech Scene." Retrieved 03/18/2016, from http://seriousstartups.com/2013/01/29/rise-silicon-beach-disruptive-la-tech-scene/.

Global Connect (2010). "Biotechnology Cluster Project - San Diego Analysis." United States Studies Centre at the University of Sydney Retrieved 03/18/2016, from http://globalconnect.ucsd.edu/documents/Global_Connect_USSC_Report_April_2010.pdf.

Graham, J. (2012). "Silicon Beach emerges as a tech hotbed." Retrieved 03/08/2016, from http://usatoday30.usatoday.com/tech/news/story/2012-07-15/silicon-beach/56241864/1. 
Grimaldi, R., et al. (2011). "30 years after Bayh-Dole: Reassessing academic entrepreneurship." Research policy 40(8): 1045-1057.

Guerrero, M. and D. Urbano (2012). "The development of an entrepreneurial university." The Journal of Technology Transfer 37(1): 43-74.

Gupta, M., et al. (2006). "The LA Motion Picture Industry Cluster." The Microeconomics of Competitiveness: Firms, clusters and economic development, Harvard Business School.

Hall, P. G. and K. Pain (2006). The polycentric metropolis: learning from mega-city regions in Europe, Routledge.

Hanley, C. and M. T. Douglass (2014). "High road, low road, or off road? Economic development strategies in the American states." Economic Development Quarterly 28(3): 220-229.

Hardin, J. W. (2008). "North Carolina's Research Triangle Park." Overview, History, Success Factors and Lessons Learned, Wageningen UR Frontis Series 24: 27-51.

Hood, L. (2013). "L.A.'s future: 'Silicon Beach'." Los Angeles Times. Retrieved 03/08/2016, from http://articles.latimes.com/2013/jan/09/opinion/la-oe-hood-silicon-beach-los-angeles-20130109.

HR\&A Advisors (2014). "The New York City Tech Ecosystem: Generating Economic Opportunities for All New Yorkers." Retrieved 03/18/2016, from http://www.hraadvisors.com/nyctechstudy/.

Kaiser, D. (2010). Becoming MIT: moments of decision, MIT Press.

Kenney, M. (2000). Understanding Silicon Valley: the anatomy of an entrepreneurial region, Stanford University Press.

Kenney, M. and D. Patton (2011). "Does inventor ownership encourage university research-derived entrepreneurship? A six university comparison." Research policy 40(8): 1100-1112.

Kenney, M. and U. Von Burg (1999). "Technology, entrepreneurship and path dependence: industrial clustering in Silicon Valley and Route 128." Industrial and corporate change 8(1): 67-103.

Kofman, A. (2013). "The Science Park Bubble." Yale Daily News. Retrieved 03/18/2016, from http://yaledailynews.com/blog/2013/04/07/the-science-park-bubble/. 
Langlois, S. (2015). "Silicon Beach: Los Angeles emerges as contender for tech crown." Retrieved 03/18/2016, from http://www.marketwatch.com/story/silicon-beach-los-angeles-emerges-as-contenderfor-tech-crown-2015-07-16.

Lee, C.-M. (2000). The Silicon Valley edge: A habitat for innovation and entrepreneurship, Stanford University Press.

Lee, E. (2012). "California's 'Silicon Beach' Draws Tech Start-Ups." Retrieved 03/18/2016, from http://www.voanews.com/articleprintview/1448148.html.

Lerner, J. (1995). "Venture capitalists and the oversight of private firms." The Journal of Finance 50(1): 301-318.

Leydesdorff, L. and M. Meyer (2010). "The decline of university patenting and the end of the Bayh-Dole effect." Scientometrics 83(2): 355-362.

Link, A. N. and J. T. Scott (2003). "The growth of research triangle park." Small Business Economics 20(2): 167-175.

Link, A. N. and J. T. Scott (2005). "Opening the ivory tower's door: An analysis of the determinants of the formation of US university spin-off companies." Research policy 34(7): 1106-1112.

Lissoni, F. (2001). "Knowledge codification and the geography of innovation: the case of Brescia mechanical cluster." Research policy 30(9): 1479-1500.

Lockett, A., et al. (2003). "Technology transfer and universities' spin-out strategies." Small Business Economics 20(2): 185-200.

Markman, G. D., et al. (2005). "Innovation speed: Transferring university technology to market." Research policy 34(7): 1058-1075.

Markman, G. D., et al. (2005). "Entrepreneurship and university-based technology transfer." Journal of Business Venturing 20(2): 241-263.

Maskell, P. (2001). "Towards a knowledge-based theory of the geographical cluster." Industrial and corporate change 10(4): 921-943.

Mowery, D. C. and B. N. Sampat (2005). The Bayh-Dole act of 1980 and university-industry technology transfer: a model for other OECD governments? Essays in honor of Edwin Mansfield, Springer: 233245. 
Mowery, D. C., et al. (2002). "Learning to patent: Institutional experience, learning, and the characteristics of US university patents after the Bayh-Dole Act, 1981-1992." Management Science 48(1): 73-89.

Mowery, D. C. and A. A. Ziedonis (2000). "Numbers, quality, and entry: How has the Bayh-Dole Act affected US university patenting and licensing?" Innovation policy and the economy: 187-220.

Mueller, P. (2006). "Exploring the knowledge filter: How entrepreneurship and university-industry relationships drive economic growth." Research policy 35(10): 1499-1508.

Nikias, C. L. M. (2015). "Los Angeles has the right DNA to become biotech hub." Los Angeles Times. Retrieved 03/18/2016, from http://www.latimes.com/opinion/op-ed/la-oe-0226-nikias-los-angelesbiotech-corridor-20150226-story.html.

Norberg, A. L. (1976). "The origins of the electronics industry on the Pacific coast." Proceedings of the IEEE 64(9): 1314-1322.

O'Shea, R. P., et al. (2005). "Entrepreneurial orientation, technology transfer and spinoff performance of US universities." Research policy 34(7): 994-1009.

O'Shea, R. P., et al. (2007). "Delineating the anatomy of an entrepreneurial university: the Massachusetts Institute of Technology experience." R\&d Management 37(1): 1-16.

O'Shea, R. P., et al. (2008). "Determinants and consequences of university spinoff activity: a conceptual framework." The Journal of Technology Transfer 33(6): 653-666.

OECD (2005). The Measurement of Scientific and Technological Activities: Guidelines for Collecting and Interpreting Innovation Data: Oslo Manual, Third Edition.

Otis College (2014). "2013 Otis Report on the Creative Economy." Retrieved 08/04/2015, from http://laedc.org/wp-content/uploads/2014/02/2013_Otis_Report_Creative_Economy.pdf.

Patton, D. and M. Kenney (2010). "The role of the university in the genesis and evolution of researchbased clusters." Emerging Clusters: Theoretical, Empirical and Political Perspectives on the Initial Stage of Cluster Evolution: 214-238.

Picard, R. (2012). "GEODIST: Stata module to compute geodetic distances." Statistical Software Components.

Pickert, K. (2014). "Silicon Valley Goes to the Beach." Time Magazine. Retrieved 03/18/2016, from http://time.com/57159/silicon-valley-goes-to-los-angeles/ 
Porter, M. E. (2011). Competitive advantage of nations: creating and sustaining superior performance, Simon and Schuster.

Powers, J. B. (2003). "Commercializing academic research: Resource effects on performance of university technology transfer." The Journal of Higher Education 74(1): 26-50.

Rafferty, M. (2008). "The Bayh-Dole Act and university research and development." Research policy 37(1): 29-40.

Rao, D. (2013). "Should universities become entrepreneurial campuses?" Forbes Magazine. Retrieved 03/18/2016, from http://www.forbes.com/sites/dileeprao/2013/11/18/should-universities-becomeentrepreneurial-campuses/\#42d7a7fa7ed3.

Rasmussen, E. and O. J. Borch (2010). "University capabilities in facilitating entrepreneurship: A longitudinal study of spin-off ventures at mid-range universities." Research policy 39(5): 602-612.

Rivera, C. (2012). "Caltech tops list of world's universities." Los Angeles Times. 03/18/2016, from http://latimesblogs.latimes.com/lanow/2012/10/caltech-tops-list-of-world-universities.html.

Rogers, E. M., et al. (2001). "Lessons learned about technology transfer." Technovation 21(4): 253-261.

Röpke, J. (2000). "The Entrepreneurial University. Innovation, academic knowledge creation and regional development in a globalized economy."

Rothaermel, F. T., et al. (2007). "University entrepreneurship: a taxonomy of the literature." Industrial and corporate change 16(4): 691-791.

Rothaermel, F. T. and D. N. Ku (2008). "Intercluster innovation differentials: the role of research universities." Engineering Management, IEEE Transactions on 55(1): 9-22.

Salmi, J. (2009). The challenge of establishing world-class universities, World Bank Publications.

Sampat, B. N. (2006). "Patenting and US academic research in the 20th century: The world before and after Bayh-Dole." Research policy 35(6): 772-789.

Saxenian, A. (1996). Regional advantage, Harvard University Press.

Scott, A. J. (1996). "The craft, fashion, and cultural-products industries of Los Angeles: competitive dynamics and policy dilemmas in a multisectoral image-producing complex." Annals of the Association of American Geographers 86(2): 306-323. 
Scott, A. J. (2005). On Hollywood: The place, the industry, Princeton University Press.

Shane, S. (2004). "Encouraging university entrepreneurship? The effect of the Bayh-Dole Act on university patenting in the United States." Journal of Business Venturing 19(1): 127-151.

Sorensen, P., et al. (2008). "Reducing Traffic Congestion in Los Angeles."

Startup Genome (2012). "Startup Ecosystem Report 2012." Retrieved 08/04/2015, from http://blog.startupcompass.co/pages/entrepreneurship-ecosystem-report.

Stevens, A. J. (2004). "The enactment of Bayh-Dole." The Journal of Technology Transfer 29(1): 93-99.

Storper, M., et al. (2015). The Rise and Fall of Urban Economies: Lessons from San Francisco and Los Angeles, Stanford University Press.

Sturgeon, T. J. (2000). "How Silicon Valley came to be." Understanding Silicon Valley: Anatomy of an Entrepreneurial Region: 15-47.

Thorp, H. and B. Goldstein (2013). Engines of innovation: The entrepreneurial university in the twentyfirst century, UNC Press Books.

Thursby, J. G. and M. C. Thursby (2011). "Has the Bayh-Dole act compromised basic research?" Research policy 40(8): 1077-1083.

Tornatzky, L. G. (2000). Building state economies by promoting university-industry technology transfer, National Governors' Association.

Trune, D. R. and L. N. Goslin (1998). "University technology transfer programs: A profit/loss analysis." Technological Forecasting and Social Change 57(3): 197-204.

Van Looy, B., et al. (2011). "Entrepreneurial effectiveness of European universities: An empirical assessment of antecedents and trade-offs." Research policy 40(4): 553-564.

Vanderhoef, J. (2014). "Silicon Beach Shows Promise, Not Profits." Retrieved 08/04/2015, from http://www.carseywolf.ucsb.edu/mip/article/silicon-beach-shows-promise-not-profits.

Vest, C. M. (2004). Pursuing the endless frontier: Essays on MIT and the role of research universities. 
Walcott, S. M. (2002). "Analyzing an innovative environment: San Diego as a bioscience beachhead." Economic Development Quarterly 16(2): 99-114.

Walshok, M. L., et al. (2002). "Building regional innovation capacity: The San Diego experience." Industry and Higher Education 16(1): 27-42.

Williams, S. and E. Currid-Halkett (2011). "The emergence of Los Angeles as a fashion hub: a comparative spatial analysis of the New York and Los Angeles fashion industries." Urban Studies: 0042098010392080.

Youtie, J. and P. Shapira (2008). "Building an innovation hub: A case study of the transformation of university roles in regional technological and economic development." Research policy 37(8): 11881204.

Zimmerman, E. (2013). "Is Silicon Beach Over-Hyped?" New York Times Retrieved 03/18/2016, from http://boss.blogs.nytimes.com/2013/09/06/is-silicon-beach-being-over-hyped/?_r=2. 


\section{Appendix}

\section{USC Stakeholder Analysis - Focus Group Protocol}

Start with a brief introduction to USC's biotech science park project, based on USC's public, bi-lingual fact sheet, which is available from

https://communities.usc.edu/files/2014/10/USCBiotechOutreachFlyer.pdf

Also provide an opportunity for participants to ask clarifying questions, so that there is a clear understanding of the park's objectives and outcomes with regard to community development prior to proceeding with the research questions.

\section{Research question 1 - Assessing people's previous interactions and experiences with USC}

1.1 Please briefly describe your interactions and experiences with USC.

- Have you, your family or your friends been in contact with the university?

If yes, in what capacity?

- As a vendor - have sold things to USC.

- As a client - received funding from USC.

- As a student or employee

- Have attended events that were held or sponsored by USC.

- If not, what has prevented you, your family and your friends from getting involved with the university?

- Do you consider USC as part of your community?

- If yes, how would you describe its role?

Now that you have heard a little bit more about USC's plans to develop a Biotechnology Science Park, we would like to hear your opinions about the initiative. 
Research question 2 - What are perceived opportunities and hopes for the Biotech Corridor? What are the main fears and concerns?

2.1 Let's talk about some of the features of the Science Park. Please talk about the following aspects and let us know how they make you feel:More people in the area, working with the Science Park

- The Science Park bringing jobs to the area, both temporary and permanent

- New businesses in the area forming around the Science Park.

- Opportunities for students to study at USC and Cal State Los Angeles

- The Science Park's impact on safety and community

- Potential for expanded recreational facilities and cultural benefits such as museums and parks

- Opportunities to acquire professional skills through vocational training programs

2.2 Are there any other potential impacts of the Science Park that you would like to discuss? 


\section{Research question 3 - How can the Biotech Corridor involve respondents and the local community to achieve local economic development?}

3.1 Now that we have talked about the positive and negative aspects of the project, what is your opinion about a Science Park in East Los Angeles?

3.2 In what capacity do you think the local community can be involved in the Science Park?

3.3 Which of the following types of jobs do you think are best suited for the local community? Please rank these jobs from least suited $(=1)$ to best suited $(=4)$ and briefly explain your ranking.

A Science Park will need people to work in a large variety of jobs such as:

Research and technical support

Maintenance and facilities

Administrative and clerical work

Local business and retail

3.4 Do you think there are other ways in which the local community could get involved in the Science Park?

3.5 What are some things that may make it difficult for the local community to get involved in the Science Park?

3.6 What can be done to close the gaps and involve the local community in the Science Park?

3.7 Aside from the strategies already discussed, local colleges are thinking about vocational education and retraining to involve as many local community members as possible.

- What types of skills do you think are needed the most?

- What are the challenges in terms of retraining? 
USC Stakeholder Analysis - Questionnaire for Faculty Entrepreneurs

For a brief introduction to USC's biotech science park project, please see USC's public, bi-lingual fact sheet, which is available from https://communities.usc.edu/files/2014/10/USCBiotechOutreachFlyer.pdf

\section{Section 1 -USC's impact on academic entrepreneurship}

Please briefly describe your research focus at USC.

Have you tried to commercialize your inventions / research products or know someone at USC who $\underline{\text { has? }}$

Yes

No

Based on the experiences of you and your colleagues, please describe the commercialization process at USC:

Did you reach out to your colleagues to learn about their experiences in academic entrepreneurship?

Yes

No

Have you worked with USC Stevens or a similar university-based entity focused on technology transfer? Yes

No

What types of help, advice or resources did you receive in the process (please indicate yes or no)?

- Patenting process

- Licensing process

- University funding

- Referrals to venture capital or other sources of funding

- Connections to specialized legal firms, real estate agents and other business support entities?
Yes No

Yes No

Yes No

Yes No

Yes No 


\section{Section 2 - Impact of the local innovation ecosystem on academic entrepreneurship}

Think about the variety of ways in which the Los Angeles region has impacted your work: please rank the factors below by circling a number ( $1=$ least important, $6=$ most important)

- $\quad$ Funding environment and venture capital

- Business support system

- Entrepreneurial network

- Transportation infrastructure

- Availability of lab space

- Local labor force and talent pool

$\begin{array}{llllll}1 & 2 & 3 & 4 & 5 & 6 \\ 1 & 2 & 3 & 4 & 5 & 6 \\ 1 & 2 & 3 & 4 & 5 & 6 \\ 1 & 2 & 3 & 4 & 5 & 6 \\ 1 & 2 & 3 & 4 & 5 & 6 \\ 1 & 2 & 3 & 4 & 5 & 6\end{array}$

Which of these factors are particular strengths and weaknesses of the Los Angeles region? Please describe your choices:

Are there any other environmental factors that contribute to the success or failure of academic entrepreneurship? Please describe how these factors have affected your work: 


\section{Section 3 - Factors in firm location choices}

Looking at both internal and external factors of business success, what do you consider most important in your decision WHETHER to start a business based on your research?

Looking at both internal and external factors of business success, what do you consider most important in your decision WHERE to start a business based on your research?

Please describe how you feel about starting a business in the current environment. 


\section{Section 4 - Assessing entrepreneurial needs for a Science Park in South-East Los Angeles}

Do you think that a Science Park could address some of the deficits in these environmental influences?

What are features that you would like to see addressed in a Science Park focused on biotech? Please rank the features below by circling a number ( $1=$ least important, $5=$ =most important):

- Rigorous business training for faculty entrepreneurs $\quad \begin{array}{llllll}1 & 2 & 3 & 4 & 5\end{array}$

- Expanded technology transfer and research $\begin{array}{lllllll}\text { commercialization support } & 1 & 2 & 3 & 4 & 5\end{array}$

- Increased lab space

$\begin{array}{lllll}1 & 2 & 3 & 4 & 5\end{array}$

- Development of a commercialization support network of venture capitalists, legal and real estate
Enhanced opportunities for academic entrepreneurs to meet, share research ideas and collaborate

$\begin{array}{lllll}1 & 2 & 3 & 4 & 5 \\ 1 & 2 & 3 & 4 & 5\end{array}$

Please briefly explain your ranking:

Aside from the features discussed above, are there any other features that you would like to see addressed in the Science Park? 


\section{Section 5 - The local community and the Science Park}

In what capacity do you think the local community in Boyle Heights could be involved in the Science $\underline{\text { Park? }}$

Which of the following types of jobs do you think are best suited for the local community? Please rank these jobs from least suited $(=1)$ to best suited (=4):

- Research and technical support

- Maintenance and facilities

- Administrative and clerical work

- Local business and retail

$\begin{array}{llll}1 & 2 & 3 & 4 \\ 1 & 2 & 3 & 4 \\ 1 & 2 & 3 & 4 \\ 1 & 2 & 3 & 4\end{array}$

Please briefly explain your ranking:

Do you think there are other ways in which the local community could get involved in the Science Park?

What are some things that may make it difficult for the local community to get involved in the Science $\underline{\text { Park? }}$

What can be done to close the gaps and involve the local community in the Science Park? 
For a brief introduction to USC's biotech science park project, please see USC's public, bi-lingual fact sheet, which is available from https://communities.usc.edu/files/2014/10/USCBiotechOutreachFlyer.pdf

\section{Section 1 - Impact of the local innovation ecosystem on academic entrepreneurship and innovation}

Think about the variety of ways in which the Los Angeles region has impacted entrepreneurship and innovation: please rank the factors below by circling a number ( $1=$ least important, $6=$ most important)

- Funding environment and venture capital

- Business support system

- Entrepreneurial network

- Transportation infrastructure

- Availability of lab space

- Local labor force and talent pool

$\begin{array}{llllll}1 & 2 & 3 & 4 & 5 & 6 \\ 1 & 2 & 3 & 4 & 5 & 6 \\ 1 & 2 & 3 & 4 & 5 & 6 \\ 1 & 2 & 3 & 4 & 5 & 6 \\ 1 & 2 & 3 & 4 & 5 & 6 \\ 1 & 2 & 3 & 4 & 5 & 6\end{array}$

Which of these factors are particular strengths and weaknesses of the Los Angeles region? Please describe your choices:

Are there any other environmental factors that contribute to the success or failure of academic entrepreneurship? Please describe your choices: 


\section{Section 2 - Assessing entrepreneurial needs for a Science Park in South-East Los Angeles}

Do you think that a Science Park could address some of the deficits in these environmental influences?

What are features that you would like to see addressed in a Science Park focused on biotech? Please rank the features below by circling a number ( $1=$ least important, $5=$ =most important):

- Rigorous business training for faculty entrepreneurs

- Expanded technology transfer and research commercialization support

- Increased lab space

- Development of a commercialization support network of venture capitalists, legal and real estate

- Enhanced opportunities for academic entrepreneurs to meet, share research ideas and collaborate

$\begin{array}{lllll}1 & 2 & 3 & 4 & 5 \\ 1 & 2 & 3 & 4 & 5 \\ 1 & 2 & 3 & 4 & 5 \\ 1 & 2 & 3 & 4 & 5 \\ 1 & 2 & 3 & 4 & 5\end{array}$

Please briefly explain your ranking:

Aside from the features discussed above, are there any other features that you would like to see addressed in the Science Park? 


\section{Section 3 - The local community and the Science Park}

In what capacity do you think the local community in Boyle Heights could be involved in the Science $\underline{\text { Park? }}$

Which of the following types of jobs do you think are best suited for the local community? Please rank these jobs from least suited (=1) to best suited (=4):

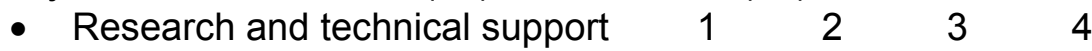

- Maintenance and facilities $\quad 1 \quad 20 \begin{array}{llll} & 2 & 3 & 4\end{array}$

- Administrative and clerical work $\quad 1 \quad 2 \quad 304$

- Local business and retail $\quad 1 \quad 2 \quad 2 \quad 3 \quad 4$

Please briefly explain your ranking:

Do you think there are other ways in which the local community could get involved in the Science Park?

What are some things that may make it difficult for the local community to get involved in the Science $\underline{\text { Park? }}$

What can be done to close the gaps and involve the local community in the Science Park? 


\section{Crunchbase.com Database Overview}

(Extracted from http://data.crunchbase.com)

\section{About}

CrunchBase is the leading platform to discover innovative companies and the people behind them. Founded in 2007 by Mike Arrington, we began as a simple crowd sourced database to track startups covered on TechCrunch.

Today, we deliver market insights to millions of users and businesses around the world. The CrunchBase Dataset is constantly expanding through contributions from our community of users, investment firms, and network of global partners.

- The Business Graph

- CrunchBase API

- CrunchBase Data Exports

- CrunchBase Startup Calendar

- CrunchBase Venture Program

- CrunchBase FAQ

- Jobs at CrunchBase

- Development and Release Notes

And here are the requisite documents about our policies...

- Content Guidelines

- Licensing Guidelines

- Terms of Service

- Privacy Policy

If you have any questions about CrunchBase or the data contained within, please feel free to contact us at info@crunchbase.com. Our office is located at:

410 Townsend St

San Francisco, CA 94107 


\section{basic Introduction}

The CrunchBase API is a RESTful service that enables approved developers to retrieve data from the CrunchBase Dataset.

The CrunchBase API can be accessed programmatically (the most common use case), and a number of developers have written Language-Specific Libraries to jump-start your development.

For simple testing / inspection, the CrunchBase API can also be accessed through any web browser capable of displaying JSON.

\section{basic Authentication}

The CrunchBase API uses token-based authentication, which means that developers must pass their individual user_key parameter with every request. An example request for the /organizations endpoint would read as follows:

Text .

https://api.crunchbase.com/v/3/organizations?user_key=[user_key]

This user_key is used to validate each developer's access to the API and ensure that any rate limits or quotas are respected.

If a developer omits the user_key, overruns a rate limit, or exceeds a quota, the system will respond with an error message.

Developers can learn about access to the API and requesting user_keys in the Getting Started section.

\section{basic Collections}

The CrunchBase API provides Collection endpoints to retrieve the entire set and core properties of many of the important Item types in the CrunchBase Dataset, as follows:

\begin{tabular}{|l|l|}
\hline Node Type & Endpoint \\
\hline Organization & /organizations \\
\hline Person & /people \\
\hline Product & /products \\
\hline Category & /categories \\
\hline Location & /locations \\
\hline
\end{tabular}

\section{basic Item Details}


Further, the CrunchBase API provides Item Detail endpoints to retrieve not only the core properties of each Node but also the details of related Items.

Such endpoints are available for the following Items:

\begin{tabular}{|l|l|}
\hline Node Type & Endpoint \\
\hline Organization & /organizations/:permalink \\
\hline Person & /people/:permalink \\
\hline Product & /products/:permalink \\
\hline FundingRound & /funding_rounds/:uuid \\
\hline Acquisition & /acquisitions/:uuid \\
\hline Ipo & /ipos/:uuid \\
\hline Fund & /funds/:uuid \\
\hline
\end{tabular}




\section{Organization}

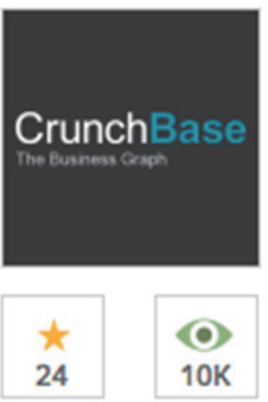

\section{Status}

UPDATE $\checkmark$

\section{Brand of $\mathrm{AOL}$}

Headquarters: San Francisco, CA

Description: CrunchBase is the world's most comprehensive dataset of startup activity and it's accessible to everyone.

Founders: Michael Arrington

Categories: Business Services, Finance, Startups, Technology, Curated Web

Website: http://www.crunchbase.com

\section{$f$ in}

An Organization, in CrunchBase, is a business. That generally means that it can employee People, receive Funding Rounds, launch Products, and have both Competitors and Customers.

Currently, Organizations can be one of the following types:

- Company

- Investment Firm / Group

- Group / Association

- School

Organizations can also "belong" to other Organizations. For example, CrunchBase is a Brand of AOL.

\section{basic Properties}

\begin{tabular}{|l|l|l|}
\hline property & type & description \\
\hline permalink & String & unique identifier within "Organization" namespace \\
\hline api_path & Path & \\
\hline web_path & Path & \\
\hline name & String & User-friendly name (as presented on CrunchBase) \\
\hline also_known_as & Array of String & Aliases and previous names \\
\hline short_description & String & $<=140$ characters \\
\hline description & String & Long description. \\
\hline primary_role & String & "company","investor","school", "group" \\
\hline role_company & Boolean & Does this Organization act as a Company? \\
\hline
\end{tabular}




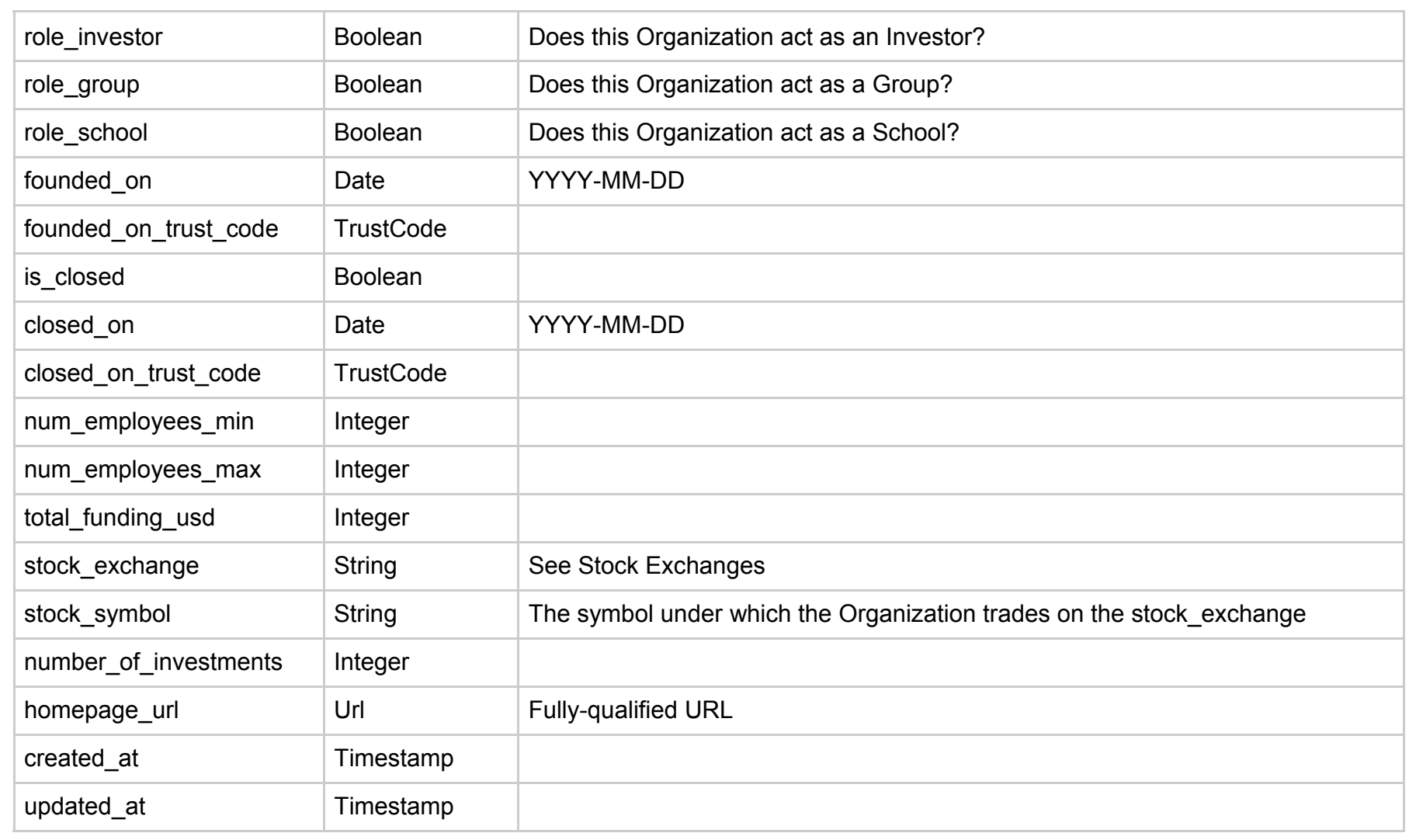

\section{basic Relationships}

\begin{tabular}{|c|c|c|}
\hline primary_image & one-to-one & Image \\
\hline current_team & one-to-many & Job \\
\hline past_team & one-to-many & Job \\
\hline investors & many-to-many & Organization or Person \\
\hline owned_by & many-to-one & Organization \\
\hline sub_organizations & one-to-many & Organization \\
\hline categories & many-to-many & Category \\
\hline customers & many-to-many & Organization \\
\hline
\end{tabular}




\begin{tabular}{|l|l|l|}
\hline competitors & many-to-many & Organization \\
\hline members & many-to-many & Organization or Person \\
\hline memberships & many-to-one & Organization \\
\hline funding_rounds & one-to-many & FundingRound \\
\hline investments & one-to-many & Investorlnvestment \\
\hline acquisitions & one-to-many & Acquisition \\
\hline acquired_by & one-to-one & Organization \\
\hline ipo & one-to-one & Ipo \\
\hline funds & one-to-many & Fund \\
\hline websites & one-to-many & Website \\
\hline images & one-to-many & Image \\
\hline videos & one-to-many & Video \\
\hline news & many-to-many & News \\
\hline
\end{tabular}




\section{Person}

A Person in CrunchBase is a real person in the business world. People can have Jobs, Degrees, participate in Events, and invest in Funding Rounds (thereby investing in /organizations).

A Person can be an Investor and takes on that role if (s)he has participated in a Funding Round.

\section{Primary Location}

Each Person optionally has a "Primary Location". This is the Location with which that Person is most commonly associated. For example, Ron Conway is most commonly linked with San Francisco, CA.

\section{Primary Role}

People have what are called "Primary Roles". These are the Jobs or positions (Board Memberships / Advisorships) with which People are most commonly associated. A good example of this is Ron Conway. Although Ron sits on the board of literally dozens of Companies, his Primary Role is Founder @ SV Angel.

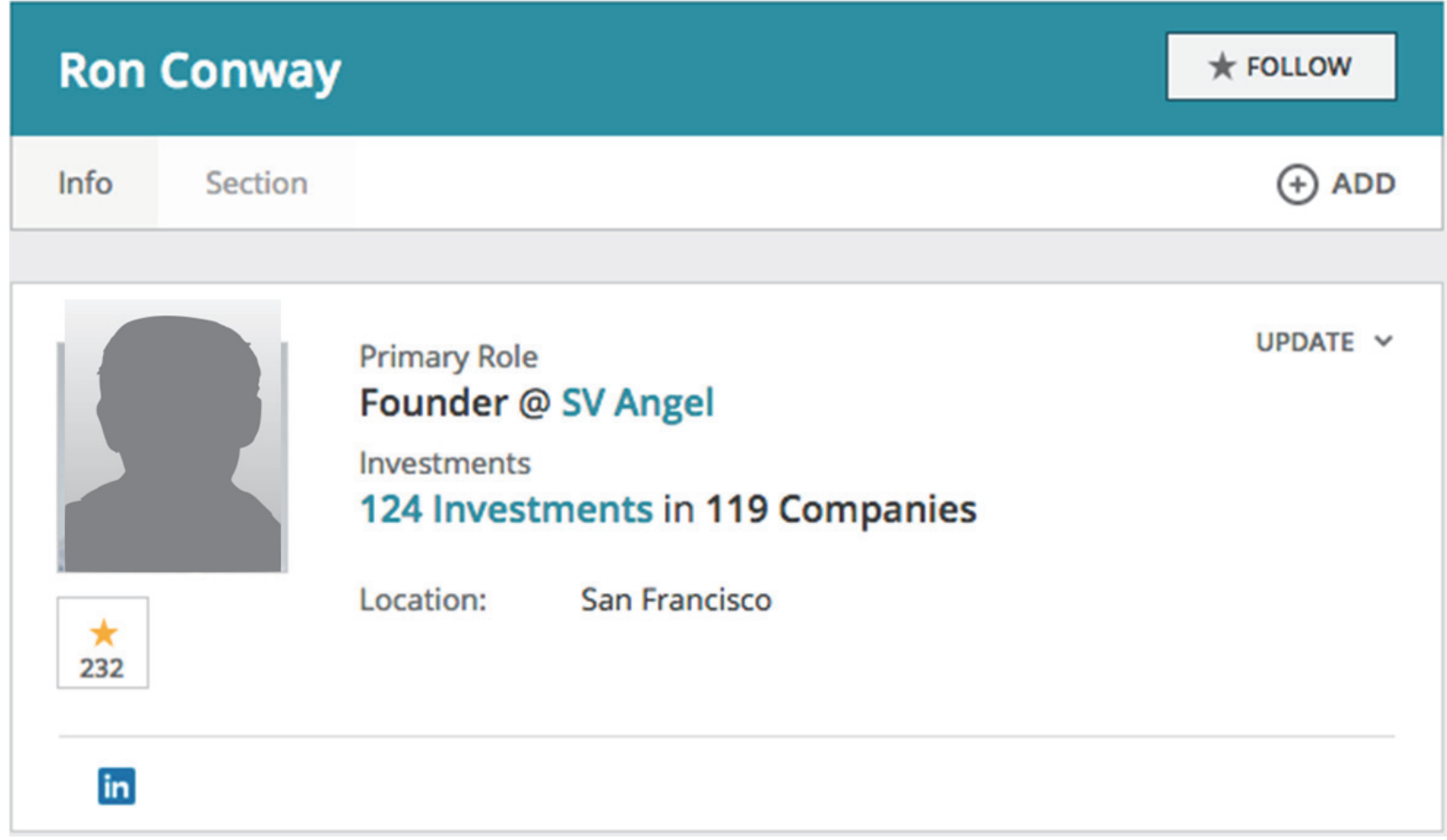

\section{basic Properties}




\begin{tabular}{|c|c|c|}
\hline permalink & String & \\
\hline first_name & String & \\
\hline also_known_as & Array of String & $\begin{array}{l}\text { Aliases / Past Names } \\
\text { omitted when item is a related Entity }\end{array}$ \\
\hline bio & $\begin{array}{l}\text { String } \\
\text { omitted when a related Entity }\end{array}$ & \\
\hline is_deceased & Boolean & \\
\hline died_on & Date & \\
\hline died_on_trust_code & TrustCode & \\
\hline created_at & Timestamp & \\
\hline updated_at & Timestamp & \\
\hline
\end{tabular}

\section{basic Relationships}

\begin{tabular}{|c|c|c|}
\hline name & cardinality & type \\
\hline primary_image & one-to-one & Image \\
\hline websites & one-to-many & Website \\
\hline jobs & one-to-many & Job \\
\hline advisory_roles & one-to-many & Job \\
\hline founded_companies & one-to-many & Organization \\
\hline images & one-to-many & Image \\
\hline videos & one-to-many & Video \\
\hline
\end{tabular}


News

Appendix, Page 146 


\section{Product}

A Product in CrunchBase is most often a piece of software or a website. Products are owned by Organizations.

\section{basic Properties}

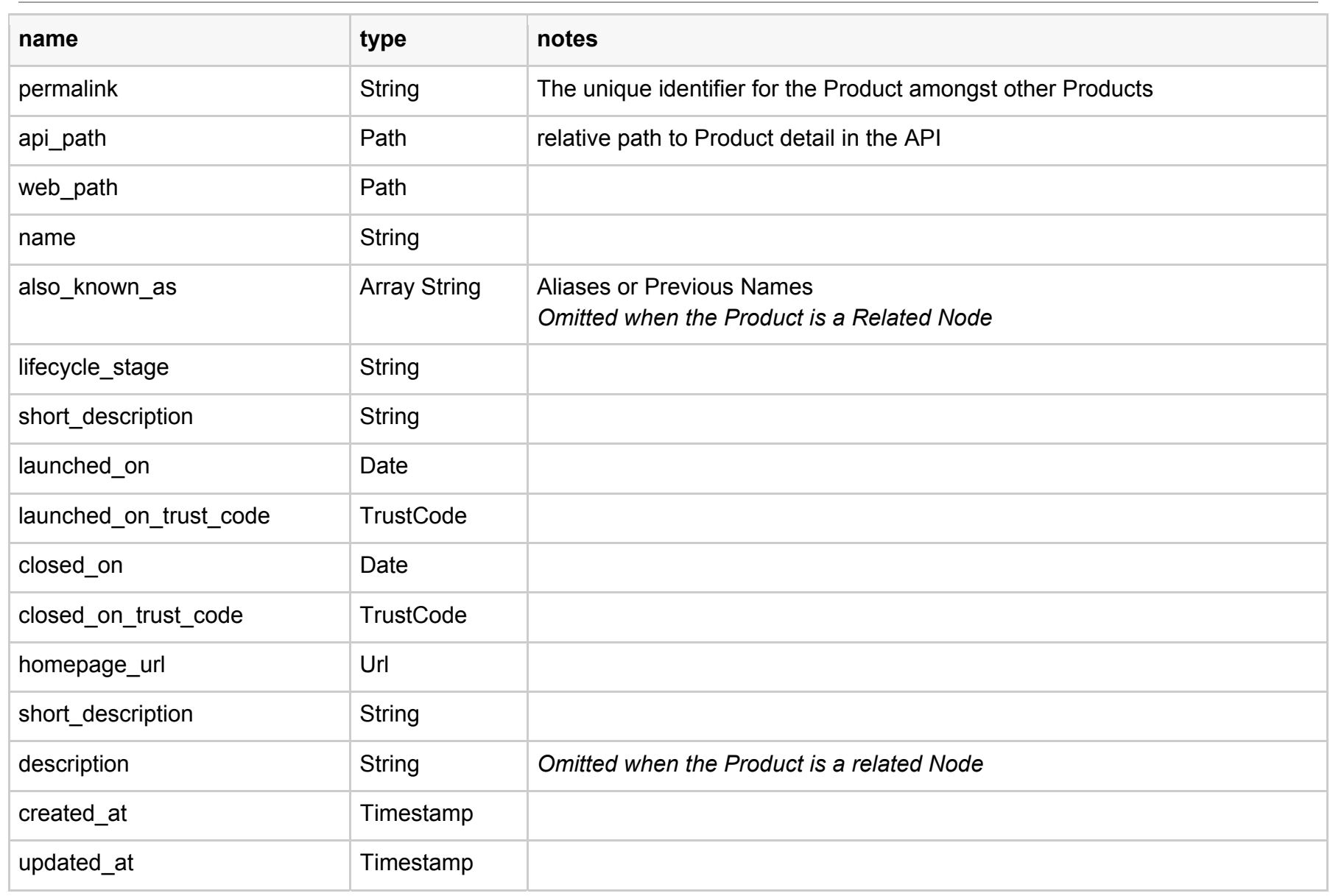

\section{basic Relationships}

\begin{tabular}{|l|l|l|}
\hline name & cardinality & type \\
\hline owner & many-to-one & Organization \\
\hline categories & many-to-many & Category \\
\hline primary_image & one-to-one & Image \\
\hline competitors & many-to-many & Product \\
\hline
\end{tabular}




\begin{tabular}{|l|l|l|}
\hline customers & many-to-many & Organization \\
\hline websites & one-to-many & Website \\
\hline images & one-to-many & Image \\
\hline video & one-to-many & Video \\
\hline news & many-to-many & News \\
\hline
\end{tabular}




\section{Category}

Organizations can be attached to one or more Categories. The properties of a Category are as follows:

\begin{tabular}{|l|l|l|}
\hline property & type & description \\
\hline path & Path & The relative path at which to retrieve the details of the Category \\
\hline name & String & The user-friendly name of the Category \\
\hline organizations_in_category & Integer & Number of Organizations in this Category \\
\hline products_in_category & Integer & Number of Products in this Category \\
\hline created_at & Timestamp & When the Category was added to CrunchBase \\
\hline updated_at & Timestamp & When the Category was last updated \\
\hline
\end{tabular}




\section{Location}

A Location is a geographic place. The finest-grained Location is a City. The coarsest grained Location is a Continent.

\section{basic Properties}

\begin{tabular}{|l|l|l|}
\hline property & type & notes \\
\hline web_path & Path & \\
\hline name & String & \\
\hline location_type & String & "city", "region", "country" \\
\hline parent_location_uuid & UUID & Returned only on the /locations endpoint \\
\hline created_at & Timestamp & \\
\hline updated_at & Timestamp & \\
\hline
\end{tabular}

\section{basic Relationships}

\begin{tabular}{|l|l|l|}
\hline name & cardinality & type \\
\hline parent_locations & one-to-many & Location \\
\hline
\end{tabular}


Distribution of firms by industry (scatter plots of latitude-longitude combinations)

\section{Scatter plots of firms coordinates by industry}
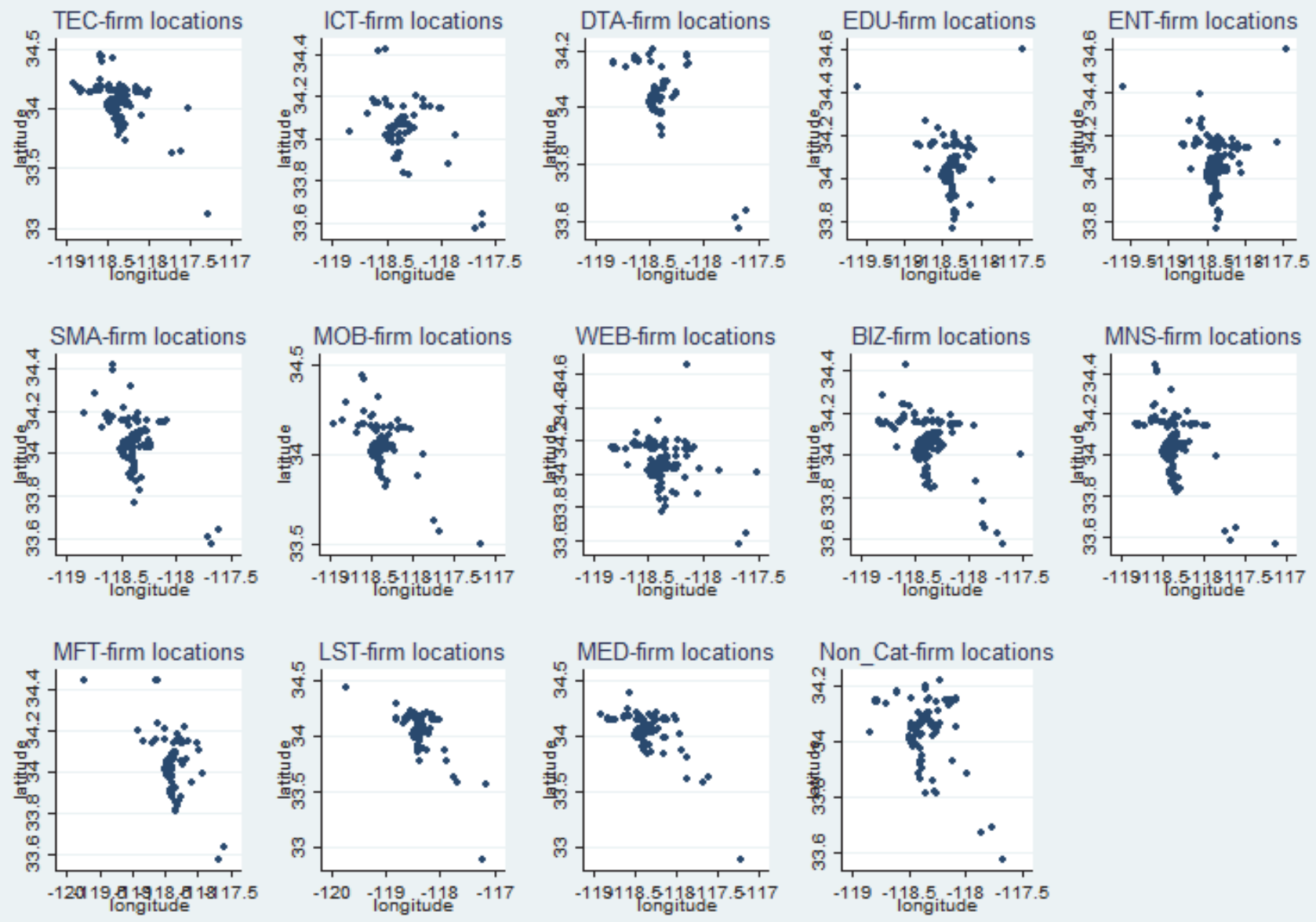


\section{Stems, Leafs and Mode Estimates for industry longitudes Technology - Mobile sectors}

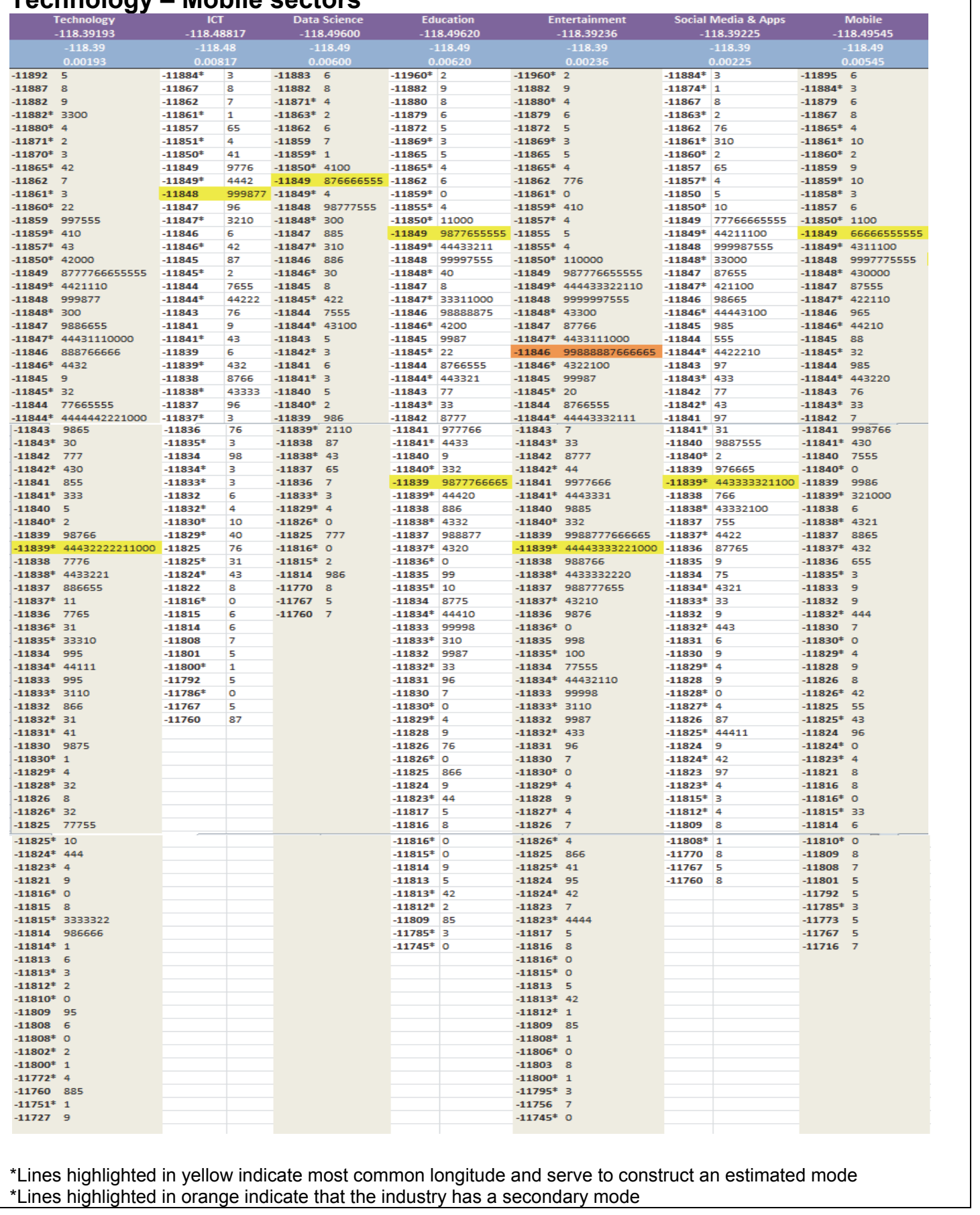




\begin{tabular}{|c|c|c|c|c|c|c|c|c|c|c|c|}
\hline \multicolumn{12}{|c|}{$\begin{array}{l}\text { Stems, Leafs and Mode Estimates } \\
\text { Web - No Category sectors }\end{array}$} \\
\hline \multirow{2}{*}{\multicolumn{2}{|c|}{$\begin{array}{l}\text { Web } \\
-118.49646\end{array}$}} & \multirow{2}{*}{\multicolumn{2}{|c|}{$\begin{array}{l}\text { Business Support } \\
-118.49200\end{array}$}} & \multirow{2}{*}{\multicolumn{2}{|c|}{$\begin{array}{l}\text { Marketing \& Sales } \\
-118.49567\end{array}$}} & \multirow{2}{*}{$\begin{array}{l}\text { Manufacturing } \\
-118.44313\end{array}$} & & Lufestyle & Health \& Metical & & o category \\
\hline & & & & & & & & $\begin{array}{l}118.39217 \\
-118.39\end{array}$ & $\begin{array}{c}-118.39189 \\
-118.39\end{array}$ & & $\frac{118.44236}{-118.44}$ \\
\hline & 0.00646 & & & & & & & & & & \\
\hline$-11883^{*}$ & 1 & $-11883^{*}$ & & -11882 & 8 & $-11974 \quad 5$ & -11974 & 5 & $-11892 * 44$ & $-11884^{*}$ & \\
\hline $\begin{array}{l}-11882^{*} \\
-11880^{ \pm}\end{array}$ & ${ }_{41}$ & $-11882^{*}$ & & $-11882^{*}$ & & -118925 & $-11882^{*}$ & 0 & $\begin{array}{l}-11883^{*} \\
-11987\end{array}$ & -11879* & ${ }^{*} 33$ \\
\hline $\begin{array}{l}-11880^{*} \\
-11879\end{array}$ & $\frac{41}{6}$ & $\begin{array}{l}-11880 \\
-11880^{*}\end{array}$ & & $\begin{array}{l}-111880^{*} \\
-11879\end{array}$ & $\begin{array}{l}3 \\
6\end{array}$ & $\begin{array}{l}-1188 z^{2} \circ \\
-11870 * 43\end{array}$ & -11881 & $=\frac{9}{2}$ & 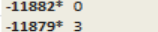 & -11878 & 8 \\
\hline$-11878^{*}$ & 4 & -11879 & & -11878 & 5 & $\begin{array}{l}-118764^{*}=4 \\
-64\end{array}$ & $\begin{array}{l}-11880^{*} \\
-11879\end{array}$ & $\frac{2}{6}$ & $\begin{array}{l}-11879^{*} 3 \\
-11876^{*} 421\end{array}$ & $\begin{array}{l}-11877 \\
-11870\end{array}$ & 66 \\
\hline$-11870^{*}$ & & $-11878^{*}$ & & -11877 & 9 & $-11863^{*} 1$ & -11867 & $\begin{array}{l}6 \\
8\end{array}$ & $-11874^{*} 20$ & -11860 & 5 \\
\hline$-11869^{*}$ & & -11877 & & $-11871^{*}$ & 4 & $-11860^{*} 4$ & -11865 & 7 & -11863 6 & - & $* 2$ \\
\hline$-11863^{*}$ & & -11875 & & $-11864^{*}$ & 4 & و99 & $-11864^{*}$ & & -118627 & $-11850^{*}$ & 100 \\
\hline-11862 & 76 & $-11871^{*}$ & & $-11863^{*}$ & 2 & $-11850^{*} 1$ & -11862 & 6 & $-11860^{*} 2$ & -11849 & 98655555 \\
\hline-11860 & 6 & -11867 & & -11862 & 6 & $-11849 \quad 7765$ & $-11859^{*}$ & 10 & -118597 & $-11849^{*}$ & 30 \\
\hline$-11859 *$ & 10 & $-11866^{*}$ & & $-11861^{*}$ & 0 & $-11849 * 210$ & $-11857^{*}$ & 2 & $-11858 \quad 6$ & -11848 & \\
\hline $\begin{array}{l}-11857 \\
-11957\end{array}$ & 5 & $-11865^{*}$ & & -11860 & 6 & $\begin{array}{ll}-11848 & 999777\end{array}$ & $-11855^{*}$ & 4 & $-11857 * 42$ & $-11847^{*}$ & $=3000$ \\
\hline $\begin{array}{l}-11851 \\
-11850^{*}\end{array}$ & 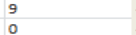 & $\begin{array}{l}-11864^{*} \\
-11863\end{array}$ & & - $11860^{*}$ & 22 & $\begin{array}{l}-11848^{*} \\
-11897\end{array}$ & $-11850^{*}$ & $=1100$ & $\begin{array}{l}-118565 \\
-11880^{*} \\
-10\end{array}$ & - -11846 & 9966 \\
\hline $\begin{array}{l}-11880^{*} \\
-11849 \\
\text { a }\end{array}$ & $\begin{array}{l}0 \\
8877777765555\end{array}$ & $\begin{array}{l}-11863 \\
-11862\end{array}$ & & $\begin{array}{l}-11859 \\
-11859^{*}\end{array}$ & $\begin{array}{l}95 \\
410\end{array}$ & $\begin{array}{l}-11847885 \\
-11847=44311000\end{array}$ & $\begin{array}{l}-11849 \\
-11849^{*}\end{array}$ & $\begin{array}{l}9777766555 \\
444410\end{array}$ & $\begin{array}{l}-11150^{*} \\
-11849\end{array}$ & $\begin{array}{l}-11884^{*} \\
-11845\end{array}$ & 400 \\
\hline -11849" & & $-11861^{*}$ & & & & $\begin{array}{l}-11846=44311000 \\
-1180\end{array}$ & $\begin{array}{l}-11849^{\circ} \\
-11848\end{array}$ & 999977 & & - -118844 & \\
\hline-11848 & 999877775 & -11860 & & $\begin{array}{l}-11857 \\
-11851\end{array}$ & 6655 & $\begin{array}{l}-11846^{*} \\
-11845^{*} \\
422\end{array}$ & $\begin{array}{l}-11848 \\
-11848^{*}\end{array}$ & 33007 & $\begin{array}{l}-11849 * 0 \\
-11848 \quad 977\end{array}$ & - $118844^{*}$ & $=4463533222111$ \\
\hline$-11848^{*}$ & 4320 & $-11860^{*}$ & & $-11850^{*}$ & 111000 & -1184495 & -11847 & 88655 & $-11848^{*} 0$ & - 11843 & \\
\hline-11847 & 8887766555 & -11859 & & -11849 & 998777777766555000 & $-11844=44444320$ & $-11847^{*}$ & 433322110000 & $-11847 \quad 9985$ & $-11842^{*}$ & \\
\hline$-11847^{*}$ & 4100000000 & $-11857^{*}$ & & $-11849^{*}$ & 443000 & $\begin{array}{ll}-11843 \quad 87 \\
\end{array}$ & -11846 & 99886 & $-11847^{*} 210$ & -11841 & 888876555 \\
\hline-11846 & 99887666665 & $-11855^{*}$ & & -11848 & 9999977777755555 & $-11843^{*} 43$ & $-11846^{*}$ & 4330 & $-11846 \quad 9888$ & $-11841^{*}$ & 441 \\
\hline $\begin{array}{l}-11846^{*} \\
-x_{1185}\end{array}$ & $\begin{array}{l}4322100 \\
99985\end{array}$ & $\begin{array}{l}-11850^{*} \\
-11849\end{array}$ & $\begin{array}{l}410000 \\
86555\end{array}$ & . & $\begin{array}{l}32000 \\
988887776\end{array}$ & $\begin{array}{ll}-11842 & 7 \\
-11901 & 79\end{array}$ & -11845 & 985 & $-11846^{*} 4$ & -11840 & 876 \\
\hline $\begin{array}{l}-11845 \\
-11845^{*} \\
\text { - }\end{array}$ & $\begin{array}{l}99985 \\
44420\end{array}$ & $\begin{array}{l}-11849 \\
-11849^{*}\end{array}$ & $\begin{array}{l}866555 \\
4442110\end{array}$ & $\begin{array}{l}-11847 \\
-11847^{*}\end{array}$ & $\begin{array}{l}9888887776 \\
3221000\end{array}$ & $\begin{array}{l}-11841 \\
-11844^{*} \\
-43 \\
43\end{array}$ & $-11845^{*}$ & 42211 & $\begin{array}{l}-11845 \quad 775 \\
-11844 \\
76655\end{array}$ & $-11840^{*}$ & $=322$ \\
\hline $\begin{array}{l}-11885^{*} \\
-11844\end{array}$ & $\begin{array}{l}44420 \\
98766665555\end{array}$ & $\begin{array}{l}-118499^{\circ} \\
-11848\end{array}$ & $\begin{array}{l}4442110 \\
99998775\end{array}$ & $\begin{array}{l}-11887^{*} \\
-11846\end{array}$ & $\begin{array}{l}3221000 \\
988866655\end{array}$ & $\begin{array}{l}-118184=43 \\
-11840\end{array}$ & $\begin{array}{l}-11844 \\
-11844^{*}\end{array}$ & 8855 & $\begin{array}{l}-11844 \\
-11844^{*} \\
73320 \\
3325\end{array}$ & $\begin{array}{l}-11839 \\
-11839^{*}\end{array}$ & $\begin{array}{l}98765 \\
4 \\
42222210\end{array}$ \\
\hline - & 4444332220 & $-11848^{*}$ & $\begin{array}{l}94300 \\
4400\end{array}$ & $\begin{array}{l}-111846^{*} \\
-1846\end{array}$ & 43332222000 & $-11840^{*} 21$ & - & 97776 & $-11843^{*} 321$ & - & 82655 \\
\hline-11843 & 99 & -11847 & $\begin{array}{l}44300 \\
9877655\end{array}$ & $\begin{array}{l}-111846^{\circ} \\
-11845\end{array}$ & $\begin{array}{l}433322222000 \\
998555\end{array}$ & $\begin{array}{l}-11840^{*} \\
-11839\end{array} 766$ & $\begin{array}{l}-11848 \\
-11843^{*}\end{array}$ & 433 & $\begin{array}{l}-11840^{*} \\
-11842 \quad 6\end{array}$ & - $-118388^{*}$ & $=311$ \\
\hline-11842 & 87 & $-11847^{*}$ & 432111000 & $-11845^{*}$ & 442211 & $-11839 * 44432221$ & -11842 & 87 & $-11841 \quad 96$ & $-11837^{*}$ & 3 \\
\hline$-11842^{*}$ & 44432 & -11846 & 886666665 & -11844 & 8665555 & -118385 & $-11842^{*}$ & 4420 & $-11841^{*}{ }^{1}$ & - $-11835^{*}$ & $=2$ \\
\hline-11841 & 8665 & $-11846^{*}$ & 4432220 & $-11844^{*}$ & 4444444332210 & $-11838^{*} 2$ & -11841 & 9986666 & $\begin{array}{lll}-11840 & 5\end{array}$ & -11834 & 98 \\
\hline$-11841^{*}$ & 210 & -11845 & 8855 & -11843 & 977 & $\begin{array}{lll}-11837 & 97\end{array}$ & $-11841^{*}$ & 32 & -118396 & $-11834^{*}$ & 30 \\
\hline-11840 & 97755 & $-11845^{*}$ & 4221 & $-11843^{*}$ & 43330 & $-11837^{*} 3$ & -11840 & 95555 & $-11839 \div 443221100$ & -11833 & 887 \\
\hline - $-11840^{*}$ & 2 & -11844 & 887655555555 & - 11842 & 976 & $\begin{array}{l}-1183696 \\
-118365\end{array}$ & $-11840^{*}$ & 4400 & $\begin{array}{l}-1183897 \\
-118385 \\
-32\end{array}$ & $-11833^{*}$ & $=4$ \\
\hline -11839 & $\begin{array}{l}9966 \\
4443332221100\end{array}$ & $\begin{array}{l}-11844^{*} \\
-{ }_{-11843}\end{array}$ & $\begin{array}{l}{ }_{96444443333200} \\
\text { 465 }\end{array}$ & $\begin{array}{l}-11881 \\
-11841^{*}\end{array}$ & $\begin{array}{l}9987766666 \\
320\end{array}$ & $\begin{array}{ll}-11836^{*} & 1 \\
-1185^{*} & 2\end{array}$ & $\begin{array}{l}-11839 \\
-11839^{*}\end{array}$ & $\begin{array}{l}876666655 \\
44443220000\end{array}$ & $\begin{array}{l}-11838^{*} 32 \\
-118378666\end{array}$ & $\begin{array}{l}-11832 \\
-11832\end{array}$ & 65 \\
\hline $\begin{array}{l}-11899^{*} \\
-11838 \\
\end{array}$ & 8443332221100 & $\begin{array}{l}-11843 \\
-11842\end{array}$ & $\begin{array}{l}965 \\
87\end{array}$ & $\begin{array}{l}-111881^{*} \\
-11840\end{array}$ & $\begin{array}{l}320 \\
97555\end{array}$ & $\begin{array}{ll}-118355^{*} & 2 \\
-11834 & 99\end{array}$ & $\begin{array}{l}-11839^{*} \\
-11838\end{array}$ & $\begin{array}{l}444433220000 \\
65\end{array}$ & $\begin{array}{l}-11837 \quad 8666 \\
-11836\end{array}$ & $\begin{array}{l}-11831 \\
-{ }_{-11380^{*}}\end{array}$ & $=\frac{9}{3}$ \\
\hline $\begin{array}{l}-11838 \\
-1188^{*}\end{array}$ & 444333221 & $\begin{array}{l}-11842 \\
-11841\end{array}$ & 998766666655 & $\begin{array}{l}-1118400^{*} \\
-118\end{array}$ & $\begin{array}{l}9755 \\
2100\end{array}$ & $\begin{array}{l}-118544^{4}=49 \\
-6\end{array}$ & $\begin{array}{l}-118388 \\
-11838^{*}\end{array}$ & 4322110 & $-11835^{*}=3$ & $\begin{array}{l}-11880^{*} \\
-11829^{*}\end{array}$ & $=200$ \\
\hline - 11837 & 987655 & $-11841^{*}$ & 42 & - & 966666555 & $\begin{array}{l}-1183434 \\
-11833 \\
-9\end{array}$ & $\begin{array}{l}-118387^{-18} \\
-1837\end{array}$ & $\begin{array}{l}4922110 \\
99888765\end{array}$ & $\begin{array}{ll}-118354 & 3 \\
-11834 & 88\end{array}$ & - & $\frac{200}{6}$ \\
\hline$-11837^{*}$ & 3211 & -11840 & 55 & $-11839^{*}$ & 444432221100 & $-11833^{*}$ зо & $-11837^{*}$ & 32210 & -118337 & $-11827^{*}$ & 22 \\
\hline-11836 & 88765 & $-11840^{*}$ & & -11838 & 9886655 & -11832986 & -11836 & 88765 & $-11833^{*}$ 。 & $-11826^{*}$ & 30 \\
\hline$-11836^{*}$ & 2 & -11839 & 999888766655 & $-11838^{*}$ & 4433322221110 & $-11831^{*} 4$ & -11835 & 999 & $-11832^{*} 44$ & -11825 & 7655 \\
\hline $\begin{array}{l}-11835 \\
-1190250\end{array}$ & 9 & $-11839^{*}$ & 4443322222111100 & -11837 & 9888877665 & -118309 & $-11835^{*}$ & 0 & -118317 & $-11825^{*}$ & F 4433222 \\
\hline$-11835^{*}$ & 40 & -11838 & 87766 & $-11837^{*}$ & 43 & $-11828 * 2$ & - 11834 & 985 & $-11831^{*} 1$ & -11824 & 6 \\
\hline $\begin{array}{l}-11834 \\
-\int_{11833^{*}}\end{array}$ & $\begin{array}{l}5 \\
4441\end{array}$ & $\begin{array}{l}-11838^{*} \\
-11837\end{array}$ & $\begin{array}{l}433221 \\
865\end{array}$ & $\begin{array}{l}-11836 \\
-11836^{*}\end{array}$ & 9998766655 & $\begin{array}{l}-11825 \quad 8855 \\
-11822^{*}\end{array}$ & - $11834^{*}$ & 44422 & $\begin{array}{l}-1183099 \\
-11830^{*} \\
-1\end{array}$ & 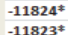 & $=3$ \\
\hline $\begin{array}{l}-11883^{*} \\
-11833 \\
\end{array}$ & $\begin{array}{l}4841 \\
885\end{array}$ & $\begin{array}{l}-11837 \\
-11837^{*}\end{array}$ & $\begin{array}{l}865 \\
4332\end{array}$ & $\begin{array}{l}-11886^{*} \\
-11835\end{array}$ & $\begin{array}{l}21 \\
99\end{array}$ & $\begin{array}{l}-118224=40 \\
-11823 \quad 5\end{array}$ & $\begin{array}{l}-11833 \\
-11832^{*}\end{array}$ & $=9440$ & 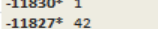 & $\begin{array}{l}-x_{-11822^{*}} \\
-x^{2}\end{array}$ & 1 \\
\hline - & 11 & -11836 & 9938877766655 & $\begin{array}{l}-118855 \\
-11835^{*}\end{array}$ & 4420 & $\begin{array}{l}-118235 \\
-11822 \\
9\end{array}$ & $\begin{array}{l}-111832^{*} \\
-11831\end{array}$ & 6440 & $\begin{array}{ll}-118277^{-} & 42 \\
-11826 & 75\end{array}$ & $\begin{array}{l}-11822^{*} \\
-{ }_{-11817}\end{array}$ & $\begin{array}{l}3 \\
7\end{array}$ \\
\hline - 11832 & 66 & $-11836^{*}$ & 2 & - 11834 & 95 & $\begin{array}{l}-11822 \\
-11820 \\
-6\end{array}$ & $\begin{array}{l}-11881 \\
-11830\end{array}$ & 5 & $\begin{array}{ll}-11826 \\
-11825\end{array} 6665$ & - & $=3$ \\
\hline$-11832^{*}$ & 4443 & -11835 & & $-11834^{*}$ & 44 & $-11818^{*} 2$ & $-11830^{*}$ & 1 & -11824 g & -11814 & \\
\hline-11830 & 6 & $-11835^{*}$ & & -11833 & 999887 & $\begin{array}{lll}-11815 & 8\end{array}$ & $-11828^{*}$ & 0 & $-11824^{*} 4$ & $-11814^{*}$ & 42220 \\
\hline$-11829^{*}$ & 4 & $-11834^{*}$ & 41 & -11832 & 998 & $-11815^{*} \quad 33333$ & -11826 & 5 & $-11822 \quad 88$ & -11813 & 7 \\
\hline-11827 & 7 & -11833 & 998 & $-11832^{*}$ & 444 & $-11814 \quad 9$ & -11825 & 986 & $-11821^{*} 4$ & -11811 & 8 \\
\hline$-11827^{*}$ & 4 & $-11833^{*}$ & 30 & -11831 & 6 & $\begin{array}{l}-11813^{*} 32 \\
-1180 \% 7\end{array}$ & $-11825^{*}$ & 43 & $\begin{array}{l}-11815 \quad 9865 \\
-1975\end{array}$ & $-11811^{*}$ & $=3$ \\
\hline $\begin{array}{l}-11825 \\
-11825^{*}\end{array}$ & 7765 & $\begin{array}{l}-11832 \\
-11832^{*}\end{array}$ & ${ }_{44}^{6}$ & $\begin{array}{l}-11830 \\
-118289^{*}\end{array}$ & 9 & $\begin{array}{l}-11808^{*} \text { o } \\
-11800^{*}\end{array}$ & $\begin{array}{l}-11824 \\
-11824^{*}\end{array}$ & $=9$ & $\begin{array}{l}-11815^{*} 433 \\
-11813^{*}\end{array}$ & $\begin{array}{l}-11808 \\
-11800^{*}\end{array}$ & $=65$ \\
\hline$-11825^{*}$ & $\begin{array}{l}311 \\
996 \\
996\end{array}$ & $\begin{array}{l}-11832^{*} \\
-11830\end{array}$ & $\begin{array}{l}44 \\
75\end{array}$ & $\begin{array}{l}-11829^{*} \\
-11227^{*}\end{array}$ & ${ }_{2}^{40}$ & $\begin{array}{l}-11800^{*} 11 \\
-11797^{*} \\
4\end{array}$ & $-11824^{*}$ & $=0$ & $\begin{array}{l}-11813^{*} \\
-11812^{*} \\
33\end{array}$ & $\begin{array}{l}-1180^{*} \\
-117799\end{array}$ & $=210$ \\
\hline - & 496 & 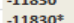 & 等 & . & 75 & (1) & .11823 & $=42$ & 年 & - & ${ }_{8}^{5}$ \\
\hline-11823 & 5 & -11828 & 88 & - 11825 & 975 & $\begin{array}{l}-11719674 \\
-117675\end{array}$ & $\begin{array}{l}-11823^{-1} \\
-1821\end{array}$ & ${ }_{9}^{42}$ & $\begin{array}{l}-118180^{*} \\
-1180 \\
-1\end{array}$ & - & $=0$ \\
\hline$-11823^{*}$ & 44 & $-11828^{*}$ & 11 & $-11825^{*}$ & 11 & -117605 & $-11818^{*}$ & & $-11800^{*} 2$ & -11767 & 5 \\
\hline-11822 & 98 & $-11827^{*}$ & & -11824 & 66 & & $-11816^{*}$ & $=0$ & -117959 & & \\
\hline$-11817^{*}$ & & -11826 & & $-11824^{*}$ & 430 & & -11815 & 86 & $-11792 \quad 5$ & & \\
\hline$-11816^{*}$ & & $-11826^{*}$ & & $-11823^{*}$ & 4 & & -11814 & 9 & $-11787^{*} 2$ & & \\
\hline-11815 & 8 & -11825 & 776 & $-11822^{*}$ & 0 & & $-11810^{*}$ & $=0$ & $-11786^{*} 2$ & & \\
\hline$-11815^{*}$ & 33310 & $-11825^{*}$ & 442 & $\begin{array}{l}-11821 \\
-11890\end{array}$ & 8 & & -11808 & 7 & -1176755 & & \\
\hline-11814 & 986 & $-11823^{*}$ & 4 & $\begin{array}{l}-11820 \\
-118181^{4}\end{array}$ & 9 & & $-11800^{*}$ & ${ }^{*} 1$ & $\begin{array}{l}-11760^{*} \\
-1172 *^{*}\end{array}$ & & \\
\hline $\begin{array}{l}-11811^{*} \\
-1183^{*}\end{array}$ & 321 & $\begin{array}{l}-11816 \\
-11816^{*}\end{array}$ & & $\begin{array}{l}-11811^{*} \\
-1185^{*}\end{array}$ & 3332 & & $\begin{array}{l}-117792 \\
-11786\end{array}$ & $\begin{array}{l}5 \\
6\end{array}$ & & & \\
\hline$-11812^{*}$ & 2 & -11815 & & -11814 & 86 & & -11773 & 5 & & & \\
\hline$-11810^{*}$ & 40 & $-11815^{*}$ & 33320 & $-11812^{*}$ & 1 & & -11767 & 5 & & & \\
\hline$-11808^{*}$ & 1 & -11814 & 99986 & $\begin{array}{l}-11810^{*} \\
-1180^{*}\end{array}$ & 0 & & $\begin{array}{l}-11721^{*} \\
-111713\end{array}$ & $\begin{array}{l}1 \\
7\end{array}$ & & & \\
\hline $\begin{array}{l}-1.1805 \\
-11803\end{array}$ & $\begin{array}{l}5 \\
8\end{array}$ & $\begin{array}{l}-11814^{*} \\
-11812^{*}\end{array}$ & & $\begin{array}{l}-11880^{*} \\
-11799^{*}\end{array}$ & $\frac{1}{2}$ & & & & & & \\
\hline$-11786^{*}$ & 0 & $-11810^{*}$ & & $-11795^{*}$ & 3 & & & & & & \\
\hline $\begin{array}{l}-11767 \\
-11760\end{array}$ & 55 & $\begin{array}{l}-11809 \\
-11807^{*}\end{array}$ & & $\begin{array}{l}-11785^{*} \\
-11773\end{array}$ & $\begin{array}{l}3 \\
5\end{array}$ & & & & & & \\
\hline$-11751^{*}$ & & $-11795^{*}$ & 3 & -11767 & 55 & & & & & & \\
\hline & & -11792 & 5 & -11760 & 7 & & & & & & \\
\hline & & $\begin{array}{l}-11786 \\
-11785\end{array}$ & ${ }_{9}^{6}$ & & & & & & & & \\
\hline & & -11784 & 9 & & & & & & & & \\
\hline & & - 11773 & 5 & & & & & & & & \\
\hline & & $\begin{array}{l}-11767 \\
-11751^{*}\end{array}$ & & & & & & & & & \\
\hline
\end{tabular}




\section{Stems, Leafs and Mode Estimates for industry latitudes, Technology - Mobile sectors}

\begin{tabular}{|c|c|c|c|c|c|c|c|c|c|c|c|c|}
\hline & $\begin{array}{c}\text { Technology } \\
34.01526\end{array}$ & & $\begin{array}{c}\text { ICT } \\
34.01731\end{array}$ & & $\begin{array}{c}\text { Data Science } \\
34.01747\end{array}$ & & $\begin{array}{l}\text { Education } \\
3401343\end{array}$ & & $\begin{array}{l}\text { Entertainment } \\
34,01238\end{array}$ & & $\begin{array}{l}\text { Social Media \& Apps } \\
3401367\end{array}$ & $\begin{array}{c}\text { Mobile } \\
34.01382\end{array}$ \\
\hline & $\begin{array}{l}34.01526 \\
34.01\end{array}$ & & $\begin{array}{l}34,01 / 31 \\
34.01\end{array}$ & & $\begin{array}{l}34.01 / 47 \\
34.01\end{array}$ & & $\begin{array}{l}34.01343 \\
34.01\end{array}$ & & $\begin{array}{l}34.01238 \\
34.01\end{array}$ & & $\begin{array}{c}34.01367 \\
34.01\end{array}$ & $\frac{34.01382}{34.01}$ \\
\hline & 0.00526 & & 0.00731 & & 0.00747 & & 0.00343 & & 0.00238 & & 0.00367 & 0.00382 \\
\hline 3311 & 7 & $3357^{*}$ & 4 & $3357^{*}$ & 4 & $3377^{*}$ & & $3377^{*}$ & & $3357^{*}$ & 4 & $3350^{*} 2$ \\
\hline 3362 & 6 & 3358 & 9 & 3360 & 9 & $3381^{*}$ & & $3381^{*}$ & & 3360 & 9 & $3357^{*} 4$ \\
\hline 3363 & 789 & 3363 & 9 & 3363 & 8 & $3383^{*}$ & 2 & $3383^{*}$ & & 3363 & 9 & 33627 \\
\hline 3373 & 8 & $3383^{*}$ & 0 & $3390^{*}$ & 13 & 3383 & 7 & $3384^{*}$ & & $3377^{*}$ & $=2$ & $3382^{*} 3$ \\
\hline $3377^{*}$ & 0 & 3383 & 8 & 3392 & 89 & $3384^{*}$ & 4 & 3384 & 5 & $3382^{*}$ & 4 & $3384 \quad 8$ \\
\hline 3381 & 56 & 3387 & 8 & $3393^{*}$ & & 3384 & 5 & $3385^{*}$ & 4 & $3387^{*}$ & 3 & $3387^{*} 3$ \\
\hline $3383^{*}$ & 4 & $3390^{*}$ & 13 & $3397^{*}$ & 4 & $3385^{*}$ & 4 & 3388 & 5 & 3388 & 56 & $3387 \quad 8$ \\
\hline 3383 & 57 & 3390 & 5 & 3397 & 7 & 3387 & 5 & $3390^{*}$ & * 123 & $3390^{*}$ & 12 & $3388 \quad 6$ \\
\hline $3384^{*}$ & 34 & 3392 & 8 & $3398^{*}$ & 1144 & $3390^{*}$ & 3 & 3390 & 559 & 3390 & 59 & $3390^{*} 11$ \\
\hline 3384 & 8 & $3393^{*}$ & 0 & 3398 & 589 & 3390 & 5 & 3391 & 788 & 3391 & 7 & $3390 \quad 5$ \\
\hline $3385^{*}$ & 2 & 3397 & 89 & $3399^{*}$ & 14 & 3391 & 788 & $3392^{*}$ & $* 1$ & 3392 & 99 & $3391 \quad 7$ \\
\hline 3385 & 8 & 3398 & 89 & 3399 & 89 & $3392^{*}$ & 1 & 3392 & 9 & $3393^{*}$ & 1 & $3394 \quad 6$ \\
\hline $3386^{*}$ & 0 & 3399 & 99 & $3400^{*}$ & 4 & 3392 & 9 & $3393^{*}$ & $=0$ & 3394 & 6 & $3395 \quad 8$ \\
\hline $3390^{*}$ & 24 & $3400^{*}$ & 0 & 3400 & 6 & $3393^{*}$ & 0 & $3394^{*}$ & $* 0$ & 3395 & 8 & $3397 * 4$ \\
\hline 3390 & 59 & 3400 & 6 & $3401^{*}$ & 12444 & $3394^{*}$ & 0 & 3394 & 66 & $3397^{*}$ & 4 & $3397 \quad 899$ \\
\hline $3391^{*}$ & 4 & $3401^{*}$ & 244 & 3401 & 555678888889999 & 3395 & 8 & 3395 & 8 & 3397 & 889 & $3398^{*} 114$ \\
\hline 3391 & 8999 & 3401 & 5677777888889 & $3402^{*}$ & 4 & 3396 & 6 & 3396 & 6 & $3398^{*}$ & 11234 & $3398 \quad 58$ \\
\hline $3392^{*}$ & 1 & $3402^{*}$ & 13 & 3402 & 77 & $3398^{*}$ & 22234 & $3397^{*}$ & 4 & 3398 & 88899 & $3399 * 1124$ \\
\hline $3393^{*}$ & 1 & 3402 & 667 & $3403^{*}$ & 1234 & 3398 & 578 & 3397 & 888 & $3399^{*}$ & 14 & $3399 \quad 5589$ \\
\hline 3394 & 67 & $3403^{*}$ & 114 & 3403 & 677 & $3399^{*}$ & 14 & $3398^{*}$ & 12223444 & 3399 & 8 & $3401^{*} 12344444$ \\
\hline $3397^{*}$ & 4 & $3404^{*}$ & 2 & $3404^{*} 2$ & 24 & 3399 & 589 & 3398 & 55789 & $3400^{*}$ & 3 & $3401 \quad 5557777888888880000000000000$ \\
\hline 3397 & 778899 & 3404 & 56677 & 3404 & 77799 & $3400^{*}$ & 344 & $3399^{*}$ & 1114 & 3400 & 779 & $3402^{*} 1134444$ \\
\hline $3398^{*}$ & 1111223 & $3405^{*}$ & 1234 & $3405^{*}$ & 3 & 3400 & 777 & 3399 & 89 & $3401^{*}$ & 13444 & $3402 \quad 6667888$ \\
\hline 3398 & 5568899 & 3405 & 678999 & 3405 & 67 & $3401^{*}$ & 14 & $3400^{*}$ & 34 & 3401 & 555566777778888000000000000 & $3403^{*} 4$ \\
\hline $3399^{*}$ & 3 & $3406^{*}$ & 12233 & $3406^{*}$ & 13 & 3401 & 5555666777777880000000000000 & 3400 & 777 & $3402^{*}$ & 4444 & $3403 \quad 67$ \\
\hline 3399 & 78 & 3406 & 777 & 3406 & 78 & $3402^{*}$ & 122334 & $3401^{*}$ & 1134 & 3402 & 5566688 & $3404^{*} 2223$ \\
\hline $3400^{*}$ & 3 & $3407^{*}$ & 34 & 3407 & 7 & 3402 & 666888 & 3401 & 5555556666677770000000000000000000000 & $3403^{*}$ & 11112222234 & $3404 \quad 57789$ \\
\hline 3400 & 567 & $3408^{*}$ & 1 & $3409^{*}$ & 12 & $3403^{*}$ & 12 & $3402^{*}$ & 12233444 & $3404^{*}$ & 224 & $3405^{*} 2444$ \\
\hline $3401^{*}$ & 134444444 & 3408 & 9 & 3413 & 9 & 3403 & 77 & 3402 & 5666667788888 & 3404 & 77899 & $3405 \quad 889$ \\
\hline 3401 & 5555567777888890000 & $3409^{*}$ & 11 & $3414^{*}$ & 24 & $3404^{*}$ & 222344444 & $3403^{*}$ & 1112223 & $3405^{*}$ & 2223444 & $3406^{*} 222334$ \\
\hline $3402^{*}$ & 223444 & 3409 & 89 & 3414 & 56 & 3404 & 557778889 & 3403 & 7 & 3405 & 788899 & $3406 \quad 79$ \\
\hline 3402 & 6678888 & $3410^{*}$ & 1 & $3415^{*}$ & 3 & $3405^{*}$ & 11112334 & $3404^{*}$ & 2222344444 & $3406^{*}$ & 1123344 & $3407^{*} 13$ \\
\hline $3403^{*}$ & 122234 & 3410 & 8 & 3415 & 67 & 3405 & 78888999 & 3404 & 55677777888999 & 3406 & 6778 & $3407 \quad 677$ \\
\hline 3403 & 69 & 3411 & 8 & $3416^{*}$ & 1 & $3406^{*}$ & 122222 & $3405^{*}$ & 111222334 & $3407^{*}$ & 134 & 34089 \\
\hline $3404^{*}$ & 2233344 & 3413 & 9 & 3416 & 57 & 3406 & 777888 & 3405 & 788888899 & 3407 & 6667 & $3409^{*} 123$ \\
\hline 3404 & 567777889 & $3414^{*}$ & 3 & 3417 & 9 & $3407^{*}$ & 134 & $3406^{*}$ & * 1111222222344 & $3408^{*}$ & 14 & 34098 \\
\hline $3405^{*}$ & 122222334 & $3415^{*}$ & 23 & $3418^{*}$ & 0 & 3407 & 666 & 3406 & 5777777888 & $3409^{*}$ & 111 & $3410 \quad 58$ \\
\hline 3405 & 567788899 & 3415 & 57 & 3418 & 67 & $3408^{*}$ & 1 & $3407^{*}$ & 1134 & 3409 & 689 & 34118 \\
\hline $3406^{*}$ & 112233 & 3416 & 99 & 3420 & 5 & 3408 & 689 & 3407 & 6666 & $3410^{*}$ & 2 & $3413^{*} 3$ \\
\hline 3406 & 77778 & 3418 & 667 & & & $3409^{*}$ & 1112 & $3408^{*}$ & 124 & 3410 & 58 & 34139 \\
\hline $3407^{*}$ & 224 & $3420^{*}$ & 3 & & & 3409 & 589 & 3408 & 6899 & $3411^{*}$ & 1 & $3414^{*} 0$ \\
\hline 3407 & 67 & 3441 & 7 & & & $3410^{*}$ & 122 & $3409^{*}$ & $=111122$ & 3411 & 8 & $3414 \quad 6666789$ \\
\hline $3408^{*}$ & 1 & 3442 & 6 & & & 3410 & 55 & 3409 & 5667889 & $3413^{*}$ & 3 & $3415^{*} 1223$ \\
\hline 3408 & 9 & & & & & $3411^{*}$ & 1 & $3410^{*}$ & * 1222 & 3414 & 55667 & $3415 \quad 557$ \\
\hline $3409^{*}$ & 33 & & & & & 3413 & 7 & 3410 & 559 & $3415^{*}$ & 234 & $3416^{*} 4$ \\
\hline 3409 & 5688889 & & & & & $3414^{*}$ & 0 & $3411^{*}$ & $* 1$ & 3415 & 5678 & $3416 \quad 77899$ \\
\hline $3410^{*}$ & 122222 & & & & & 3414 & 666799 & $3413^{*}$ & * 24 & $3416^{*}$ & 4 & $3417^{*} 1$ \\
\hline 3410 & 89 & & & & & $3415^{*}$ & 122344 & 3413 & 7 & 3416 & 56999 & $3418 \quad 78$ \\
\hline 3413 & 678899 & & & & & 3415 & 5556 & $3414^{*}$ & 23 & $3417^{*}$ & 1 & $3421^{*} 4$ \\
\hline $3414^{*}$ & 23444 & & & & & $3416^{*}$ & 3 & 3414 & 5666999 & 3417 & 9 & $3421 \quad 6$ \\
\hline 3414 & 56666666777889900 & & & & & 3416 & 579 & $3415^{*}$ & 122334444 & 3418 & 68 & $3424^{*} 3$ \\
\hline $3415^{*}$ & 112234 & & & & & $3417^{*}$ & 0 & 3415 & 556668 & $3419^{*}$ & 2 & $3428 \quad 5$ \\
\hline 3415 & 556666778 & & & & & 3417 & 8 & $3416^{*}$ & 34 & 3421 & 6 & 34318 \\
\hline 3416 & 557 & & & & & $3418^{*}$ & 0 & 3416 & 567799 & 3427 & 9 & $3441 \quad 7$ \\
\hline $3417^{*}$ & 14 & & & & & $3419^{*}$ & 2 & $3417^{*}$ & 0 & 3431 & 8 & $3444^{*} 2$ \\
\hline 3417 & 6 & & & & & $3420^{*}$ & 1 & 3417 & 8 & $3439^{*}$ & 2 & \\
\hline $3418^{*}$ & 0 & & & & & 3420 & 5 & $3418^{*}$ & 0 & 3441 & 7 & \\
\hline 3418 & 55666779 & & & & & $3423^{*}$ & 1 & 3418 & 6667 & & & \\
\hline $3419^{*}$ & 24 & & & & & 3426 & 6 & $3419^{*}$ & 22 & & & \\
\hline $3420^{*}$ & 3 & & & & & $3442^{*}$ & 2 & $3420^{*}$ & $* 1$ & & & \\
\hline 3423 & 99 & & & & & $3460^{*}$ & 2 & $3423^{*}$ & 1 & & & \\
\hline 3424 & 7 & & & & & & & 3424 & 7 & & & \\
\hline $3439^{*}$ & 2 & & & & & & & 3426 & 6 & & & \\
\hline 3442 & 7 & & & & & & & 3427 & 5 & & & \\
\hline $3443^{*}$ & 0 & & & & & & & $3439^{*}$ & 2 & & & \\
\hline $3444^{*}$ & 23 & & & & & & & $3442^{*}$ & & & & \\
\hline & & & & & & & & $3460^{*}$ & 2 & & & \\
\hline
\end{tabular}

*Lines highlighted in yellow indicate most common latitude and serve to construct an estimated mode

*Lines highlighted in orange indicate that the industry has a secondary mode 


\section{Stems, Leafs and Mode Estimates for industry latitudes, Web - No Category sectors}

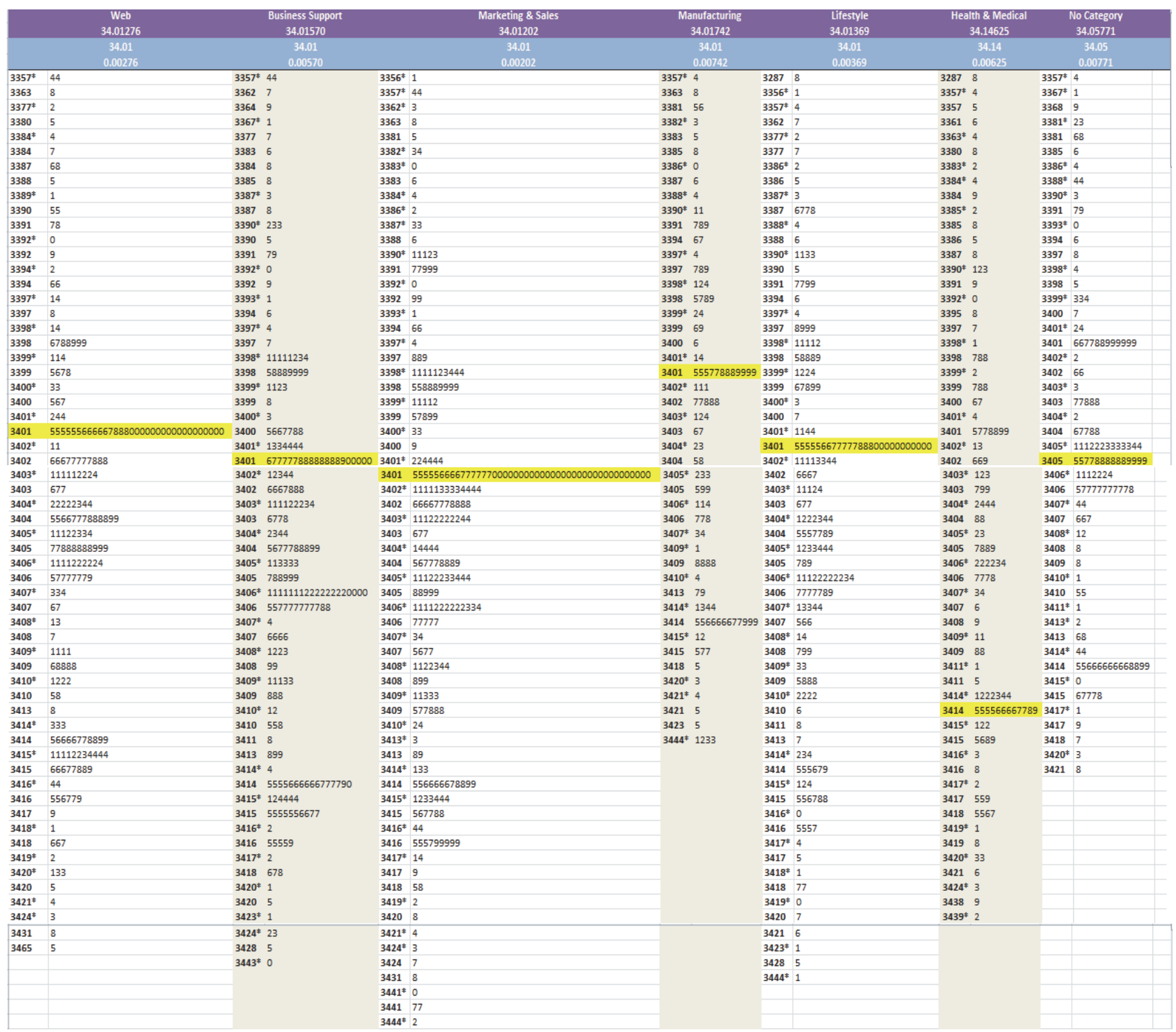

*Lines highlighted in yellow indicate most common latitude and serve to construct an estimated mode

* Lines highlighted in orange indicate that the industry has a secondary mode 
Industry spreads around mode centroids

\section{Histogram and Kernel distribution of distances from mode centroid estimate for all firms in a given industry}
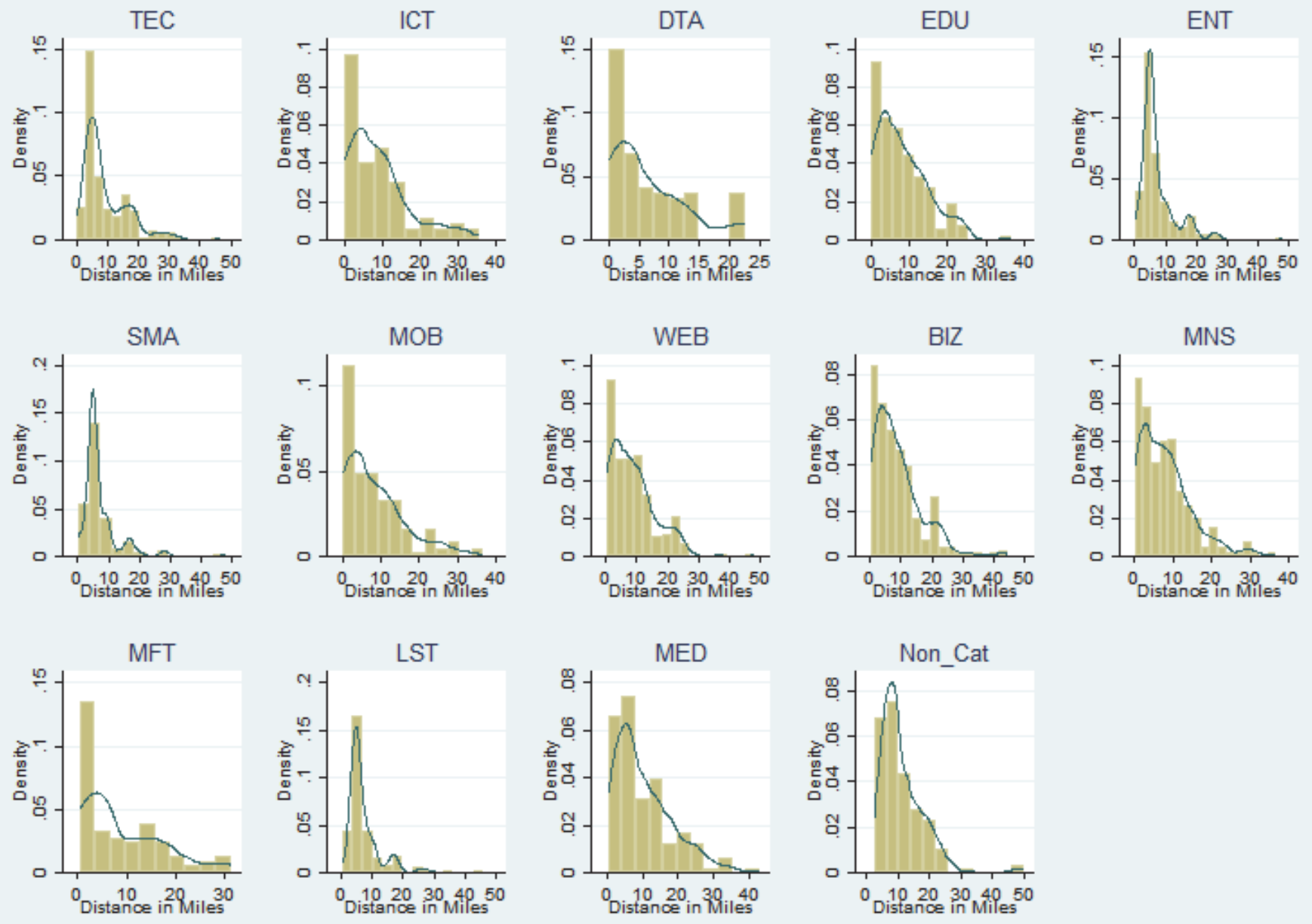


\section{Comparison of industry centroid measures}

\begin{tabular}{|c|c|c|c|c|c|c|c|c|c|c|c|c|c|c|c|}
\hline \multirow{3}{*}{ Industry } & \multirow{3}{*}{$\mathrm{n}=$} & \multicolumn{2}{|c|}{ Industry Centroid (Mean) } & \multicolumn{12}{|c|}{ Distances from Centroid } \\
\hline & & \multirow{2}{*}{ Latitude } & \multirow{2}{*}{ Longitude } & \multicolumn{2}{|c|}{$<1$ miles } & \multicolumn{2}{|c|}{$<5$ miles } & \multicolumn{2}{|c|}{ 5-10 miles } & \multicolumn{2}{|c|}{$10-15$ miles } & \multicolumn{2}{|c|}{ 15-20 miles } & \multicolumn{2}{|c|}{$>20$ miles } \\
\hline & & & & $\mathrm{n}$ & $\%$ & $\mathrm{n}$ & $\%$ & $\mathrm{n}$ & $\%$ & $\mathrm{n}$ & $\%$ & $\mathrm{n}$ & $\%$ & $\mathrm{n}$ & $\%$ \\
\hline Technology & 274 & 34.171001 & -118.523087 & 0 & $0.00 \%$ & 13 & $4.74 \%$ & 45 & $16.42 \%$ & 112 & $40.88 \%$ & 40 & $14.60 \%$ & 64 & $23.36 \%$ \\
\hline ICT & 101 & 34.205307 & -118.557152 & 0 & $0.00 \%$ & 4 & $3.96 \%$ & 3 & $2.97 \%$ & 46 & $45.54 \%$ & 19 & $18.81 \%$ & 29 & $28.71 \%$ \\
\hline Data Science & 93 & 34.10973 & -118.498665 & 0 & $0.00 \%$ & 6 & $6.45 \%$ & 58 & $62.37 \%$ & 14 & $15.05 \%$ & 4 & $4.30 \%$ & 11 & $11.83 \%$ \\
\hline Education & 200 & 34.137833 & -118.501579 & 0 & $0.00 \%$ & 5 & $2.50 \%$ & 109 & $54.50 \%$ & 39 & $19.50 \%$ & 23 & $11.50 \%$ & 24 & $12.00 \%$ \\
\hline Entertainment & 303 & 34.172447 & -118.521385 & 0 & $0.00 \%$ & 12 & $3.96 \%$ & 59 & $19.47 \%$ & 150 & $49.50 \%$ & 40 & $13.20 \%$ & 42 & $13.86 \%$ \\
\hline Social Media and Apps & 189 & 34.076855 & -118.447113 & 0 & $0.00 \%$ & 80 & $42.33 \%$ & 60 & $31.75 \%$ & 32 & $16.93 \%$ & 5 & $2.65 \%$ & 12 & $6.35 \%$ \\
\hline Mobile & 165 & 34.091324 & -118.448509 & 0 & $0.00 \%$ & 41 & $24.85 \%$ & 74 & $44.85 \%$ & 25 & $15.15 \%$ & 9 & $5.45 \%$ & 16 & $9.70 \%$ \\
\hline Web & 269 & 34.151363 & -118.310097 & 0 & $0.00 \%$ & 16 & $5.95 \%$ & 88 & $32.71 \%$ & 120 & $44.61 \%$ & 19 & $7.06 \%$ & 26 & $9.67 \%$ \\
\hline Business Support & 271 & 34.128319 & -118.487602 & 0 & $0.00 \%$ & 10 & $3.69 \%$ & 158 & $58.30 \%$ & 44 & $16.24 \%$ & 35 & $12.92 \%$ & 24 & $8.86 \%$ \\
\hline Marketing and Sales & 309 & 34.096798 & -118.298531 & 0 & $0.00 \%$ & 46 & $14.89 \%$ & 86 & $27.83 \%$ & 127 & $41.10 \%$ & 26 & $8.41 \%$ & 24 & $7.77 \%$ \\
\hline Manufacturing & 124 & 34.118027 & -118.471001 & 0 & $0.00 \%$ & 8 & $6.45 \%$ & 57 & $45.97 \%$ & 20 & $16.13 \%$ & 16 & $12.90 \%$ & 23 & $18.55 \%$ \\
\hline Lifestyle & 218 & 34.062279 & -118.431465 & 7 & $3.21 \%$ & 95 & $43.58 \%$ & 57 & $26.15 \%$ & 35 & $16.06 \%$ & 7 & $3.21 \%$ & 17 & $7.80 \%$ \\
\hline Medical and Health & 135 & 34.152546 & -118.481071 & 1 & $0.74 \%$ & 3 & $2.22 \%$ & 51 & $37.78 \%$ & 31 & $22.96 \%$ & 20 & $14.81 \%$ & 29 & $21.48 \%$ \\
\hline No Category & 151 & 34.161144 & -118.494591 & 1 & $0.66 \%$ & 0 & $0.00 \%$ & 67 & $44.37 \%$ & 25 & $16.56 \%$ & 28 & $18.54 \%$ & 30 & $19.87 \%$ \\
\hline
\end{tabular}

\begin{tabular}{|c|c|c|c|c|c|c|c|c|c|c|c|c|c|c|c|}
\hline \multirow{3}{*}{ Industry } & \multirow{3}{*}{$\mathbf{n}=$} & \multicolumn{2}{|c|}{ Industry Centroid (Median) } & \multicolumn{12}{|c|}{ Distances from Centroid } \\
\hline & & \multirow{2}{*}{ Latitude } & \multirow{2}{*}{ Longitude } & \multicolumn{2}{|c|}{$<1$ miles } & \multicolumn{2}{|c|}{$<5$ miles } & \multicolumn{2}{|c|}{ 5-10 miles } & \multicolumn{2}{|c|}{$10-15$ miles } & \multicolumn{2}{|c|}{$15-20$ miles } & \multicolumn{2}{|c|}{$>20$ miles } \\
\hline & & & & $\mathrm{n}$ & $\%$ & $\mathrm{n}$ & $\%$ & $\mathrm{n}$ & $\%$ & $\mathrm{n}$ & $\%$ & $\mathrm{n}$ & $\%$ & $\mathrm{n}$ & $\%$ \\
\hline Technology & 274 & 34.0513 & -118.4233 & 6 & $2.19 \%$ & 112 & $40.88 \%$ & 54 & $19.71 \%$ & 28 & $10.22 \%$ & 40 & $14.60 \%$ & 34 & $12.41 \%$ \\
\hline ICT & 101 & 34.0514 & -118.4358 & 10 & $9.90 \%$ & 40 & $39.60 \%$ & 15 & $14.85 \%$ & 14 & $13.86 \%$ & 6 & $5.94 \%$ & 16 & $15.84 \%$ \\
\hline Data Science & 93 & 34.0202 & -118.4537 & 3 & $3.23 \%$ & 54 & $58.06 \%$ & 12 & $12.90 \%$ & 10 & $10.75 \%$ & 5 & $5.38 \%$ & 9 & $9.68 \%$ \\
\hline Education & 200 & 34.0459 & -118.4173 & 8 & $4.00 \%$ & 99 & $49.50 \%$ & 45 & $22.50 \%$ & 19 & $9.50 \%$ & 16 & $8.00 \%$ & 13 & $6.50 \%$ \\
\hline Entertainment & 303 & 34.0483 & -118.4138 & 10 & $3.30 \%$ & 129 & $42.57 \%$ & 92 & $30.36 \%$ & 28 & $9.24 \%$ & 21 & $6.93 \%$ & 23 & $7.59 \%$ \\
\hline Social Media and Apps & 189 & 34.0323 & -118.4267 & 0 & $0.00 \%$ & 112 & $59.26 \%$ & 36 & $19.05 \%$ & 22 & $11.64 \%$ & 8 & $4.23 \%$ & 11 & $5.82 \%$ \\
\hline Mobile & 165 & 34.0273 & -118.4424 & 3 & $1.82 \%$ & 85 & $51.52 \%$ & 27 & $16.36 \%$ & 25 & $15.15 \%$ & 8 & $4.85 \%$ & 17 & $10.30 \%$ \\
\hline Web & 269 & 34.0493 & -118.4388 & 19 & $7.06 \%$ & 120 & $44.61 \%$ & 51 & $18.96 \%$ & 30 & $11.15 \%$ & 25 & $9.29 \%$ & 24 & $8.92 \%$ \\
\hline Business Support & 271 & 34.0530 & -118.4267 & 11 & $4.06 \%$ & 129 & $47.60 \%$ & 54 & $19.93 \%$ & 25 & $9.23 \%$ & 24 & $8.86 \%$ & 28 & $10.33 \%$ \\
\hline Marketing and Sales & 309 & 34.0323 & -118.4332 & 4 & $1.29 \%$ & 167 & $54.05 \%$ & 62 & $20.06 \%$ & 35 & $11.33 \%$ & 17 & $5.50 \%$ & 24 & $7.77 \%$ \\
\hline Manufacturing & 124 & 34.0420 & -118.4133 & 0 & $0.00 \%$ & 58 & $46.77 \%$ & 19 & $15.32 \%$ & 12 & $9.68 \%$ & 18 & $14.52 \%$ & 17 & $13.71 \%$ \\
\hline Lifestyle & 218 & 34.0414 & -118.4158 & 4 & $1.83 \%$ & 120 & $55.05 \%$ & 46 & $21.10 \%$ & 21 & $9.63 \%$ & 12 & $5.50 \%$ & 15 & $6.88 \%$ \\
\hline Medical and Health & 135 & 34.0619 & -118.3936 & 4 & $2.96 \%$ & 35 & $25.93 \%$ & 36 & $26.67 \%$ & 21 & $15.56 \%$ & 12 & $8.89 \%$ & 27 & $20.00 \%$ \\
\hline No Category & 151 & 34.0581 & -118.3987 & 15 & $9.93 \%$ & 43 & $28.48 \%$ & 47 & $31.13 \%$ & 10 & $6.62 \%$ & 21 & $13.91 \%$ & 15 & $9.93 \%$ \\
\hline
\end{tabular}

\begin{tabular}{|c|c|c|c|c|c|c|c|c|c|c|c|c|c|c|c|}
\hline \multirow{3}{*}{ Industry } & \multirow{3}{*}{$\mathbf{n}=$} & \multicolumn{2}{|c|}{ Industry Centroid (Mode) } & \multicolumn{12}{|c|}{ Distances from Centroid } \\
\hline & & \multirow{2}{*}{ Latitude } & \multirow{2}{*}{ Longitude } & \multicolumn{2}{|c|}{$<1$ miles } & \multicolumn{2}{|c|}{$<5$ miles } & \multicolumn{2}{|c|}{$5-10$ miles } & \multicolumn{2}{|c|}{$10-15$ miles } & \multicolumn{2}{|c|}{$15-20$ miles } & \multicolumn{2}{|c|}{$>20$ miles } \\
\hline & & & & $\mathrm{n}$ & $\%$ & $\mathrm{n}$ & $\%$ & $\mathrm{n}$ & $\%$ & $\mathrm{n}$ & $\%$ & $\mathrm{n}$ & $\%$ & $\mathrm{n}$ & $\%$ \\
\hline Technology & 274 & 34.0153 & -118.3919 & 6 & $2.19 \%$ & 82 & $29.93 \%$ & 86 & $31.39 \%$ & 26 & $9.49 \%$ & 41 & $14.96 \%$ & 33 & $12.04 \%$ \\
\hline ICT & 101 & 34.0173 & -118.4882 & 16 & $15.84 \%$ & 20 & $19.80 \%$ & 26 & $25.74 \%$ & 17 & $16.83 \%$ & 3 & $2.97 \%$ & 19 & $18.81 \%$ \\
\hline Data Science & 93 & 34.0175 & -118.4960 & 19 & $20.43 \%$ & 29 & $31.18 \%$ & 16 & $17.20 \%$ & 15 & $16.13 \%$ & 1 & $1.08 \%$ & 13 & $13.98 \%$ \\
\hline Education & 200 & 34.0134 & -118.4962 & 31 & $15.50 \%$ & 46 & $23.00 \%$ & 53 & $26.50 \%$ & 33 & $16.50 \%$ & 15 & $7.50 \%$ & 22 & $11.00 \%$ \\
\hline Entertainment & 303 & 34.0124 & -118.3924 & 8 & $2.64 \%$ & 114 & $37.62 \%$ & 109 & $35.97 \%$ & 25 & $8.25 \%$ & 24 & $7.92 \%$ & 23 & $7.59 \%$ \\
\hline Social Media and Apps & 189 & 34.0137 & -118.3923 & 8 & $4.23 \%$ & 68 & $35.98 \%$ & 79 & $41.80 \%$ & 11 & $5.82 \%$ & 12 & $6.35 \%$ & 11 & $5.82 \%$ \\
\hline Mobile & 165 & 34.0138 & -118.4955 & 32 & $19.39 \%$ & 37 & $22.42 \%$ & 42 & $25.45 \%$ & 23 & $13.94 \%$ & 9 & $5.45 \%$ & 22 & $13.33 \%$ \\
\hline Web & 269 & 34.0128 & -118.4965 & 34 & $12.64 \%$ & 67 & $24.91 \%$ & 73 & $27.14 \%$ & 40 & $14.87 \%$ & 16 & $5.95 \%$ & 39 & $14.50 \%$ \\
\hline Business Support & 271 & 34.0157 & -118.4920 & 27 & $9.96 \%$ & 71 & $26.20 \%$ & 83 & $30.63 \%$ & 35 & $12.92 \%$ & 15 & $5.54 \%$ & 40 & $14.76 \%$ \\
\hline Marketing and Sales & 309 & 34.0120 & -118.4957 & 42 & $13.59 \%$ & 80 & $25.89 \%$ & 92 & $29.77 \%$ & 47 & $15.21 \%$ & 19 & $6.15 \%$ & 29 & $9.39 \%$ \\
\hline Manufacturing & 124 & 34.0174 & -118.4431 & 3 & $2.42 \%$ & 54 & $43.55 \%$ & 17 & $13.71 \%$ & 17 & $13.71 \%$ & 16 & $12.90 \%$ & 17 & $13.71 \%$ \\
\hline Lifestyle & 218 & 34.0137 & -118.3922 & 6 & $2.75 \%$ & 89 & $40.83 \%$ & 79 & $36.24 \%$ & 13 & $5.96 \%$ & 17 & $7.80 \%$ & 14 & $6.42 \%$ \\
\hline Medical and Health & 135 & 34.0577 & -118.3919 & 2 & $1.48 \%$ & 37 & $27.41 \%$ & 34 & $25.19 \%$ & 23 & $17.04 \%$ & 12 & $8.89 \%$ & 27 & $20.00 \%$ \\
\hline No Category & 151 & 34.1463 & -118.4424 & 0 & $0.00 \%$ & 2 & $1.32 \%$ & 80 & $52.98 \%$ & 25 & $16.56 \%$ & 21 & $13.91 \%$ & 23 & $15.23 \%$ \\
\hline
\end{tabular}

$$
\begin{array}{llll}
\text { Highlight Cell Rules } & 15 \% & 20 \% & 30 \% \\
\hline
\end{array}
$$

